

\section{DISCLAIMER}

This report was prepared as an account of work sponsored by an agency of the United States Government. Neither the United States Government nor any agency Thereof, nor any of their employees, makes any warranty, express or implied, or assumes any legal liability or responsibility for the accuracy, completeness, or usefulness of any information, apparatus, product, or process disclosed, or represents that its use would not infringe privately owned rights. Reference herein to any specific commercial product, process, or service by trade name, trademark, manufacturer, or otherwise does not necessarily constitute or imply its endorsement, recommendation, or favoring by the United States Government or any agency thereof. The views and opinions of authors expressed herein do not necessarily state or reflect those of the United States Government or any agency thereof. 


\section{DISCLAIMER}

Portions of this document may be illegible in electronic image products. Images are produced from the best available original document. 


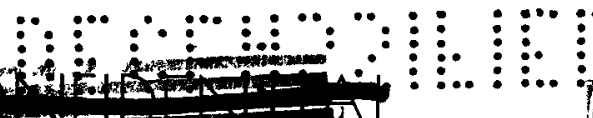 \\ UTNCLASSIFIED}
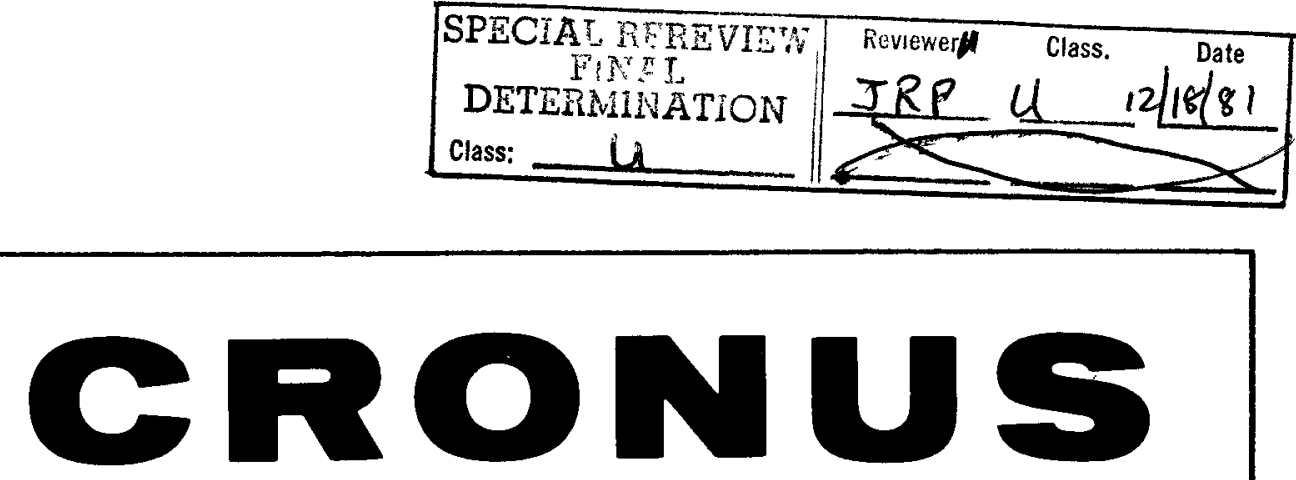

Controlled Reentry Orbiting NUclear System

\section{Study for 250-Watt \\ Controlled Reentry Orbiting NUclear System}

NOTICE

This report was prepared as an account of work sponsored by the United States Government. Neither the United States nor the United States Atomic Energy Commission, nor any of their employees, nor any of their contractors, subcontractors, or their employees, makes any warranty, express or implied, or assumes any legal liability or responsibility for the accuracy, completeness or usefulness of any information, apparatus, product or process disclosed, or represents that its use would not infringe privately owned rights. nited

ccu-

s use

ringe

$n$ the

em-

$t$ that

ares,

itract

\section{VOLUME III \\ DEVELOPMENT \\ PROGRAM PLAN}

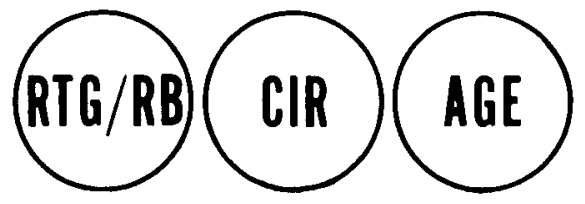

RESTRICTED DATA

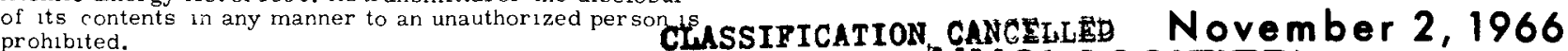

A tomic Energy Act of 1954 . Its transmittal or the disclosur o 
This report was prepared as an account of Government sponsored work. Neither the Unites States, nor the Commission, nor any person acting on behalf of the Commission:

A. Makes any warranty or representation, expressed or implied, with respect to the accuracy, completeness, or usefulness of the information contained in this report, or that the use of any information, apparatus, method, or process disclosed in this report may not infringe privately owned rights; or

B. Assumes any liabilities with respect to the use of, or for damages resulting from the use of any information, apparatus, method, or process disclosed in this report.

As used in the above, "person acting on behalf of the Commission" includes any employee or contractor of the Commission, or employee of such contractor, to the extent that such employee or contractor of the Commission, or employee of such contractor prepares, disseminates, or provides access to, any information pursuant to his employment or contract with the Commission, or his employment with such contractor. 


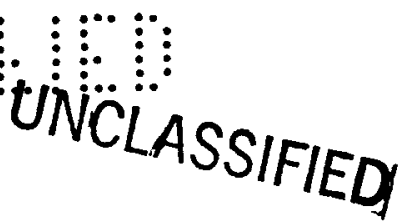

\section{FOREWORD}

The United States Atomic Energy Commission awarded the Martin Company Contract AT(29-2)-2050 for a six-month study, effective May 2, 1966, to develop and evaluate a feasible concept(s) for a 250watt(e) radioisotopic thermoelectric generator providing controlled intact reentry of the fuel from earth orbit. A concept(s) for handling and fueling the RTG at a Titan III launch site was also to be developed and evaluated. Based upon the selected system concept, a development program plan was to be prepared, including estimated costs, for the design, development, flight test and delivery of operationally flight qualified hardware systems.

The flight and ground systems have been integrated by Martin into a single system concept designated CRONUS, an abbreviation for Controlled Reentry Orbiting NUclear System. Major CRONUS systems include the 250-watt(e) generatorTreentry body (RTG/RB), the controlled intact reentry ( $C I R$ ), and required ground support (AGE) systems which include fuel loading (GHE).

The following is a complete list of the documents prepared and submitted in accordance with Contract AT(29-2)-2050.

\author{
Volume I--Summary \\ Volume II--Technical \\ Volume II--Appendices \\ Volume III--Development Program Plan \\ Volume IV--Specifications and Data Management \\ Volume V--Budgetary Estimate \\ Volume VI--Quality Assurance Plan
}

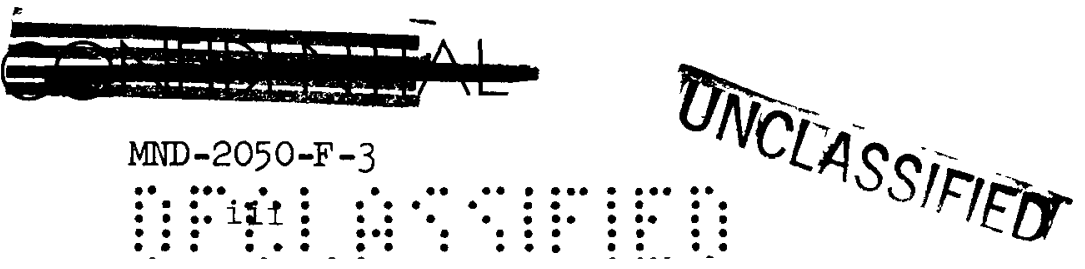


Legal Notice............................... ii

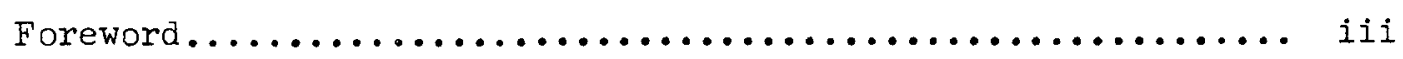

Contents.................................. v

Chapter I Introduction.......................... I-I

Chapter II Summary............................... II-I

a) Synopsis of CRONUS Program Activity (Table II-I)...........II-I2

b) Summary Schedule by Control Point (Figure II-1)...........II-13

c) Milestone and Delivery Schedule (Figure II-2)............II-14

d) CRONUS Integrated Test Plan (Figure II-3)...............II-I5

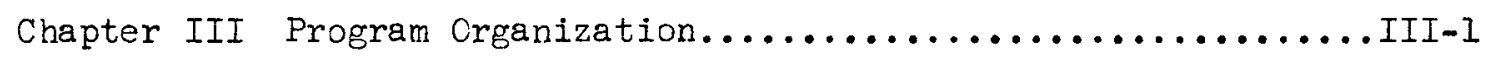

a) Program Organization and Responsibility Structure (Figure III-I) ...........................

b) Nuclear Programs Organization (Figure III-2).............II-4

c) CRONUS Program Organization (Figure III-3).............III-5

Chapter IV Detailed Program Plan..................... IV-I

a) Program System and Subsystem Breakdown By Control Point (Figure IV-I)....................

b) Agency/Contractor and Contract/Specifications Relationship (Figure IV-2) ......................

c) Summary Development Plan Control Points (Table IV-I).................... IV-3D

d) Control Point 1000--Program Administration and Management............................... IV -4

e) Control Point 2000--Systems Lvaluation and Integration...............................

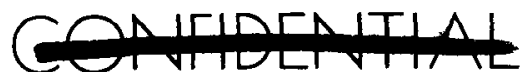

MND-2050-F -3 


\section{CONTENTS (continued)}

Page

f) Control Point 3000--Generator System Program............ IV-29

g) Control Point 4000--Controlled Intact Re-Entry Program..... IV-119

h) Control Point 5000--Aerospace Ground Equipment Program............................. IV -179

Chapter $v \quad$ Detailed Program Schedules................... V-I

Control Point 1000................................ V-4

Control Point $2000 . \ldots \ldots \ldots \ldots \ldots \ldots \ldots \ldots \ldots \ldots \ldots \ldots \ldots \ldots \ldots$ v -5

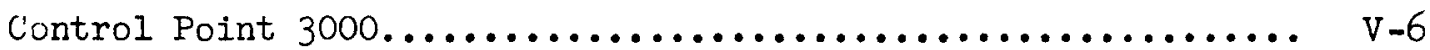

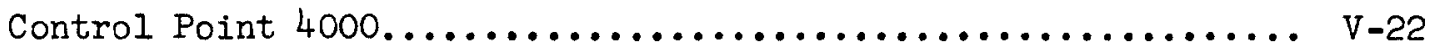

Control Point $5000 \ldots \ldots \ldots \ldots \ldots \ldots \ldots \ldots \ldots \ldots \ldots \ldots \ldots \ldots$.

Appendix A--Reliability Program Plan.................... A-I 


\section{con}

I. INTRODUCTION

The recommended development plan for CRONUS, a principal system composed of a radioisotope thermoelectric generator (RTG) system, a controlled intact reentry (CIR) system and a system of aerospace ground equipment (AGE) is described in this document. Chapter II summarizes the content and objectives of the development plan while Chapters III and V discuss organization and schedules. Chapter IV comprises the detailed work breakdown and program phasing to develop CRONUS from the conceptual design through utilization of operational hardware.

Chapter IV provides for the performance of the complete CRONUS program in a logical arrangement of phases with areas of work and the furnishing of articles broken down into control points (tasks, subtasks and sub-subtasks). The control points have been arranged to accomplish management and technical functions essential to integration of RTG, CIR and AGE systems at one level (1000 and 2000 Control Points). The performance of work and the furnishing of articles for each of the three individual systems is accomplished at a subordinate level (3000, 4000 and 5000). This arrangement permits, if desired, independent initiation of the program for each system and the staffing and growth of management/integration functions to match the particular contracting arrangement selected for accomplishing individual system programs. Further, structuring of the overall program, as established by the control points, assures centralization of control, minimization of duplicate and overlapping functions and efforts, and assures central responsibility for adequacy of end products.

To the extent practicable, the control point structure is arranged to identify individual tasks, subtasks and sub-subtasks within the individual phases which make up the complete program. 


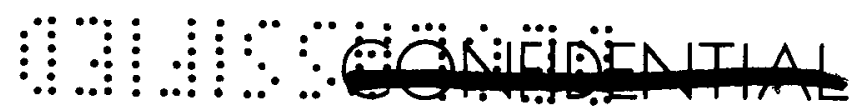

BLANK

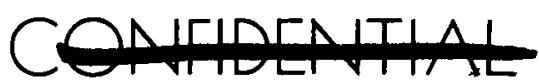

MND-2050-F-3

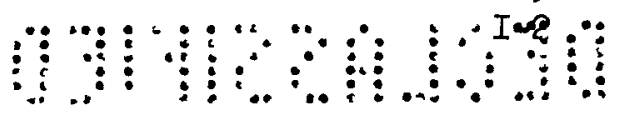




\section{$-1$}

\section{II - SUMMARY}

\section{A. INTRODUCTION}

The study of feasible concepts under AEC Contract AT(29-2)-2050 for a nuclear fueled space power system has been accomplished in conformance with the requirements of the contract and amplifying technical direction furnished the Martin Company under the provisions of the contract. The design concepts established in performance of the study form the basis for the development program discussed in detail in the following chapters of this volume. The content of the chapters cover the planned program to extend the design concepts, established by the study, into operating flight systems. Included within the plan is a brief description of the Martin Company organizational structure to carry-out the program. The procedures, arrangement and description of work and the articles of hardware and software to be produced and delivered under the program are discussed in detail. Both detail and master schedules of program activity and delivery of articles are contained within a single chapter.

The total network of: program phases, equipment systems and subsystems, schedules, work and costs are tied together by a system of control points. The control point structure is explained in detail in the initial part of the program plan. Basically the objective of the control point structure is to establish a direct correlation of "what is to be done", "when it is to be done" and "for how much".

\section{B. DEVELOPMENT PROGRAM}

\section{Program Subdivision}

The detailed plan contained in Chapter 4 independently treats each of the three systems which make up CRONUS. A separate development program is detailed for the generator system (RTG/RB), controlled intact re-entry system (CIR) and the system of aerospace ground equipment (AGE). Integration of the three systems is accomplished as a separate area of work under a single control point (C.P. 2000). The integration activity includes the effort to interrelate the three systems of CRONUS and to integrate CRONUS into the space mission program. Also maintained as a separate area of work are the activities performed without direct cost to the program and those functions which are best apportioned over the complete program. Included in this last category are the activities of total program management and technical direction, configuration management, and total program planning and scheduling. These management and general activities are retained under a single control point (1000).
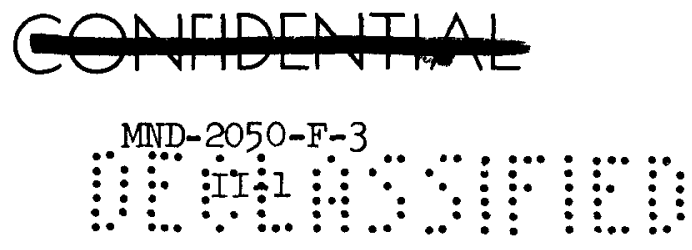


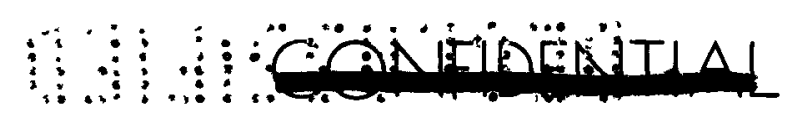

Table II-1 provides a synopsis of the activities which make up the total program and their relation to the individual program phases. The correlation of program phases and iime spans with the control point structure is illustrated in Figure II- 1 . Major milestones within the program and the schedule for delivery of articles is depicted in Figure II-2. Figure II-3 presents a comprehensive summary of the CRONUS integrated test plan through delivery of seven flight qualified systems.

\section{Basis for the Development Program}

The development plan for CRONUS has as its foundation two sets of basic criteria. The primary criteria or the "ground rules" for the development plan are the provisions of the contract and technical direction established by the Sandia Corporation. Additional criteria, the second set, have been established by the Contractor within the framework of the ground rules. A summary of these governing criteria is furnished in the following.

\section{a. Contractually established baselines}

Criteria furnished under the contract affect the design and construction of CRONUS and the services, activities and responsibilities of the Contractor. Significant criteria affecting the development program are obligations and requirements placed on the Contractor and end products for:

(1.) Capability of integration of CRONUS with specified mission parameters and launch sites

(2.) Attainment of certain reliability levels

(3.) Subdivision of the program by Phase and certain product functions

(4.) Conformance with certain product performance, characteristics, and configuration requirements

(5.) Delivery of demonstrated and accepted GHE and delivery of a GHE mock-up at specific points in time

(6.) Delivery of RTG/RB-CIR systems for both a demonstration flight and performance of a generator fueling/defueling demonstration at a specified time

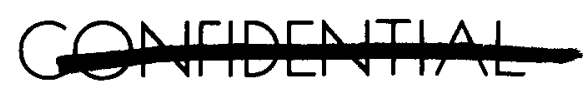

MND-2050-F-3 


\section{1}

(7.) Furnishing of RTG/RB-CIR systems for life testing at stated times

(8.) Performance of an advanced technology program in support of the CRONUS program

(9.) Product support efforts including maintenance of GHE, training of User personnel, and furnishing of checkout equipment to handle, transport and protect the RTG/RB-CIR systems until assembled on the launch vehicle

b. Program bases established by the contractor

Within the constraints of the preceding criteria, further baselines have been established by the Contractor as the basis for the development program. Particularly noteworthy baselines which have been established for the work and articles to be included in the CRONuS program are summarized in the following. The criteria listed relate to program methods, flight test and User support activities and government furnished services and articles. Other baselines are apparent in the later discussion of the program phases.

\section{(1.) Program methods}

Particular methods and approaches selected for performance of the program include:

(a) Planned initiation of the program on February 1, 1967 to provide an adequate time span for performance of required design, development, procurement, fabrication and test activities within milestones specified by Sandia technical direction for fueling and flight demonstrations.

(b) Subdivision of the span for the complete program into four phases, as illustrated in Figure II-1, with the arrangement of work and results to be attained as described in Section 3 following.

(c) Accomplishment of the complete program by the Contractor with individual development of each system within CRONUS but with the work related to both program management and systems integration retained, as previously discussed, as separate elements.

(d) Provision for: preparation of schedules, PERT/time networks, drawings, and specifications and the use of configuration and data management techniques, all based on established USAF practices. The Air Force methods will be

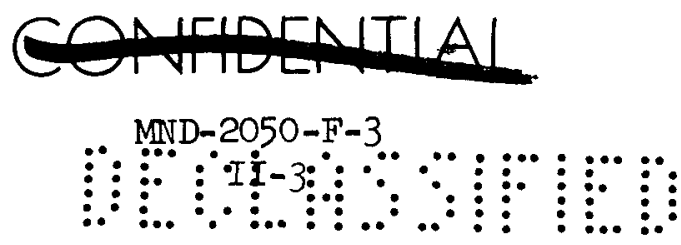


used to facilitate liaison, coordination and integration of the contractor's services and products into the User's space mission program.

(2.) Flight test and user support

The development plan includes furnishing of articles and services to implement and support flight test, launch site and User agency programs on the basis of one launch site, a particular mission, and an individual combination of a specific launch vehicle and spacecraft. Contractor responsibilities provided for within the development plan include:

(a) Development and furnishing of operational ground equipment and maintenance ground equipment, in addition to the fuel handling equipment (GHE), required in operational use and support of CRONUS.

(b) Furnishing of data and documentation required by the test range as a prerequisite to use of the launch site and test range.

(c) Liaison, coordination and the furnishing of hardware and software items to the User's integrating and/or spacecraft contractor(s) to permit integration of the effect of CRONUS into the equipment and services to be provided by others.

(d) Performance of a generator fueling and defueling demonstration with GHE equipment at the Contractor's facility prior to delivery of the equipment to the launch site. The demonstration will be performed with a simulated heat source.

(e) Demonstration of generator fueling and defueling at the launch site with an inert heat source followed by a repeat of the demonstration with an $\mathrm{Sr}-90$ heat source.

(f) Furnishing of an RTG/RB fueling demonstration model for use in the fueling demonstration to permit simulation of operational flight unit fueling procedures and the monitoring of temperature characteristics under prelaunch conditions.

(g) Furnishing of special equipment and instrumentation in the prototype RTG/RB-CIR for the initial demonstration flight to permit monitoring of inflight operation of CIR system functions, re-entry attitudes and orientation and ability of the thermoelectric equipment to sustain launch loads.

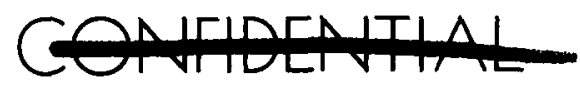




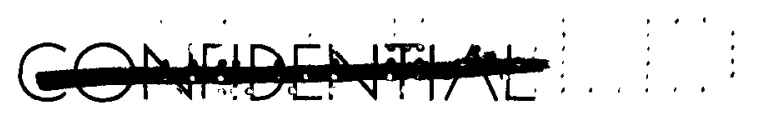

(h) Demonstration of CIR system functions at the launch site, including arming and lock-out features of ordnance subsystem equipment and operational performance of spaceto-ground link equipment.

(i) Furnishing of equipment spares for CRONUS during launch site operations performed during Phase III of the CRONUS program; Articles will be furnished to effect replacement for normal wear and tear and equipment malfunction. During Phase IV, GHE refurbishment articles will be provided in kit form to compensate for expected wearout.

(j) Accomplishment of CRONUS equipment maintenance at the launch site during Phase III and performance of GHE checkout and routine maintenance during generator fueling operations performed by the contractor in Phase IV of the program.

(k) Training of the User's launch site personnel and furnishing of training aids to effect integration of CRONUS into pre-launch and countdown operating procedures.

(1) Furnishing of technical consultation services at the launch site, as required, during both Phase III and Phase IV portions of the program.

(m) Performance of engineering analyses of flight test data obtained by the User in the prototype demonstration to establish correlation of actual versus programmed impact locations and flight trajectories of the re-entry body.

(3.) Government furnished services and articles

The development plan for cRonus contemplates that certain services and articles will be the responsibility of government agencies. These responsibilities are for the most part well within the capabilities of the contractor and its subcontractors. They are assigned to the government, as the most logical, timely and economical way of accomplishing end objectives. Historically, the responsibilities tabulated below have been assigned to government agencies on similar programs.

(a) Furnishing of nuclear fuel, fuel encapsulation, shipment of the encapsulated fuel to the launch site and accountability and storage of the fuel while at that location.

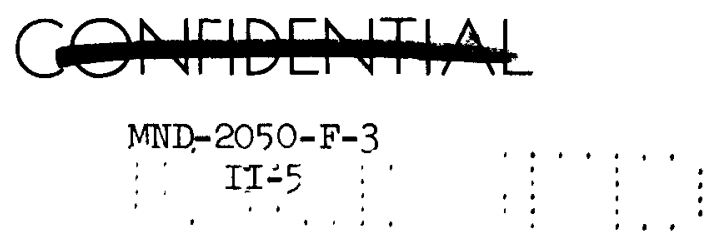


(b) Development of adequate processes of fuel encapsulation and quality assurance of completed heat sources in cooperation with contractor development efforts.

(c) Accomplishment of nuclear health physics programs at the launch site, including personnel surveillance, radiation surveys and implementation of nuclear safety controls and procedures.

(d) Obtaining licenses, permits and certifications where required for possession and utilization of the nuclear fuel. However, the contractor will provide technical analysis and documentation in support of applications for approvals and licensing.

(e) Modification and set-up of equipment and facilities to be provided by others to permit installation of CRONUS equipment. It is planned that such modification and installation be accomplished in accordance with fully coordinated interface specifications and drawings.

(f) Installation and integration of CRONUS equipment into the facilities and equipment of others with the technical assistance of the Contractor.

(g) Services required for operation and use of launch complex equipment and facilities where tied-in with operation and functional use of CRONUS equipment. It is expected that the User will provide and accomplish all countdown, launch, and flight control operations.

(h) Performance of tests at Government facilities are certain test articles furnished by the contractor. For example, wind tunnel tests and high velocity impact tests to verify nuclear safety where use of specialized government facilities is warranted.

(i) Items of equipment which the Government may elect to provide. However, pending resolution of GFE items during Phase I, cost estimates furnished with this development plan have assumed all articles of CRONUS to be contractor furnished.

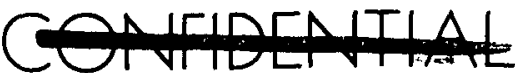




\section{Program Phases}

The CRONUS program is arranged into four separate phases. Each phase spans a particular period of time and includes certain categories of work activity. A summary of these activities is provided by subject listing in Table II-l. A summary description of significant areas within each phase is provided below to depict the nature of each phase.

a. Phase I - Design, Analysis and Component Development

Phase I includes the basic design effort to extend the reference conceptual design of each of the three systems within CRONUS into a firm definition of hardware configuration, design parameters and governing criteria. In conjunction with design and analysis effort, an intensive liaison activity will be conducted with the Sandia Corporation and, to the extent directed, with the User Agency and its contractors and launch site and test range personnel. Liaison will also be accomplished with other cognizant government agencies such as the organizations responsible for supplying and encapsulating the Nuclear fuel of the thermoelectric generator and performance of discrete test at government facilities. The liaison activity will have as its objective the formulation of design criteria and definition of interfaces between contractor furnished equipment and activities and the articles and responsibilities of others. The results of liaison will be reflected in contractor prepared specifications and interface drawings. These documents as coordinated and accepted will form the baselines for plans, efforts and products of the CRONUS program.

Other basic docümentation prepared in Phase $I$ will include preparation of formal plans for the conduct of: the complete program, functional activity within the contractor's organization and efforts related to specific disciplines. The plans prepared in Phase I and the corresponding schedules will include extension and firm-up of the development plan contained in Chapter 4 and also the subsidiary plans provided as part of this final summary report. The plans in final form will reflect both the provisions of the contract and the results of coordination liaison.

The Phase I portion of the program includes initiation of comprehensive test efforts such as aerodynamic and radiation effects studies. In addition, component testing and tests essential to verification of design approach and selected design parameters will be performed. For example, testing will include parametric and performance studies of materials and parts and investigations of environmental effects. A summary of the testing to be accomplished and the test articles required for test is presented in Figures II-3 and II-4.

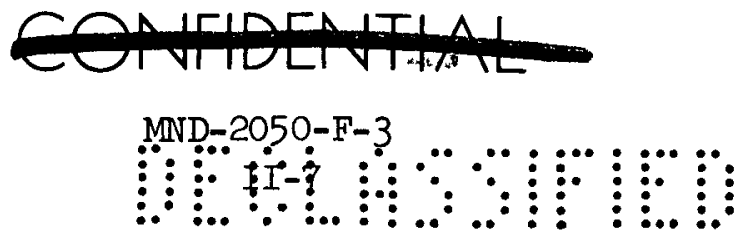




\section{1.}

b. Phase II - Component and Subsystem Development

Within this portion of the program the contractor will complete drawings and other documentation needed to fabricate the prototype articles for flight demonstration of the controlled intact re-entry system. Documentation efforts will include firm-up of interface drawings and interface specifications based on continuation of the liaison activity started in Phase $I$. Also, both system and CEI specifications will be formally completed based on the results of a critical design review (CRD) conducted along lines established by USAF AFSCM 375 exhibits. To accommodate delivery schedules established for AGE, the span of Phase II will cover proof and verification testing of GHE articles and include both development and acceptance tests of operating and maintenance ground equipment articles (OGE \& MGE). Phase II also includes continuation of component development testing carried over from Phase $I$ and the growth of testing activities to provide breadboard and subsystem tests of RTG/RB-CIR equipment. The nature of this testing will include performance, parametric and environmental tests with the objective of establishing qualified components and subsystems.

A particularly important element of the test program included in Phase II is the performance of tests relating to system(s) safety and accomplishment of corollary analyses to provide a basis for both equipment design and definition of safety provisions and criteria.

\section{c. Phase III - Systems Development and Qualification}

The third phase of the CRONUS program includes extensive activity both at the contractor's facility and at the Eastern Test Range launch site to qualify and demonstrate the systems which make up cRONUS. In this phase, testing of RTG/RB and CIR equipment will be accomplished to complete component qualification and assure that equipment to be flown in a demonstration flight of the CIR system is qualified for the intended application. Qualification of equipment will be accomplished with hardware provided specifically for that purpose. Equipment articles to be flown in the demonstration flight will be of the same configuration and characteristics as test articles used to verify conformance with requirements and governing criteria. Prior to delivery, flight articles will be subjected to acceptance tests in accordance with governing contract end item specifications prepared and coordinated in earlier program phases. Acceptance type tests to be accomplished in Phase III also include demonstrations, at the Contractor's facility, of the functions and operation of AGE. This demonstration will be accomplished with GHE and $O G E$ in a test set-up which provides simulation of fueling operations to be demonstrated at the launch site.

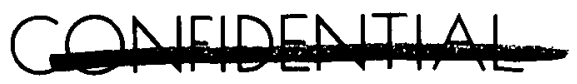




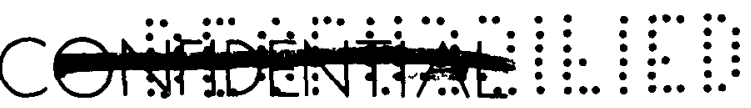

Phase III also encompasses the furnishing of contractor services at the launch site. These services cover performance of fueling demonstratjons and assistance in the integration of CRONUS into the operations, facilities and equipment of the launch complex and flight vehicle. In addition to services of a direct nature, the contractor's responsibilities embrace the furnishing of technical documentation required for installation and use of CRONUS equipment; also, items of equipment and services previously described under the subject of program baselines will be provided by the Contractor.

\section{d. Phase TV - Flight Articles and Mission Support}

The final phase of the program, Phase IV, includes the furnishing of CRONUS systems in quantity for flight operational use and the furnishing of services at the launch site. The work to be accomplished at the Contractor's facility entails completion of equipment qualification tests, using test articles provided for that purpose, and completion of other testing initiated earlier such as equipment life tests. Equipment to be delivered will be subjected to final acceptance tests in accordance with governing specifications.

Subsequent to delivery of a flight operational system, the contractor will provide the support services outlined in the program baselines. It is expected that the contractor's responsibility for accomplishment of generator fueling operations and technical support will be provided over a periodic rather than a continuous bases, to coincide with the programmed launch intervals.

\section{Plans-for-Execution of the Cronus Program}

The CRONUS program will be accomplished through the interrelated activities of the functional departments of the contractor's organization. These activities will follow formal plans prepared by the contractor and coordinated with the AEC prior to their implementation. Preliminary issues of the more significant of these plans form a part of this summary report. These initial issues include a quality assurance plan (Vol. VI), a reliability plan (Appendix A hereto) and plans for: configuration management effort, the furnishing of program documentation, and the preparation of program specifications (Vol. IV). Preliminary system and interface specifications forming part of the total array of specifications contemplated by the specification plan are included in Volume IV. These specifications, although preliminary, form the technical base for both the contemplated program and the development plan in Chapter 4 following.

A particularly important plan, the quality assurance plan for CRONUS, extends into the functional activities of most of the company's

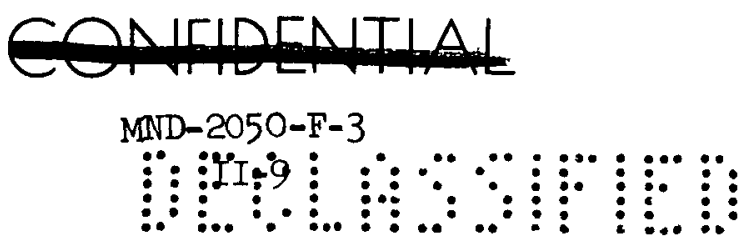


departments. The inter-tie between organizational segments to effect quality assurance and product integrity is shown diagrammatically in Figure 17 of Volume VI. This volume defines the efforts and responsbilities to achieve product integrity. Primarily, the volume is concerned with methods and techniques of quality assurance. The more direct, product oriented quality assurance efforts such as design and analysis efforts, engineering controls, testing, reliability, maintainability, and product inspection are embodied directly within the development plan structure where they are an integral part of the work to be performed. Accordingly, provision for quality assurance with respect to design, product, product use and environment, and the effects of malfunction are treated within the discipline or activity concerned with that aspect of CRONUS.

5. Program Facility Requirements

An analysis of the facilities required to accomplish the proposed program from development through the fabrication and test of flight hardware has been conducted for the manufacturing and test program described in the cRONUS development plan. The results of the study indicate that the contractor's current in-house facilities or those of other related industrial and/or Government installations will enable the completion of the program on a timely basis.

During Phase I the most significant requirement for facilities relates to testing materials and components that have not been qualified in the close proximity of a nuclear heat source and require assessment of radiation damage or degradation effects. Several modes are available for this testing, all of which currently exist including: Cobalt -60 sources, Flash $\mathrm{x}$-ray, gamma neutron generators and test reactors. Environmental testing during this phase will require, in addition to the normal vibration, shock, fatigue and mechanical properties test capabilities; facilities for high level impact tests, blast pressure tests, and life testing under the combined environments of temperature and vacuum capabilities. These facilities are available. Electronic and electric capabilities for breadboard testing, antenna development and pattern measurement equipment, including qualification of sub-systems, are within the current state of the art and present no foreseeable facility problems. Other facilities required include: plasma arc, "Hot Shot" and other wind tunnels and test media for simulating the flight regimen of the re-entry body. Propulsion and ordnance components in conjunction with associated electronic parts necessitate remote areas for testing either at the prime contractor's plant or at component supplier facilities.

Phases II and III require environmental test facilities capable of accommodating combined subsystems and prototype flight hardware. A review of required facility needs indicates that necessary facilities

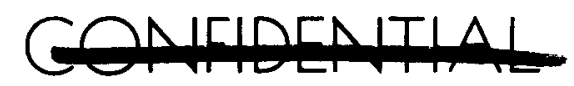

$$
\begin{gathered}
\text { MND-2050-F-3. } \\
\text { II }=10 \vdots
\end{gathered}
$$




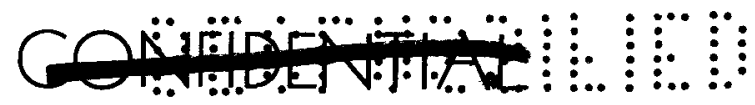

are readily available and are, in all cases, the same facilities needed during Phase I. Combined system tests involving CIR and spacecraft separation tests will make use of the same remote testing facilities of Phase I with increased instrumentation and additional monitoring equipment. RTG/RB-CIR separation tests will be conducted in this same area.

Experience with other space system hardware has shown the merit of conducting a combined systems test for all systems, with its ground equipment, to insure overall systems reliability. Therefore, facility planning includes a combined systems acceptance test facility where the compatibility of all systems will be demonstrated before delivery to the launch site.

Fabrication and testing of the nuclear fuel handling machine can be accomplished without the need of any new facilities or technologies. Fabrication and assembly of the various systems are within existing manufacturing capabilities in all affected areas, 1.e., machining, welding, finishing, sheet metal, electrical and electronic, and assembly disciplines. All processes and operations will be monitored under the cognizance of a Quality Control Department which has laboratory and facility installations separate from those of Engineering and Manufacturing for such monitoring.

\section{CONCLUSION}

The development plan for chovus contained in this volume represents a complex inter-arrangement of contractor and government agency activities evolving from baselines established under contract AT(29-2)-2050. The plan provides for subdivision of both the program to be accomplished and the system of equipment to be produced. It provides for further breakdown of the elements created by subdivision to arrive at convenient packages of work and products which lend themselves to planning, costing and evaluation of required efforts. Since the program defined by the plan represents a contemplated approach, the plan has been structured to permit convenient recognition and manipulation of individual packages in evaluating the total plan or initiating work in one area before or apart from other areas.

In summary, the plan has been structured to serve both the intent of the feasibility study objectives and to comprehensively define responsibilities, functions, efforts to be accomplished and the hardware and software to be produced in the performance of the Cronus program. It considers the contractor's responsibilities to its customer the AEC. Also, it provides for the necessary support of the User Agency and its contractors and makes provision for services and equipment to be supplied by government agencies.

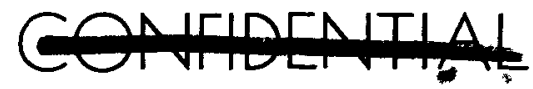


TABLE II-1 SXNOPSIS OF CRONUS PROGRAM ACTIVITY

\begin{tabular}{|c|c|c|c|}
\hline PHASE_I $(8 \mathrm{mos})$ & PHASE IT (15 mos.) & PHASE III (25 mos.) & PHASE IV $(3 \operatorname{yrg} 8 \mathrm{mos})$ \\
\hline $\begin{array}{l}\text { Design, Analysis and } \\
\text { Component Development }\end{array}$ & $\begin{array}{l}\text { Component \& Subsystem } \\
\text { Development }\end{array}$ & $\begin{array}{l}\text { Systems Development \& } \\
\text { Qualification }\end{array}$ & $\begin{array}{c}\text { Flight Articles \& } \\
\text { Misston Support }\end{array}$ \\
\hline $\begin{array}{l}\text { Component and Process Development } \\
\text { Materials Studies } \\
\text { T/E Element, Sub module \& Module } \\
\text { Development } \\
\text { Fuel Containment and Encapsulation } \\
\text { Studies } \\
\text { Performance and Parametric Tests of } \\
\text { Selected Parts/Compnents } \\
\text { Environmental Iffects Studies } \\
\text { GHE Mock up } \\
\\
\text { Formal Plans } \\
\text { Program } \\
\text { Operations (Systems Ut1lization) } \\
\text { Maintenance } \\
\text { Quality Program } \\
\text { Manufacturing and Tooing } \\
\text { Test } \\
\text { Reliability } \\
\text { Configuration Management } \\
\text { Documentation } \\
\text { Specifications } \\
\text { Pert and Detail Schedules } \\
\text { ather Documentation } \\
\text { Drawings (System(s) \& Interface) } \\
\text { Specifications } \\
\text { System Interface CEI Part I } \\
\text { Subcontractor } \\
\text { Reports } \\
\text { Program Reviews and Briefings } \\
\text { Preliminary Design Review (PDR) }\end{array}$ & $\begin{array}{l}\text { Systems Detail Design \& Analysis } \\
\text { Detall Manufacturing Drawings } \\
\text { and Processes } \\
\text { Component and Subsystem Fabrication and } \\
\text { Test--RTG/RB and CIR } \\
\text { Continuation and Expansion of } \\
\text { Phase I Component Investigations } \\
\text { Breadboard and Subsystem Perfor } \\
\text { mance and Environmental Tests } \\
\text { Component Quallification/Vertfica } \\
\text { tion Tests }\end{array}$ & $\begin{array}{l}\text { AGE Articles Fabrication and Site } \\
\text { Installation For } \\
\text { Inert Fueling Demonstration } \\
\text { Fueling Demonstration } \\
\text { Prototype Flight Test } \\
\text { Fuel Transport } \\
\text { Fabrication, Test and Delivery of } \\
\text { Prototype RTG/RB and CIR Systems (GTY 2) } \\
\text { Pre delivery Acceptance Tests } \\
\text { Spares for Prototype and AGE } \\
\text { Documentation } \\
\text { Reports } \\
\text { Operating and Maintenance Manuals } \\
\text { Installation Drawing } \\
\text { Range Data } \\
\text { Launch Site Activity (Contractor's) } \\
\text { Personnel Training } \\
\text { Technical Support Services } \\
\text { Fueling Demonstrations } \\
\text { Equipment Check-out } \\
\text { Support of System User s Integrating/ } \\
\text { Spacecraft Contractor(s)-Furnish } \\
\text { Operating Models/Equipment } \\
\text { Data } \\
\text { Lialson } \\
\text { Technical Services } \\
\text { Evaluation of Prototype Flight Test Results }\end{array}$ & $\begin{array}{l}\text { Qualification of Operational Flight } \\
\text { Test Article Configuration } \\
\text { Acceptance Tests of Deliverable Hardware } \\
\text { Fabrication, Test and Delivery Flight } \\
\text { Test Systems (QTY 7) } \\
\text { Nuclear Licensing Assistance } \\
\text { Spares Provisioning } \\
\text { Launch Ste Activity (Contractor's) } \\
\text { Technical Support Services } \\
\text { Maintenance GHE During Fueling } \\
\text { AGE Up date Modifications }\end{array}$ \\
\hline
\end{tabular}

$\therefore: .:$ :

$\vdots . . . \vdots$

.

$\vdots . .$.

$\ldots$

...:

$\because \because$

Continuation and Expansion of

Cha $I$ Component Investigations

ance and Environmental Tests

GEE Articles Fabrication and Sit

Fueling Demonstration

ion, Test and Delivery of

entation

Operating and Maintenance Manuals

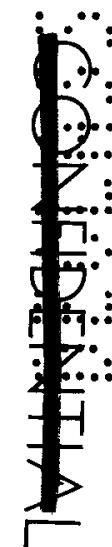

Fabrication and Delivery of GHE Mock up

Lia1son Activity 


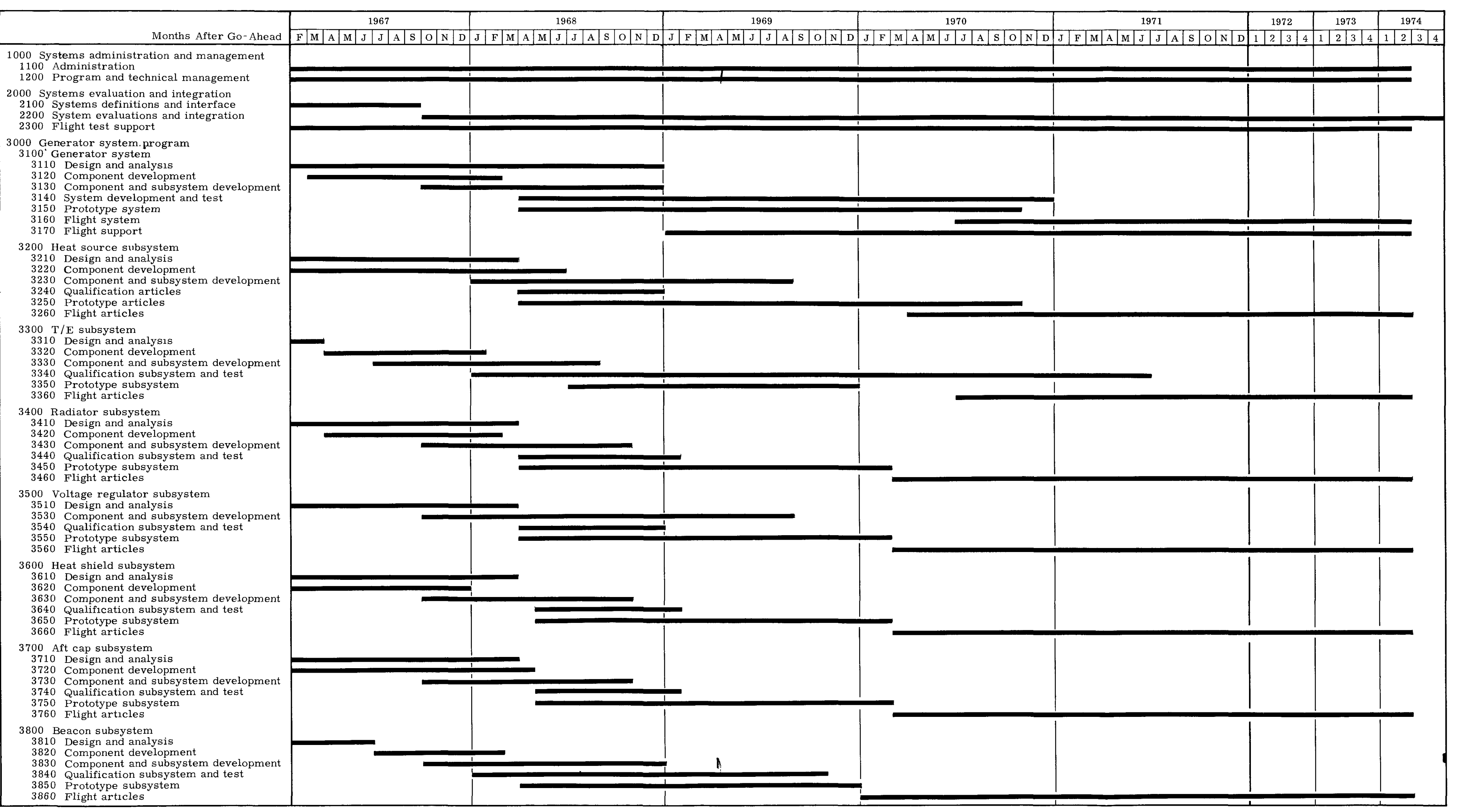



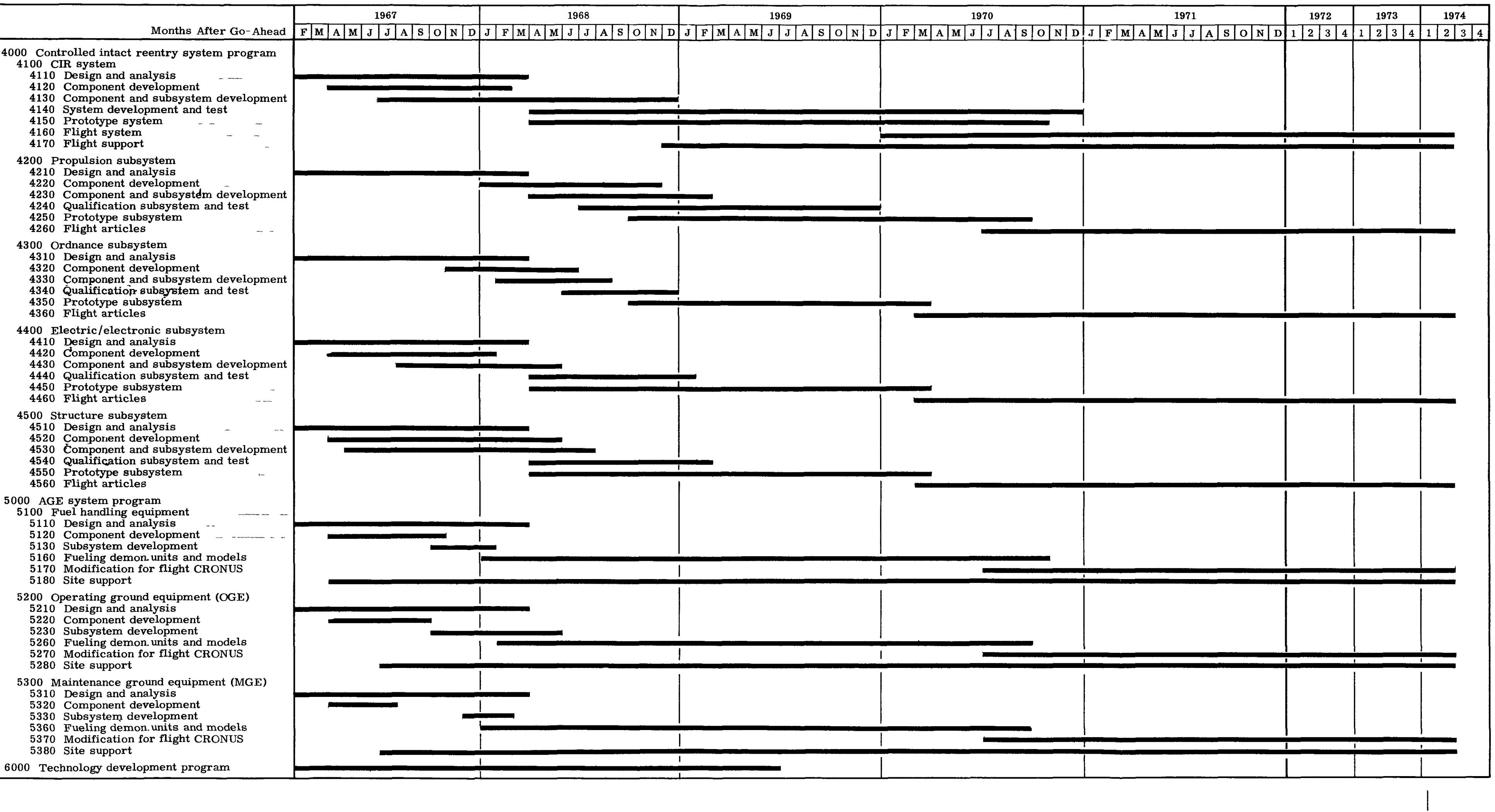


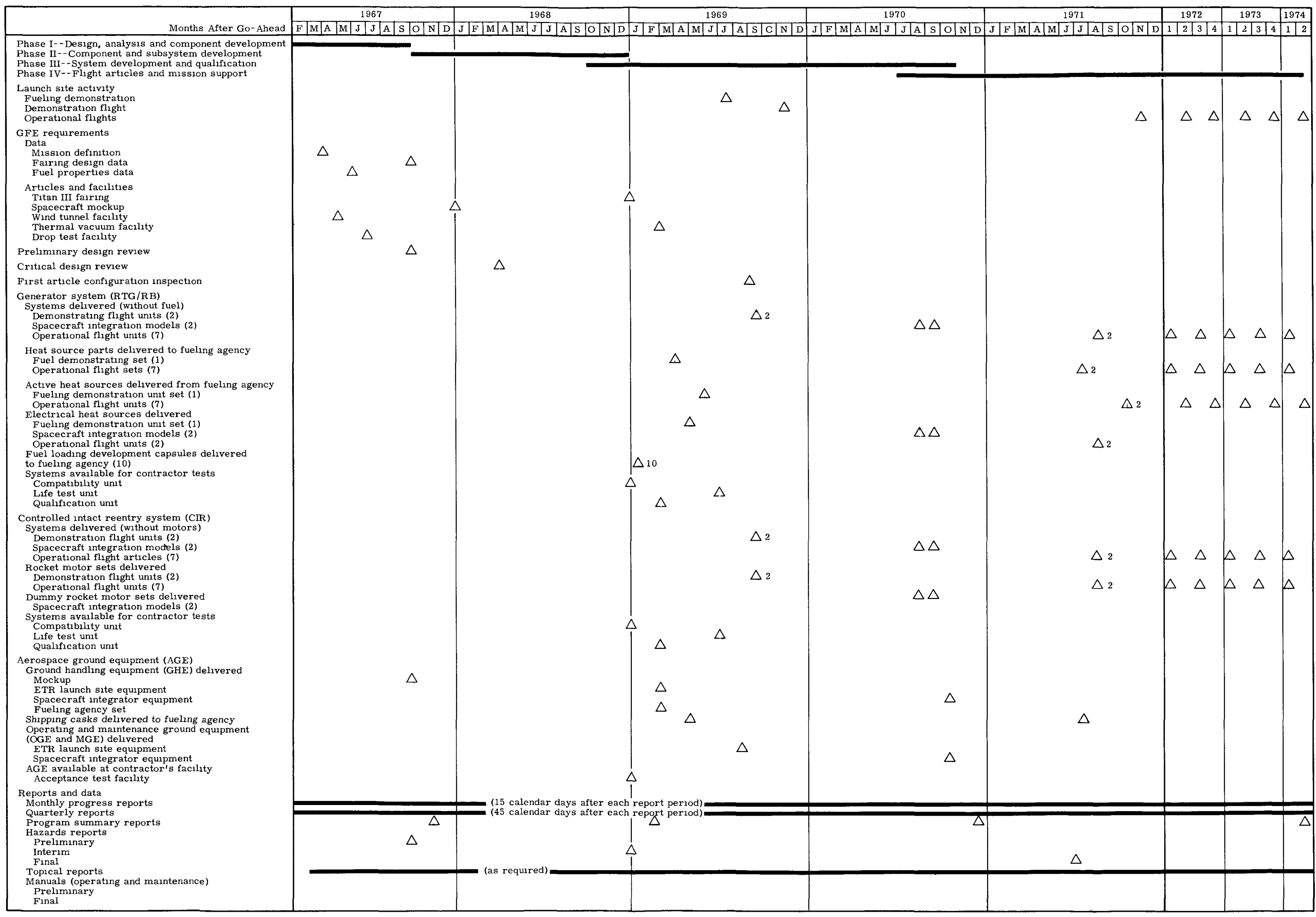

COATHOEATIALL 
•ִ

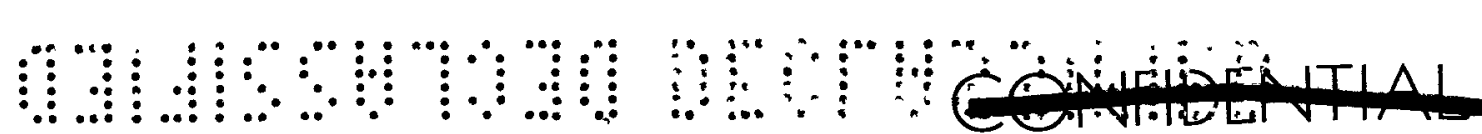

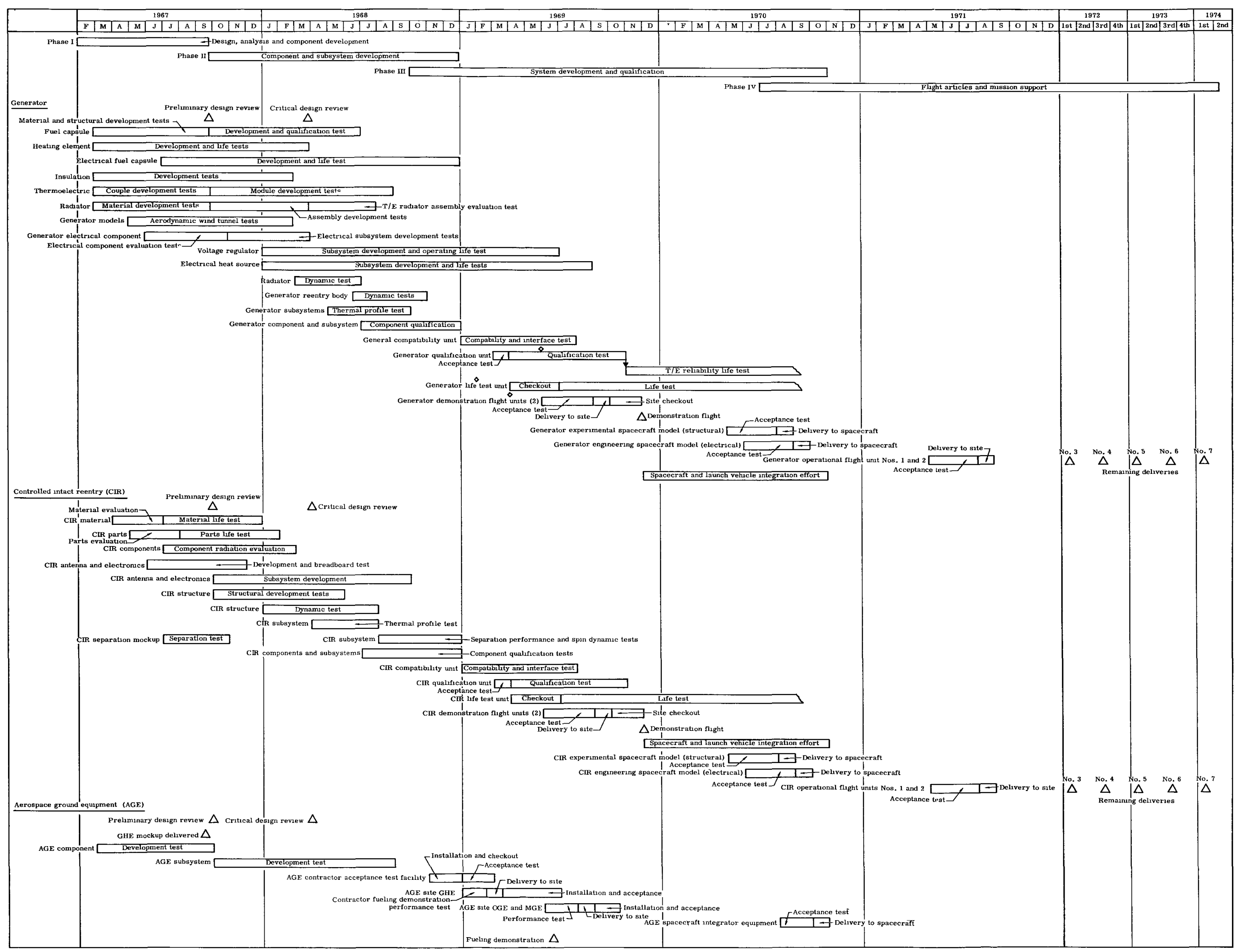

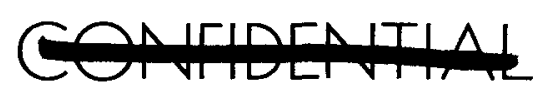

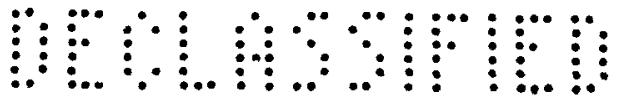

MND-2050-F-3

年 
BIANK 


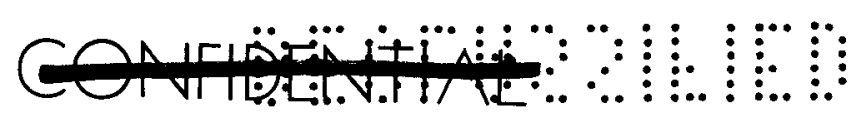

\section{PROGRAM ORGANIZATION}

The program organization and the program plan presents the Martin Company's plan for accomplishing all elements of the CRONUS program with the assistance of qualified subcontractors, under a contract with the U. S. Atomic Energy Commission. Execution of the contract will be accomplished under the technical direction of the Sandia Corporation, Albuquerque, New Mexico. Further, it is assumed that the Sandia Corporation will act as the interface and coordinating agency between Martin and the organization of government agencies and contractors employing the products and services.

The overall organization for the program is shown in Fig. III-l. The organization places the functions of a systems manager and integrator above the three major product elements of the program; namely, the generator, controlled intact reentry, and aerospace ground equipment systems. The organization shown is the basis for the development plan contained in Chapter IV and the basis used in estimating the cost of accomplishing the development plan. This organizational arrangement provides considerable freedom in assignment of responsibilities if the actual program as established by the AEC contains fewer elements than those covered by the development plan or if a subcontractor or government agency is to be assigned responsibility for some segment of the program.

\section{A. MARTIN COMPANY ORGANIZATION}

Martin Company is one of four separate operating entities within the Martin Marietta Corporation. Martin has facilities located at Baltimore, Maryland, Orlando and Cape Kennedy, Florida, Denver, Colorado and Wheeling, Illinois, with the General offices located a Friendship Airport, Maryland. The Research Institute of Advanced Studies in Baltimore is owned by the Martin Company.

In the organizational structure, Staff Vice Presidents are in charge of equivalent functional activities such as Research and Engineering, Sales and Requirements, Advanced Programs, Public Relations, Industrial Relations, Finance, Contracts and Administration. The Vice Presidents of the Martin Company report to Mr. W. B. Bergen, President. Accordingly, each functional area is represented at the General office level, assuring application of maximum resources to major programs.

\section{Baltimore Organization}

The Baltimore facility, under Vice President, V. R. Rawlings, has each major product area managed by its own general manager or

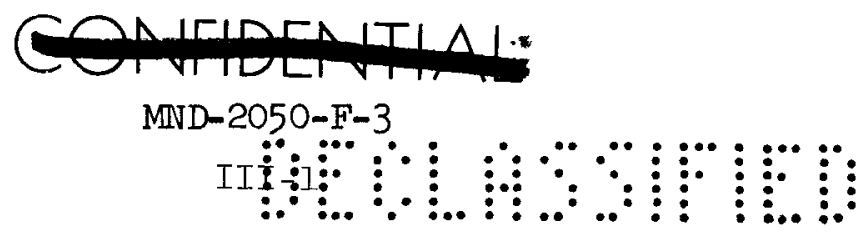


…::

¿...:.:

......

....:.:

......

$\because \because$

$\because \because$

$\because: \because$

¿.....

$\therefore \therefore$

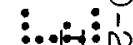

: :

No

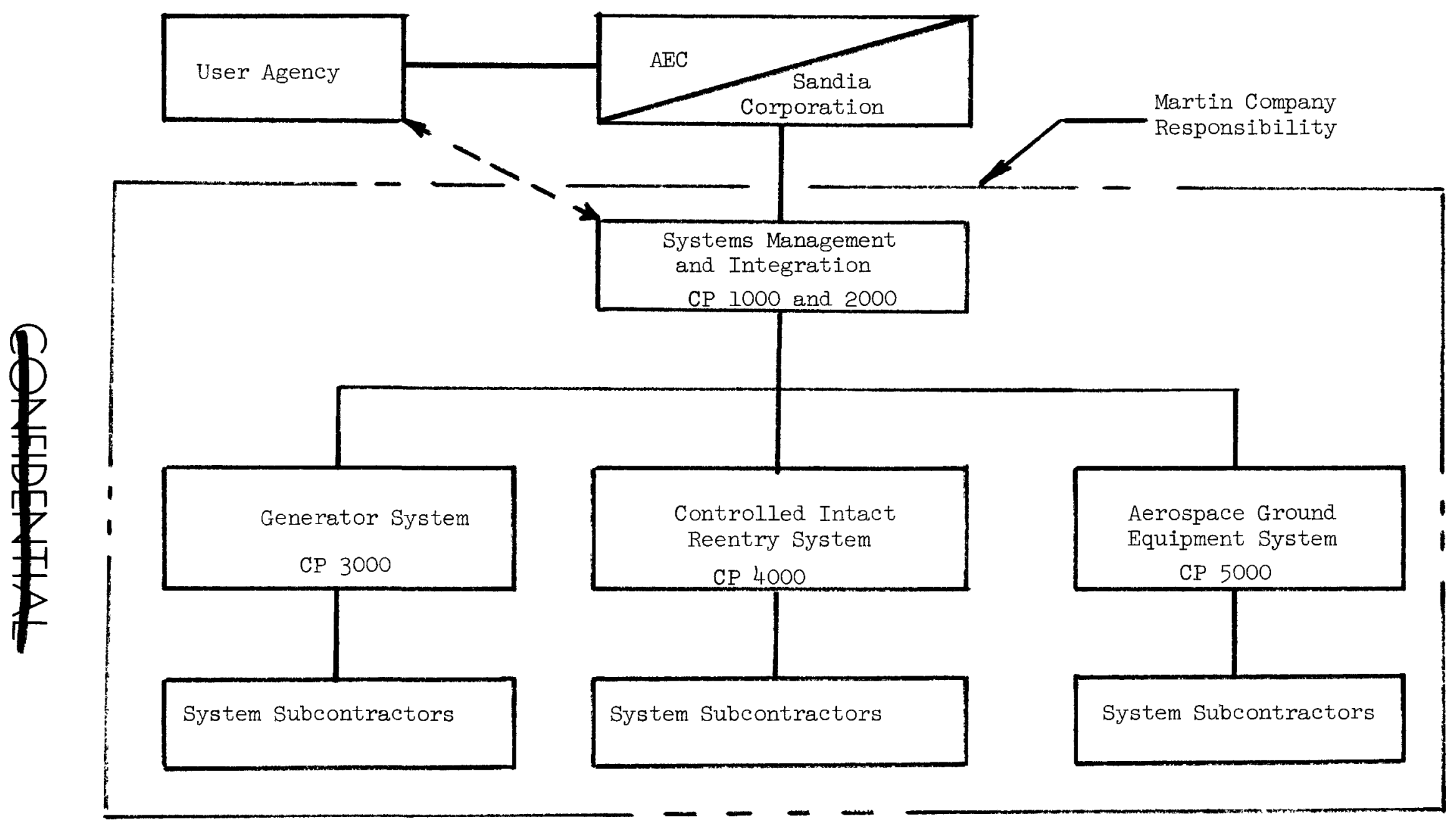

Fig. III-1. Program Organization and Responsibility Structure

:....:

$\vdots . . . . \vdots$

.....

$\vdots . .$.

$\cdots$

$\because \because$

$\because \because$

$B$ 


\section{(1)}

director. The organization of product and functional areas is employed by Nuclear Programs, one of the product areas, directed by General Manager, N. E. Felt, Jr. The product area is organized by product lines, under individual program managers, with associated supporting functions as shown in Fig. III-2. Representatives from the various disciplines are assigned from the functional departments to support the program managers.

\section{CRONUS Program Organization}

The nucleus of the CRONUS organization within Martin was established in August 1965 in response to an AEC Request for Proposal for an engineering study of a nuclear fueled 250- to 300-watt(e) generator. This nucleus has been essentially retained and expanded in the performance of Contract AT(29-2)-2050, awarded to Martin following response to the RFP. The CRONUS program organization as contemplated for performance of this plan is shown in Fig. III-3. The organization has been established to provide fluidity and accommodation to the actual program as it will be established by the AEC. For example, accomplishment within the Martin Company of the complete development plan of Chapter IV will require a minimum management-technical integration activity because of the physical proximity of personnel and experience in working together on other programs. If a major subcontractor is assigned a segment of the program, such as a complete system, there will be appropriate reductions in line functions and increased integration activity to accomodate the required coordination between organizations.

The CRONUS Program Manager will have direct and complete authority and responsibility for meeting all contractual obligations including schedule, cost and technical performance. In this position, he will direct and coordinate all program activities. These activities are accomplished under the further supervision of directors, managers and representatives from functional departments to provide integrated direction for each of the major hardware and software items to be developed. Under the supervision of a project technical director, a project engineer will be assigned to each of the systems; i.e., RTG, CIR and AGE systems. Each project engineer will have functional engineers assigned to his area for the analysis, design and test of items within his purview. In this manner, a strong project organization is superimposed over participating functional organizations, thereby providing an integrated, product-oriented team.

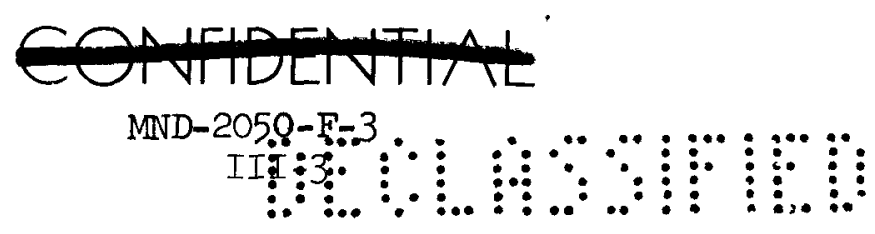




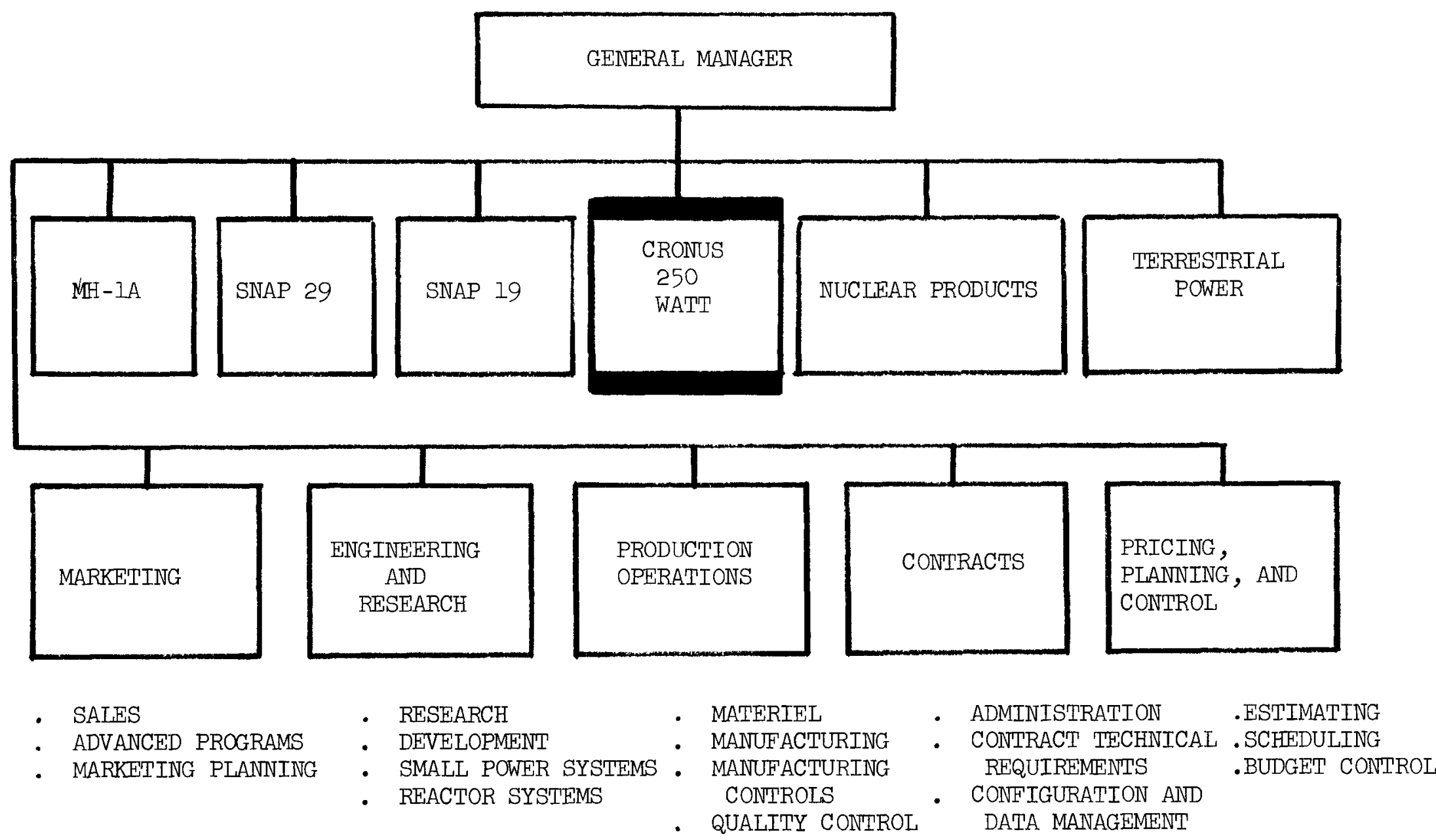

Fig. III-2. Nuclear Programs Organization 

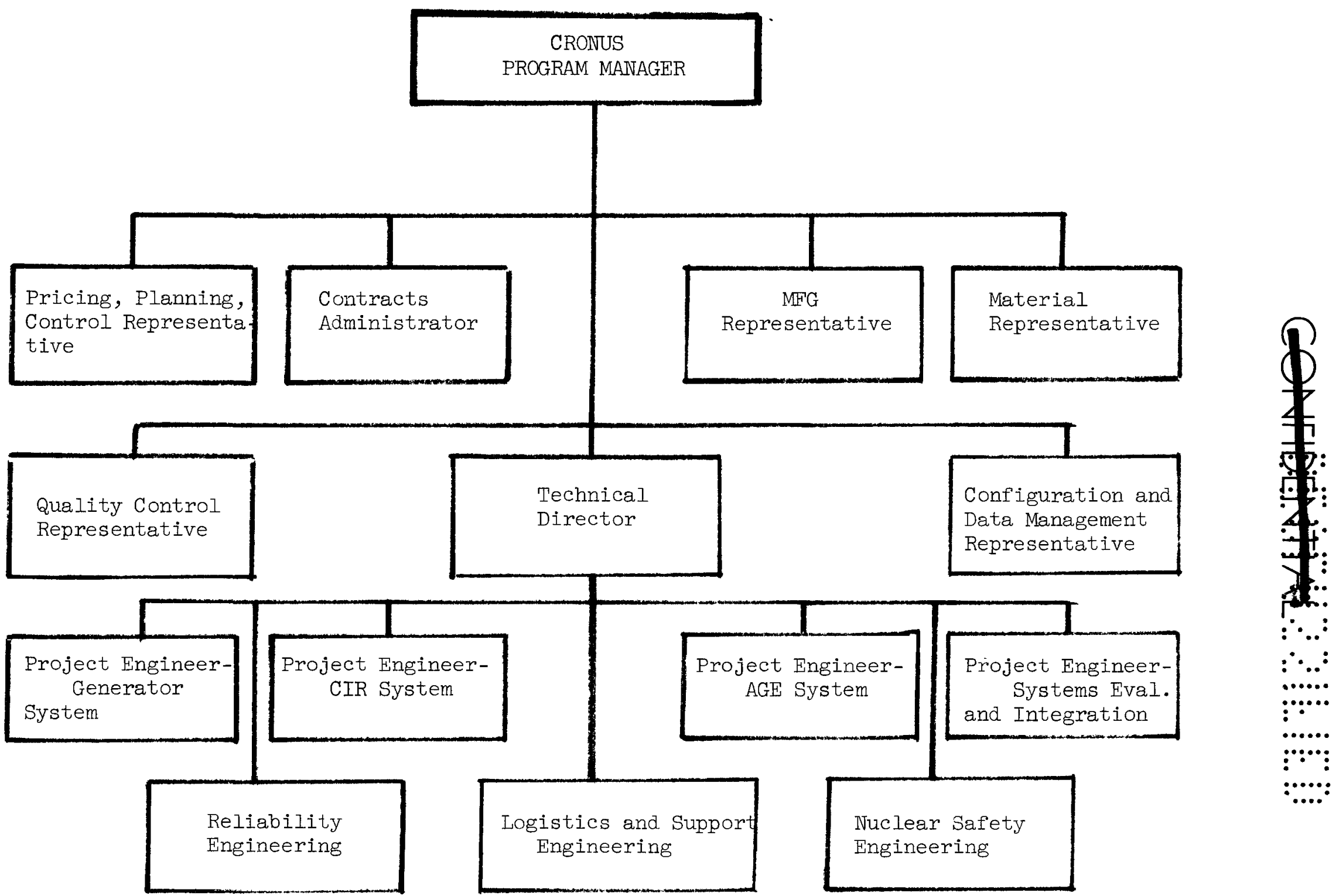

Fig. III-3. CRONUS Program Organization 


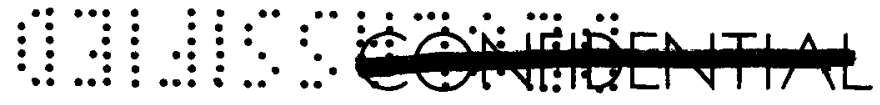

BIANK

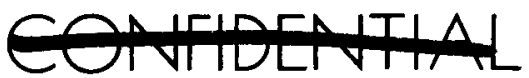

MND-2050-F-3

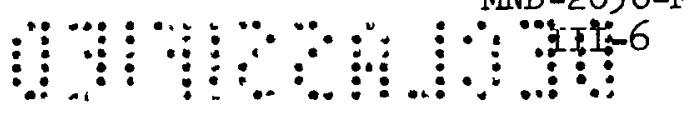




\section{min!}

\section{DETAILED PROGRAM PLAN}

This program plan describes the necessary effort from conceptual design through fabrication and testing that is required to provide operational 250-watt(e) nuclear fueled generator systems, their related controlled intact reentry systems and associated ground equipment. It includes, distributed over a program composed of four phases, program management, component and system development, design and evaluation, component and system qualification, systems integration, equipment demonstrations, system deliveries and support of launch site activities.

\section{A. DEVELOPMENT PROGRAM OBJECTIVES}

The program plan contained has been prepared to satisfy a specific set of objectives created by the nature of the CRONUS program and the provisions of Contract AT(29-2)-2050. Primary objectives are created by criteria specified in the contract and in amplifying technical direction supplied by the Sandia Corporation in the initial period of contract performance. Additional objectives are the result of particular design concepts developed under the study contract and the complex interrelation of agencies, contractors and equipment systems, superimposed over CRONUS program phasing and costing.

The program plan described satisfies the objectives which have shaped its construction. Specifically, these objectives are:

(1) Satisfy the provisions of the contract

(2) Segment the program into elements and phases and arrange the equipments which comprise CRONUS into a matrix to facilitate, if desired, $A E C$ rearrangement and implementation of the elements of the program

(3) Correlate the activity, products, schedules, and costs in the breakdown structure of the program

\section{B. CONTRACT PROVISIONS}

In accordance with the provisions of the contract, the CRONUS program plan has been arranged to provide a development plan for the generator system, the controlled intact reentry system and a system of ground support equipment. The elements of a total quality assurance plan, also required by contract, have been integrated into individual system plans. However, functions and responsibilities of the quality program which are applicable to all systems are described in Volume VI.

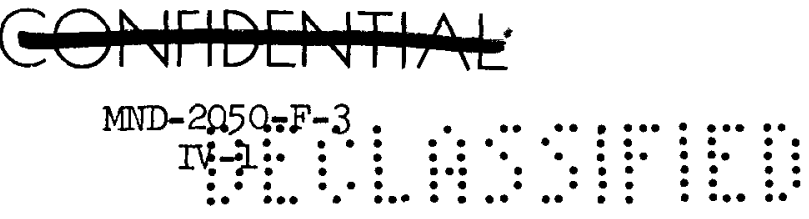




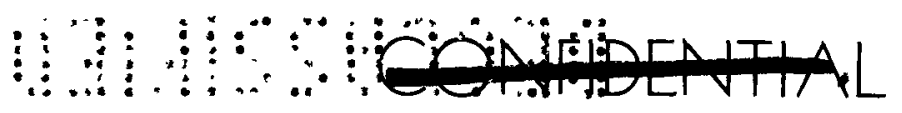

In addition to following the provisions of the contract, the CRONUS program plan is based on technical direction contained in the following letters.

(1) ALO Letter, "Scope of Work," (C.E. Morrison), March 2, 1966

(2) Sandia Ietter, "Basic Parameters," (I. O. Cropp), May 23, 1966

(3) Sandia Letter, "Fuel Data and Impact Area Data," (L. O. Cropp), July 5, 1966

(4) Martin Letter, "Interpretation of Parameters," (G. Iinkous), July 19, 1966

(5) Sandia Letter, "Development Plan Inputs," (I. O. Cropp), July 22, 1966

(6) Sandia Letter, "Additional Study Guidelines," (L. O. Cropp), August 15, 1966

(7) Sandia Letter, "Verification of Ref. (4) Comments," (I. 0. Cropp), August 16, 1966

(8) Sandia Letter, "Briefing Aids and Data," (L. O. Cropp), August 30, 1966

\section{PROGRAM PLAN ARRANGEMENT}

The program plan for CRONUS is composed of five principal tasks. One task encompasses management and direction of the complete program on it would be accomplished within the Martin Company (Control Point 1000). Included within this task are the activities necessary to direct the design, fabrication and test of the three systems which make-up CRONUS. The technical efforts necessary to integrate the three systems with each other and with the space mission program are designated on a separate task (Control Point 2000). To the extent practicable, all work and the furnishing of articles is accomplished within one of the program tasks created for each individual system.

RTG/RB System--Control Point (task) 3000

CIR System--Control Point 4000

AGE System--Control Point 5000

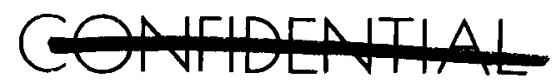


Each task is further delineated into successively smaller pieces of hardware or work. The control point breakdown with respect to major elements and articles of the program is illustrated in Fig. IV-1. The complete control point breakdown is summarized in Table IV-1 and the control point structure by individual system and phase is presented in Tables IV-2 and IV-3. In Phase I, the control point breakdown illustrated will be expanded and used as a totally integrated control system for all program outputs such as drawings, equipment and test specifications, documentation and correspondence, PERT/TMME detail networks, and PERT/COST. 

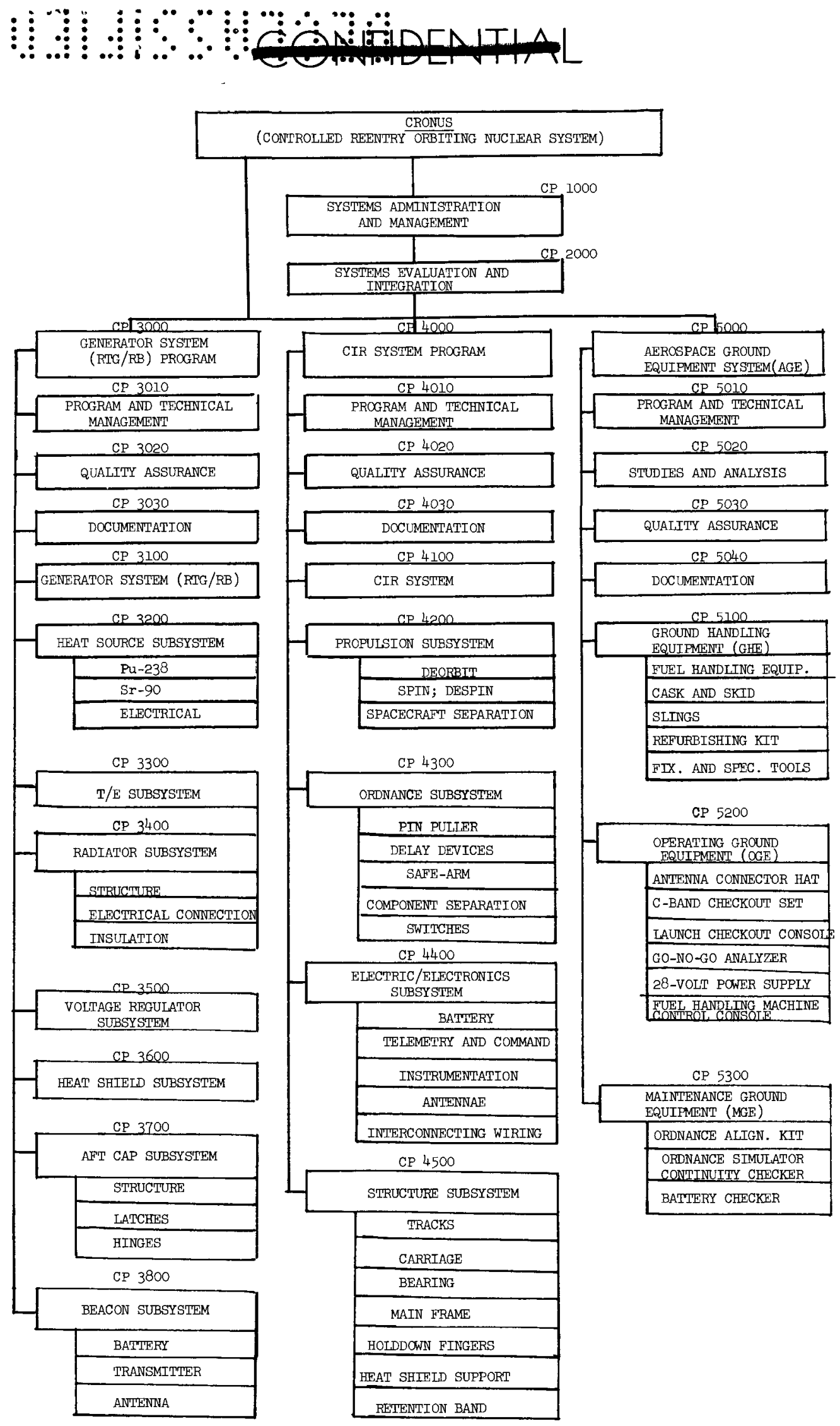

Fig. IV-1. PROGRAM SYSTTM AND SUBSYSTEM BREAKDOWN BY CONTROL POINT
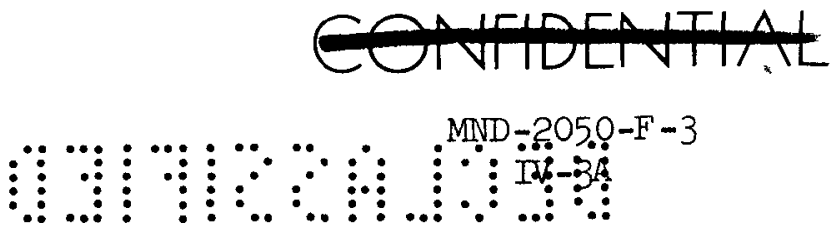

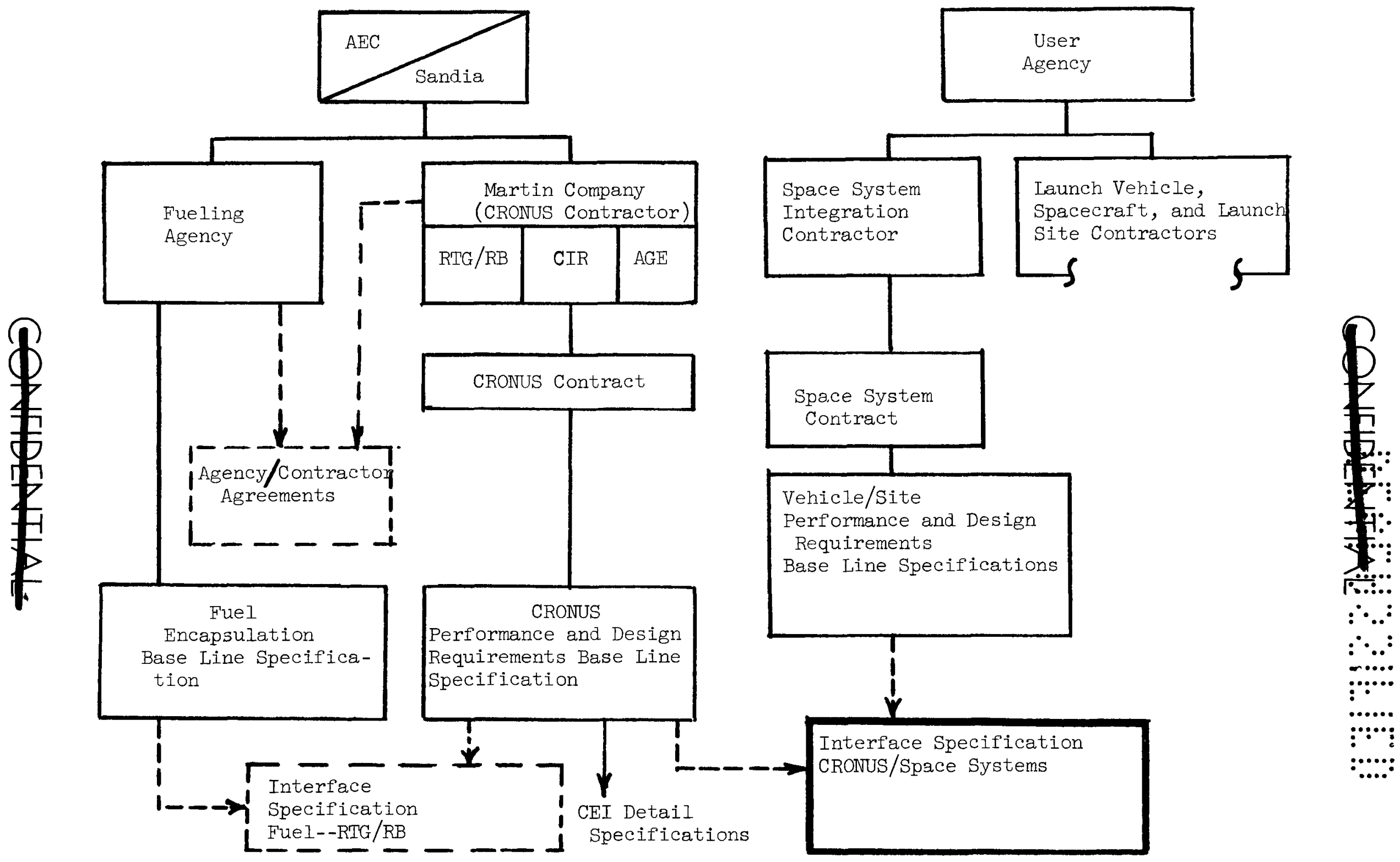

Fig. IV-2. Agency/Contractor and Contract/Specification Relationship 

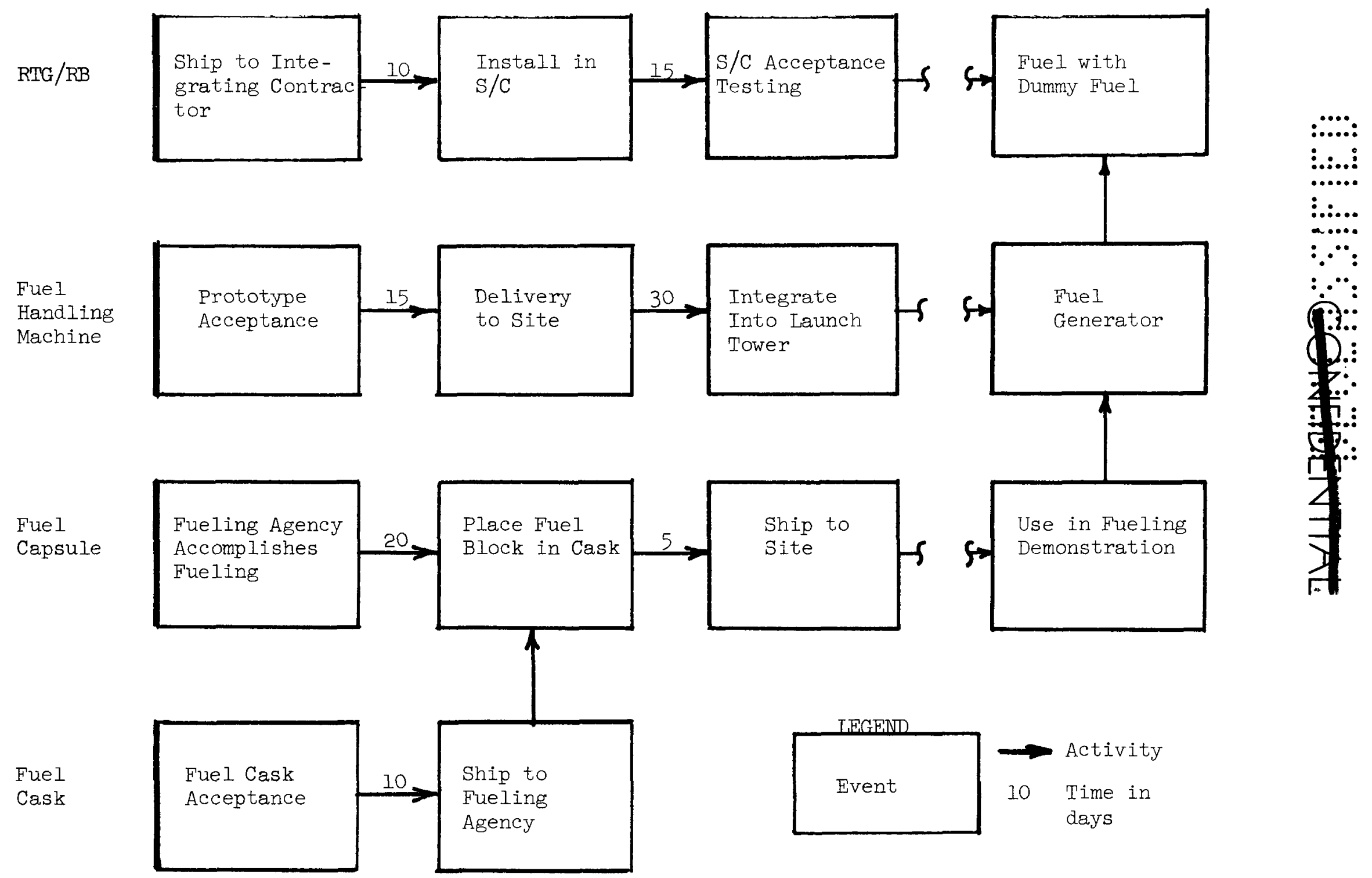

Fig. IV-3. Sample Block Diagram Flow Chart Form of Operations Plan 


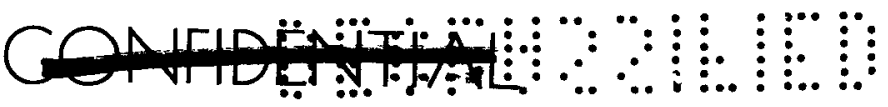

\section{TABLE IV -1}

Summary of Development Plan Control Points

1000: Systems Administration and Management
1100: Administration (no direct charge to contract)

1200: Program and Technical Management

2000: Systems Evaluation and Integration

3000: Generator System Program

2100: System Defunition and Interfaces

2200: Systems Bvaluation and Integration

2300: Flight Test Support

3010: Program and Techmical Management
4000. Controlled Intact Reentry System Program

5000: AGE System Program
3020: Quality Assurance

3030: Report and Manual Preparation

3100: Generator System (design, analysis, assembly, test, delivery and flight support)

3200: Heat Source Subsystem

3300: $T / E$ Subsystem

3400: Radiator Subsystem

3500 Voltage Regulator Subsystem

3600: Heat Shıeld Subsystem

3700: Aft Cap Subsystem

3800: Beacon Subsystem

4010: Program and Technical Management

4020: Quality Assurance

4030: Report and Manual Preparation

4100: CIR System (design, analysis, assembly, test, delivery and flight support)

4200: Propulsion Subsystem

4300: Ordnance Subsystem

4400: Electric/Electronıcs Subsystem

4500: Structure Subsystem 5010: Program and Technical Manage-

5020: Intrasystem Studies/Analyses

5030: Quality Assurance

5100. Fuel Handlıng Equipment (GHE)
1110: Contract Administration

1120: Procurement and Subcontract Administration

1130: Finance Management

1210: Program Direction and Control

1220: Configuration and Data Management

1230: Program Plans and Schedules

1240: Program Reviews and Briefings

1250: Program Reports and Manuals

Same as 1210 to 1250 Breakdowns

3021: Reliability

3022: Quality Control

3023: Maintainability

3024: Value Engineering

3025: Engineering Controls

3026: System Testing (plans, analyses, reports)

(see Table IV-2 for typical system breakdown by phase)

(see Table IV - 3 for subsystem breakdown by phase)

Same as 1210 breakdown

Same as 3020 breakdown

(see Table IV-2 for typical system breakdown)

(see Table IV- 3 for typical subsystem breakdown by phase)

Same as 1210 to 1250 breakdown

5021: Interface Analysis and Definition Same as 3020 breakdown

5110. Design and Analys1s

5120: Component Development and Verification

5130: Subsystem Development, Design

Verification and Proof Tests

5140: Manufacturing

5150: Quality Control

5160: Fuelıng Demonstration Units and Models

Packaging and Delivery

5170: Articles for Flight Operational CRONUS

Packaging and Delivery

5180: Site Support

5200. Operatıng Ground Equipment (OGE)

5300: Maintenance Ground Equipment (MGE) 
ํ.?:

$\vdots \ldots . . . ;$

$\ldots$

$\therefore$ :

$\because \because$

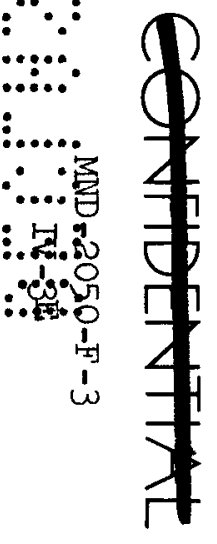
Subsystem

TABLE IV -2

Typical Control Point Breakdown for a CIR and RTG/RB Subsystem

$\begin{gathered}\text { Subsystem } \\ \text { P200, X300, etc. } \\ \text { XX10 }\end{gathered}$
$\begin{aligned} & \text { DESIGN AND ANALYSIS (includes } \\ & \text { redesign where required) }\end{aligned}$
COMPONENT DEVELOPMENT
X221: Article Fabrication/
Assembly
X222: Tests

COMPONENT AND SUBSYSTEM DEVELOPMENT

X231: Article Fabrication/ Assembly

$\mathrm{XX} 60$

$$
\begin{aligned}
& \text { SUBSYSTEM QUALIFICATION } \\
& \text { ARTICLES AND TESTS (pre- and } \\
& \text { post prototype flight) } \\
& \text { X241: Article Fabrication/ } \\
& \text { Assembly } \\
& \text { X242: Tests } \\
& \text { PROTOTYPE SUBSYSTEM } \\
& \text { ASSEMBLY AND TEST } \\
& \text { X251: Fabrication/Assembly } \\
& \text { X252: Test (Performance/ }
\end{aligned}
$$

Phase IV

\section{$\therefore$ :...:}

$\vdots . . . . \vdots$

(......

¿.....

$\because \cdots$

$\because:$

$\because \cdots$

$\because \ldots$

R.:

D:0.
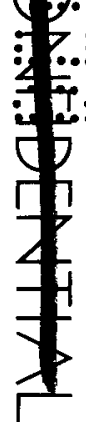

\section{Subsystem No.}

System No.

FLIGHT ARTICLE FABRICATION/ ASSEMBLY AND TEST

X261: Fabrication/Assembly

X262: Test 
System $\times 100$

Control Point

$\mathrm{X} 110$

$\mathrm{X} 120$

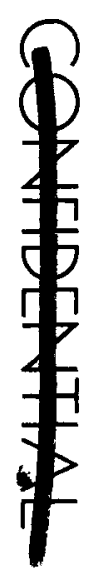

$\mathrm{X} 130$

$\mathrm{X} 140$

$\mathrm{X} 150$

$\mathrm{X} 160$
Design, Analysis and
Component Development
Phase I

DESIGN ANALYSES (includes redesign where required)

X111 Interface Definition

X113 Trajectory and Aerodynamic Analyses
X114 Thermal and Structural
Analyses, etc

COMPONENT DEVELOPMENT (only if required for system level)

X121 Article Fabrication/

$\begin{array}{ll}\mathrm{X} 122 & \begin{array}{l}\text { Assembly } \\ \text { Tests (typically includes } \\ \text { evaluation of results) }\end{array}\end{array}$

$\mathrm{X} 170$

System No

e g 30000 or 5000

series
Component and Subsystem

Development
Phase II

Systems Development

and Qualification
Phase III
Flight Articles and

Phase IV
COMPONENT AND SUBSYSTEM DEVELOPMENT (only if required system level)

\section{X131 Art1cle Fabrication/}

$\mathrm{X} 132$ Assembly
SYSTEM DEVELOPMENT AND TEST* (only if required at system $\begin{array}{ll}\mathrm{X} 141 & \text { Test Article Fabrication } \\ \text { and Assembly } \\ \text { X142 }\end{array}$

PROTOTYPE SYSTEM(S) ASSEM-
BLY, TEST AND DEVELOPMENT

$\mathrm{X} 151$ Assembly

X152 Permoly /Qualification Tests

$\mathrm{X} 153$ Acceptance Tests

\section{FLIGHT TEST SUPPOR}

$\mathrm{X} 171$ Technical Support Service

X173 Fueling Operations

X174 Equipment Maintenance

$\times 175$ and Repair

X175 Equipment Spares and

$\mathrm{X} 176$

Loans (Phase III only)

X177 Support or Nuclear Saftey (Health Physics) and Nuclear Accountability

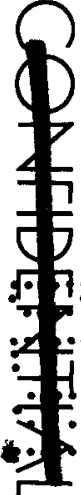
OPERATIONAL FLIGHT ARTICLES
ASSEMBLY, TEST AND DELIVERY $\begin{array}{ll}\text { X161 } & \text { Assembly } \\ \text { X162 } & \text { Acceptance Tests } \\ \text { X163 } & \text { Delivery }\end{array}$

$\mathrm{x} 163$ Aceptance

*Includes subsystem combinations for test

NOTE Refer to schedules for specific location of control points with respect to phases and time spans 
TABLE IV -4

1000 Summary of Program Administration and Management

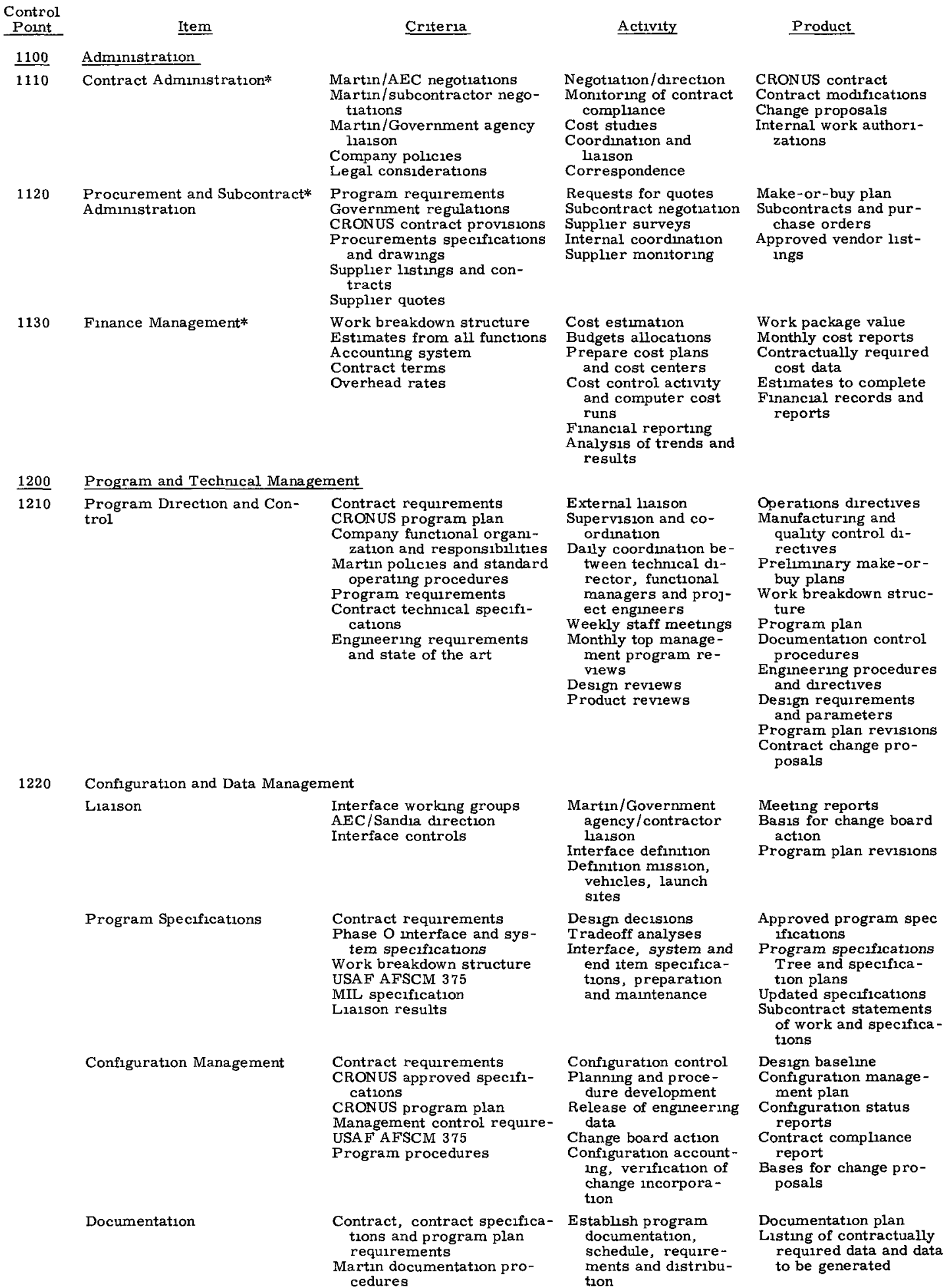

* Not direct charges to program.

Contract requirement hase interface and sys tem specifications USAF AFSCM 375 MIL specificatio

Contract requirement CRONUS approved specif 1 cation

CRONUS program plan USAF AFSCM 375

Program procedure
Negotiation/direction oring of contract

Coordination an liaison lier surveys

Cost estimation dgets allocations ost control activity and computer cost

alysis of trends and ordination

sign review

Martin/Governmen agency/contracto

efinition mission vehicles, launch

on decisions deoff analyses erface, system and end item specifica tions, preparation

nfiguration contro anning and proce elease of engineer nents and distribution sontract

cations

ange proposals ernal work author1-

ake-or-buy plan contracts and purhase orders

cproved vendor listings

ork package value onthly cost reports ontractually required

to complete nancial records and reports ectives

ry make-or buy plans

ture

Program pla

procedures

esign requirement

d parameters

ogram plan revision

ptract change pro-

Meeting reports

Basis for change board

Approved program spec ification

rogram specifications tion plans

dated spe contract statements tions

esign baseline ment plan

onfiguration status

ases for change pro-

ocumentation plan required data and data

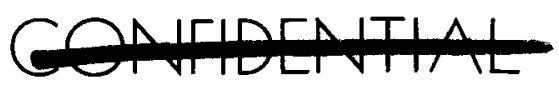




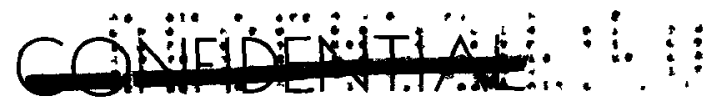

TABLE IV - 4, (contınued)

\begin{tabular}{|c|c|c|c|c|}
\hline $\begin{array}{c}\text { Control } \\
\text { Point } \\
\end{array}$ & Item & Criteria & Activity & Product \\
\hline \multirow{5}{*}{1230} & Planning and PERT/TIme & $\begin{array}{l}\text { Development plan, estab- } \\
\text { lished interfaces and } \\
\text { milestones } \\
\text { Contract requirements } \\
\text { Activity of functional areas }\end{array}$ & $\begin{array}{l}\text { Master phasing and } \\
\text { milestone chart pre- } \\
\text { paration } \\
\text { Coordination of sched- } \\
\text { ule interfaces } \\
\text { Prepare and maintain } \\
\text { PERT / Time net- } \\
\text { works, time esti- } \\
\text { mates for activities } \\
\text { Computer runs }\end{array}$ & $\begin{array}{l}\text { Master schedules, inter- } \\
\text { face schedules and } \\
\text { delivery schedule } \\
\text { PERT / Time detail and } \\
\text { summary networks }\end{array}$ \\
\hline & Schedules & $\begin{array}{l}\text { PERT networks and status } \\
\text { records }\end{array}$ & $\begin{array}{l}\text { Prepare, monitor and } \\
\text { maintain detanl bar } \\
\text { chart schedules }\end{array}$ & $\begin{array}{l}\text { Inputs to maintain PERT } \\
\text { networks }\end{array}$ \\
\hline & $\begin{array}{l}\text { Planning Reports and Man- } \\
\text { agement Displays }\end{array}$ & $\begin{array}{l}\text { PERT status-computer out- } \\
\text { puts }\end{array}$ & $\begin{array}{l}\text { Prepare program } \\
\text { progress reports for } \\
\text { management }\end{array}$ & $\begin{array}{l}\text { Output, status and man- } \\
\text { agement reports }\end{array}$ \\
\hline & Manufacturing Plan & $\begin{array}{l}\text { Engineerıng drawings and di- } \\
\text { rection } \\
\text { Program schedules } \\
\text { Quality requirements } \\
\text { Manufacturing standards, } \\
\text { processes and manuals }\end{array}$ & $\begin{array}{l}\text { Plan utılization of fa- } \\
\text { c1lities, tools and } \\
\text { personne1 } \\
\text { Establish criterıa for } \\
\text { processes, produc- } \\
\text { tron flow and reten- } \\
\text { tlon of design, spec- } \\
\text { ffication and drawing } \\
\text { constraints }\end{array}$ & $\begin{array}{l}\text { Manufacturing flow chart } \\
\text { and implementation } \\
\text { plan }\end{array}$ \\
\hline & Operations Plan & $\begin{array}{l}\text { Schedule } \\
\text { Launch site facilities } \\
\text { Interface specifications } \\
\text { Ground support equpment } \\
\text { Customer requirement }\end{array}$ & $\begin{array}{l}\text { Establish sequence of } \\
\text { events in use of de- } \\
\text { livered systems } \\
\text { Define organization } \\
\text { responsible for ac- } \\
\text { complishing events } \\
\text { Coordinate plan with } \\
\text { Customer and inte- } \\
\text { grating contractor }\end{array}$ & $\begin{array}{l}\text { Preliminary operations } \\
\text { plan } \\
\text { Approved operations } \\
\text { plan }\end{array}$ \\
\hline 1240 & $\begin{array}{l}\text { Program Reviews and } \\
\text { Briefıngs }\end{array}$ & $\begin{array}{l}\text { Contract requirements } \\
\text { USAF AFSCM } 375-1 \\
\text { Approved specifications }\end{array}$ & $\begin{array}{l}\text { Preliminary design re- } \\
\text { view } \\
\text { Critical design review } \\
\text { First article configu- } \\
\text { ration inspection } \\
\text { Customer briefings }\end{array}$ & $\begin{array}{l}\text { Verification of correla- } \\
\text { tion of contract re- } \\
\text { quirements, specif1- } \\
\text { cations, product design } \\
\text { and end item hardware }\end{array}$ \\
\hline \multirow[t]{3}{*}{1250} & $\begin{array}{l}\text { Program Reports and } \\
\text { Manuals }\end{array}$ & $\begin{array}{l}\text { Contract requirements } \\
\text { Documentation plan }\end{array}$ & $\begin{array}{l}\text { Supervision approval } \\
\text { of printing and dis- } \\
\text { tribution of reports } \\
\text { and manuals such } \\
\text { as }\end{array}$ & $\begin{array}{l}\text { Documentation in accord- } \\
\text { ance with provisions of } \\
\text { the contract }\end{array}$ \\
\hline & & & Reports & \\
\hline & & & $\begin{array}{l}\text { Monthly } \\
\text { Quarterly } \\
\text { Summary } \\
\text { Topical } \\
\text { Fllm }\end{array}$ & \\
\hline
\end{tabular}

NOTE

Quality Program Plan--see Volume 6 Specification Plan--see Volume 4

Documentation Plan--see Volume 4

Configuration Management Plan--see Volume 4

Test Plan--see Control Points 3026, 4026 and 5036

Reliability Plan--see Volume 6 


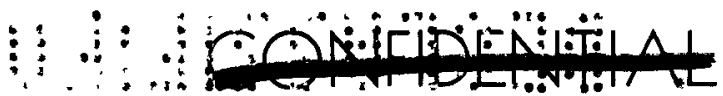

\section{0--PROGRAM ADMINISTRATION AND MANAGEMENT}

This control point (task) encompasses the overall management effort of the CRONUS program and includes all of the management functions essential to conducting a program involving complex interrelations between contractors and Government agencies. These functions include administration and management, scheduling and control of the program and external activities such as negotiation, liaison, integration and communication with the AEC, User Agency, Fueling Agency and subcontractors. The task represents the focal point of the program, linking external requirements and activities to internal correlation with the requirements and actions. The task relates to all aspects of the program over its full span and cannot logically be apportioned among other elements of the program.

To permit further definition for cost accumulation and control purposes, the control point is further broken down into:

\section{(1) 1100: Administration}

(2) 1200: Program and Technical Management

These efforts are further subdivided as shown in Table IV-4.

\section{A. 1100--ADMINISTRATION}

The administrative functions to be accomplished under this control point are, for the most part, activities which are not direct charges against the contract. These particular functions are closely linked to program and technical management activities discussed under control Point 1200. Personnel responsible for these administrative elements on the CRONUS program are assigned to the Program Manager's staff and their responsibilities are categorized as follows:

1110--Contract Administration

1120--Procurement and Subcontract Administration

1130--Finance Management

1. 1110--Contract Administration

The Contracts Manager, as a member of the Program Manager's staff functions in a capacity very similar to the Government's contracting officer. Basically, his responsibility is to ensure that an acceptable agreement is negotiated on behalf of the Corporation and to ensure

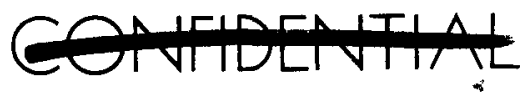




\section{G}

that the functional departments perform the obligations assumed under the agreement. He also is responsible for ensuring that all appropriate changes are properly and equitably incorporated in the Contract agreement. One of his primary obligations is to assist the Program Manager in the separation and segration of the various tasks under the contract and to establish responsibilities for the performance of these assignments. Working with the program, engineering, finance, control and functional managers, work packages or tasks are developed and budgets established, based upon the schedule, manpower and formal requirements of the contract.

The definition and assignment of work, overall schedule requirements and budgets are issued with Program Manager approval, in the form of Operations Directives which are distributed to the departmental managers and program representatives as program guidelines and as the basis for work to be performed. The receiving functional departments and sections subsequently undertake the effort required for their assigned tasks within the framework established by the Operations Directives. Where appropriate, individual departments and sections assigned to the program prepare and issue, within their respective areas of assignments, additional directives to implement their activities.

The Operations Directive is the means utilized to translate customer inputs and requirements into the basic control document that is used throughout the Martin organization. The Operations Directive iterates and amplifies the contract requirements for the functional departments, thus assuring a common basis of understanding and avoids individual interpretations of contractual language. As necessary, the Operations Directives issued on the program, are revised to authorize and reflect new, or changed requirements such as additional effort, contract schedule revisions and revised funding limitations. It is also utilized to issue Master Account Numbers and accompanying Suffix Control Numbers for cost accumulation and control purposes. These controls are related to specific work packages and tie into the internal program schedules and budget limitations. These documents are also used to authorize the cessation of work where appropriate and for purposes of closing out a phase of the program.

As a member of the Program Manager's staff the Contracts Manager participates in the review of customer correspondence and assesses the impact relative to the effort on contract requirements. It is his function to determine if the direction is within or beyond the scope of the contract. When appropriate, he coordinates the activities of the other staff and functional departments in preparing contract change proposals for customer submittal and negotiations. This portion of his charter requires that he take an active role in the program prosecution and dictates that he be aware of the activities of key elements of the

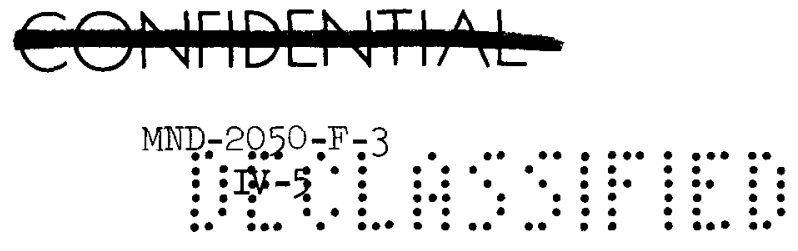




\section{LII:}

program. This identification and close relationship with the program provides a focal point of contact with the customer on contractual matters and enables retention of contractual obligations as the prime consideration in conducting the program.

The administrative team formed by Contract, Pricing and Control Managers and their staffs maintain close physical proximity. This team concept ensures that the required communication and interchange of management information and data takes place expeditiously. It provides an atmosphere of complete consideration of all the aspects of a particular problem, avoiding the problems of a centralized administrative operation which may lack program identification and team cohesiveness.

The Contracts Manager is the liaison or the communication link with the legal and patent departments within the Company. His active participation in day-to-day program activities provides him with the necessary background to interpret problems in the light of contract requirements and provide management with information relative to Company obligations. This program exposure enables a better presentation of problems to the legal department and other groups not directly associated with the program and facilitates timely resolution. Examples of these other groups which periodically interface with the program and rely on the Contracts Manager as a central source or beginning point in attacking a program problem are the Insurance, Labor Relations, Personnel, Management Engineering, Property Accountability, Public and Community Relations, Industrial Safety and Facilities Departments. The re!iance by these support departments personnel upon the Contracts Manager relieves the program and technical managers of these problems and thus permits them to devote more of their attention to the more direct management and technical aspects of the program.

\section{1120--Procurement and Subcontract Administration}

Producing reliable products depends upon the ability to establish and maintain a supply base, to purchase economically, and to obtain quality materials and services on schedule. The accomplishment of these objectives is the responsibility of the Materiel Manager, whose organization encompasses every phase of the materiel cycle beginning prior to the determination of a requirement through delivery of the material to the ultimate user. Under this concept, the Materiel Manager controls the cost and scheduling of all materiel. He is responsible for management of all equipment, parts, supplies, materials and services required by a Nuclear Program, from definition of the requirement, to disbursement of material to the user, to contract completion. He has cognizance over purchasing, production and inventory control and all materiel support functions. These support functions with respect to subcontracts and procurement include: subcontract evaluation; proposal pricing and budget control; material control; material handling; price and cost
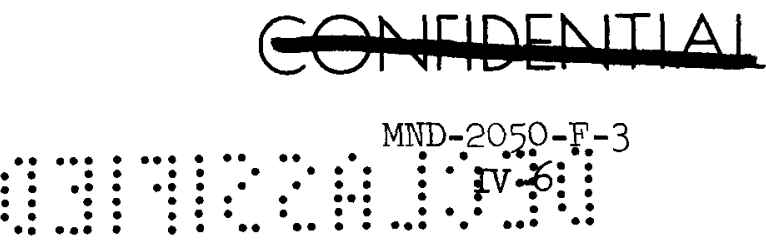


\section{(1)}

analysis; value analysis; and administrative services such as order processing, source data maintenance, small business liaison, systems and surplus sales.

\section{Make-or-Buy Decisions}

Nuclear Programs has an operating make-or-buy program. The Makeor-Buy Committee determines whether items are to be made or work is to be performed within the Corporation or subcontracted. Items of work to be performed within the Martin-Marietta Corporation subsidiaries or affiliates are classified as make items. Those to be procured from outside sources are classified as buy items.

Items of work are normally referred to the Make-or-Buy Committee when:

(1) Nature of the work or item differs significantly from work normally performed or items normally made within the Corporation.

(2) Production of the item or performance of the work will create a requirement; either directly or indirectly, for additional facilities to be furnished by the Government

(3) The item or work has been subcontracted and because of problems in delivery, cost, quality, performance, etc., it appears necessary to withdraw it and either make it within the Corporation or to resubcontract it.

(4) The item or work, because of its complexity, quantity, or cost, normally would require Martin Company management review of the make-or-buy decision.

(5) A make-or-buy review has been requested by the customer on an important item or work that does not fall under the direct parameters of the criteria stated but which, under the intent of customer policy, should be subject to a make-or-buy review.

The General Manager, Nuclear Programs serves as Chairman of the Nuclear Make-or-Buy Committee. Members of the committee include the cognizant Program Manager, the Assistant Director of Engineering and Research, the Manager of Materiel, the Chief of Production and the Marketing Representative. The Chairman may delegate his authority to an alternate chairman on an ad hoc basis and may invite other personnel to participate as required.
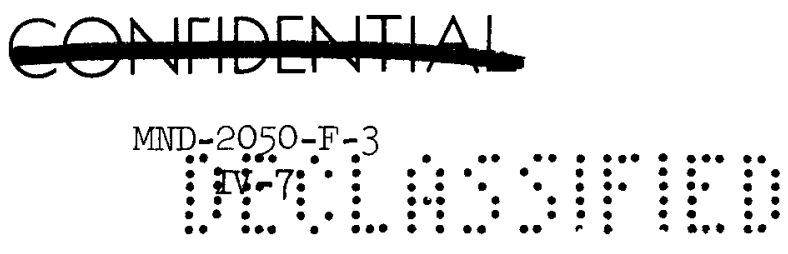


\section{III)}

The Program Manager is responsible for the compilation of pertinent data necessary for the Committee to arrive at decisions. In establishing or revising make-or-buy programs, the Committee gives consideration to such factors as costs, prime contract terms and conditions, schedule requirements, mobilization base policy, availability of manpower, facilities, supplier quality capabilities, technology, previous makeor-buy operating experience, future requirements, market conditions, availability of the material, and where applicable, the circumstances and data which were the basis for the original make-or-buy program.

\section{Source Selection}

Supplementing the Materiel Manager's own resources, there is available to him a comprehensive source data file on more than 10,000 active and potential suppliers. Prepared, maintained and supplemented entirely by Martin, this file contains product, Company and financial information; correspondence and reports; and surveys and evaluations. These products are also included in a Martin-prepared cross index. In addition to these Martin-prepared files, there are the usual registers, directories and source books in print, and a microfilmed subscription service covering over 14,000 suppliers.

\section{Supplier Performance Evaluation}

For several years, Martin has utilized a supplier evaluation system that is sensitive to performance data as reported by Quality Control and Procurement personnel. In this system every receipt is noted, with actual receipt and contract dates, variance and responsibility for the variance. Each rejection is shown, with origin and disposition dates, cognizant buyer, authorization for disposition, type of rejection, disposition of rejection, responsibility and notation as to whether source inspection was performed.

The buyer, having access to these tabulations, can immediately detect any probelm areas, recognize trends, and intelligently plan future action. The performance tabulations are sufficiently detailed so as to provide a basis for discussion of a supplier's performance without reference to other documents. The record shows the actual performance, and all tabulations are cumulative and released monthly, making a complete record of receipts and rejections available for permanent reference at the year's end.

\section{Subcontract Administration}

In subcontracting, the placement of the subcontract, the administration of changes and the surveillance of subcontractor costs and schedules are more highly organized and involve more paperwork than is generally required for ordinary procurement. On the CRONUS program, 
the Materiel Manager and his most experienced contract administrators will be responsible for the major subcontract transactions. Make-orbuy decisions will establish the extent of required subcontracting. It is anticipated that subcontracts will be let in the following areas:

(1) Thermoelectric subsystem--A subcontract was let to Radio Corporation of America during Phase 0 to participate in development of a silicon-germanium module suitable for the CRONUS application. This development plan is based on continued development and fabrication of thermoelectric modules for the generator by RCA under subcontract to Martin.

(2) Propulsion rocket system--Initial liaison and discussion of program requirements has been accomplished with major rocket fabricators. Preliminary product performance, schedule and cost data have been received, indicating a strong desire to pursue a formal rocket program under subcontract with Martin.

(3) Insulation developmnet--Investigations during Phase 0 have established a desired approach in resolving needs for thermal insulation. Preliminary data have been received from a major insulation supplier along with indications of willingness to cooperate further with Martin in the determination of thermal insulation requirements and the fabrication of required materials.

(4) Space ground link system and aerospace ground equipment-Subcontracting of selected components or subsystems in these areas appears desirable. Exploratory inquiries have been made to qualified companies interested in this type work in anticipation of the establishment of more definitive requirements.

On major subcontracts, periodic visits will be made by the Materiel Manager and his contract administrators. When necessary, qualified technical and financial personnel will accompany the Procurement Representative. A Resident Procurement Representative may be assigned, if warranted, on larger subcontracts to expedite problem resolution and communications.

\section{3. $1130--F$ inance Management}

The Finance Manager, working as a member of the Program Manager's staff, has the responsibility of coordinating and effecting sound financial and accounting practices throughout the entire program. The basic objective is to keep AEC and contractor management appraised of the financial status of the program at all times. His responsibility

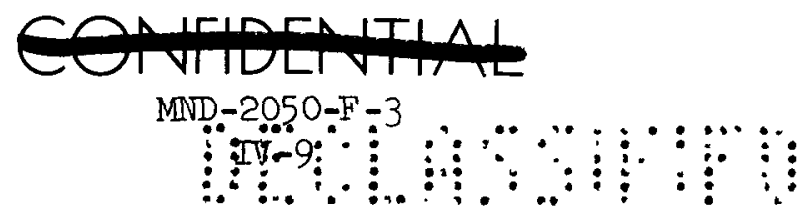




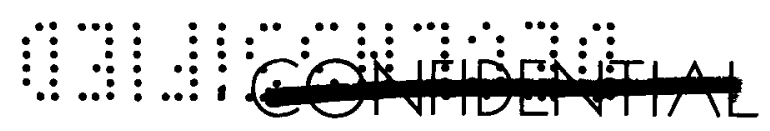

entails implementation of the following departmental functions and activities with respect to the program.

\section{Accounting}

The centralized Accounting Department utilizes a job order cost system that is tied into the general ledger. The contract is assigned a se-arate master account number for cost accumulation. A suffix number identifies specific categories of cost within the master account. A subaccount number provides company division identification, class of cost, e.g., departmental, direct or overhead, type of cost and applicable overhead. A detail number is used to further identify component costs that cannot be obtained through the use of suffix numbers.

Direct labor charged to individual accounts is the actual hours worked (recorded by Timekeeping) extended by the respective employee's rate. Material is charged as invoiced when ordered directly for a specific program. Inventoried stock material costs are reaveraged at each buy and contracts are charged at the current average at the time of withdrawal. Overhead is booked throughout the year at standard rates. The standard rates are forecasts, based on anticipated business expenditures, and are re-evaluated periodically to reflect any significant change.

Adjustments are made at the end of the year to incorporate actual overhead costs. Weekly detail labor computer reports, and complete monthly cost summaries are utilized for management appraisal of performance and status.

\section{$\underline{\text { Pricing }}$}

Pricing personnel prepare all parts of cost estimates, including hours required for various types of labor, material and subcontract costs and other direct costs and rate applications. Estimating is not confined to summarization and review. It also ensures that all parts of the estimate--engineering, tooling, manufacturing, material subcontracting and quality control--are compatible. In addition to preparation of cost proposals, these personnel are responsible for negotiation of profit rates, prices, cost incentive provisions and other financial terms and conditions. Pricing personnel are also responsible for maintaining financial information on a current basis, for notifying AEC of significant changes affecting current cost or pricing data and preparation of contract change proposal financial data. 


\section{Cost Control}

Cost planning. The initiation of cost control begins with the establishment of a cost plan. Cost objectives and goals are developed in conjunction with the functional organizations, identified with cor ractual financial requirements and projected by time phasing for purposes of budgeting and reporting. Operating budgets are issued to departments by means of the financial limitations contained in Operations Directives. The budgets also specify manpower levels and must be compatible with departmental personnel planning.

Direct labor costs. Various means are used to measure cost and direct labor performance. In engineering areas, detailed planning of work by tasks and functional groups is gantted in terms of manpower versus span time. These values are summarized for comparison to operational budgets. Deficit budget variances are reviewed and investigated to establish recovery plans. In the manufacturing area, the various operating departments establish performance controls over the total contract effort. Specific operations are reviewed, standard times are established by time and motion studies and tied into schedule and manpower requirements. Weekly and monthly summaries are prepared for all departments to indicate performance.

Overhead expense. Overhead controls are implemented through the use of budgets for specific accounting periods based upon estimates of indirect manpower and expense of various departments. These estimates are summarized and evaluated against performance and future business levels. Operating budgets by department are determined and issued to the department director who, in turn, issues budget on sectional levels. Actual cost is recorded against these budgets and variances reported. Responsibility for efficient performance rests with the department directors who report directly to the divisional vice president.

Labor rates. Overall labor rates are periodically reviewed to determine out-of-line conditions and corrective action plans implemented. In addition, organization structure and labor rates are subjected to periodic review and approval by government agencies.

Material costs. Operating budgets are established for direct material purchases. Buying practices which ensure that orders are let to the lowest bidder, after proper consideration as to quality and schedule, are basic operating procedures. Frequent audits by both Company and government agencies initiate action to modify procedures to guarantee procurement practices which foster competitive sources of supply. 


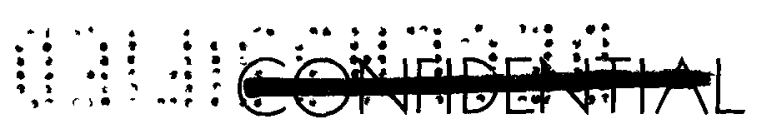

Subcontract costs. In the area of subcontract procurement, extensive evaluations of the costs proposed by subcontractors are made prior to negotiating the price. This evaluation considers the subcontractor's accounting system, production, capability and cost performance in relation to industry standards. Major emphasis is placed upon cost performance in determining the ultimate price negotiated. Evaluations are usually conducted on purchase orders over $\$ 100,000.00$ and those of a $\mathrm{CPFF}$ or redeterminable nature.

\section{$\underline{\text { Reporting }}$}

The flexibility of the cost accounting charge number and the cost control techniques previously discussed provide full capability to furnish monthly cost status reports. These reports will be furnished to the AEC on/or about the eighth working day of each month, showing the status as of the close of the accounting period for the preceding month.

Internally, numerous divisional performance and manpower reports are used in controlling contract costs. In preparing these reports, Cost Control personnel perform an evaluation of performance versus the cost plan. This evaluation detects out-of-line conditions and permits determination of the reasons so that management action can be taken.

\section{B. 1200--PROGRAM AND TECHNICAL MANAGEMENT}

This control point encompasses the program management functions of direction, coordination, control, planning and management liaison activities with Government Agencies and other contractors. In brief, it represents the major focal point of the program, linking external requirements to the internal execution of these requirements. Included within the control point are the activities concerned with formulation and coordination of plans, and program planning and scheduling activities. Also, it includes management review, and the distribution of program documentation such as program and functional plans, formal reports and the manuals to be furnished under the contract.

The elements of the control point consist of:

$$
\begin{aligned}
& \text { 1210--Program Direction and Control } \\
& \text { 1220--Configuration and Data Management } \\
& \text { 1230--Program Schedules and Plans } \\
& \text { 1240--Program Reviews and Briefings } \\
& \text { 1250--Program Reports and Manuals }
\end{aligned}
$$

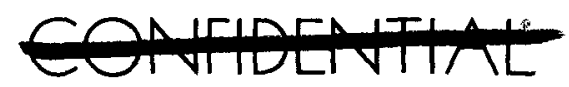


1. 1210--Program Direction and Control

This control point includes planning, direction, coordination, control and liaison activities performed by the following functions:

\author{
Program Nanagement \\ Manufacturing \\ Technical Direction \\ suality Control
}

\title{
Program Management
}

As indicated in Chapter III, the program covered by this development plan will be conducted in accordance with the program management concept. The Program Manager will have the responsibility and authority to direct integration and liaison activity, the technical and manufacturing programs, financial expenditures, planning and scheduling, procurement activity and implementation of control administrative functions. It will be his responsibility to assure that all contractual obligations are met and, further, to maintain the proper balance between these factors. To achieve this balance, the Program Manager will use a number of management procedures to control and integrate the program, including:

(1) Coordination meetings, on an informal basis, with the Technical Director, project engineers and functional managers.

(2) Weekly program meetings with all members of the supporting staff.

(3) Monthly program review meetings, conducted by the Program Manager, with the top management to assure:

(a) Proper dissemination of information to top management levels.

(b) Assistance of top management in applying the experience available throughout the Company to the CRONUS program.

(c) Upper levels of company management that the program is proceeding properly or, if delinquent, to obtain their aid in correcting deficiencies.

(4) Engineering Design Reviews held at appropriate design milestones to assure compliance with specifications, adequacy of design and the consideration of alternate design and development approaches.

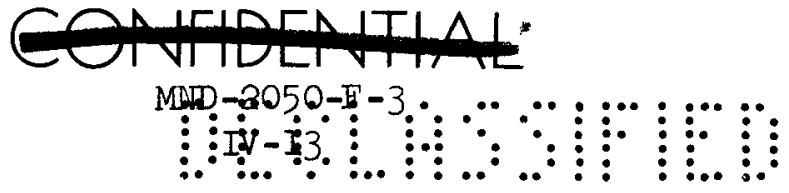




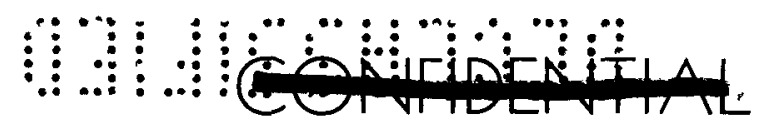

(5) Coordination among the Program Manager, his staff, the Atomic Energy Commission, cognizant Government agencies and, when appropriate, the User Agency as required throughout the program.

(6) Implementation of a system of schedule controls, employing the following elements:

(a) Major milestone charts showing the schedules relationship of major milestones of the program.

(b) Detailed gantt charts establishing the chronological time for minor milestones, providing inputs on the progress toward major milestones.

(c) Page and line schedules of detailed day-to-day scheduling for each control point, listing activities to be accomplished (analysis, design, purchase order release, material and components available, quality inspection, fabrication, qualification, acceptance, etc.). These schedules will be reviewed in detail on a weekly basis to assure schedule compliance or to pin point deficiencies so corrective action can be taken. The results of page and line schedule reviews are reflected in updated PERT networks. The deficiencies uncovered, which create critical path or major milestone delays, are subjected to immediate corrective action.

(d) PERT/TIME charts such as summary network to control interfaces and areas of work which affect integration and coordination of individual systems with each other.

(7) Implementation of a system of cost control employing the following elements:

(a) Layout of cost estimates by control point by the month. This expenditure plan establishes the base line of dollars for accomplishment of the requirements of the control point, and each control point is identified by its own cost control center.

(b) Establishment of funding limitations, by cost control centers, or by functional department, by issuing Operations Directives which indicate limiting expenditures, by whom, for what and the span time in which the expenditure is authorized.

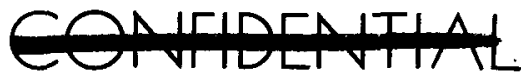


(c) Weekly unaudited IBM cost runs are prepared for review at program meetings in conjunction with a review of the accomplishment. Financial problems encountered are subjected to corrective action and the customer is notified at the earliest time if funding under the contract is affected. Graphical representations showing curves of input versus output are prepared and maintained to provide visual display of planned spending rates and planned accomplishments versus actual spending rates and actual accomplishments.

\section{Technical Direction}

The Technical Director is responsible to the Program Manager for the technical direction of the program. In this capacity he is responsible for all engineering technical effort including liaison, analyses, design, testing, systems integration, reliability, and technical support services furnished to the customer. His responsibilities include:

(1) Integration of the technical efforts of Martin and its subcontractors to assure optimum products in conformance with contractual specifications and within prescribed schedule and budget limitations.

(2) Furnishing competent technical leadership to his program team and to lead Engineering efforts in consonance with Company operating procedures and policies.

(3) Approval and control of ingineering schedules, budgets, and expenditures.

(4) Establishment and maintenance of program documentary files of technical correspondence, drawings, vendor and subcontractor data and technical documents furnished in accordance with contract requirements.

(5) Supervision of the forming and preparing of contractually required technical data and documentation, such as progress and technical reports and equipment manuals.

\section{Manufacturing}

The Marufacturing Representative has the responsibility to establish, coordinate and control all manufacturing and related functions from program inception through delivery with relation to required schedule, budget and quality. He also acts in a liaison capacity for manufacturing,

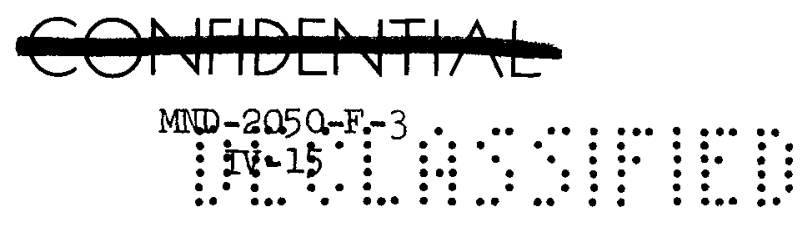




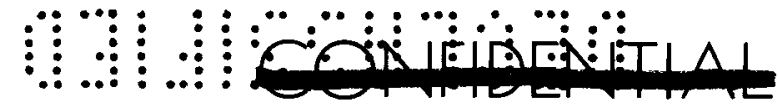

tooling, receiving and shipping functions. The duties of the Manufacturing Representative include:

(1) Coordination with the Program Manager in establishing estimates and schedules and implementation of manufacturing functions in accordance with Operations Directives received from the Program Manager.

(2) Issue of Manufacturing Project Directives which establish authorization and direction for all manufacturing requirements.

(3) Direction to Production Planning to develop and issue detail schedules along with subsequent detail Manufacturing schedules in coordination with program master plans and schedules.

(4) Direction to Manufacturing Engineering in establishing a detail manufacturing plan and covering needed processes, facilities and tools.

(5) Direction to Tool Engineering in their planning, scheduling, tool design, purchase of tool materials and the manufacture of tools. Reviews jointly, with Tool Engineering, the methods for manufacturing new technology materials and products.

(6) Assistance in preparing bills of materials for components to be manufactured.

(7) Generation, authorization and monitoring of purchase requisitions.

(8) Assistance to the Materiel Department on purchased and outside vendor items and monitoring of schedules and the budget. Assistance includes field trips to vendors and suppliers, when required, to assure both manufacturing capability and conformance to schedules.

(9) Coordination of the manufacturing activity of Martin suppliers, where required.

(10) Establishment with Health Physics personnel, of acceptable safe material handling during work processing and shipping。

(11) Providing for manufacturing support for field site requirements.

(12) Arranging and conducting coordination and progress review meetings for assigned programs.

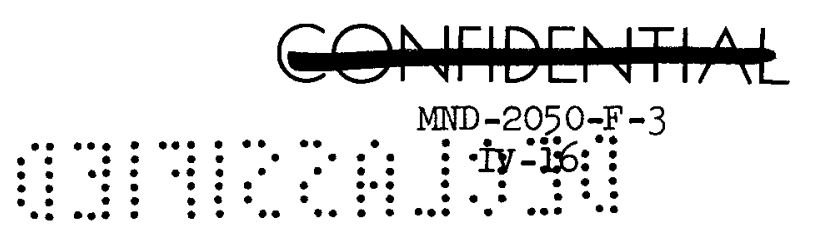




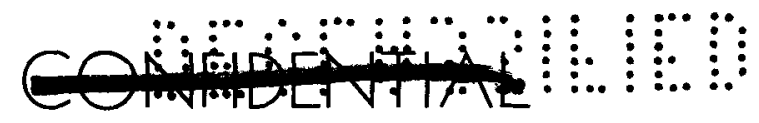

(13) Establishment, with Quality Department, of statistical and quality manufacturing controls to be implemented.

(14) Assistance to shop supervision, as required, on manufacturing problems and monitoring of work progress relative to schedule, budget and quality.

(15) Direction and authorization inputs for shipping of deliverable items.

(16) Development and issuance of detailed status and summary reports.

(17) Assistance to the Program Manager, in liaison with customer representatives, on reviewing program accomplishments.

\section{Quality Control}

This element of work is primarily concerned with establishing, implementing and coordinating the quality assurance activities of individual functional departments and groups. A Quality Department Representative, reporting to the Program Manager, is responsible for establishing controls to provide the desired degree of assurance that products satisfy contractual quality requirements. Through implementation of a quality program plan(s) and issuance of Quality Project Directives, the Quality Representative will direct and control the performance of the Quality organization to assure compliance with contractual requirements. His duties include coordination and surveillance of the following:

(I) Establishing and internal coordination of detailed quality procedures for each phase of the program in consonance with contract requirements and program specifications.

(2) Maintenance of certified test data files.

(3) Performance of receiving inspection of all materiel to assure compliance with requirements of program documentation.

(4) Performance of inspection of all parts to assure compliance with Engineering criteria and documentation.

(5) Maintenance of compliance logs and/or charts as applicable to reflect specific verification of inspection check points on subassemblies, assemblies, in-process control, final assembly and testing.

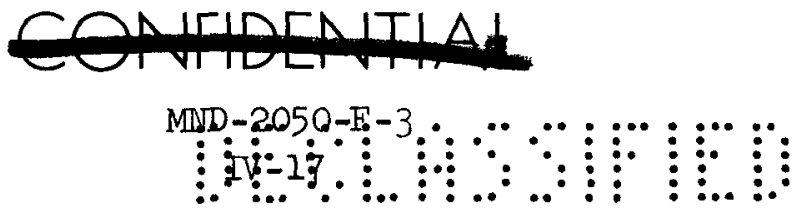




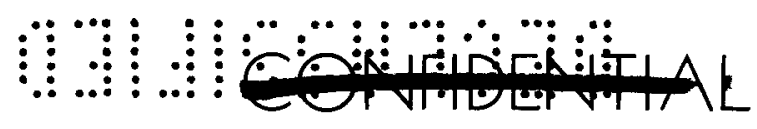

(6) Maintenance of calibration systems for all tools, equipment and test instrumentation.

(7) Performance of on-site inspection of suppliers and subcontractors (where required) and establishment of an adequate supplier Quality program.

(8) Performance of tests using the facilities of the quality Department which include Material and Process, Electromechanical and Standards Laboratories.

(9) Implementation of corrective action programs to promptly detect and correct conditions adverse to maintenance of quality.

(10) Monitoring and assurance of proper handling, storage, preservation and delivery of equipment to applicable requirements.

2. 1220--Configuration and Date Management

This subtask encompasses the procedures, documentation and coordination between Martin and other organizations that is necessary to establish and maintain effective requirement base lines for design, development, test and fabrication and the integration of CRONUS into the operation, equipment and facilities which make up the total mission program. This effort is further defined to include interface liaison, interface control and Configuration Management.

To define the technical requirements and objectives for CRONUS and the interface between the articles and services furnished by Martin. with the products and services of others, a series of interrelated specifications and plans have been prepared under contract AT(29-2)2050. These documents are contained in Volume IV of this report; the summary report for Phase $O$ of the CRONUS program. Volume IV includes the specifications, Configuration Management and documentation plans for the complete CRONUS program and the system and interface specifications which form the basis of program technical requirements including interface and interface control requirements.

\section{Interface Liaison and Interface Control}

The CRONUS program necessarily entails a complex interface relationship between Martin, The AEC/Sandia, User Agency and contractors of the User Agency concerned with the total or segments of the space mission program. Requirements as generated, coordinated and approved during Phase I of the program, will where required, be reflected in up-dated and amplified specifications and related documentation. It 
is anticipated that during the CRONUS program the interface relationship shown in the diagram of Fig. IV-2 will exist. Accordingly it is recommended that an interface working group be established representing agencies and contractors affected by CRONUS. This group would review and establish an acceptable base for system changes affecting the respective contractors in preparation for the formal change negotiation cycle between contractors and their procurement agencies. In addition, the group would act as a focal point for establishing agreements to promote working relationships; for example, between Martin and the contractor designated by User Agency as his integration contractor.

\section{Configuration Management}

The procedures and techniques described in MN-2050-1 through $\# 3$ (Volume IV of this report) will be used to identify, control and account for contractor technical efforts and the articles to be furnished under the contract. Specifically, configuration management will perform the following:

(1) Establish and define functional and physical interfaces between contractor-furnished articles and services and the equipments, facilities and activities of others.

(2) Define the technical requirements for design, fabrication, test and delivery of contractor-furnished articles.

(3) Define efforts and services to be furnished by the contractor.

(4) Establish and define procedures and documentation to be implemented and supplied by the contractor and which are compatible with or necessary to both AEC, User and other agency activities.

(5) Control contractor-procured articles and the efforts and products of subcontractors.

(6) Establish and control the interrelation of contractual and technical requirements.

(7) Provide for verification of compliance with contractual and technical requirements.

(8) Furnish a basis for acceptance of contractor-furnished articles and efforts.

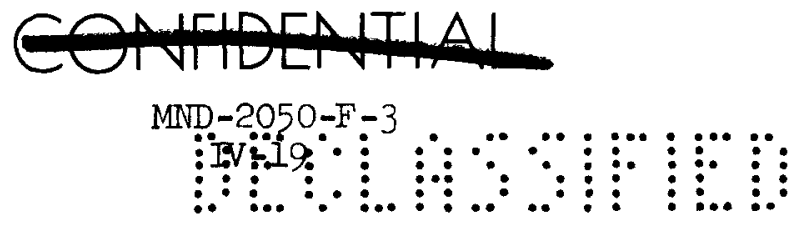




\section{4}

Comprehensive specifications will be prepared as a part of Configuration Management activity and coordinated with the AEC. Preparation and finalization of these documents will be accomplished as early as practicable in Phase $I$. However, the specific points in the span of program phases where the documents will be considered as firm will be based on the scheduled point at which interface criteria between the Contractor and the User Agency must be considered frozen. This schedule point necessarily occurs at that time where changes by either Martin or the User Agency will appreciably affect the effort and end articles of the other organization.

3. 1230--Program Schedules and Plans

PERT/TIME and Planning

The integrated schedule control and management reporting technique referred to as PERT/TIME will be used on the CRONUS program to enhance decision making at various levels of Martin management. The PERT/TIME system, based on USAF methods, will assist program management in the coordination of program planning, assessment of project status, reprogramming to cope with difficulties or program changes and the coordination of progress data.

A Planning and Control Representative, responsible for PERT/TIME and scheduling activities, will be assigned to the Program Manager's staff. The Representative will be responsible for master plans, phasing charts and milestone schedules to be developed and coordinated among customer, contractor and subcontractors. This planning activity will include preparation and maintenance of PERT summary and detail networks for each level of the program. The networks will be structured in coordination with the systems breakdown and control point structure. Summary networks will contain all major milestones and interface points of the program to permit ready interpretation or the effects of schedule delays or changes. Detail networks will be prepared for each subsystem within CRONUS. In all, it is expected that up to 10,000 PERT events will be used to adequately control the program. These events will be based on estimates of work derived from coordination of the activities of functional areas. Time estimates for the work to be done will form the basis for preparation of computer input forms and computer runs to generate output reports of schedule status.

Throughout the entire span of the program, detail page and line schedules will be prepared and issued for coordination and guidance of all functional areas. Both page and line schedules (bar charts) and PERT networks will incorporate the same control point numbering system as a direct link between the two forms of scheduling and control activity. Weekly meetings will be conducted to review page and line schedules and

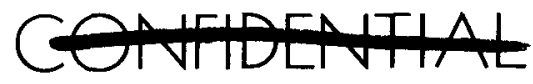




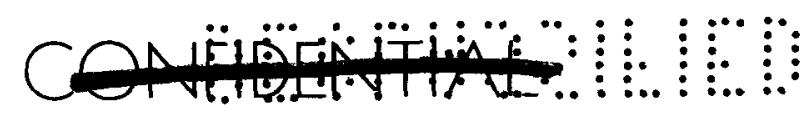

the resultant status data used to up-date computer input forms and to obtain PERT status output reports. The up-dated output reports will be analyzed and reflected in program control charts for management review and, if necessary, direction for corrective action. PERT status reports will also be provided on a monthly basis to accompany narrative progress reports supplied to the customer.

a. Total program plan

The development plan contained in this volume is based on the particular provisions of Contract AT(29-2)2050. It is expected that the contract for the follow-on phases of the CRONUS program will entail up-dating of this development plan to reflect customer requirements. This up-dated plan, showing the work to be performed and the articles to be furnished, will be prepared and submitted to AEC/Sandia at the earliest practicable date after the effective date of the follow-on contract. Pexformance of the program will conform to the plan as approved.

\section{b. Manufacturing plan}

Fabrication and manufacturing operations required for development and test articles and the contract end items to be furnished for the CRONUS program entail a complex interrelation of personnel skills, facilities, tools, methods and schedules. To integrate responsibilities, functions and equipment necessary to fabricate CRONUS hardware items, a Manufacturing plan will be prepared during Phase I for all fabrication effort involved in the program from component development through operational flight article delivery. The plan will reflect or include the manufacturing operations discussed under individual control points of this chapter. It will provide the criteria to establish and implement all fabrication controls and approaches, including:

(1) Establishment and maintenance of proper skill levels; tooling and production on facilities, and the fabrication techniques, methods and processes to be developed or utilized.

(2) Definition of the sequence of fabrication operations with elements of the flow sequence directly interrelated to control point breakdowns and schedules.

(3) Definition of tooling requirements and the utilization of tools in the fabrication of hardware.

(4) Retention of engineering design concepts and criteria such as integrity of manufacturing processes and inherent reliability of products. 


\section{กิ)}

(5) Establishment of bases for: planning of manpower requirements and use of facilities; the use of certified personnel and certified manufacturing operation; fabrication process development; and use of standardized tools; materials and manufacturing techniques.

c. Operations plan

A time-sequenced plan will be prepared with the objective of defining all of the steps or events that CRONUS hardware will encounter after acceptance testing, and the organizations responsible for accomplishing each event. The preparation of the Operations Plan will include:

(1) Studies of the launch facilities, launch vehicle, spacecraft, general mission schedule, interface specifications, launch countdown, generator fueling sequence and the like to determine the phasing of CRONUS hardware into all mission prelaunch activities.

(2) Preparation of a preliminary Operations Plan based on the study results and liaison with Customer, User and User's integrating contractor. The plan will include a block diagram flow chart, Fig. IV-3, similar to that illustrated in the sample shown. It will depict the time sequence of events for the CIR, RTG/RB, $A G E$ and the fuel block/capsule as separate flow diagrams and indicate points of integration.

(3) Submittal of the preliminary plan to Customer, User and Associate Contractors for negotiation and approval.

(4) Preparation and distribution of the Operations Plan in final approved form and maintenance of the plan, through coordination with cognizant agencies, to reflect program changes.

(5) Use of the plan as a tool in decision making related to maintenance, technical manuals, training, repair parts provisioning, field support personnel planning, detailed program scheduling and design considerations.

d. Maintenance plan

To define the overall requirements related to adequate and timely maintenance of CRONUS hardware, a Maintenance Plan will be prepared and coordinated with AEC and User organizations. Preparation and use of the plan will conform to the following:
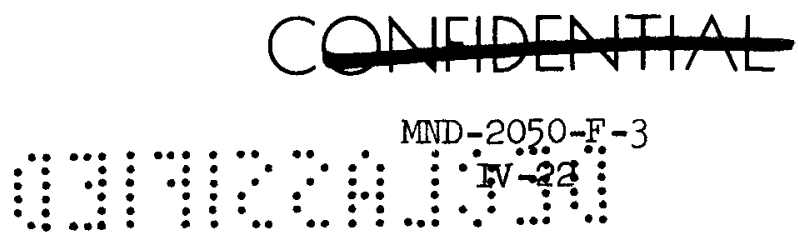
(1) A mutually acceptable general, maintenance concept will be established through liaison with AEC and User organizations. This concept will reflect the provisions of the o erations Plan and estahlish qualitatively the degree of maintenance to be conducted at the launch site, the facility of the User's Integrating Contractor(s) and at the CRONU's manufacturer's Iacility. The agreed upon concept will be reflected in updated issues of interface specifications.

(2) Based on the maintenance concept and Operations Plan, studies will be performed to establish a preliminary Maintenance Plan covering requirements and criteria for:

(a) Maintenance facilities and special equipment for each required maintenance level.

(b) Manning requirements (quantities, skills, and skill levels) and the organizations responsible.

(c) Level of repair part provisioning requirea at each facility.

(d) Specific levels and types of maintenance to be accomplished at each facility.

(3) The preliminary maintenance plan will be submitted to AEC and User organizations for approval and acceptance, respectively. During the span of the program, necessary changes to the plan will be prepared and resubmitted to keep the plan current.

(4) The Maintenance Plan will be used as a basis in establishing the required depth and scope of maintenance manuals and determination of training requirements for both Contractor and User personnel. Further, the Maintenance Plan will be used as a guide in determining repair parts requirements for launch site activities during Phase III (prototype test flight and fueling demonstrations) and spares provisioning needs during Phase IV launch site operations.

4. 1240--Program Reviews and Briefings

During the course of the program, periodic reviews will be used to assure both integration of Company functional areas and satisfaction of $A E C$ and User Agency requirements. These reviews, discussed further in the Configuration and Data Management Plan within Volume IV, will include three types patterned after USAF AFSCM 375-1 exhibits. Each type is iscussed separately. 


\section{Preliminary Design Review (PDR)}

The preliminary design review is a formal technical review of the basic design approach for a contract end item. The PDR is accomplished prior to, or very early in, the detail design phase to establish the system compatibility of the design approach. The primary product of a PDR is the formal identification of specific engineering documentation which establishes the existence of the physical interfaces and the functional interface relationship of the CEI to other (including inventory) equipment/facilities.

\section{Critical Design Review (CDR)}

The critical design review is a formal technical review of the design which is accomplished to identify specific engineering documentation for release to production and to establish a basis for provisioning, preparation of technical manuals and other supporting activities dependent upon a detail design definition of a CEI.

\section{First Article Configuration Inspection (FACI)}

The first article configuration inspection is a formal audit of the as-built configuration of a CEI against its technical documentation to establish the product configuration baseline for the contract end item. One action of the FACI is formal approval of Part II of the CEI detail specification.

Supplementing the formal reviews, periodic briefings will be made to AEC/Sandia personnel on the technical aspects, progress and status of the program. These briefings are expected to range from informal meetings to formal presentations accompanied by briefing alds such as slides, films and supporting reports.

\section{1250--Program Reports and Manuals}

The specific progress and technical reports and the instructiontype manuals to be furnished are itemized within the documentation plan Mi-2050-2 contained in Volume $I V$. The reports furnished will include monthly, quarterly, summary topical and film reports covering progress, status and technical aspects of the program. Manuals to be provided, such as for operation and maintenance manuals, are described under subsequent control points. For the most part, these dccuments will be prepared under the appropriate control point mark centers assigned to each system within CRONUS. However, work related to supervision, integration and approval of these documents and their printing and distribution will be accomplished under control Point 1250.

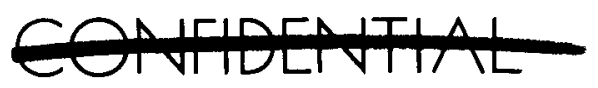




\section{cortontion}

\section{SYSTEMS EVALUATION AND INTEEGRATION}

CRONUS consists of three major systems, each one of which has certain primary functions to perform. The primary functions necessary for a successful mission are:

(1) The RTG/RB System must produce 250 watts of power for five years

(2) The AGE System must provide safe transport of the heat source to the launch site and remote fueling of the RTG/RB when installed in the launch vehicle

The primary functions which might need to be performed in the event of an unsuccessful mission are:

(3) The RTG/RB System must protect the heat source during re-entry and maintain fuel capsule integrity under all circumstances

(4) The CIR System must, when necessary, accomplish separation of the RTG/RB from the host satellite and, if necessary, alter the normal re-entry trajectory to effect impact at a more desirable place

Each of the functions listed in (1) and (2) must be satisfactorily performed if the mission is to be successiul. The individual functions listed in (3) and (4) must be capable of accomplishment if a safe recovery from an unsuccessiul mission is to be assured. It is equally important that, as each CRONUS system performs its functions, the intraaction within CRONUS be complimentary. Moreover, the inter-action between CRONUS and the mission satellite, launch vehicle and ground facilities must be satisfactory if the mission is to be both safe and successful. It is the objective of the Systems Evaluation and Integration task, Control Polnt 2000, to assure that these intra- and inter-actions are mutually compatible in order to achieve total mission success.

The task will entail coordination and monitoring of CRONUS program activities to produce a system which will satisfy all of the mission requirements and be fully integrated within itself and with other mission systems. The task necessarily includes: (1) establishment and coordination of the functional and physical requirements for CRONUS, (2) determination that these requirements are adequate, accurate and maintained current, and (3) assurance that the systems being developed will, in fact, satisfy all requirements.

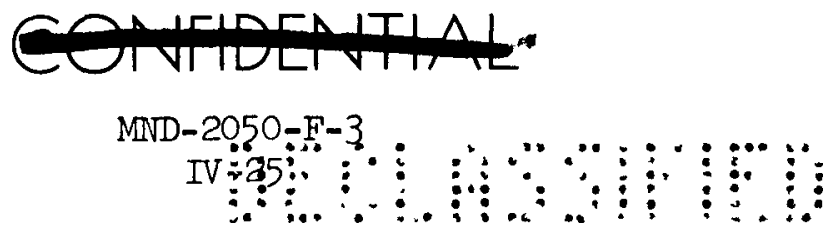


The Systems Evaluation and Integration task consists of three major categories of effort, namely;

\author{
2100 Systems Definition and Interfaces \\ 2200 Systems Evaluation and Integration \\ 2300 Flight Test Support
}

\title{
A. 2100 SYSTEMS DEFINITION AND INTERFACES
}

The objective of this effort is to establish and coordinate the technical framework of CRONUS. This framework will be defined primarily within system and interface specifications based on the results of technical liaison and coordination conducted under this task, with the $A E C$, cooperating government agencies; and the User Agency and its contractors. Additional framework definition will be defined within program plans coordinated with the cognizant government agencies.

Early in the program, an agreement must be reached on the space mission program. Coordination of the technical aspects of these relationships will be a primary accomplishment under this control point. Baseline interfaces will be established along with the details of the methods for maintaining the interfaces on a current basis. The mechanics of exchanging technical data and the types and frequency of technical interchange meetings will be established. A master schedule will be prepared and coordinated covering the timely accomplishment of interfacing tasks which affect cooperating organizations.

Over-all plans for program safety, reliability, and quality assurance will be developed to coordinate the individual cRONUS system efforts and assure that the program goals will be achieved. These plans will form the basis for all program efforts in the areas they encompass. Safety criteria and analyses requirements will be established and coordinated so that documentation needed to meet range safety requirements and applicable governing regulations, etc., will be complete and available on a timely basis. The relationship between safety requirements, reliability goals and quality control responsibilities will also be established as a portion of this task.

As mentioned, the requirements for CRONUS will be documented in interface specifications supported by interface drawings, system specifications and contract end item specifications. These documents will reflect the mission performance requirements as well as the safety requirements. The specifications will define requirements between and within CRONUS systems so that all parameters are satisfied in the most efficient manner. As the specifications for the RTG/RB, CIR and AGE
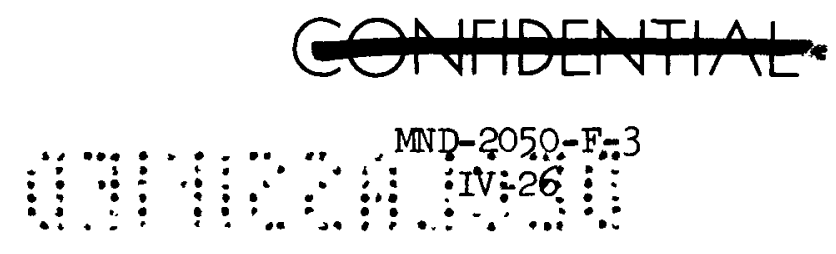
are developed, they will be evaluated with respect to mission requirements, to ensure adequate coverage of all CRONUS requirements. Interfaces between CRONUS and the satellite, launch vehicle and ground facilities will be examined to assure completeness, clarity and accuracy. Conflicts in both the inter- and intra-faces will be resolved by coordination and negotiation with affected agencies.

\section{B. 2200--SYSTEMS EVALUATION AND INTEGRATION}

The objective of this task is to evaluate and integrate the design and analysis efforts performed under each system control point. The purpose of the tasks includes determination of the adequacy and accuracy of individual system activities. Primary consideration will be given to effects on the individual systems of CRONUS. Changes in customer and/ or mission requirements will be evaluated for their impact on the CRONUS development program. Schedules and technical accomplishments of other mission systems (satellite, launch vehicle, etc.) will be monitored for impact on CRONUS and vice versa. A coordinating effort will be performed to maintain the CRONUS program consistent with progress on other programs.

The Nuclear Safety effort associated with each CRONUS system will be monitored to assure that all aspects are examined. Evolving conclusions will be examined for realism and adequacy of consideration given to safety requirements. Safety data and analyses will be compiled into a single CRONUS Safety Report for use by the customer.

Studies which involve more than one system will also be coordinated to assure consistency with overall CRONUS requirements and that adequate consideration is given to both sides of all interfaces. Allocation of reliability goals between systems will be evaluated for schedule and cost impact and feasibility of attainment. Trade-off studies will be recommended and monitored so that intra-system trade-offs may be made realistically. Where appropriate, recommendations will be made to the customer and/or user agency for changes to most effectively embody the results of trade-off studies.

Test plans and specifications will be reviewed and evaluated as the program moves into the test phase. The use of equipment mockups in intrasystem tests will be controlled to provide efficient use and assure that they are accurate for the purposes of the test. When possible, arrangements will be made to use available hardware from one system for the tests of another system with the objective of minimizing effort devoted to fabrication of mockups.

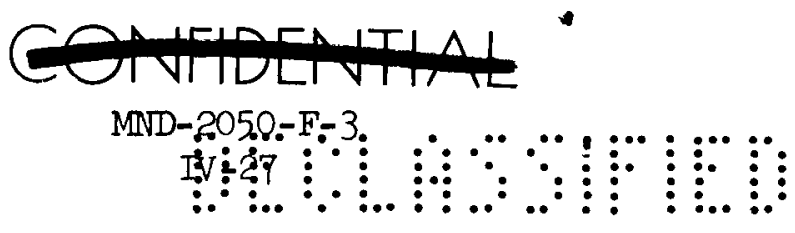




\section{2300--FLIGHT TEST SUPPORT}

The objective of this effort is to coordinate and integrate CRONUS with the launch vehicle, spacecraft and launch site complex. It will be accomplished through continuing technical coordination with the payload and/or spacecraft contractor as well as the customer and using agency. Liaison will start as the test flights are conceived and will initially involve definition of the flight necessary to accomplish program objectives. As the designs of the flight test proceed, the payload contractor will be kept informed of the CRONUS status and will be consulted as to improvements or changes that could be made to enhance the flight. Interface documentation will be reviewed and coordinated among all cognizant parties.

Data requirements will be coordinated for each flight to assure that the necessary documents will be available on a timely basis. Manuals will be coordinated so that adequate instructions are available at the launch site and the spacecraft contractor's facility. Personnel training at both facilities will be coordinated to assure that all CRONUS systems may be properly operated and maintained. Where CRONUS contractor personnel are to perform operations at other than the contractor's site, these activities will be coordinated in advance.

Operations at the launch site will be coordinated under this task. This includes the fueling demonstration, the demonstration flight and the operational flights. Equipment requirements lists for each of these operations will be reviewed for completeness and scheduling of arrival dates and verified with site representatives. Logistics operations in support of site activities such as receiving and storing the heat source will be coordinated.

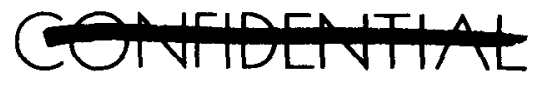




\section{0--GENERATOR SYSTEM PROGRAM}

The objective of this effort is to design, develop, fabricate, assemble, test, and qualify a radioisotope thermoelectric generator which is capable of producing 250 watts (e) for 5 years while in earth orbit. In addition, the generator design will provide protection of the isotopic heat source during an earth impact in the event of a launch abort or failure to achieve a sufficiently long-lived orbit. This protection is accomplished by:

(I) designing and demonstrating the heat source capsules to survive a single-capsule terminal velocity impact

(2) proper aerodynamic shaping of the generator and providing a generator protective ablative heat shield so that the heat source will survive re-entry heating

The generator system consists of seven major subsystems with indiviaual control point numbers for most efficient completion:

$$
\begin{aligned}
& \text { 3200--Heat Source Subsystem } \\
& \text { 3300--Thermoelectric Subsystem } \\
& \text { 3400--Radiator Subsystem } \\
& \text { 3500--Voltage Regulator Subsystem } \\
& \text { 3600--Heat Shield Subsystem } \\
& \text { 3700--Aft Cap Subsystem } \\
& \text { 3800--Beacon Subsystem }
\end{aligned}
$$

The subsystems are combined into the Generator System under Control Point 3100. Under this control point are all combined-subsystems efforts and any system-level efforts. Thermal and thermal efficiency design and analysis, safety definition and analysis, and trajectory and aerodynamic heating analys is are examples of "across-the-boara" ifforts which are performed under this control point.

Because the primary function of CRONUS is to supply power is space, the Generator System effort is designated as responsible for the total safety and trajectory analyses. The safety requirements are considered to be the requirements for isotopic fuel disposition and therefore form the basis for the design of the RTG/RB and the "service" requirements of the CIR. Total mission (including abort) analysis will be performed

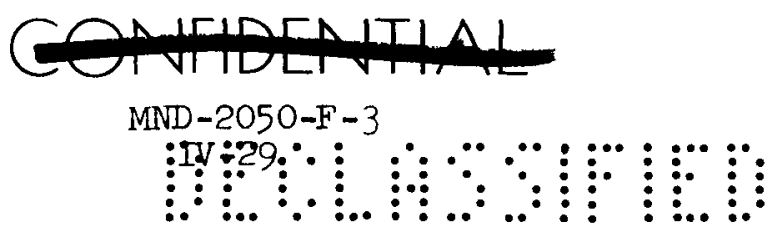


under the G nerator jystem effort. Based on impact point and dispersion area results, the trajectory alteration requirements of the CIR system will then be furnished as input to that Program.

At the Generator System Program level, Control Point 3000 will be ciforts such as the program and technical management and quality Assurance. This includes establishment of Reliability goals, apportionment of the goals to various subsystems and determination and demonstration in each phase that these goals are being met. Overall efforts of quality Control, Value Engineering and similar broad functions will also be done on this level.

1. 3010--Program and Technical Management

This effort is essentially the same as Control Point 1210 and is described in detail under that Control Point.

\section{3020--quality Assurance}

Quality Assurance will be built into the RTG/RB end items through the integrated efforts of the functional departments comprising the orgarizational structure. The primary efforts to be used to obtain quality assured product are:

(I) Reliability

(2) Quality Control

(3) Maintainability

(4) Value Engineering

(5) System Tisting

(6) Engineering Controls to assure that the $\mathrm{RTG} / \mathrm{RB}$ is designed to meet the contract performance goals

to ascertain the delivered end items are as specified in the contract anc specifications

to establish and demonstrate maintenance criteria consistent with program goals and reliability

to obtain specification performance and reliability at minimum cost

to develop system confidence and demonstrate specification performance of the system

to ascertain that system development and design data and analysis are reflected in the end product design 
(7) Manuals and Reports

to document system development, operational characteristics and other operational and maintenance use criteria

\section{$\underline{\text { Reliability }}$}

The goals of the RTG/RB System reliability program are:

(1) To assure that the system will provide 250 watts of power for one ycar with a reliability of $99 \%$ and for five years with a reliability of either $75 \%$ or $95 \%$.

(2) To assure that the probability of release of ranioactive fuel

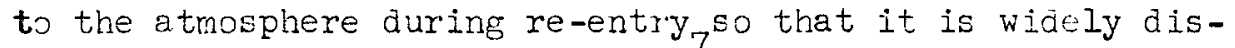
persed shall be less than 1 in $10^{7}$

(3) To assure that the probability of release of the fuel upon impact aue to failure of the capsule integrity is consistent with the apportioned goal for radiation injury criteria and ground handling criteria

Appendix A of Volume III presents the proposed reliability plan based on specifications DOD MIL-STD-785 "Requirenents for Reliability Program for Systems and E lipment" and NASA INPC 250-1 "Reliability Program Provisions for Space Systems Contractors." During Phase I, a comprehensive Reliability Program Plan will be finalized, based on the program plan proposed in Appendix A. This plan will identify the effort necessary to mret total reliability requirements for the RTG/RB and assure that the system components, parts and materials are selected to meet allocated reliability requirements. This plan is designed to provide criteria to guide system design, part and material selection, test programs and qualification of manufacturing processes.

The reliability program plan will be implemented in all phases to assure that designs are fully evaluated and that the established integrated test program provides the maximum reliability data to demonstrate compliance with the reliability objectives.

Presented below is a brief example of some aspects of implementing those plans.

a. Component level controls and test evaluation for reliability

(1) Selection of components in Phase I that are of known reliability. 


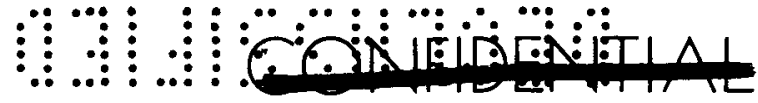

(2) Prepare procurement specifications that clearly establish reliability requirements for the components based on predetermined apportionment of the subsystems.

(3) Select suppliers that have produced similar or identical equipment that has demonstrated its reliability through use on other programs.

(4) Monitor supplier activities to assure compliance with specification requirements.

(5) Conduct acceptance testing of supplied hardware.

(6) Perform in-house qualification testing of the component and monitor subcontractor qualification test programs.

b. Subsystem level controls and test evaluation

(1) Conduct timely design reviews.

(2) Reliability sign-off of all engineering drawings, specifications, and test procedures area prerequisite to release.

(3) Assure the finalized integrated test plan contains adequate testing to provide the data necessary to indicate subsystem qualification.

(4) Life testing of electronic/electrical subsystems, repeating the operating cycle a sufficient number of times to assure the required reliability.

(5) Failure reporting analysis in depth and corrective action loop to assure elimination of mode of failure requiring the corrective action.

c. System level controls and test evaluation for reliability

(1) Design reviews at system level.

(2) Initial system qualification.

(3) Establish rigid configuration control after base-line design is defined.

(4) Perform cyclic life testing of systems.

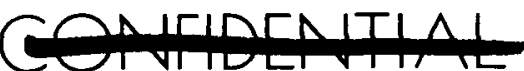


The above examples are not meant to be all inclusive but to describe the general intent and approach in implementing the $\mathrm{RTG} / \mathrm{RB}$ reliability plan.

The RTG system reliability evaluation will be based on considering the failure modes of the individual components with respect to mission operational environments. Launch environments are considered to be a critical factor in reliability evaluation.

During the development test program, it will be necessary to determine the effects of thermal cycling on the thermoelectric couples. The results of these tests will determine the necessity forestablishing restraints on the installation and removal of heat sources (i.e., electrical or nuclear). The number of checkout tests or permissible launch scrubs for an individual generator unit will be determined.

Since the voltage regulator is considered a subsystem of the RTG system, the effects of nuclear radiation, as well as critical launch and separation environments must be evaluated. Selection of components becomes a critical task for this unit because of the unique environments it must withstand. The voltage regulator will be investigated for long Iife characteristics, drift and failure modes that cause loss of individual regulator block components of the regulator..

Electrical connectors and components will be selected from vendors having histories of providing uniformly reliable components. Vendor audits will be made periodically to ensure reliability controls are being maintained. Testing of the thermoelectrics will be started as early as possible to attain sufficient couple test hours to demonstrate adequate confidence levels in the reliability values assumed in the generator design. The recommended couple tests are discussed below in terms of the confidence levels to be achieved.

Periodic reports will be issued on reliability prediction status, failure analysis and corrective action status. The integrated test program is defined to provide data for determining reliability failure rate data for maintaining an updated reliability prediction. Data for all tests will be so accumulated from all tests, using electronic data processing techniques from all tests, such that it can be stored for immediate access and availability for up-dating reliability status, making trade-off studies and evaluating failures.

\section{Thermoelectric Couple Confidence Levels}

The reliability block diagram in Chapter VI of Volume II shows that the reliability of the thermoelectrics is a major factor in the probability of the Generator System to produce 250 watts for five years. The key
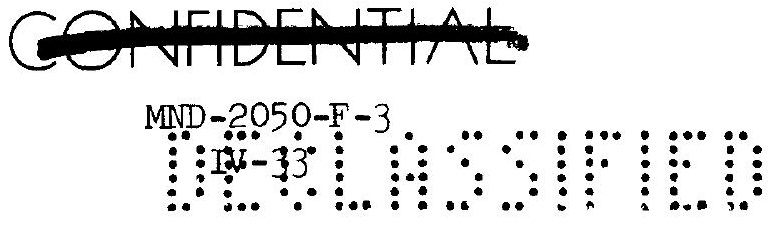


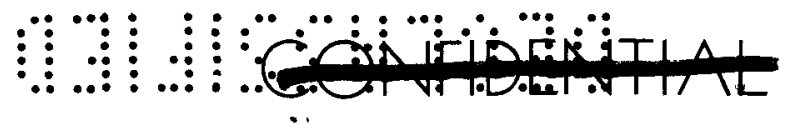

parameters determining the reliability of the thermoelectrics are:

(1) The number of extra couples in the generator available to compensate for random couple failures

(2) The random failure rate for an individual couple

To assure that the reliability requirement apportioned to the thermoelectrics can be achieved, it is essential to demonstrate to an adequate confidence level, the couple failure rates assumed for $\mathrm{T} / \mathrm{E}$ couples.

The recommended testing of couples is presented in the integrated test plan. The majority of couple test data will come from two sources:

(1) T/E Couple testing at the $T /$ s couple subcontractors' facilities starting early in Phase II

(2) T/E couples being tested within two complete generators on life test at the Contractor's facilities. Both will involve five year life tests.

Figure 3000-1I was prepared to show the growth of confidence in the minimum fallure rates required to meet the reliability goals. Three specific failure rates were selected for the evaluation:

(1) A fallure rate of $.0270 \% / 1000 \mathrm{hrs}$. which is required to attain a $76.4 \%$ probability of operation for five years if six couple failures are allowed in the operational RTG.

(2) A failure rate of $.0100 \% / 1000 \mathrm{hrs}$. which is required to attain a $95.3 \%$ probability of operation for five years, if five couple fallures are allowed in the operational RTG.

(3) A failure rate of $.0035 \% / 1000 \mathrm{hrs}$. which is required to have a $95.8 \%$ probability of operation for five years if six couple failures are allowed in the operational RTG.

The graph shows the accumulated successful T/E couple operating hours from Phase II through Phase IV. It indicates that at the end of Phase IV as many as 34 million couple hours may have accumulated. At the time of delivery of the first operational unit some fifteen million $T / E$ couple hours will have accumulated. Based on these hours, and the stated failure rates, six confidence level curves were plotted. Two curves were produced for each failure rate:

(1) Assuming zero failures during testing
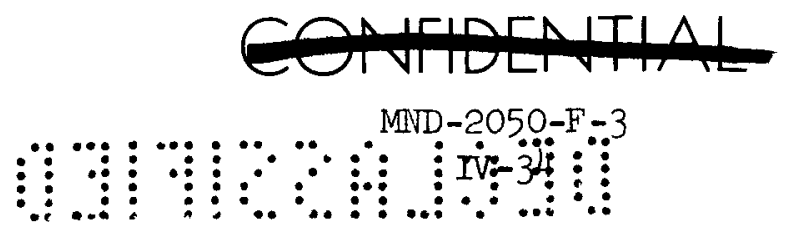


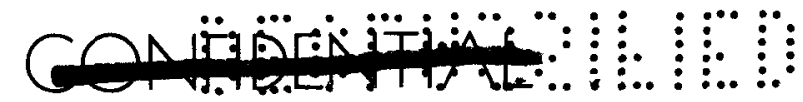

(2) Assuming one failure during testing

The relationship between $\mathrm{T} / \mathrm{E}$ couple reliability and confidence level is given in the equation

$$
R^{N}=e^{-\lambda t N}=(I-C)
$$

Where $\mathrm{C}=$ confidence level in $\mathrm{T} / \mathrm{E}$ couple reliability or failure rate

$$
R=e^{-\lambda t}=T / E \text { couple reliability }
$$

$\lambda=$ failure rate

$t=1 \mathrm{hr}$. (for we are seeking confidence level in the failure rate of a $\mathrm{T} / \mathrm{E}$ couple)

$\mathbb{N}=$ accurnulated $T / E$ couple hours

For the simple case of zero failures, we may merely vary the confidence level and compute the required test hours by using:

$$
\begin{aligned}
e^{-\lambda t N} & =1-C & & t=1 \\
-\lambda N & =\ln (1-C) & & \lambda \text {-expressed failure } \\
N & =\frac{-\ln (I-C)}{\lambda} & & \text { rate per hour }
\end{aligned}
$$

When apparent failures occur during testing, they must be analyzed to determine the nature of the failure. All failures during testing are not necessarily assignable as $\mathrm{T} / \mathrm{E}$ couple failures in calculating failure rates. The following must be evaluated:

(1) Was the failure induced by conditions outside of the environment to which the generator will be subjected. If so, the failed couple(s) may be replaced, the test continued, the accumulated hours for the failed couple will be discounted, and the failure(s) not counted.

(2) Was the cause of failure one which resulted from a design weakness that is capable of being designed out of the system. If so, redesign will be required and testing of the new design initiated. The degree of design change will determine the degree to which previously accumulated hours are applicable.

(3) Was the cause of the failure one which is inherent in the material and no presently known state-of-the-art techniques can eliminate the failure. If so, the failed unit shall be

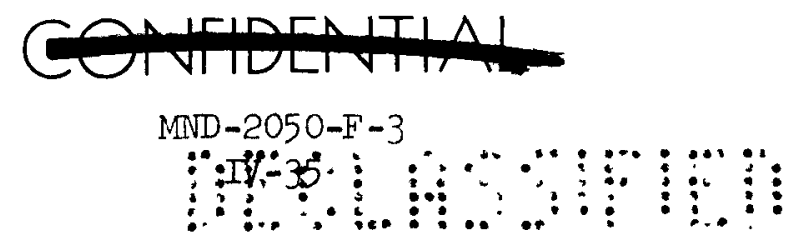




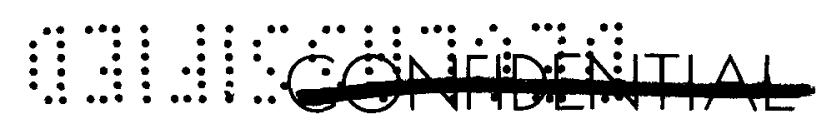

replaced, the test continued, and the failure counted in the failure rate calculation.

(4) Vas: the failure unique to the individual failed couple and not considered repeatable in other couples. If so, the $T / E$ couple will be removed, its accumulated operating hours subtracted from the total, the couple replaced, and the test continued. The failure will not be statistically counted.

\section{Quality Control}

Quality effort associated with the development of the RTG/RB System will include reviews of specifications, designs review, test procedures and processes; preparation of inspection instructions and log books to cover detail fabrication, assembly and test operations; and evaluation of procurement plans to determine requirements for vendor surveys, receiving acceptance plans and source inspection requirements. A detailed description of these efforts is contained in the Quality Assurance Plan in Volume VI.

A continuous monitoring and periodic review of the engineering design will be performed to ensure that all quality assurance requirements have been considered. Close liaison will be maintained with engineering and procurement department to obtain this compliance. All procurement initiated by engineering will be reviewed to determine that the necessary design, test, documentation, quality and delivery requirements are included.

During the period of component and subsystem development, Quality Engineers will monitor test laboratory, vendor and sub-contractor activities in accordance with the approved Quality Assurance Plan to assure full compliance with all test specifications, procurement specification and data requirements.

The Quality Laboratories will support the Quality Engineers by performing material and component tests, failed parts analysis, development of new processes, etc. During the period of system development and fabrication, the duality Engineers will concentrate their efforts on the fabrication of prototype systems, qualification test programs and system demonstration. During the period of flight article fabrication and modification, if required, Quality Control will continue the functions described for the efforts in addition to shipping inspection and launch site flight support.

Maintainability

The object of this effort is to assure that the design and hardware meet the maintainability requirements established by the contract. This
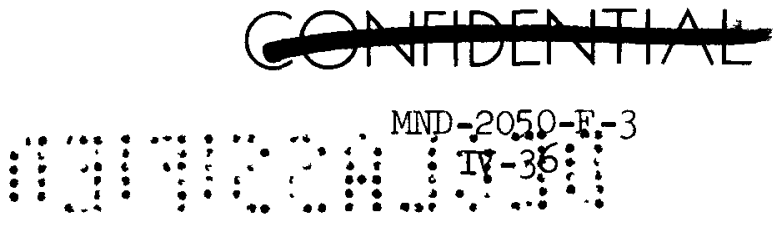


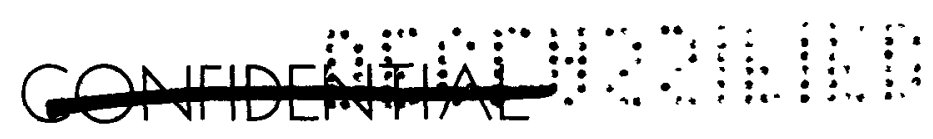

will be accompliched by establishing maintainability criteria for the equipment design. The equipment designers will then be indoctrinated in the maintainability requirements and goals to be factored into the design. Periodic reviews of the design and trade-off studies related to maintainability itens will be conducted. A topical report presenting the incorporated maintainability features, the maintainability trade-off studies perforned and the predicted mean-times-to-repair. A maintainability demonstration will be conducted during the maintenance manual verification.

\section{Value Engineering}

Tais effort will be directed toward reducing the cost of producing CRONUE RTG/RB hardware without sacrifice of product performance or reliability. In the performance of this task, the following will be accomplished:

(1) Reviews of the design, manufacturing processes, and hardware by a specialist to reduce costs without impairing the functional design of the equipment. Where Customer approval is granted, such changes shall be incorporated.

(2) The total cost savings (value of re-engineering) will be determined.

System Taxting

Purpose

The Integrated $T$ st lrogram Plan defines the basic test approaches and test philosophy, the phasing of the test cycles in coordination with the design and fabrication cycles, and the integration and sequencing of incividual tests for a well balanced program at a minimur cost and effort.

\section{Scope}

Each phase of the test program will be identified and discussed with cmphasis in those areas where variations in test philosophies may be possible. Special test considerations, test fixtures and test facility requirements will be iaentified. Tust and document control practices will be identified and implementation indicated in relation to the various departmental functions.

Test philosophy and approach

The basic guidelines for the implementation of the Test Program Plan must be defined in order to provide a uniform frame of reference. The . guidelines include the following:

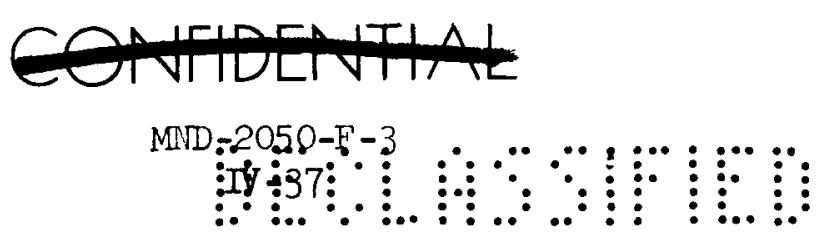


(1) The Frogram Plan implemented and approved between the Martin Company and the customer shall be the master document having precedent over all other instructions.

(2) The prescribed mission operational requirements for each assigned mission will be used as a fundamental background for assessment of required hardware system functions by phase of flight and the operational environments to be considered during simulated flight test operations (See Table I for format).

(3) The System Design Specification and the mission requirements establishes the basic System Test Requirements Specification for the fabricated system. The component and subsystem test requirements and performance serve as building blocks for the combined system and must be compatible to the final system operational performance.

(4) A single functional group will be responsible for the total integrated test program to provide continuity of test efforts and coordination of test activities in the most logical sequence and combination of tests. The performance of all tests is not considered the function of this group.

(5) The Integrated Test Program as presented represents the types of test to be performed at all phases and levels of test. Since some of these tests are to be performed at a subcontractor or vendor and priced separately, the summary of components used during the test program reflect only the inhouse test program quantities.

(6) The design philosophy emphasizes the use of hardware components and designs from previous programs wherever feasible. The test program will reflect this philosophy in two basic areas. Where hardware designs have been previously developed and proven, the development program will stress evaluation performance tests on the hardware to verify that it will satisfactorily meet the system requirements in the operational environments. If the hardware meets the evaluation test criteria and has been previously qualified, requalification of the new fabrication hardware will be limited to a minimum number of units with major emphasis on critical environments.

\section{Integrated Test Program Development}

Each of the major systems will be subjected to the integrated test program approach in the fabrication and checkout of each system's hardware from parts and components level to the complete system level. The interface functions and environmental requirements between the major
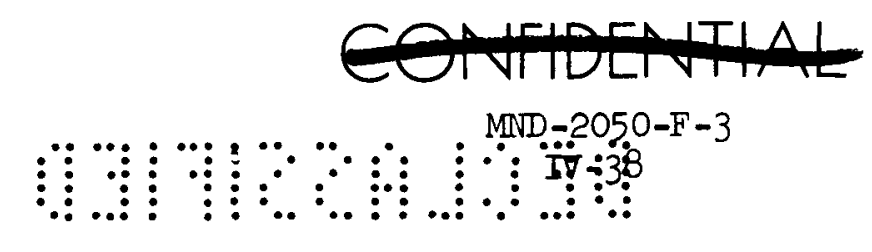


\section{(4)}

systems will also be investigated and verified.

The basic features of the Integrated Test Program are:

(1) Definition of each of the discrete test phases of the program.

(2) Definition of the special problem areas of investigation based on the mission functional requirements of the system (Table I).

(3) Plan the scope of testing required to demonstrate systems operational capability and development during each of the program phases.

(4) Coordinate or combine tests or series of tests to supplement or complement each other in the most logical and contributory manner.

(5) Coordinate interface tests with co-contractor or integrating contractors.

(6) Schedule tests that are consistent with design and delivery committments but with no compromise in required operational performance.

(7) Specify special test equipment and test facility requirements and coordinate their provision with the providing agency.

(8) The accumulation and correlation of test data will be an essential part of the integrated test performance to optimize the system verification. Test reports will be prepared for each test or series of tests to formalize data presentation and to distribute results to all groups requiring the information to optimize their efforts.

Chart I indicates the test flow of hardware components and system from the preliminary development phase through the final launch checkout of the flight hardware. A summary of each test phase is presented below; more detailed test plans are discussed under each subsystem by Control Point and for the complete system in subsequent sections of the Development Plan.

Component, subsystem, and system nardware requirements for the complete test program are shown in Table II, the Generator System Hardware Matrix. This matrix has been generated to assist in the basic planning and pricing functions for the Martin test activity, and it excludes thermoelectric components fabricated by RCA for their own development tests. Hardware which is procured for one test, and then re-used in other test activities is so indicated. The tests are defined in the test writeups under the control point designations in subsequent sections.

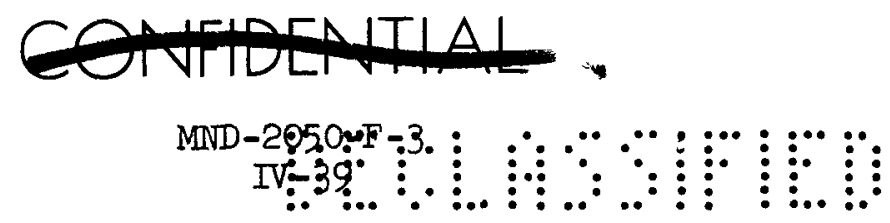




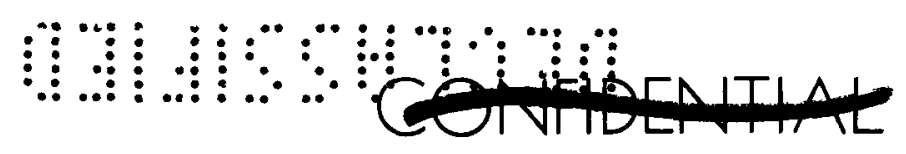

The test phases and major areas of investigation for the Generator System are discussed below and follow the general breakdown as indicated on Chart I.

a. Development test phase

The development tests are performed to assist the design engineer in confirming his design philosophy by hardware fabrication and performance demonstrations. The tests are closely coordinated with the design groups and primarily performed by the design personnel or under cognizance. Test Integration will monitor and coordinate these tests to accomplish combined tests between different design groups where possible to minimize duplication of test setups and test objectives.

The safety and operational life requirements of the Generator System imposes stringent development areas of investigation. In addition, the close proximity of the nuclear power source to other operating equipments requires radiation level exposure tests for assessment of radiation damage or degradation.

The major safety considerations are associated with the radiation hazards during fuel system installation and with maintaining the integrity of the nuclear fuel capsules in the event of a necessary mission abort.

(1) Preliminary Development and Evaluation Phase - During Phase I of the program initial component development will be performed based on preliminary subsystem and component design philosophy. Many of the parts and material selection criteria may be common to more than one subsystem and must therefore be coordinated at the systems level although the actual test evaluations may be assigned to the subsystems. Evaluation tests will be performed on prior usage components to determine whether problem areas exist due to new environmental exposures.

(2) Subsystem and Component Development Phase (Phase II) - Detailed development tests in the component and subsystem areas progress with finalization of design. Initial system development tests are performed for structural dynamic responses and thermal profile feedback to subsystem design and fabrication. The interface activities with the other systems (CIR and AGE) are more formalized with preliminary interface tests performed (either with actual designed units or with simulators).

b. Prototype systems and qualification phase (Phase III)

This phase of the test program covers design verification testing of prototype system, qualification and reliability tests, and flight
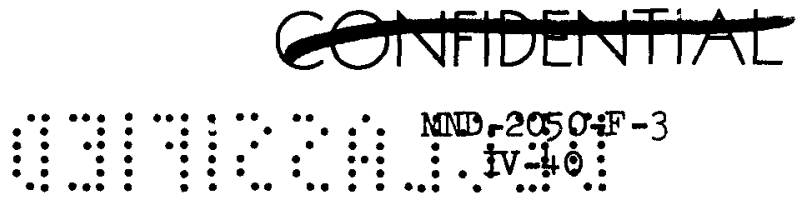


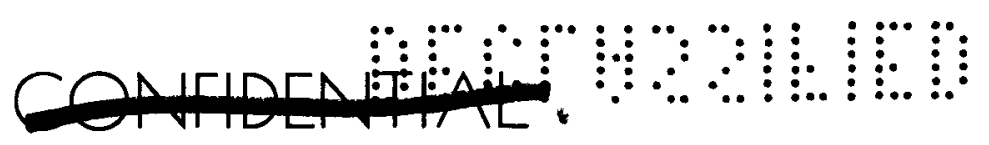

demonstration systems tests.

(1) Compatibility System Tests - The first fabricated system will serve as a system design verification article and a test bed for system redesign verifications. In addition to the intersubsystem and system sequence tests as design development verification, this same system will verify interfaces with AGE and Launch Complex activities. Separate systems will be delivered to the spacecraft contractor for interface compatibility and performance tests under dynamic and thermal environments.

(2) Qualification and Reliability Tests - These test phases are closely associated and will overlap to a large extent on this program. Component and subassembly test quantities were increased under the qualification test area to provide more test data results which will also be provided as reliability backup information. The qualification and life test vehicles will also provide the dual data outputs. In addition, the other test systems and demonstration test vehicles will provide a source of data.

(3) Demonstration Flight Systems Tests - The Demonstration Flight Systems will be subjected to a detailed acceptance test program from test article delivery to launch similar to that indicated on the test flow chart for the Production Flight Systems in Phase IV. The addition of a telemetry and data recording re-entry data during the demonstration flight will require a deviation in the operational and environmental test performance checkouts.

(4) Spacecraft Integrator Compatibility Tests - The Dynamic and the Thermal/Electrical RTG/RB Systems will be acceptance tested prior to delivery to the Spacecraft Integrating Contractor. Test support will also be provided as required during the integration test program.

c. Production flight systems test phase (Phase IV)

Esch of the production flight systems will be subjected to the acceptance test program and launch operation tests as shown on the attached chart. A thermal simulated heat source will be used during the acceptance checkout cycles and in-house fuel loading demonstration for fit checks.

In the final performance of the Combined System Test and the Environmental System Tests, the Controlled Intact Re-entry (CIR) System

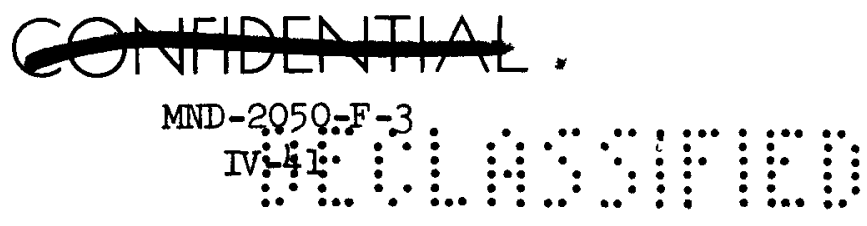


must be available to demonstrate system acceptance performance.

\section{Test Analyses and Reports}

Each test performed during the test program beyond the component breadboard stage will be planned and documented as to objectives, configurations, procedures to be followed, and the expected test results. At the completion of each test, the performance results will be analyzed and reviewed against previous test results and subsequent test plans to coordinate and incorporate required changes for the best integrated test and program effort. All test results and plans will be documented in a formal report at the end of the test. Where individual tests are a portion of a series of tests, a preliminary quick look report will be issued to provide a data base for program and system performance review. The high degree of safety and reliability requirements of the Generator System necessitates a continuous evaluation and accountability of data to minimize the needs for large specific tests for safety or reliability purposes. 


\section{WHEI}

\section{Engineering Controls}

The functions accomplished by the Engineering Department to assure product integrity are itemized in Fig. 17 of Volume VI. In particular, Engineering will maintain control of the product specifications and drawings to assure that the program goals are achieved. A system of Engineering Directives will be issued to define areas of responsibility and requirements of each functional groups for achieving these goals.

Specifications will be prepared to establish the requirements for all Contract End Items. These will establish the criteria for acceptable product and enable determination as to whether or not compliance has been achieved. Engineering Process Specifications will be prepared for all critical manufacturing requirements. A Drafting and Checking Manual will be used to assure standard illustrations, nomenclature, format, etc. on all program drawings to minimize misinterpretation. All drawings for hardware to be delivered will be subjected to $100 \%$ checking before release for fabrication. Drawing Change controls will be used on described in MN-2050-3 of Volume IV. Resident Technical representation will be at all subcontractors to monitor their technical performance. Engineering analysis of the subcontractor products will also be continuously conducted. Engineering will participate in the Configuration Change Board and Malfunction/Discrepancy Automatic Report System (MARS) action meetings.

Manuals and Reports

a. Operating manual

Objective

To develop operating instructions for the generator system covering step-by-step procedures for transportation, handling, check-out and/or pre-launch operations at an integrating contractor's facility designated by the User and at the launch site. These procedures will include sequential instiuctions for: checking out each generator subsystem, performing combined subsystems testing and accomplishing launch preparations and the launch countdown.

Safety procedures and precautions required for generator fuelingdefueling operations will be the subject of a specific section of the manual.

Approach

(1) A topical outline will be developed covering complete installation and check-out operations of the generator system through

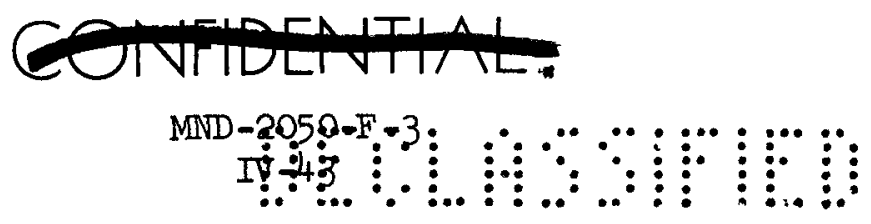




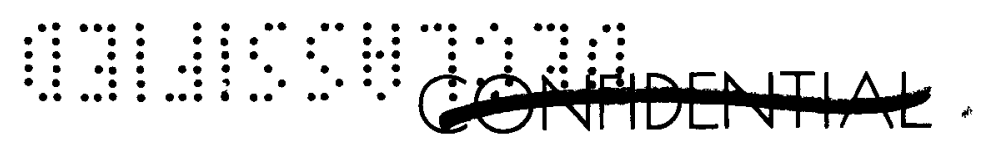

analysis of generator system design and the results of liaison with launch site personnel and evaluation of required tests of the system after delivery.

(2) The preliminary operating manual will be developed in conjunction with the establishment of launch site test procedures.

(3) Those portions of generator system procedures which affect spacecraft and launch vehicle contractors hardware or operating procedures will be developed in preliminary form through liaison with the customer and the contractors involved.

(4) The operating manual will be verified during in-plant test and checkout and during the generator fueling demonstration and countdown operations of the prototype system.

(5) The final copy of the operating manual will be prepared for delivery concurrent with the delivery of first operational flight hardware.

(6) Revisions will be generated and issued as required through program completion.

\section{Problem Area}

(1) Development of integrated procedures which cover the fueling, defueling and operational checkout during launch vehicle and spacecraft pre-launch activities, particularly if the airborne and ground handling segments of CRONUS are not developed by the same contractor.

\section{Solution}

The solution to the problem of developing integrated launch site procedures may be effected through the User's integrating contractor. Close coordination between integrating and generator system contractors is contemplated to achieve a mutually satisfactory generator system operating manual.

b. Maintenance manual

Objective

To provide a complete set of preventative maintenance procedures required to assure operational readiness of the generator system. In addition, provide preventive and corrective maintenance procedures based on spares provisioning concepts to assure the timely return to operational

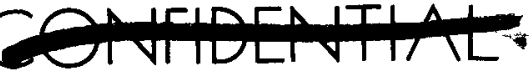




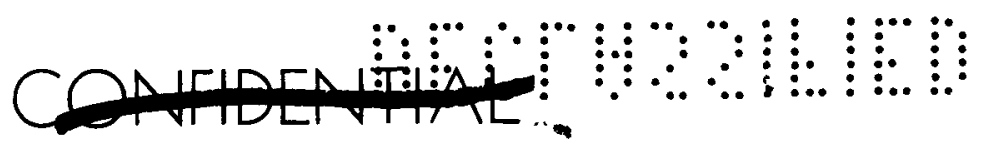

status in the event of a malfunction.

Preventive maintenance data will include criteria for calibration, servicing, testing, mandatory replacement, and inspections. Corrective maintenance procedures will include removal and replacement procedures for all major component. In addition, malfunction isolation procedures will be defined as an aid in isolating malfunctions.

\section{Approach}

(1) The maintenance manual will be based on the maintenance concepts as defined in the maintenance plan and the particular support equipment and spares (repair parts) to be made available for maintenance of the system at both the launch site and the facility of the User's integrating contractor.

(2) A topical outline will be developed from the criteria established in the maintenance plan and the results of maintainability analyses of the generator system.

(3) The preliminary maintenance manual will be developed concurrently with the in-plant test operations of the CRONUS Systems hardware. Maintainability analysis, Failure Mode Analysis data, spare provisioning data, etc., will be factored into the maintenance procedures.

(4) The preventative maintenance procedures will be verified during tests of equipment at the contractor's facility and during launch preparation for the prototype system, prior to the preparation of the final manual.

(5) The final maintenance manual will be prepared and delivered concurrent with delivery of the operating manual for the first operational flight hardware.

(6) Revisions will be generated and issued as required through program completion.

Problem Area

The major problem will be the isolation of equipment malfunctions.

\section{Solution}

Provide a Go-No-Go Analyzer which can be used in malfunction isolation. This item of equipment is discussed under the Operating Ground Equipment section of this report. Malfunction correction

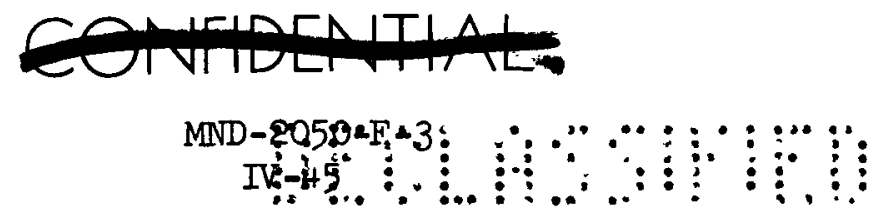




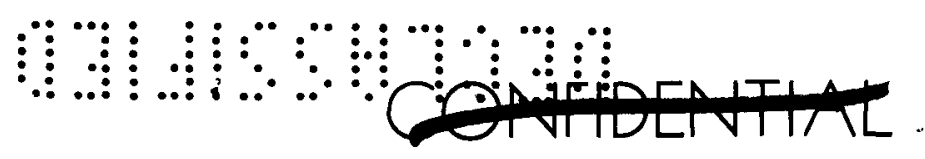

procedures will be developed to rectify improper equipment operation reported by the No-Go indications. 


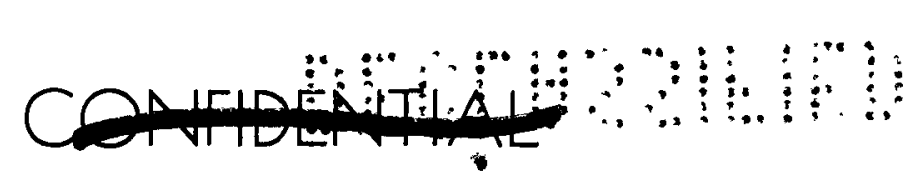

A. 3100--GENERATOR SYSTEM

\section{Objective}

The objective of this task is to design, develop, assemble, test, and qualify a generator system which is capable of producing 250 watts (e) during a five-year orbital mission and meet the safety and reliability criteria associated with transportation, installation and checkout, launch, orbital operation, and re-entry.

\section{Problem Areas}

(1) Early integration of subsystem designs and identification of compatibility and interface problems.

(2) Accumulation of system performance data prior to finalization of subsystem designs.

(3) Identification and development of instrumentation associated with the flight demonstration system and later flight--qualified systems.

(4) Large facilities required for system qualification.

(5) Demonstration of structural integrity during re-entry.

(6) Demonstration of fuel cepsule integrity after system impact.

\section{Approach}

The approach will be to assemble and integrate the subsystems under this control point and to perform whatever system design, analysis, testing, and qualification that cannot be performed at the subsystem level. The assembly and installation of the RTG/RB is illustrated in Fig. 3000-1. The problem areas listed above will be expedited through the following items of action:

(1) A systems engineering group will be established during initial component and subsystem development to review each design at the system level and impose constraints on the subsystem design at the system level and impose constraints on the subsystem design to ensure compatibility.

(2) Data relating to component and subsystem performance will be reviewed as it becomes available, to assess the effect on overall system performance. Thermal performance testing will be initiated at the earliest possible date with simulated heat

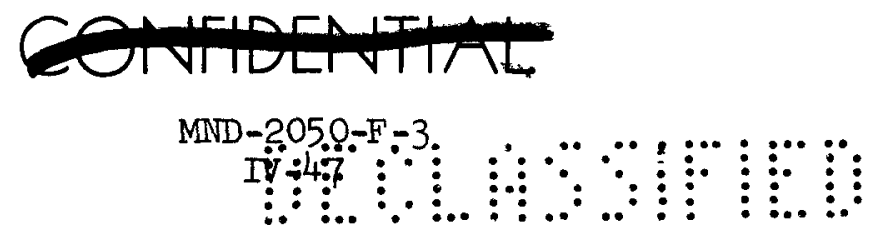




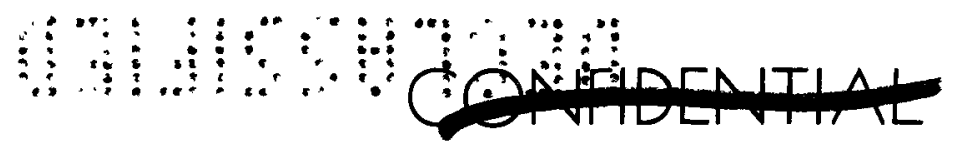

source, insulation, radiator, and thermoelectric properties. Thermoelectric performance testing will be done in a scaleddown system containing actual thermoelectric modules. This will be the first verification of component temperatures and thermal conductivity of the thermoelectric elements.

(3) Since airborne instrumentation often introduces technical problems which are not present in the relatively flexible ground test set-ups, there is incentive to minimize flight data requirements. Essential instrumentation will be dictated by critical areas identified during initial ground testing and by overall mission objectives designated by the user. Instrumentation errors will be determined and evaluated at the system level prior to releasing final specifications.

(4) Because of the relatively large size of the generator system, test facilities available for system qualification tests are limited, especially for orbital (thermal vacuum) conditions. The general approach will be to use existing facilities and tolerate certain compromises which are introduced. For instance, system performance will be measured experimentally with simulated vibration and shock loading and with full solar simulation, but sustained acceleration tests will not be performed. A single qualification system is planned.

(5) The structural integrity of the radiator, heat source, and heat source support will be verifled using the best possible mechanical and thermal simulation prior to the flight demonstration.

(6) Statistical demonstration of fuel capsule integrity after system impact would be prohibitively expensive. Energy absorption of the generator system will be calculated for various angles of impact, and damage to the fuel capsules will be predicted empirically and analytically. The prediction is expected to show that impact of individual capsules at their terminal velocity is more severe than impact of the total system. One complete system will be dropped from a helicopter to an earth surface to verify (a) aerodynamic stability considerations, (b) terminal velocity calculations, (c) breakup characteristics of the beryllium radiator and internal components, and (d) fuel capsule survival. No other complete system impact tests will be performed unless a fuel release hazard is discovered that requires additional test evaluation.

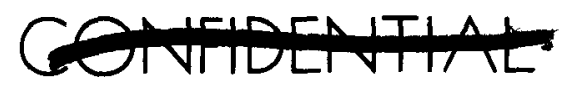




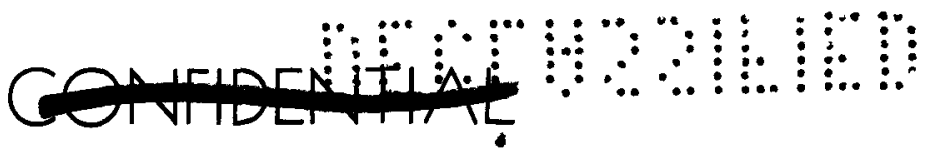

1. 3110--Design and Analysis

This task includes all activities which cannot be done on a subsystem level because they affect more than one subsystem. Examples are generator system design, system thermal and thermal efficiency analyses in which component temperatures and heat losses are determined, analysis of re-entry body capabilities, and system integration interface definition. These activities are outlined below.

\section{a. Interface definition}

All interface areas between the generator system and the CIR system, $\mathrm{AGE}$, and the spacecraft will be identified. Interface meetings with the customer, spacecraft and payload integrating contractors, fueling agencies, and other organizations or agencies will be attended as required to establish interface requirements. The required interface documents will be prepared on the basis of these requirements.

b. System design and analysis

\section{Design}

Design layout drawings will be prepared at the start of the program to provide a visual reference for use in analysis, and for assembly, fueling, and flight operations studies. Mechanical tolerances will be accommodated, as well as thermal expansion and component deflections due to their mechanical environment. The layout drawings will be revised continuously during the design, analysis, and component development phase (Phase I) to reflect the most recent configuration changes. PreIiminary manufacturing drawings and specifications will be prepared at the end of this phase, using MIL-D-70327 as a guide.

Revisions to drawings and specifications will be made during the component and subsystem development phase (Phase II) to reflect all design changes, and to bring the drawings into accordance with MIL-D-70327. These are designated Martin Aerospace Division Class II drawings. They will be assigned the contractor's drawing numbers and identification codes.

The drawings will be further revised to reflect changes made during the system development phase (Phase III). Configuration control procedures will be effected to record the status of all systems built. Maintenance of the drawings will be performed through delivery of final flight articles (Phase IV).

Design reviews will be held periodically to review the operation, material selection, mechanical stress, weight, fabrication and assembly

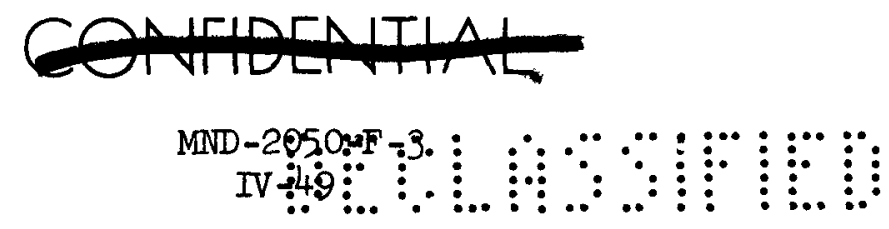




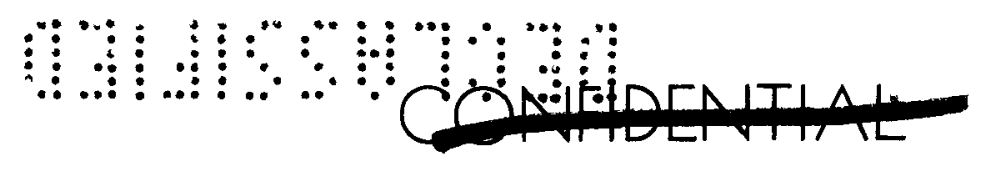

techniques, and component finishes. In this way, the design skills which have been built up in other SNAP and aerospace programs will be utilized to the greatest extent. Liaison will be performed with other functional groups to ensure that performance, quality, and reliability goals are achieved. All final drawings will be thoroughly checked prior to release.

\section{Thermal Efficiency Analysis}

A thermal efficiency analysis will be performed in order to determine the parasitic heat losses in the generator. This is necessary to predict the thermal efficiency of the generator system and the required fuel loading. Iiaison will be performed with the insulation supplier to obtain the most up-to-date conductivity data for the thermal insulation.

\section{Thermal Analysis}

Detailed thermal analyses will be performed using digital computer codes to establish component temperatures for the following cases:

\section{CASE}

(1) End of life, steady state orbital operation with appropriate solar input; parametric with respect to radiator temperature.

(2) Beginning of life, steady state orbital operation with appropriate solar input; normal operation and open and short circuit.

(3) Beginning of life-ascent

(4) Beginning of life-re-entry

(5) Beginning of life-Fireball

(6) Beginning of life-On Pad

\section{PURPOSE}

Establish radiator requirements. Provide parametric data for system optimization.

Determine temperatures throughout the system.

To determine if temperature problems exist on thermoelectric or heat source subsystems.

To determine if temperature problems exist on radiator or heat source subsystems.

To establish that capsule meltdown does not occur.

To determine on-pad air conditioning requirements.

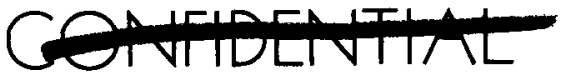




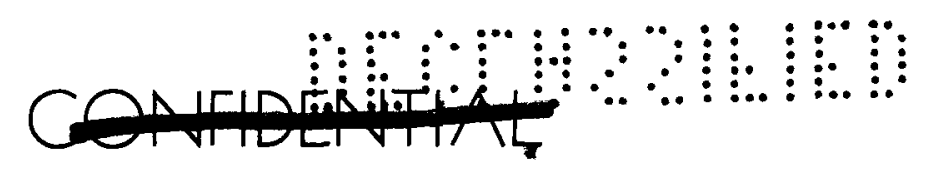

In addition, a number of thermal analyses will be performed on more limited sections of the generator system such as the interface between the hot shoes and capsules. Analyses performed on a subsystem level only (e.g., temperature distribution through hot shoe or through the fuel) will be found in the analysis control point under that subsystem.

\section{Aerodynamic Analys is}

A thorough hypersonic aerodynamic analysis must be continuously carried out in order to generate the desired aerodynamic properties (coefficients, pressure distribution, heating parameters, flow properties, etc.), evaluate specific configurations, specify the destabilization requirements of the aft cap subsystem, and conduct and evaluate wind tunnel tests. Further tests and analyses are required to determine the flight characteristics during the supersonic, transonic, and subsonic re-entry regimes. These flight characteristics (such as stability deviations, force and damping coefficients, heat transfer coefficients, etc.) will be evaluated for the normal entry configuration and also for any reasonable variation (such as: CIR attached with/without deorbit motor propellants, CIR and Spacecraft attached, etc.).

Additional test and analysis will be conducted to determine the external flow and heat transfer characteristics of the RTG/RB on the pad (with and without forced air), and in enclosed environments which may be encountered during transportation, handling, and testing of the generator system.

\section{Trajectory Analysis}

The ballistic and dynamic re-entry trajectories must be carefully computed. The actual 6 degree of freedom motion of the re-entry body as influenced by the explicit body oriented aerodynamic coefficient, must be computed for the various entry conditions that are possible. The re-entry heating on various parts of the body should be computed at the same time. This investigation must also be done parametrically to determine the worst conditions under which the body would be stabilized.

A standard ballistic re-entry trajectory analysis will also be conducted in order to fully assess the effects of $\Delta V$ and application angle on impact ranges, impact dispersion, re-entry environment, safety criteria, etc. This analysis should be coordinated with the CIR operational analysis in order to avoid a duplication of effort.

A special foot print analysis should be conducted to establish the actual impact areas, as a function of the initial conditions, launch trajectories, and vehicle characteristics. Some of the results

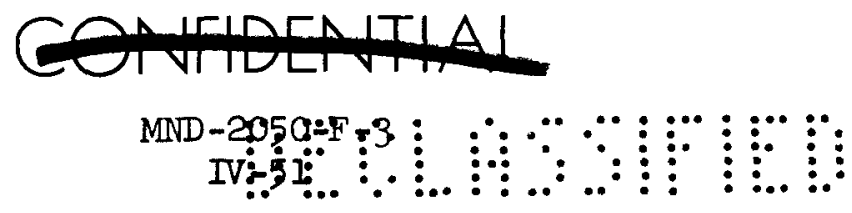




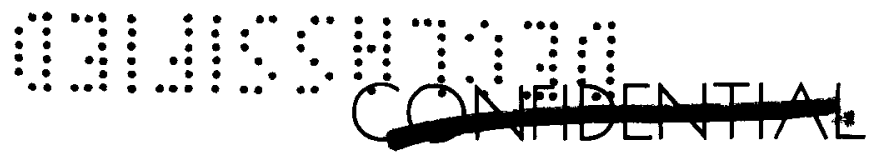

of the dynamic trajectory analysis would be integrated into this program. This high speed analog investigation can be used to map out the desired demonstration flight profiles, as well as permit a kinematic assessment of the safety problems and the recovery potential.

Mission Analysis

A mission analysis should be conducted in order to assess the optimization criteria, the need for growth potential, and the economic and political implication of recovery of nuclear fuel.

\section{Weight Analysis}

A weight and weight sensitivity analysis should be conducted throughout the program in order to assess the impact of various components and subsystems on system weight, to accurately compile the system weights and mass characteristics, and to conduct and support optimization studies.

\section{Structural Analysis}

A structural analysis will be conducted for the RTG/RB. Static and dynamic loads will be determined so that the various subsystem design requirements can be established. Interface requirements such as mounting frames and frame locations will be established. A dynamic analysis of the total body should be conducted in order to assess and optimize the non-rigid body behavior in free fall during re-entry, and in the presence of the CIR, CIR and $S / C, C I R$ and $S / C$ and LV, etc. This analysis will subsequently support the vibration test result analysis. Parametric studies will be performed to enable the selection of material and structural concepts which will perform most efficiently. The analysis will be extended to include internal subsystems, such as the heat source and radiator, where the interaction between those subsystems cannot be analyzed at the subsystem level.

\section{c. Safety evaluation and integration}

The safety evaluation and integration effort encompasses all analysis, development, testing, and evaluation functions necessary to qualify the CRONUS for nuclear and non-nuclear safety requirements. The specific requirements will be developed from safety criteria established during the initial phases of this program. The basic, generalized criterion that will be followed is that any normal or abnormal operation of the CRONUS shall not result in a significant hazard to the general public. This effort is divided into six areas:

(1) Establishment of Criteria
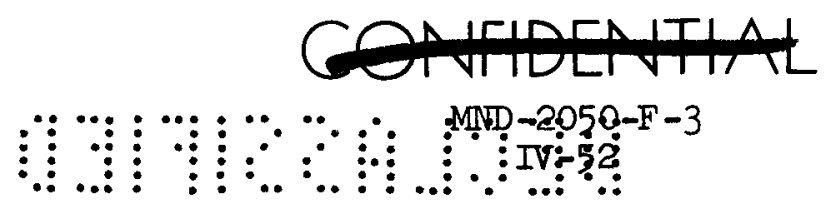
(2) Evaluation of Test Procedures and Results

(3) Failure Analysis

(4) Hazard Analysis

(5) P.D.N. Analysis (probability, dose, number of people)

(6) Radiation and Shielding

- Preliminary Safety Evaluation

Object

To establish in a preliminary report the expectations of hazards consequent to use of the CRONUS in its intended mission.

Reason

To:

(1) Provide preliminary assurance through a complete evaluation of hazard mechanisms that flight approval may be secured.

(2) Identify those occurrence probabilities or transport mechanisms requiring significant research and classify them according to their importance in influencing the hazard index for the system.

\section{Discussion}

Safety analyses reported in the technical volume of this report were limited in scope to what was considered to be the most significant hazard situations. Criteria under which the hazard expectations were evaluated were preliminary ones.

The scope of this task is to approximate the hazards expectations from all causes in the CRONUS mission and in so doing accomplish the purposes stated above. Updated safety criteria will be used in the PDN analysis technique.

- Criteria

- Biological damage

Object

To establish a set of safety criteria which are based on the

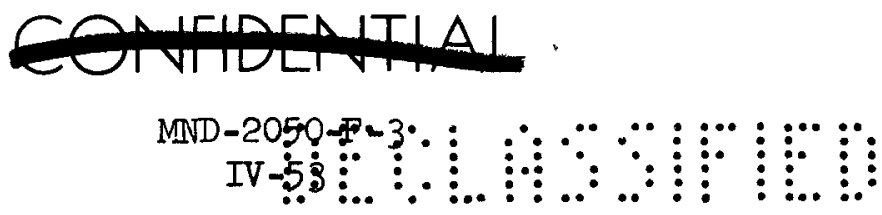


probability of a number of people receiving a given dose.

\section{Reason}

To provide a common standard of comparison for the evaluation of various types of accident hazards.

\section{Discussion}

Each radiobiological hazard resulting from an accidental deposition or release of fuel can be individually evaluated in terms of the expected number of people receiving a dose which in turn is functionally dependent on the mode of deposition or release.

Treating each accident as a separate event one always reaches a point of having to resolve the problem of which is worse, a bigh dose tc a small number of people or a low dose to a large number of people? Add to this, a different probability of occurronce for each event, and the question becomes even more complex.

If one can establish an acceptable criterion which includes occurrence probability, dose, and the number of people involved, each accident hazard can be directly compared with another. For example, a linear relationship could be established which would state that the product of the probability $(P)$, dose $(D)$ and number of people (N) shall not exceed $K$ man rem. Another approach might be a quadratic dependence on dose, i.e.,

$$
P D^{2} N \leq K \text { man rem }{ }^{2}
$$

During this phase of the safety program, an appropriate PDN relationship will be established and the man rem constant $K$ will be defined. It is anticipated that this criterion will be established as the nuclear accident criterion for the aerospace industry.

- Normal Environments

Object

To define all environments of normal generator operation from manufacture to mission.

\section{Reason}

To permit complete evaluation of the safety of the system during normal operation.
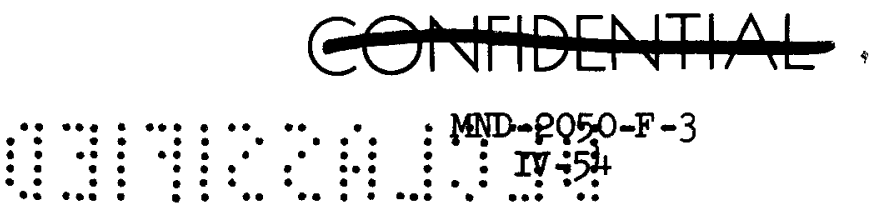


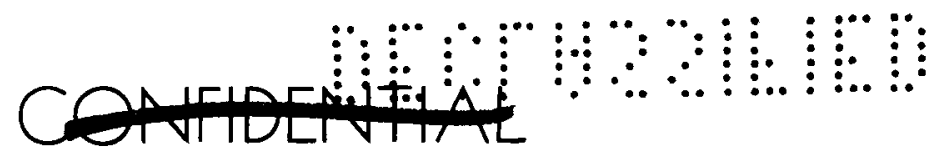

\section{$\underline{\text { Discussion }}$}

During the life of the CRONUS, normal environments may be encountered which could lead to degradation of the final space hardware. For example, excessive thermal cycling, high temperatures in air, chemical fumes at the launch site all could contribute to weakening of encapsulation. It is the intent of this phase of study to identify the environments for safety analysis. This is not anticipated to be a large effort.

- Accident Environments

\section{Object}

To define all environments which could conceivably be produced by generator malfunction or outside mechanisms such as impact, fire, and water burial.

\section{$\underline{\text { Reason }}$}

The accident environments are needed to provide test data input and to establish the accident models used to evaluate the ultimate safety of the CRONUS.

\section{Discussion}

The ultimate safety of any isotopic system is based on its ability to maintain integrity under severe accident conditions. However, these accident environments are not always well defined and are found to differ from system to system. The most severe accident appears to be the launch pad explosion and subsequent fireball. Each pad accident is functionally dependent on the type of launch vehicle being used. Each accident from a given vehicle differs in nature and magnitude as a function of the point of initiation (stuck value, skin rupture, etc.). Only in recent months has some semblance of order been assigned to the forces created in a launch pad accident under the PYRO program at Sandia. Re-entry heating, soil burial, impact velocities, shallow water deposition, transportation fires are only a few of the accident conditions which must be analyzed.

This phase of study will define the accident environments based on the latest data available from all sources and is expected to be significant effort. It is expected that much of the raw test data from simulated and actual accident monitoring will be fitted to empirical equations for ease in evaluating design response. 


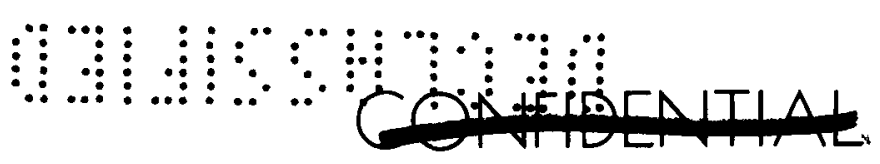

\section{- Evaluation of Test Procedures and Results}

- Test procedures

\section{Object}

To review all test procedures relating to safety testing of the CRONUS design. This includes the RTG/RB, CIR, and AGE.

\section{Reason}

To assure the test programs are meeting their objectives and have provided for realistic and meaningful environmental simulation.

\section{Discussion}

Once the normal operation and accident environments have been defined, test programs will be established for development and qualification of the CRONUS design. These tests and the results will form a fundamental input to the ultimate safety analysis of the CRONUS concept. Testing will be the responsibility of the individual contractors. However, integration of the tests will be required by safety to insure quality and completeness in test performance.

It is the intent of this phase of study to review and approve all tests conducted for system safety.

\section{- Test results}

Object

To integrate all safety test data and reports into a single document.

Reason

To produce the safety documentation required for user and launch pad operations.

\section{Discussion}

The integration of all safety test data and reports will require interpretation and conclusions compatible with the total CRONUS system. It will be the responsibility of the safety effort to integrate these test data and reports into a comprehensive document. It is anticipated that some numerical analysis will be required simply to verify test results as reported.

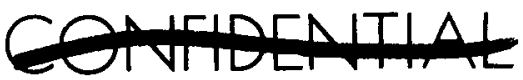




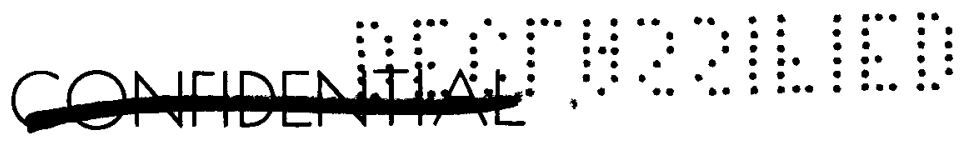

- Transportation

\section{Object}

To identify qualitatively and quantitativcly all possible accidents and the probability there of which may be encountered during transportation of the CRONUS.

\section{Reason}

To provide input data for safety reports, hazard analysis, and PDN type calculations.

\section{Discussion}

This effort will consist of diagraming all the possible accidents associated with transportation of CRONUS and shall include the description of the fuel deposition(should it occur). In this way, a systematic evaluation of ultimate hazards can be established which will ultimately be used for the final PDN safety analysis.

\section{- Flight}

\section{Object}

To analyze the mission profile so all possible impact areas and fuel deposition modes can be identified.

\section{$\underline{\text { Reason }}$}

To provide input data for safety reports, hazard analysis, and PDN type calculations.

\section{Discussion}

The ultimate biological hazard imposed on the public is directly related to the point of fuel deposition and mechanism of release. The mission flight characterisitcs can be used to identify impact areas and time intervals during which burnup could occur. This phase of study will identify these areas of possible fuel deposition.

- Booster, CIR, RTG/RB

\section{Object}

To establish the numerical reliability of each system to perform as designed under normal and accident conditions.

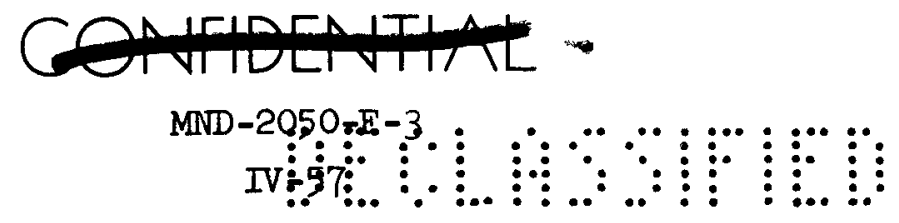




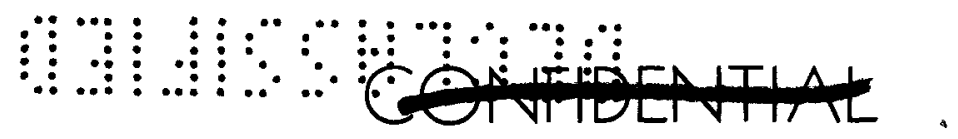

Reason

To evaluate the probability of fuel deposition in the areas described by the mission profile.

\section{Discussion}

One of the most fundamental inputs into the ultimate safety analysis of a system is the occurrence probability for any given accident. This probability is a direct function of the systems reliability to perform as designed.

In this phase of study, the failure probabilities will be established as a function of time and position of the RTG/RB relative to earth. Since during a launch, the fuel deposition site, and likewise the ultimate hazard, changes as a function of vehicle position, the failure probabilities must be known for all time and position intervals.

- $\underline{\text { Re-entry }}$

Object

To analyze the dynamics of re-entry and the consequences thereof.

Reason

To assess the probabilities of burnup and to determine impact areas and terminal velocities.

\section{Discussion}

The CRONUS is designed for recall and as such extends the possible hazards which may be encountered into the post flight region. Safe re-entry of the system (RTG/RB) is a direct function of the re-entry attitude, tumbling rates, and structural integrity of the re-entry body. Abnormal re-entry can lead to burnup, undesirable impact areas or unusually high terminal velocities which could concelvably rupture encapsulation.

This phase of study will evaluate the possible modes of re-entry and will attempt to allocate probabilities to the different modes. This will be required for the PDN analysis.
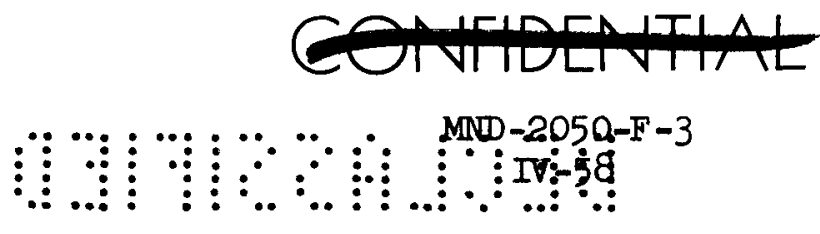


\section{WUII}

- Hazard Analysis

- Criteria

\section{Object}

To review all existing dose rate recommendations proposed by agencies such as ICRP and FRC.

\section{$\underline{\text { Reason }}$}

To provide data for establishment of the PDN criteria to be developed.

\section{Discussion}

As science discovers more about the behavior and reaction of the human body to its environment, the recommendations of allowable dose or radiation concentrations change. For example, as particulate behavior in the lung is better understood, the allowable particle concentration of any given radioactive fuel varies. Likewise, the commensuration of dose is still in question, i.e., is $X$ rem deposited in a millimeter area of lung equivalent to $X$ rem deposited uniformly over the entire lung?

This phase of study will determine commensuration and will relate it to existing dose (and dose rate) recommendations current at that time. (Additional information on this subject can be found in MND-3062-28, A Probabilistic Treatment of The Aerospace Nuclear Safety of Strontium-90).

\section{- Dose}

\section{Object}

To determine the dose received by humans for all possible fuel release modes.

\section{Reason}

To provide the dose term to the PDN analyses.

\section{Discussion}

Each fuel release affects the population differently. A shallow water fuel release relies on $f$ ish consumption and digestive action to evaluate the total dose received by an individual. A burnup relies on wind currents and particle retension in the lungs to evaluate the total

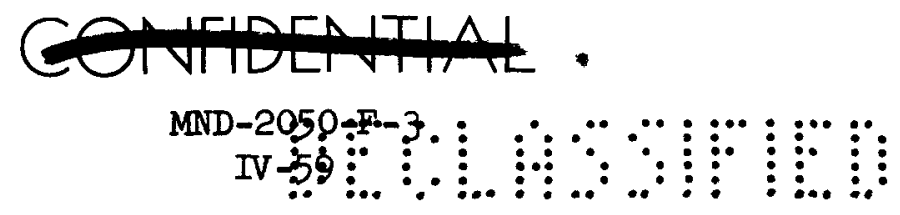


dose received by an individual.

In this phase of study, each fuel release and deposition mode will be analyzed in terms of the dose received by an individual (or group of individuals) and will form the direct input for the PDN analysis.

- Geography

Object

To evaluate the possible impact areas and their effect on fuel disposition.

$\underline{\text { Reason }}$

To determine the ultimate hazard (fuel release) which can be expected.

\section{Discussion}

Fuel deposition on the Antarctic continent will obviously yield hazards significantly different than an African deposition. The time intervals and mechanisms of fuel transportation to populated areas are significantly different in the two cases. Each fuel deposition site requires its own analysis to determine ultimate hazards. This phase of study will define the expected hazard based on the site of deposition.

\section{- Demography}

Object

To determine population effected by the hazards associated with given impact areas.

$\underline{\text { Reason }}$

To determine the population of number of people term in the PDN analysis.

\section{Discussion}

A fresh water fuel deposition in the Great Lakes will obviously affect many more people than a fuel deposition in a South American lake. Likewise, an ocean shallow water deposition may or may not have an effect on a large population density. This phase of the study will evaluate the 


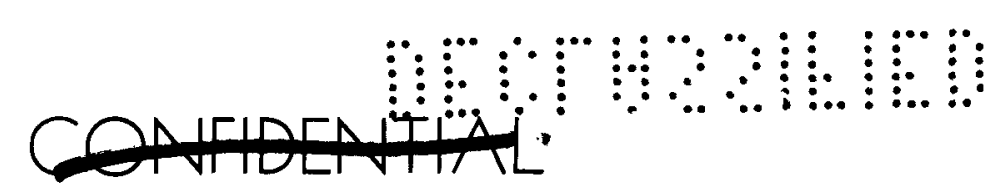

numbers of persons available for the hazards from numerous deposition sites defined by the mission profile.

PDN Analysis

Calculation model

Object

To construct a model for numerically evaluating each hazard for comparison with approval criteria. (Not all hazards will be tractable by a single model; more than one model may be required.)

\section{Reason}

To provide the mechanics necessary to evaluate the system's safety or risk level.

\section{Discussion}

The most reliable criterion for nuclear safety is the Form PDN $\leq \mathrm{Z}$ discussed earlier. In order to show a given hazard has met the criterion, it is mandatory to have a technique numerical analysis with which one can reduce basic data to terms of probability, dose, and number of people (PDN). This technique must be credible. One technique for evaluating the direct radiation hazard is shown in the technical portion of the Phase Zero Study, Section V-E. Other techniques must be developed for inhalation and ingestion hazards.

This phase of the safety program will develop these techniques.

- Accident model

Object

To develop accident models for each fuel deposition, i.e., determine the mechanisms of fuel release after an incident has occurred.

\section{$\underline{\text { Reason }}$}

To provide input to the radioblological hazard and the PDN calculations.

\section{Discussion}

A capsule impacting the earth at terminal velocity does not define the hazard. Impaction and subsequent rupture of the capsule on a hard

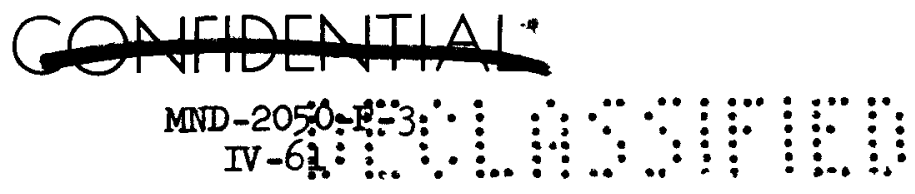




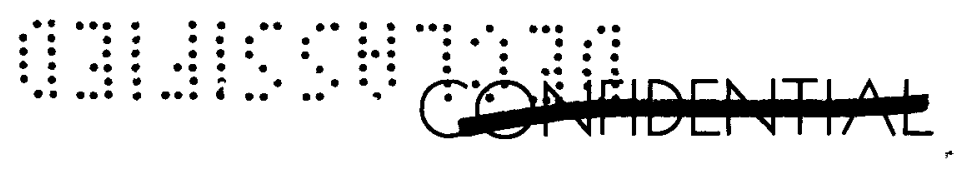

surface could lead to airborne contamination. Impaction in soft earth at terminal velocities could lead to burial, possible subsequent meltdown, and migration of contamination in the soil, possibly to fresh water supplies. A model (or models) for each fuel deposition or accident environment must be defined so the ultimate hazard can be established.

- Radiation and Shielding

\section{Object}

To provide dose rates for licensing, PDN calculations, radiation damage tests, and design of shielding.

\section{Reason}

To establish an RTG/RB design which meets the constraints imposed by direct radiation hazard criteria.

\section{Discussion}

Throughout the lifetime of the fuel source, direct radiation will be a potential hazard. All manufacturing, handling, shipping, and storage will require shielding and work procedures to limit personnel exposure to safe levels. Extensive dose rate and shielding calculations must be performed to identify the magnitudes of radiation and the required shielding and work procedures required to assure safety.

\section{- Criticality}

\section{Object}

To calculate criticality $\left(K_{\text {eff }}\right)$ for all concelvable heat source configurations.

\section{Reason}

To establish a design for the plutonium system which is incapable of achieving criticality under normal and accident environments.

\section{Discussion}

Although the basic fuel block configuration has been shown to be sub-critical even when fully moderated, accidental configuration changes (through impact) could yield a critical configuration. Substantial calculations are required to identify potential criticality hazards which may be created during transportation, storage, handling, and flight.

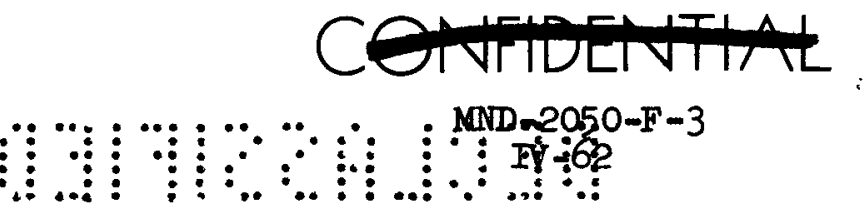




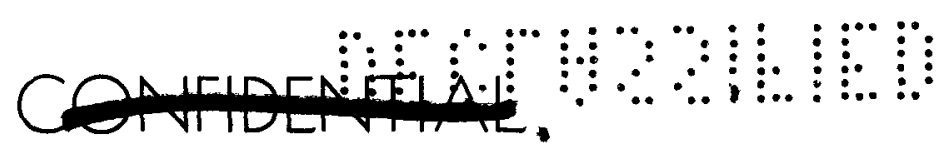

2. 3120--Component Development

The objective of this task is to verify the design and operational characteristics of the RTG/RB by fabricating and assembling portions or all of the system and testing these items under conditions which can be related to the environments seen during a mission. These tests will be limited to system or partial system tests which cannot be performed at the subsystem level.

Component development as such will not be performed at the system level during Phase I. However, scale model aerodynamic testing of the Generator System will be started during Phase I and continued during Phase II to meet contract delivery dates. A description of the aerodynamic test program is given below.

\section{a. RTG/RB aerodynamic test programs - Summary}

Aerodynamic tests will cover the complete trajectory and will require separate programs in the hypersonic, supersonic, transonic and subsonic regions of flight. Stability and force measurements will be made in sufficient detail to provide data to insure proper attitude orientation during critical heating portions of flight and to provide information to predict terminal velocity. Hypersonic heat transfer data will be obtained and also surface pressure data under conditions of simulated blast effects and deorbit rocket firing. Two possible abort configurations as well as the basic capsule configuration will be investigated.

Component and material selection dependent upon test investigations will be made at the subsystem level. Interactions and interfaces between subsystems and system interfaces will be assessed at the system level and necessary restraints will be identified. Development work required to minimize adverse interactions will be accomplished under that subsystem which can best afford modification. In this way, system type problem areas will be identified and solutions initiated prior to finalization of subsystem design. In the process of assessing interactions, Systems Engineering may require data associated with the performance of a component or the characteristics of a material which requires experimental investigation. These investigations will be made at the subsystem level and data will be factored into the system design. After processing the data, Systems Engineering will impose any necessary restraints on the subsystem. Ground and flight instrumentation will be defined and specified for subsystem development.

\section{b. Scope of tests and wind tunnel selection}

By far, the bulk of the testing will be required in the hypersonic region of flight; the lower speed tests will be performed only on the finally developed configurations. The program will take one year with

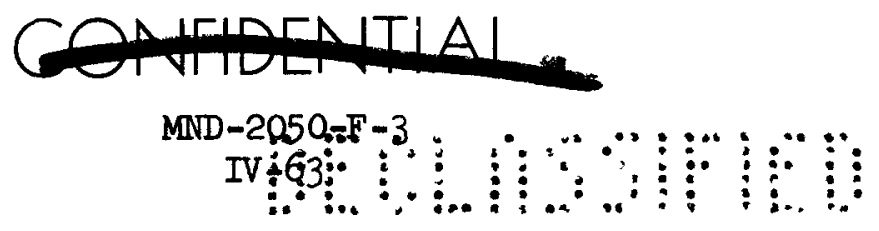




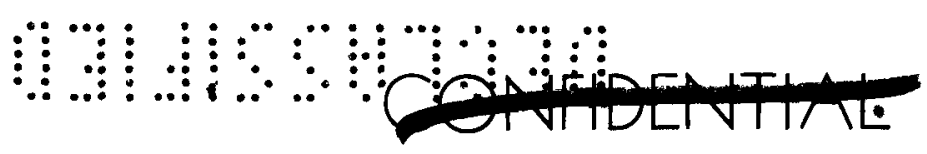

the actual wind tunnel tests completed in nine and one half months.

Wind tunnels have been selected on the basis of duplicating flight Mach numbers and Reynolds numbers in four representative speed ranges. The trajectories used for these considerations were those which fell within the band of injection angles of -.10 and $-8^{\circ}$. Thus for example, the Reynolds number variation expected at a flight speed equivalent to $M=10.0$ goes from 360,000 to 962,000 based on the 46" diameter vehicle. Utilizing an 8 " diameter model in the Arnold Engineering Development Center's hypersonic wind tunnel " $C$ ", Reynolds numbers between 200,000 and 1,600,000 can be obtained. A.E.D.C.' 's tunnel "A" was similarly chosen for the $M=5.0$ flight regime. Cornell Aeronautical Labs' $8^{\prime} \times 8^{\prime}$ tunnel was chosen for the transonic regime and the University of Maryland's $73 / 4$ ' $x 11$ ' tunnel for the subsonic tests.

The Martin hot shot tunnel was chosen for tests at $M=17$ to 20 . Reynolds numbers of 140,000 to 400,000 can be obtained with a five inch diameter model. This is representative of the basic vehicle flight Reynolds numbers. Its availability will allow configuration development early in the program. Such things as corner radii and oblique cut-off angles will be determined to provide desired stability characteristics and determine local heating rates. In addition, pressure distribution will be obtained to determine loads due to possible blasts from booster malfunctions. The effect of deorbit rocket firing will be determined through pressure distribution measurements. The vacuum chamber, rather than the normal test section of the wind tunnel will be utilized for these tests.

Concurrent with the early hot shot tests, the low speed tests will be carried out at the University of Maryland. A later low speed test is planned in the event that the hot shot tests show configuration changes to be necessary. Also tests will be started at AEDC's tunnel "C" with abort configuration consisting of the basic capsule and the CIR attached.

Following this, a second abort configuration, the capsule and CIR and the spacecraft will be tested in tunnel"C". It is fully expected that these configurations will have some unpredictable problems in either the heating area or the stability area. Consequently, retests of these configurations have been scheduled in tunnel" $C$ " as well as for a period in the Martin hot shot for diagnostic changes.

The lower speed tests are scheduled only once for the above configurations except for a check at subsonic speeds for the basic capsule. In each case, the lower speed tests are scheduled after the revisions in the critical hypersonic speed range have been factored into the model design. Minor configuration alternatives will be designed into these latter tests as needed.
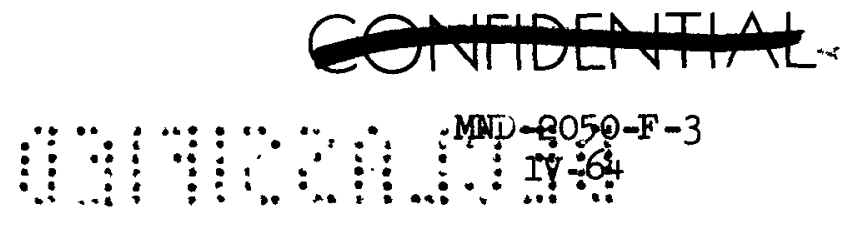


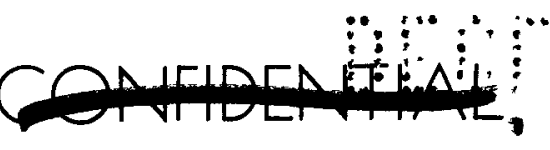

Certain local flow conditions due to special skin design on the basic capsule will be tested in tunnel " $\mathrm{C}$ ".

c. Proposed aerodynamic test schedule

Definitions and symbols for model configuration and wind tunnel facilities (See Table III)

(1) Basic Configuration 46" diameter blunt faced body with conical afterbody and oblique cut-off

(2) Configuration $A=$ Basic Body with CIR attached

(3) Configuration B = Basic Body with CIR and spacecraft attached

(4) $\overline{\mathrm{M}}$ (Ref. 1) = Martin Hot Shot Wind Tunnel, 25 " diameter test section

(5) $\mathrm{C}(\operatorname{Ref} .2)=\mathrm{AEDC}$, Mach 10, 50" diameter, bypersonic wind tunnel

(6) $\mathrm{A} \quad=$ AEDC Mach 1.5-6.0, supersonic tunnel $40 " \times 40 "$ square test section

(7) $\mathrm{CAL}$ (Ref. 3) = Cornell Aeronautical Laboratory-Transonic wind tunnel $8^{\prime} \times 8^{\prime}$ test section

(8) U = University of Maryland subsonic wind tunnel $73 / 4^{\prime} \times 1 l^{\prime}$ test section

REFERENCES

1. L. G. Cooper, S. M. Gottlieb, R. Phenney "The Martin Hot Shot Hypersonic Wind Tunnel," Martin E.R. 13427, March 1964.

2. ANON "AEDC Test Facilities Hand Book," Arnold Engineering Development Center, Tullahoma, Tennessee, January 1959.

3. ANON "8" Transonic Wind Tunnel," Transonic Tunnel Report W.T.0.-300 Cornell Aeronautical Laboratory, Revised December 1959.

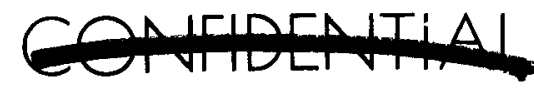




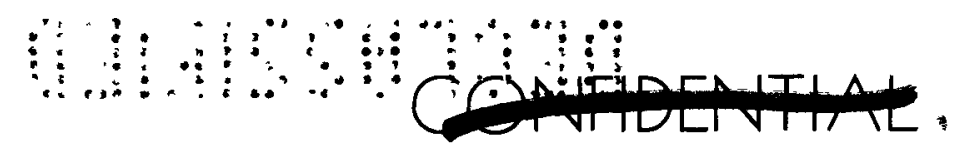

\section{3130--Generator System Development Tests}

The majority of these system development tests will be performed on the re-entry body only (less the Beacon Subsystem and with simulated fuel capsules).

\section{a. Re-entry body dynamic test unit}

A re-entry body system configuration will be provided for dynamic tests. The Beacon Subsystem components will be mass simulated and mounted as per design configuration. The radiator and thermoelectric modules will be structurally simulated. The fuel capsules in the Heat Source Subsystem will be loaded with simulated fuel for mass and rigidity simulation. The ablative surface will be mass simulated with no basic change in the structural mounting or joint configuration. Launch shock and vibration environmental modes will be imposed on the re-entry body input levels will be increased beyond qualification test levels. Separation shock environments will also be simulated for effect on structural supports. Re-entry vibration inputs will also be simulated. Tri-axial accelerometers will be mounted at critical locations to measure system responses and to provide design input data for mounting or interface details and for finalizing component qualification environment levels.

\section{b. Earth impact test}

The dynamic test unit will be refurbished as required and prepared for a terminal velocity impact test. The test will be performed by dropping the system from a helicopter at an uncontrolled angle, and tracking the system optically and with radar to its point of impact. Observations will include stabilization or tumbling, terminal velocity, breakup characteristics of the beryllium radiator, and fuel capsule survival. No other impact tests of a complete system will be performed unless a fuel release hazard is discovered that requires additional test evaluation.

\section{c. Initial thermal test}

Experimental verification of the system thermal analysis is of major interest. A wedge shaped test section including the heat source, the thermoelectric modules, insulation and the radiator will be operated in a vacuum chamber with thermal simulation of space environment. Three active thermoelectric modules will be mounted on the radiator segment. Edge effects will be minimized by insulating and applying guard heaters if necessary. Equilibrium temperatures for the radiator and heat source are of primary interest. An attempt will also be made to obtain initial system performance data.

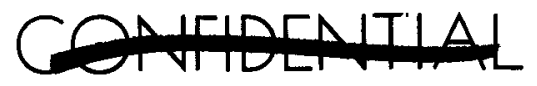




\section{आया।}

\section{d. Heat source latching test}

A heat source mock-up (constructed for dynamic tests) will be mated with the radiator subsystem and positive latching will be demonstrated.

e. Re-entry body thermal profile test

An RTG/RB structure will be provided with a complete external structure including the radiator (less thermoelectric modules). Strip heaters will be provided on all surfaces to provide expected heat inputs at the inner surfaces (radiator, aft body interface, and ablator surface. Upon verifying the surface conductive heat properties, the structure will be installed in a thermal vacuum chamber. Space temperature will be simulated and heat lamp fixtures will simulate the solar heat on the structure sides as in flight. Vacuum of approximately $10^{-7} \mathrm{~mm} \mathrm{Hg}$ will be sufficient. With the external and internal temperature applications under vacuum, the heat dissipation capability of the structure and the thermal profile of the surfaces and compartments will be monitored by thermocouple measurements. The aft cap and the CIR compartments will be used in the test for thermal monitoring.

4. 3140--Qualification Tests

\section{a. Qualification test system}

A complete Generator System (with thermal simulated fuel capsules) will be provided for a Qualification Test Vehicle. After initially passing the operational performance acceptance tests, this test vehicle will be subjected to a series of qualification tests to verify that the designed and fabricated vehicle will perform satisfactorily under the mission environments. Test levels will be higher than those anticipated to provide a margin of safety. The anticipated critical environments are launch vibration and shock, thermal vacuum, and CIR/Re-entry Body separation shock loads. The qualification tests will be performed prior to the launch of the Prototype Flight vehicle and repeated on the regular mission flight type hardware after any necessary design or fabricated changes are incorporated.

The qualification of the Generator System will include the performance as Combined System Test with a Controlled Intact Re-entry (CIR) system, a Hinged Fairing and Actuator, and the Aerospace Ground Equipment. The RTG/RB and the CIR are structurally and electrically connected and subjected to the following qualification tests:

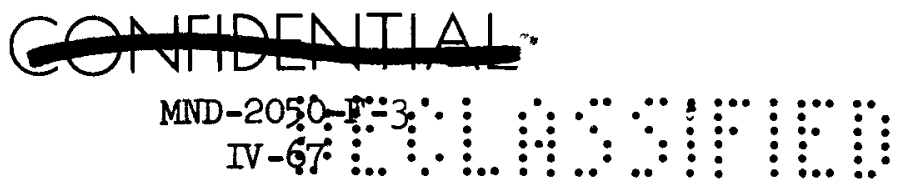


(1) Systems Electrical Performance Test - Complete mission profile performance test using simulation for all pyrotechnics and rocket motor firings. Perform EMI compatibility tests.

(2) Systems Vibration Test - Perform a launch vibration test at qualification levels with all systems operating as required during the launch environment. Check system functions after completion of vibration using simulators for pyrotechnics and rocket motors.

(3) Systems Thermal Vacuum Test - Place the combined system in a thermal vacuum chamber and perform a number of simulated exercises at periodic intervals using simulated connections for pyrotechnics and rocket motor firings. Thermal Generator outputs and voltage regulation will be continuously monitored. Also complete systems thermal gradients and responses will be monitored.

(4) Separation Test - At the completion of the thermal/vacuum test, the Spin and Separation sequences will be performed to test the effects of the space environment on the separation hardware, the pyrotechnics, and the rocket motors. The Despin and Retrothrust motors will also be verified along with the RTG/RB separation.

(5) Inspection - The complete system (RTG/RB and CIR) will be inspected for defects or other design problems at the conclusion of the Qualification Test cycle. The Re-entry Body ablator and other surfaces will be inspected in detail for any flaws in the protective coating.

(6) Reassembly and Test - The RTG/RB and CIR Systems will be reassembled into the flight configuration (with inert rocket motors and pyrotechnic simulators) and subjected to a combined system functional performance test.

b. Electrical and mechanical compatibility test system

A Generator System will be provided for electrical and mechanical systems compatibility and interface tests. The system consists of:

(1) Simulated radiator and thermoelectric module assembly

(2) Hinged Aft Cap with hinged fairing and actuator assembly

(3) Beacon Subsystem complete

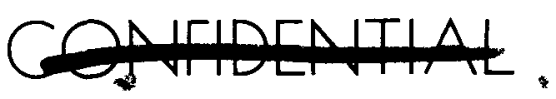




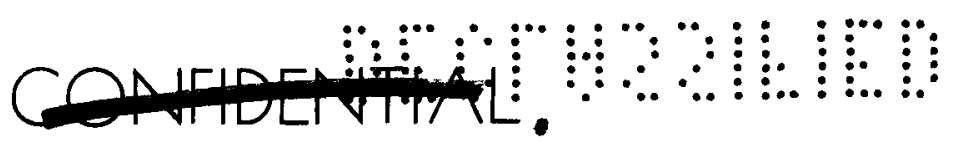

(4) Voltage Regulator Subsystem

(5) Dynamic Heat Source Subsystem model with all dimensional and latching mechanisms.

(a) Mechanical Compatibility Tests - All latching, hinging, and interconnecting devices are verified for tolerances, operating security, and indication outputs. The Heat Source Subsystem loading demonstrations are verified under both close visual inspection and operational techniques and under remote control operations simulating launch site loading. In all the above test, the applicable Ground Handling Equipment will be utilized and the applicable safety practices verified. A CIR system or a mechanical and electrical simulated system will be used to verify the interfaces between the RTG/RB and the CIR. The hinged fairing and actuator system will be verified during the fuel loading demonstration.

(b) Electrical Performance Tests - All electrical wiring and operating components will be verified by stimulating the sensors and the electrical circuits. The thermoelectric module electrical outputs will be simulated using AGE power to verify the Voltage Regulator Subsystem performance. The Beacon Subsystem will be operated using the AGE test equipment. The CIR electrical interface $w i l l$ be required for these tests.

(c) Launch Site Compatibility - Upon completion of the verification test cycle, the Compatibility Test Vehicle re-entry body will be sent to the launch location for pad operational sequences with the other co-contractor or integrating contractor pad compatibility tests. The Heat Source Subsystem loading demonstration and support equipment will be verified under simulated launch countdown conditions.

5. 3150--Prototype System Acceptance Tests

All component and subsystem hardware will be tested for adherence to specifications prior to installation into the RTG/RB systems. Each of the systems will be subjected to a normal flight vehicle acceptance test sequence prior to shipment to the Iaunch Complex or the Integrating Contractor's location. System acceptance tests will include:

(1) Mechanical Compatibility Tests - As described under Control Point 3140 .

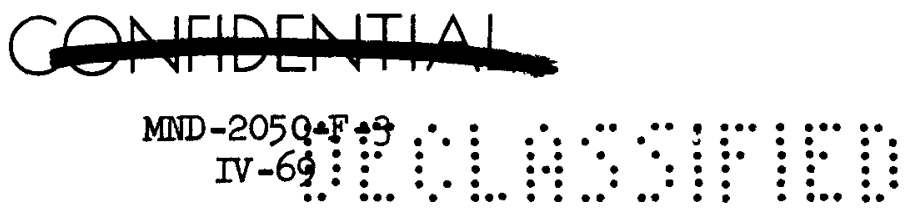


(2) Electrical Performance Tests - As described under Control Point 3140 except that a heavily-instrumented non-operational RTG will be utilized as part of the prototype system.

(3) System Vibration Test - Vibration profile as specified for flight vehicle acceptance.

(4) System Thermal/Vacuum Test - Functional performance test of the generator system in a thermal/vacuum environment to demonstrate system input and output functions under simulated flight environment. Note that these systems will be heavilyinstrumented non-operational units, and functional performance will include instrumentation and telemetry but not necessarily thermoelectric performance.

A compatibility test vehicle will be provided to the Integrating Contractor or the Spacecraft Contractor for performance of interface and inter-compatibility tests. The test vehicle will meet the external configuration requirements and any interface mechanical functional requirements. Generator system components need not be functional, but they must simulate flight article components in their mass, thermal properties, and electrical interfaces.

6. 3160--Flight Acceptance Tests

Flight Systems will be subjected to a complete acceptance test sequence similar to that indicated for the Prototype Systems under Control Point 3150. The major difference will be that the Flight System will be less heavily instrumented, and a complete electrically-powered heat source will be provided for performance testing.

\section{3170--Flight Test Support}

a. Technical support services

Technical support considerations will be evaluated early enough in the design and hardware development phases to avoid costly redesign after the product is developed. Task 3171, Technical Support Services, includes effort that will minimize life-cycle cost, and result in products ready for immediate "fleld" use during Phases III and IV of the program. This task includes several activities that will be accomplished concurrent with and integrated into design and hardware development. The essential support considerations are:

(I) An Operations Plan 


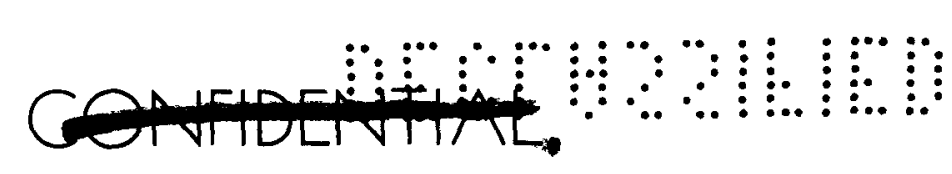

(2) A Maintenance Plan

(3) An Operating Manual

(4) A Maintenance Manual

(5) Training

(6) Spare Parts Provisioning

(7) Support Facilities

The operations and maintenance plans are discussed in Section 1230 of this report. The operating and maintenance manuals are discussed in Sections 3030,4040 and 5040 of this report. Training, spare parts provisioning and definition of support facilities is discussed in the following:

\section{Training}

Objective

To effect a highly skilled and competent team of personnel to test, checkout, maintain and integrate the RTG/RB system into the space mission program.

\section{Approach}

(1) Analyze the operations and maintenance plans of the space mission program; the design of the RTG/RB system; the skill level and skill requirements applicable to field support of the $\mathrm{RTG} / \mathrm{RB}$ system with respect to student capabilities to determine the scope of the training required.

(2) Develop a training plan covering the complete training program including a program of instruction; numbers and types of personnel to be trained; identification of courses and course lengths; identification of training equipment and materials; training aids; training facilities requirements; and instructor requirements.

(3) Utilize the training plan on the basis for developing training schedules, lesson plans and training aids.

(4) Conduct training in two increments. The first increment will consist of training the contractor's inplant personnel. The second increment will be a formal training program developed to prepare the User to take over the operation, test and checkout of RTG/RB system hardware.

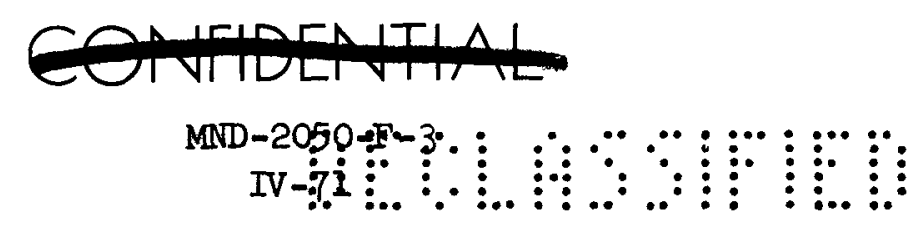




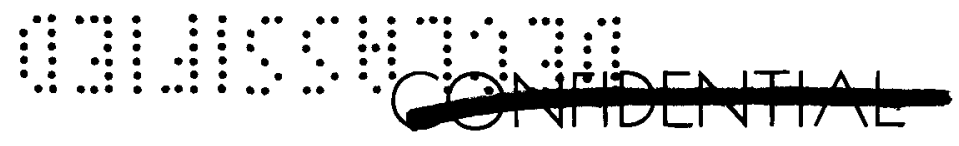

(5) Select personnel for the training program who already have a background in the discipline (or similar area) in which they are to receive training to permit concentration on system application.

(6) Conduct training during Phases II and III of the program for the purpose of providing a trained contractor test, checkout and launch team. This team will be responsible for accomplishment of the contractor's responsibilities at the launch site for the prototype system(s) and the first flight operational system.

(7) Initiate training of User personnel during Phase III of the program. These personnel will then become an integral part of the launch team of the first flight operational Generator System. The Users team will be responsible for the second operational vehicle launch and all succeeding launches except for fueling operations and certain related maintenance activities. Key members of the contractor's launch site team will remain to provide technical assistance through the completion of launch operations.

Major Problem Areas

(1) Maintaining skilled personnel during the four year span of Phase IV.

(2) Maintaining the proficiency of certain skills, e.g., the operation of fueling the generator system will be performed at infrequent intervals.

\section{Solutions}

(1) Instructional film and/or sound-slide presentation which can be used as a device for training new personnel and retraining personnel to maintain proficiency will be provided.

(2) Demonstration mockups and/or models will be furnished for the purpose of maintaining skills.

b. Equipment maintenance and repair

Objective

Provide for timely maintenance and repair of Generator System hardware during Phase III operations. This maintenance and repair will become the responsibility of the user during Phase IV operations. 


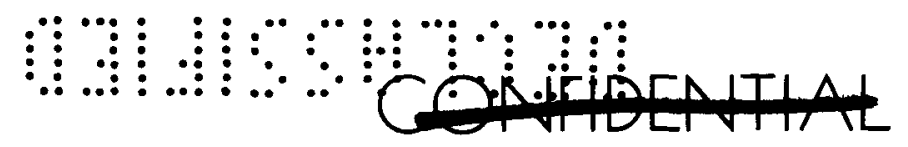

(6) All phase III residual spares will be delivered to the User at the completion of Phase III. 
B. 3200--HEAT SOURCE SUBSYSTEM

Objective

The objective is to design, develop, fabricate, assemble, test, and qualify:

(1) a strontium (-90) titanate-fueled heat source

(2) A plutonium (-238) dioxide-fueled heat source

(3) an electrically-powered heat source for use with the Generator System

The requirements of the strontium and plutonium-fueled heat sources are that they provide sufficient thermal energy to the thermoelectric subsystem for the generation of 250 watts of electrical power during a 5-year orbital mission, and that they minimize the radiobiological hazard related to fuel release and dispersion by ensuring containment of the fuel during normal operation and under designated accident environments.

The electrically-powered heat source is intended primarily as a test mock-up to duplicate the mass and thermal output of either of the radioisotope heat sources during generator system tests and fueling demonstrations. It shall therefore be qualified for flight as well as for ground operation. Clarification of the objectives of the flight demonstration test may establish the need for flight with an electrically-powered heat source to simulate operating temperatures during launch, suborbital or orbital flight, and re-entry.

$\underline{\text { Problems }}$

The most significant problem with the strontium-fueled heat source is that of ensuring complete containment of the fuel during normal operation and certain designated accidents. There is no single encapsulation material that will resist these environments and still be compatible with imposed performance objectives.

The fuel can be contained during a short-term mission (on the order of several weeks) with a bare Haynes-25 fuel capsule, but during a 5year mission there would be appreciable volatilization of chromium from the capsule surface. This would cause the capsule surface to recede and the alloy composition to be modified, and it would cause electrical shorts to develop by re-deposition of the chromium on adjacent surfaces.

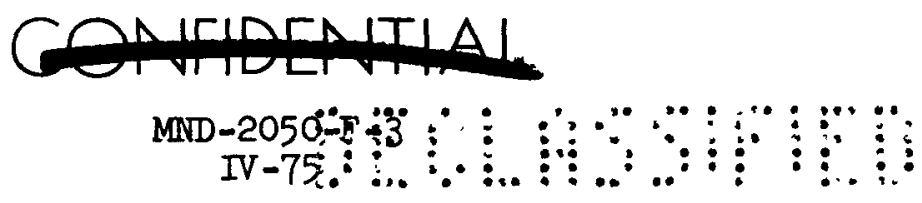




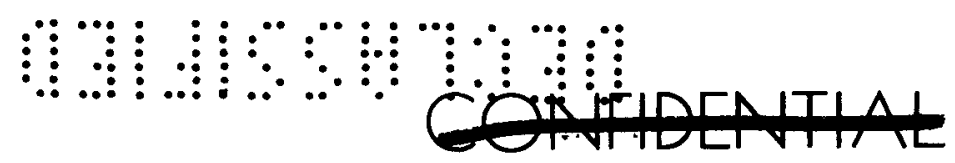

The plutonium-fueled heat source has the same fuel containment problem, as well as the problem of containment or disposal of helium gas which is generated as a result of isotopic decay. Containment of the helium would dictate the use of heavier fuel capsule walls. Disposal of the helium has been proposed by means of venting through porous plugs, calibrated leaks, and/or rupture discs. Such vents have not yet been developed, primarily because funds have not been released for their study and test.

The primary problem with the electrically-powered heat source is heater failure due to shorting or burnout. Shorting frequently occurs due to vaporization of conductive or semi-conductive chemical products and deposition of these products on insulator surfaces between electrical conductors, and by mechanical failure of intemal insulation. Burnout occurs by sustained vaporization or oxidation of the heater elements or leads, and by mechanical vibration and shock of unsupported conductors.

A secondary problem that is common to all three heat sources is that a suitable high-temperature structural insulation has not yet been developed.

\section{Approach}

The approach will be to establish design and safety criteria for the three heat sources based on imposed operational and program requirements, and to develop the heat sources which best satisfy their respective criteria. This will involve the efforts of design, analysis, nuclear safety, manufacturing, quality assurance, and testing.

A method of stabilizing the fuel capsule material will be developed to prevent volatilization of its constituents. This may be a coating applied directly to the capsule surface, or it may include additives to the capsule material to stabllize the capsule surface and prevent volatilization. Long-term thermal vacuum and emissivity tests will be performed to demonstrate material stability. If necessary, a subsequent coating or treatment will be developed to ensure adequate long-term emissivity. Development and testing will be subcontracted as required to supplement the contractor's skill and facilities.

A porous vent will be developed for the plutonium-tueled capsule which will contain the plutonlum dioxide microspheres, yet permit the helium gas to escape under normal operating and certain accident conditions. If applicable, differences in the safety philosophy for strontium and plutonium fuel will be established.

Liaison will be performed with Johns-Manville EngIneering and

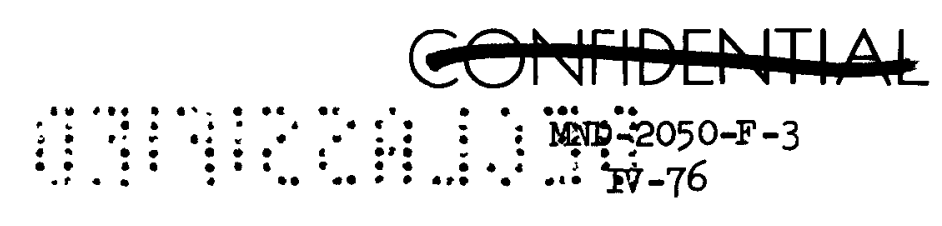




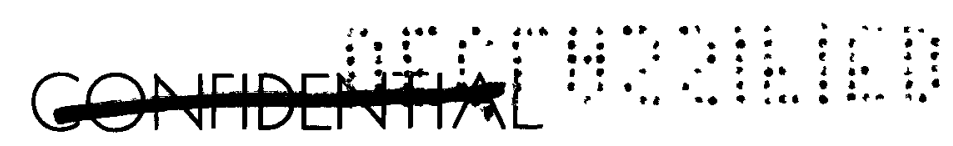

Research Center to ensure that the advanced Min-K insulation which is currently being developed will be available in the form required by the heat source subsystem.

Fabrication and Assembly

Fuel Block and Capsules

Manufacturing will, upon the release of engineering design, fabricate details necessary to enable Engineering to develop components for the heat source development tests. The heat source structure will be fabricated in three individual pieces. These pleces will be a top cap, a bottom cap, and a large diameter tube. The top cap assembly will be fabricated as a formed up section as will be the bottom cap assembly. A large diameter tube will be machined to which the top cap assembly will be welded. Both the top and bottom caps will be lined with a fibrous thermal insulation. A blanket type insulation will also be wrapped around the exterior sides of the tube assembly. Two capsule retaining rings will be fabricated out of Haynes 25 alloy for the purpose of holding the fuel capsules in position. A spline assembly will be welded to the tube assembly and will mate with a matched spline on the bottom cap. A threaded collar ring will hold the entire assembly together. A quantity of 36 fuel capsules plus the required weld test specimens will be fabricated by machining the superalloy in two pleces. Joining together of these fuel capsules and testing representative specimens will be accomplished by the fueling agency. A latch mechanism consisting of six spring powered latches will be fabricated and installed within the tube assembly of the heater block. These latch assemblies will be welded to two ring details. Both the ring assemblies and the latches will be welded or brazed to the interior of the tube wall. The interior of the tube wall will be grooved for ball detent operation of the fuel handling machine insertion probe. Fuel liners will not be supplied by Manufacturing as current information indicates that these liners will be supplied by the fueling agency.

\section{Sr-90, Pu-238 Fuel}

Manufacturing understanding in relation to this sub-task is that the existing configuration is based on Sr-90 fuel. No Manufacturing inputs are required on $\mathrm{Pu}-238 \mathrm{fuel}$. It is assumed by Manufacturing that the same detail components could be utilized by either selected fuel.

\section{Electrical Heater Block}

Since the electrical heater block or blocks will be identical to basic heater block assembly, only minor changes in Manufacturing inputs are required. Purchased heater elements of approximate 200 watt type

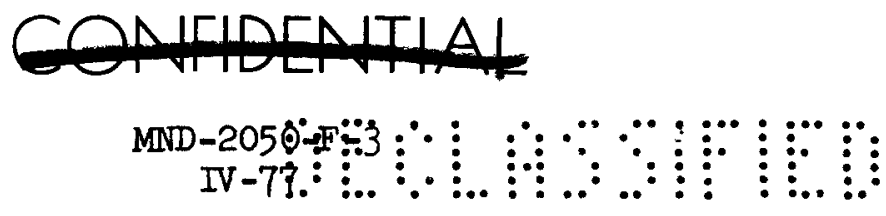




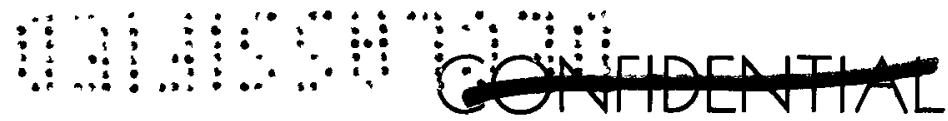

will be modified for use in a basic heater block. A high temperature wiring harness will be fabricated for power requirements to the heater block. This harness will be fabricated by conventional electronic fabrication practices, with special attention given to making vibration-resistant, high-temperature electrical connections.

Quality Control

\section{Capsules and Fuel Blocks}

The Quality Department will ensure that the contractual quality assurance and reliability requirements for the fabrication of the heat source and capsules will be built into the design through the participation in Specification and Design Reviews.

\section{Capsule Details}

Due to the importance of the RTG fuel capsule, raw material procurement and inspection will be continually monitored by Quality. Martin fabricated capsule details (two pieces machined from Haynes material) will be inspected prior to shipment to the fueling agency. The following procedure will be used.

All purchase requisitions covering procurement of fuel capsule materials will specify the following Martin Quality requirements:

(1) Four copies of actual vendor chemical and physical test reports for each lot, batch or heat of fuel capsule material must be attached to the packing sheet and accompany each shipment of material delivered to Martin.

(2) Concurrent with the shipment of production quantities of material, the vendor shall furnish test sample(s) of each lot, batch or heat in sufficient quantities for Martin to conduct acceptance tests. Each test sample must be clearly and permanently marked with: batch or lot number, specification or material control information number, vendor's designation, and purchase order number.

(3) A certificate or statement of material and process conformance covering the material must be supplied by the vendor and must stipulate that the material supplied meets all specification and purchase order requirements.

Upon receipt of fuel capsule materials at Martin, the Quality Materials Testing Laboratory will perform a chemical verification of the material certification, and general receiving inspection will perform

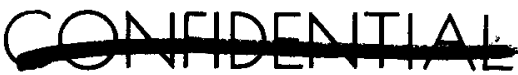




\section{(1)}

required dimensional, visual, and vendor documentation verification as directed by the Quality receiving acceptance plan. The Quality Materials Testing Laboratory will record test results of all material checked for physical and chemical requirements on a Materials test report form and distribute copies to the Receiving Inspection group and the Nuclear Quality planner.

Material accepted by Receiving Inspection will then be released to the Nuclear stockroom for subsequent issue to Nuclear Manufacturing for machining. Upon completion of capsule detail fabrication operations, each part will be subjected to a detailed visual, dimensional, dye penetrant check and helium leak test. Inspection personnel will record variable data for each detail on inspection record sheets. To facilitate in-plant dimensional inspections, Quality will utilize specially designed check gages to verify diameters, lengths and envelope configurations of the fuel capsule details. Check gage requirements will be determined early and, after initial verification, will be periodically re-inspected to assure continued accuracy. After fabrication operations are complete, the Quality Materials Testing Laboratory will again perform a chemical verification of the material on sample specimens selected from the production details. This verification will confirm that fabrication operations have not altered or affected the fuel capsule basic materials. Completed inspection logs and test reports covering each shipment of fuel capsule materials and components will be forwarded to the Fueling Agency.

\section{Heat Source Components and Assembly}

The detail fabrication of the heat source (retaining rings, top and bottom caps, tube, thermal insulation, splines, latches, springs) will be inspected in accordance with procedures outlined in the Quality Program Plan. Inspection requirements for the heat source will be determined and patterned after the stringent controls that will be implemented on the fuel capsule processing. Quality check gages necessary to verify capsule cavities and overall configuration will be provided to assure heat source uniformity and interchangeability.

\section{Fueling Agency/Martin Quality Coordination}

As soon as interface requirements are established, an Interface Specification will be prepared establishing interface requirements between Martin and the Fueling Agency pertinent to design, development, fabrication, test and delivery of fuel for the RTG.

Each shipment of capsule and heat source parts will be accompanied by a Martin Quality certification log containing material certification and test report data and a record sheet listing the variable data for

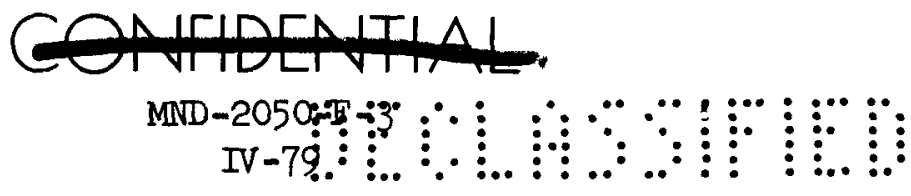




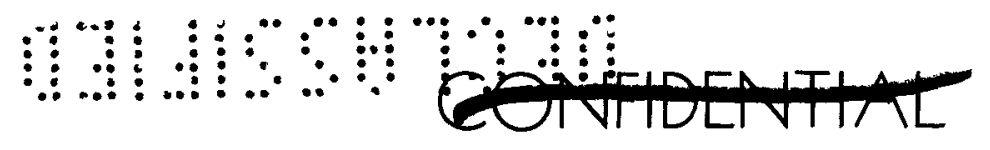

each component. To assure uniformity in completed capsules, Martin will design, fabricate and furnish gages for use by the Fueling Agency to check exterior dimensions of completed fuel capsules.

Martin Quality will perform receiving inspection on each shipment of capsule test specimens and simulated heat sources received from the Fueling Agency's plant. This will be in accordance with a Martin-prepared receiving acceptance plan (RAP) that lists the verifications/ documentation review that will be performed by an inspector. It will include:

(1) A review of the Fueling Agency's in-process and assembly inspection results.

(2) An examination of radiographs produced for weld evaluation.

1. 3210--Design and Analysis

Primary emphasis will be given to ensure that the heat source subsystem meets its intended design criteria. These criteria will be established early in the program and will be revised and maintained as required to meet the performance and safety requirements of the program.

Nuclear safety criteria established in task 3110 will be reviewed, and their effect on the heat source design will be evaluated. When applicable, the effect of alternate safety criteria will be assessed with respect to heat source size and weight. For instance, if it can be established that the re-entry body shell (radiator, heat shield, and aft cap) can be relied on to contain the fuel capsules during an explosion, then the self-imposed requirement that the fuel capsules resist their terminal velocity impact may be relaxed.

Heat source geometry will be studied to determine its effect on component temperatures and on the fueling operation. Area-emissivity calculations will be performed parametrically with view factor and temperature. Special surface requirements for intermediate insulation surfaces (between the heat source and thermoelectrics) will be established by the system thermal analysis performed at control point 3110. Geometrical factors relating to the volume of fuel to be contained will be reviewed to provide a basis for selecting the final number of 1 uel capsules. A thermal analysis will be performed to determine the operating temperatures at critical points on the fuel capsule and fuel.

Liaison will be performed with the designated fueling facility to establish that the fuel capsules can be loaded and sealed, and that the complete heat source can be assembled and casked for shipment. A capsule specification, a heat source specification, and appropriate fuel and

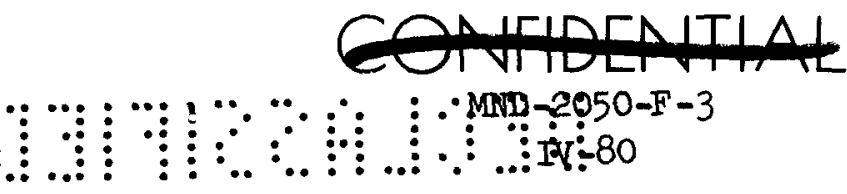




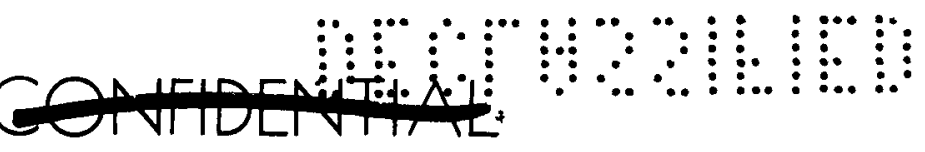

welding specifications will be prepared and delivered to the fueling facility. Loading and assembly procedures will be written for use by the fueling facility. Pertinent fuel properties, such as its impurities, half-life, mass density, power density, thermal conductivity, materials compatibility, melting point, solubility, and burnup characteristics will be provided by the government facility.

A materials analysis will be performed in support of the fuel capsule and coating development. A literature search of coating technology will be performed, and liaison will be performed with other investigators (such as Pratt and Whitney and Battelle Memorial Institute) to determine the state of the art and the most promising areas of development. Direction will be given to test personnel, and test plans and specifications will be written.

A kinematic analysis will be made of the latch mechanism to ensure that it operates correctly during fuel handling operations, and that its latching action is positive and secure. A thermal expansion analysis will be performed to determine mechanical clearances and interferences during all operating conditions. The contour of the latch hook contact surface will be designed to accommodate the anticipated limits of thermal expansion and mechanical tolerances, and to provide the desired selftightening action during the launch environment.

A stress analysis will be performed to size the heat source structural components and thermal insulation. Fuel capsule external pressure, thermal shock, and impact analyses will be performed, and the results will be compared with test results. In the case of impact analysis, theory has not been developed to the extent that impact test results can be accurately predicted. The energy method of analysis presented in the technical volume will be verified empirically and extended to provide a basis for weight and performance optimization.

A porous vent will be designed for the plutonium-fueled heat source, and tests will be specifled to ensure containment of the fuel, passage of the helium gas, and resistance to impact and the thermal and vacuum environment.

Design and analysis will be performed to ensure satisfactory operation of the electrical heater under simulated earth and space operation for extended periods of time. Electrical power requirements, instrumentation, heater temperatures, and heater replacement studies will be performed. Special test equipment and dummy heat sources will be designed as required by the program.

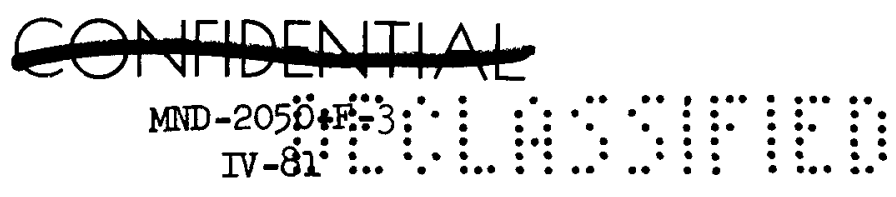




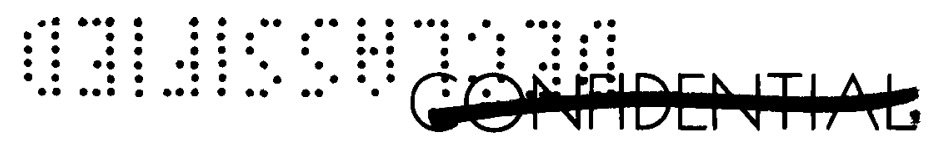

2. 3220--Component Development

Three heat sources will be developed for the program, an electrically heated simulated heat source and two different isotopic fueled sources. The individual fuel capsule constitutes the major development item. Electrical heating elements are of particular concern and will be tested for extended periods of time at operating temperatures. Exposure to launch vibration levels is another important consideration. A stable emissive coating is required on both electrically heated and fueled capsules to limit the operating temperature. Testing initiated on other programs will be extended as necessary to obtain the desired emissivity.

Testing of the fuel capsules to determine their ability to contain fuel under adverse conditions is a major area of component development work. Impact testing will be performed to demonstrate compliance with the impact criteria. Determination of the critical impact angle will be made during the component development phase. In conjunction with impact testing capsule welding configuration and techniques will be developed and optimized.

Development associated with fuel/separator material compatibility, fuel solubility, fuel properties determination, etc. will be performed by government facilities.

Development tests will be performed as necessary to produce acceptable oxidation rates, resistance to thermal shock, and sea water corrosion rates. Compatibility between capsule material and propellant vapors will be investigated as a possible launch accident exposure.

The ability to relieve gas pressure build-up while simultaneously containing fuel will be demonstrated on development models prior to finalizing the design. This applies to the plutonium fueled heat source.

Long term testing of coated fuel capsules will be performed. Volatilization and redeposition of capsule material is of major interest.

3. 3230--Component and Subsystem Development

This will be a continuation of the Phase I development effort, but emphasis will be shifted from individual components, materials, and coatings to the use of these components in the development of the heat source subsystem. The particular items of interest are the structural adequacy of the heat source and its support members and the adequacy of the heat source in containing the nuclear fuel during certain credible accidents.
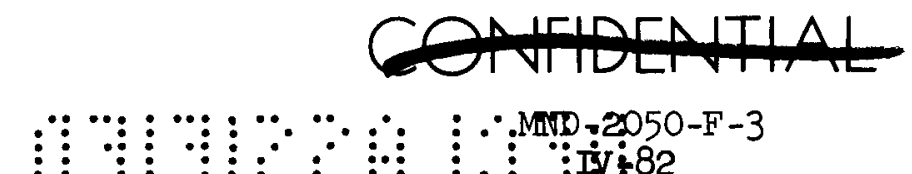


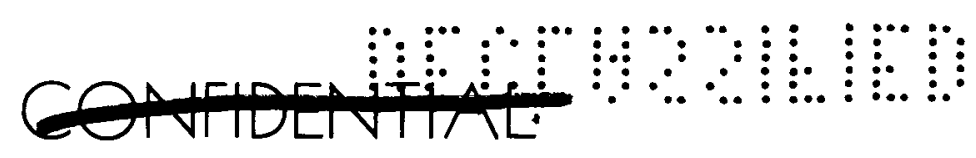

An electrically powered heat source will be used for initial vibration and shock tests to identify structural problems associated with normal operation of the heat source during launch, suborbital, and re-entry environments.

A series of four electrical heat sources will be qualified at design levels for pre-launch, launch, sub-orbital, thermal vacuum, and re-entry conditions prior to production of electrical heat sources for generator system testing. Subsystem impact tests will be performed by dropping one heat source containing dummy fuel capsules at each of three impact angles $\left(0^{\circ}, 45^{\circ}\right.$, and $\left.90^{\circ}\right)$ from the tower height to a simulated concrete launch pad. A fourth heat source will be dropped to impact broadside against a structural beam. Tests will be performed to simulate dropping of the heat source within a transportation cask, but fullscale cask drops will not be performed due to the expense of such a program. Up to ten individual capsules will be tested in this manner, using the best simulation available from the dynamic structural analysis which is performed. No additional subsystem impact tests will be performed unless the proposed tests reveal an unexpected safety hazard which requires additional evaluation tests.

A non-operating mock-up of the heat source shall be constructed and tested in conjunction with handling equipment. Initial tests to demonstrate the handling tool engagement will be performed by the AGE group. Functional testing of the heat source - radiator connections will be performed at the generator system level.

\section{3240--Qualification Testing}

Two major test efforts are planned; (I) qualification of fuel capsules and (2) qualification of the heat source sub-system. Fuel capsule qualification will include impact qualification tests, vibration qualification at temperature and thermal shock qualification.* In general qualification test results are evaluated by measuring capsule leak rates after exposure to the test environment. It is estimated that approximately 60 units will be required for the capsule qualification test program.

Heat sources will be qualified at operating temperatures simulating exposure to pre-launch, launch, sub-orbital, and orbital environments. It is anticipated that these same sources will be used for performance testing of electrically heated systems. Heat source qualification test levels related to dynamic loads will be determined from the earlier development models.

* Capsules will be coated (Emissivity Coating) for vibration and thermal shock tests. One capsule modified with a special electrical heater will be subjected to a long term sea water corrosion test.

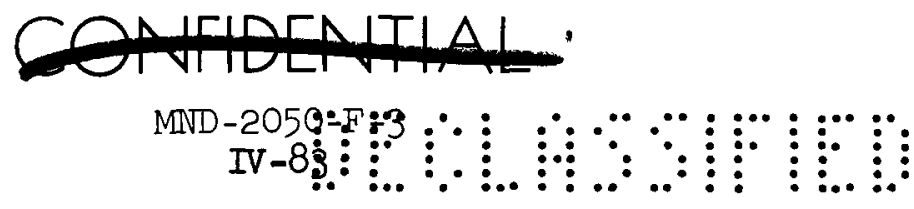




\section{mero}

\section{3250--Prototype Hardware Acceptance}

It is not known at this time whether a complete or partial heat source will be included in the flight demonstration model. This will be determined after the objectives of the demonstration flight become better defined.

Acceptance testing of full, partial, or dummy heat sources will be performed to the same level as that for actual flight hardware with respect to its anticipated mission environment, so as to establish high confidence in its performance.

6. 3260--Flight Article Acceptance

Acceptance testing of the subsystem will be performed at the system level, and is discussed under CP 3160. However, additional inprocess testing will be performed to ensure proper fit and operation of all components prior to assembly within the system in order to avoid subsequent schedule perturbations. In the case of the heat source, operation of the latch mechanism will be checked prior to shipping the heat source components to the fueling agency. This will be done using a heat source support structure mockup and special jigs and fixtures to simulate the fuel capsules, insulation, and fuel handling machine; and to measure the operating characteristics of the latch mechanism.

Delivery of the heat source subsystem components will be to the fueling agency; and delivery of the completed subsystems will be by the fueling agency to the launch site. 


\section{3300--THERMOELECTRIC SUBSYSTEM}

\section{Objective}

The objective of this task is to develop a thermoelectric subsystem which will withstand the specified dynamic and environmental conditions and produce the minimum required power over the mission life with high reliability. This task is concerned specifically with the silicon-germanium thermoelectric modules and the advanced high temperature Min-K and Micro-Quartz used for thermal insulation.

The ultimate objective is the delivery of seven flight qualified thermoelectric subsystems for incorporation into seven complete generator systems. This objective will be reached through a series of four phases during which a design concept is selected and defined, the concept, a fabrication capability and a quality assurance procedure are developed, the integrated capabllity is qualified, and assemblies are produced, qualified, and delivered.

\section{$\underline{\text { Problems }}$}

The developmental problems can be categorized into two areas: those associated with the thermoelectrics and those with the thermal insulation.

Problems in the thermoelectrics are:

(1) The large area hot shoe required has never been built or shaped to the dimensions required.

(2) A small $\triangle T$ across the couple stack and stack-radiator interface is required for efficient energy conversion and attractive system performance. It remains to be demonstrated that this $\Delta T$ can be made small with a beryllium radiator. A technique for mechanical and/or metallurgical attachment of the thermoelectric structures will have to be developed that will also withstand thermal cycling.

(3) A high (>0.80) hot shoe surface emissivity is required for reasonable capsule temperatures. Short-term data show that the emissivity is 0.80 but stability over a 5-year period remains to be demonstrated.

(4) Stringent mechanical environment requirements, particularly during launch, are placed on the insulator-stress balance thermocouple stack structure and the elements themselves.

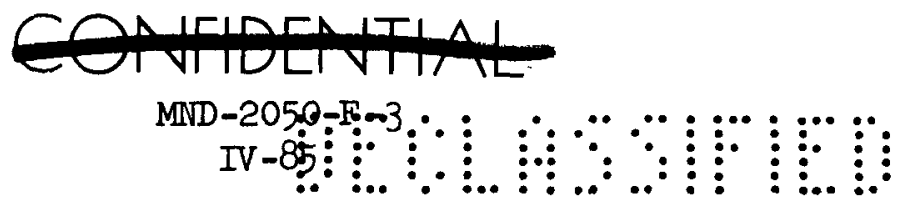




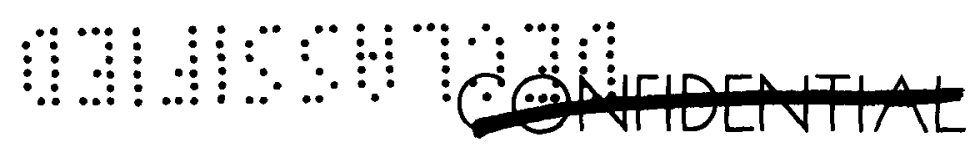

The design will have to meet these requirements and adjustments or refinements may be necessary, particularly in order to meet high reliability (e.g., 0.95 over a 5-year period on the generator system).

(5) Radiation damage effects to the elements have not been evaluated at the level that exists in the $\mathrm{Sr}-90$ referenced design generator.

(6) Power and efficiency from the SiGe couples remain to be demonstrated by test as a function of time.

(7) Exact design data are not known on the effects of thermal cycling although preliminary data indicate the problem not to be severe.

(8) The effects of thermoelement contamination due to the presence of advanced high temperature Min-K and other products within the system are not known.

(9) A technique for reliable electrical connections between modules has not been developed.

(10) A technique for a reliable washer-nut attachment system at the connecting interface between the couple terminating studs and the radiator needs further development.

(11) A technique for assembling and retaining the thermal insulation in the thermoelectric modules remains to be developed and demonstrated.

Successful development of the thermal insulation required in the modules will necessitate a complete knowledge of:

(1) Thermal conductivity under all operating conditions as a function of time.

(2) Radiation damage effects due to the presence of Sr-90.

Approach

The thermoelectric subsystem design objectives will be reflected in a set of criteria and specifications generated at the initiation of the program.

The basic thermoelectric modules shall be developed as a subcontract to $R C A$ with additional analyses and developmental and reliability
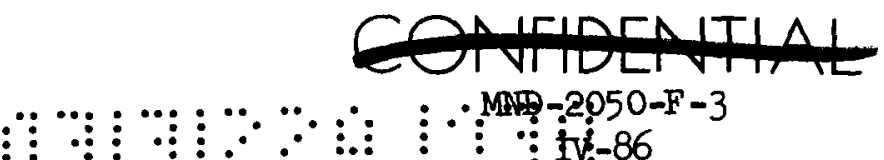


\section{WIII)}

testing performed by the generator system contractor. In Phase I, the thermoelectrics will be design optimized for integration into the overall generator system. This is the period during which materials are selected and techniques, processes, tools, facilities, quality assurance procedures, and fabrication controls and tests are determined and given preliminary definition. This phase will result in an established prototype module and converter design and in the definition of a highly feasible qualified hardware capability.

Phase II will be devoted to fuel design refinements and to the development of a fully facilitated and trained qualifiable hardware capability, including acquisition of required final tooling and equipment and specification of processes, procedures, techniques, performance and assurance tests. It will also include starting fabrication of the prototype RTG test converter for Phase III.

Phase III will be devoted to refinement of all elements of thermoelectric design and all elements of fabrication capability. It will demonstrate qualification of the total fabrication capability. The result of this phase effort will be a fully qualified hardware capability. Determination of capability qualification is to be based primarily upon the output of tests provided for this parpose. Environmental, performance process and quality control, quality assurance, and reliability tests are schedules, in some cases from Phase I, to produce data and analyses prior to Phase III completion.

Phase IV is devoted to the fabrication, assembly, test and delivery of flight qualified module assemblies to the RTG system for flight test and to support the effort required for launch approval. It will result in delivery of seven qualified module assemblies starting in 1971.

The basic thermal insulation required (advanced high temperature Min-K) is currently in development at Johns-Manville under contract to the AEC. In addition to data provided under that contract, testing will be performed to ensure the delivery of a qualified insulating material consistent with the generator requirements. The Micro-quartz insulation used for filling crevices in the module will also be qualified by testing by the generator system contractor but is currently more developed than the advanced $\mathrm{MIn}-\mathrm{K}$ and therefore will not require the same level of effort.

\section{Fabrication and Assembly}

Manufacturing will install thermoelectric module assemblies directIy to the beryllium radiator shell. This assembly will be accomplished by using RCA's flexi-mod assembly technique. Installation of these

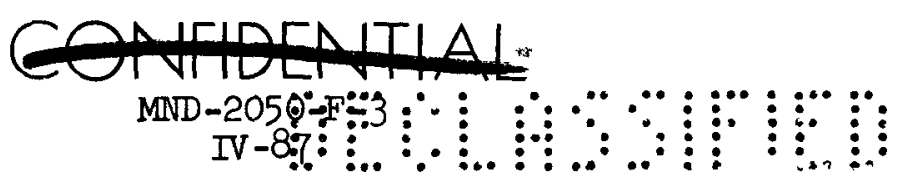


module assemblies will be accomplished by a Nuclear Manufacturing operational procedure which will be written and issued for shop use after a thorough understanding of the flexi-mod assembly technique has been obtained. These modules will be made up from a total of 396 silicongermanium thermoelectric couples. All modules will be installed in a quantity of twelve couple assemblies. The modules will be cross-connected between adjacent modules by a mechanical type connection for high reliability. After installation of the module assemblies, Min-K insulating material will be inserted between the rows of couple assemblies. Consideration will be given to the area of special tooling with which to install final pieces of insulation pieces between the couple assemblies. A specific area of manufacturing concern is the health hazard that the Min-K insulation may impose on personnel during the installation process. It is anticipated that some sort of safety equipment will have to be used in order to prevent Min-K dust from causing lung contamination. Special facilities for keeping the interior of the beryllium shell cool will be required.

\section{Quality Control}

\section{Thermoelectric Modules}

Quality Source Inspection will inspect each shipment of modules prior to leaving RCA's plant. This will be in accordance with a Martin-prepared contractor acceptance plan (CAP) that lists the verifications/documentation review that will be performed by an inspector. It will include:

(I) A review of RCA's in-process and assembly inspection results.

(2) An examination of module test results.

In order to install the thermoelectric module assemblies directly to the beryllium radiator shell using RCA's flexi-mod technique, a process development program will be performed with Quality assisting Manufacturing and Engineering.

Quality will cooperate with Manufacturing in the development of any special tooling if required to assemble the silicon-germanium thermoelectric couples and installation of insulation between the couple assemblies may present a health hazard to personnel installing it, Quality with the cooperation of Manufacturing will develop safety requirements and enforce them.

\section{3310--Design and Analysis}

Design criteria will be established at the start of the program
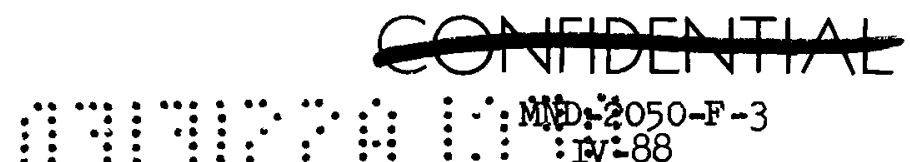


\section{ALIIII}

which will define the performance requirements of the subsystem and the imposed environmental factors. These criteria will subsequently be developed and modified as the design evolves. Detailed thermoelectric analyses will be performed on an existing digital program parametrically in cold junction (radiator) temperature in order to optimize the overall system. Electrical performance will be determined as a function of time. Much of this analytical effort will be coordinated with reliability to ensure that an adequate design with respect to catastrophic failure and degradation ensues.

Detailed analytical studies will be performed where required to incluae such items as temperature distribution in the hot shoe, Joulean resistance losses in the circuit, temperature drop through the couple stack and across the radiator interface, open and short circuit calculation and off-design-point calculations.

This task will bring the preliminary module design of the program definition phase through successive design stages to the prototype design. The result will be a design which incorporates the results of design feasibility and development tests performed concurrently with this task.

Under this task, test and material specifications will be written. Element, module and performance test data will be compared with analytical predictions and changes will be incorporated in the design where necessary.

Thermal and thermal efficiency are performed at the system level under control point 3110. Reliability analysis for the thermoelectrics and insulation is performed under control point 3020.

2. $3320--$ Component Development

Component development falls into two categories, fabrication process development and configuration development. Test structures will be fabricated and fabrication processes will be operated to supply couples for feasibility, design development and program tests and to permit initial process evaluations. Basic property measurements will be evaluated to determine both nominal design values and data variations. Couple and possibly module testing will be initiated to determine nominal values of power, voltage, and resistance as a function of time and also data variations associated with a representative sample.

As soon as module fabrication is possible, it is anticipated that preliminary system performance data will be collected in a closed assembly containing a central heat source, a reduced number of thermoelectric modules positioned on a reduced radius and a simulated cold

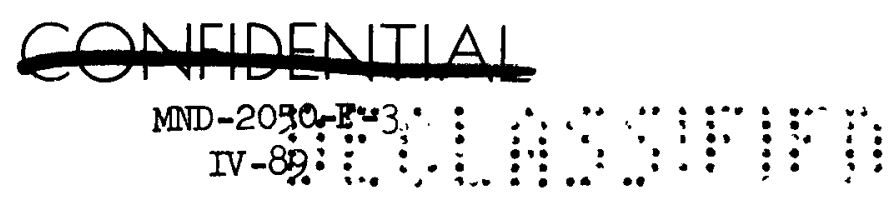




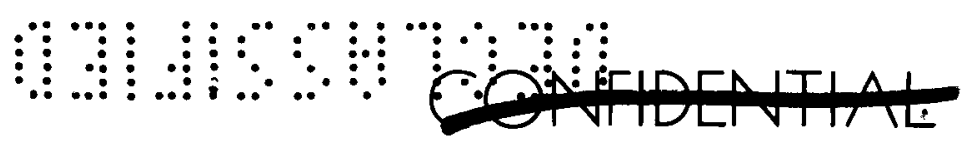

end radiator. It is anticipated that an effort equivalent to the fabrication of fifty full size twelve couple modules will be required.

An initial specification will be prepared defining environmental test exposures prior to testing. Preliminary test fixtures will be designed and fabricated. Initial testing will identify these areas which require design modifications of either thermoelectrics or the generator system. Several initial module assemblies will be included in radiator tests to aid in defining firm environmental test levels for future tests. As system component materials are selected thermoelectric material compatibility tests will be performed at a component level and results will be assessed at the system level.

\section{3330--Component and Subsystem Development}

Environmental testing of thermoelectric modules attached to simulated radiator sections will be performed by RCA. Pre-launch, launch, sub-orbital, and orbital conditions will be simulated. Electrical performance measurements, especially conversion efficiency will be of primary interest. Test results will be used by the design process and test development tasks for program guidance, leading to preparations for full system environmental qualifying tests in Phase III.

Full hardware (modules) test fixtures and facilities will be designed, secured and developed by RCA for air and vacuum operational cycling and steady state tests. Test facilities required by the quality Assurance Test Program will be included.

Couple testing initiated earlier in the program will be continued as necessary and will be supplemented with module tests to accumulate data for reliability analyses.

It is anticipated that the equivalent of 130 full modules will be processed prior to fabricating modules for the prototype RIG systems and the RTG/CIR flight demonstration units. Most of these are needed to develop and qualify the fabrication process.

4. $3340--$ Subsystem Qualification

Whereas the thermoelectric modules will be tested prior to installation in a complete $R T G / R B$, full qualification shall not be given until system qualification tests described in CP 3140 have been satisfactorily completed.
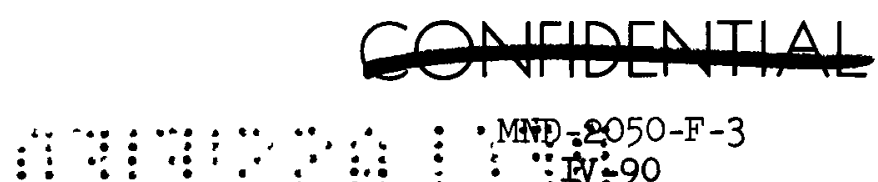
5. 3350--Prototype Article Acceptance

Prototype thermoelectric modules will be tested by RCA prior to installation in the complete RTG/RB, and in-process checks will be made during installation to ensure continuity of the thermoelectric circuit.

Final acceptance testing will be performed at the system level as described under CP 3150.

6. 3360--Flight Article Acceptance

Flight article modules will be tested by RCA prior to installation in the complete $R T G / R B$, and in-process checks will be made during installation to ensure contimity of the thermoelectric circuit.

Flight acceptance testing will be performed at the system level as described under CP 3160. 


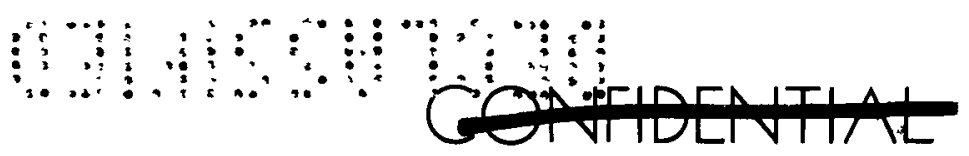

\section{3400--RADIATOR SUBSYSTEM}

\section{Objective}

To develop a radiator which will dissipate waste heat from the thermoelectric elements and also provide the structural support for the radioisotope thermoelectric generator. The heat must be dissipated within prelaunch, launch and orbital temperature environments, and the structure must maintain its integrity under all imposed mechanical environments except impact.

Problems

(1) Since beryllium is a relatively brittle material, there is danger of cracking the radiator during fabrication, assembly, or later handling.

(2) It is not known whether a suitable coating exists for the radiator exterior surface. A coating having high thermal emissivity and low solar absorptivity is required, and it must be stable under long-term exposure to unfiltered sunlight, meteoroid bombardment, and nuclear radiation.

(3) The effect of meteoroid bombardment, nuclear radiation, and thermal cycling of the beryllium has not been evaluated for the prescribed mission. Applicable data do not exist.

(4) A quick-disconnect electrical connector does not exist which is suitable for long-term operation at elevated temperatures in space. It is expected that cold welding may occur at the connector pins to prevent the mating parts from separating. A self-shorting feature is desired between the generator power leads of this connector to lower the heat source temperature prior to re-entry.

\section{Approach}

In developing the radiator subsystem, design criteria and specifications will first be assembled to define all physical limitations and interface requirements. A literature search will be made to ascertain the present state of the art for beryllium technology, emissive coatings, and material compatibilities. A detailed analysis of all radiator structures and heat flow requirements will be accomplished. Component and subsystem development testing will be performed to validate the design. The problems listed above will be solved in the following ways: 


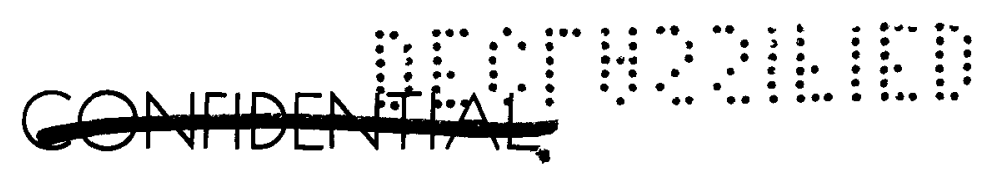

(1) Fabrication, assembly, and handling techniques will be developed to ensure that cracking of the beryllium does not occur. A fabrication subcontract will be awarded to an experienced beryllium fabricator to ensure the highest probability of success.

(2) Results will be obtained from current programs such as SNAP 27 in which coatings for beryllium are presently being evaluated. If necessary, a suitable coating or coating system will be developed which will have the desired properties.

(3) The effects of meteoroid bombardment, nuclear radiation, and thermal cycling of the radiator will be determined and evaluated. Where necessary, tests will be performed to generate applicable data.

(4) A subcontract will be awarded for the development of a suitable quick-disconnect connector. The desired self-shorting feature will be included as long as it does not sacrifice more essential properties of the connector, such as contact reliability.

Fabrication/Assembly

The thermal radiator will be a truncated conical shell which will be formed and fabricated out of a beryllium material. This conical shell will be formed and machined in one or more sections, and joined by conventional type fabrication such as brazed lap joints or by mechanical fasteners. Manufacturing anticipates fabrication problems in the machining of the beryllium sections because of the brittle characteristics which are inherent in beryllium materials. Machining facilities capable of handling beryllium are limited within the Martin-Baltimore complex, however, a fabrication knowledge of beryllium does exist within our manufacturing sections as a result of the Lifting Body program. Machining of the beryllium shell will be accomplished through AMT development effort and by the possible enlistment of subcontracting aid. The joining together of the beryllium sections and attachment of structural components will also be accomplished through this same type of effort.

Special consideration will have to be given to the drilling of the beryllium shell for detail component attachment. The reasons for this requirement are that special techniques are required for the drilling operations as a result of the tendency of beryllium to crack.

One aluminum and one beryllium radiator will be manufactured during this program phase.

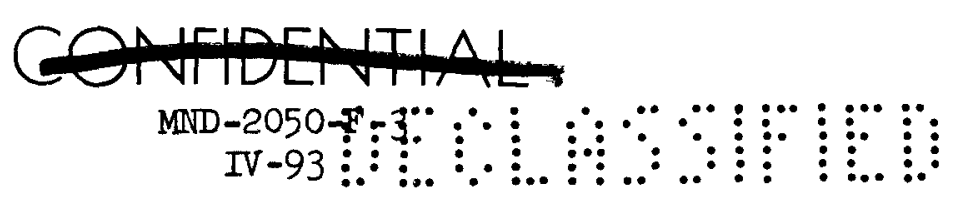




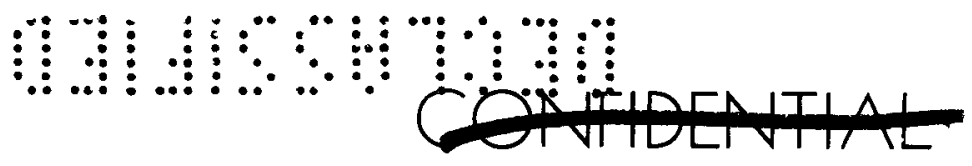

Two annular rings will be fabricated out of an insulating material-Min-K or micro-quartz--and lined with silica cloth. These rings will be fabricated to engineering specifications through a subcontractor-- preferably Johns-Manville. Assembly of these rings to the predrilled beryllium shell will be accomplished by Nuclear Manufacturing.

A circular ring made of Haynes-25 material will be fabricated and assembled to the lower end of the radiator. This ring will provide a mounting interface to accept the ablative heat shield.

A series of eight individual intermittent guides will be fabricated out of a titanium or Haynes material and assembled to the narrow end of the radiator shell. These guides will provide an alignment mode for the fuel block assembly at the time of fueling or defueling operations. Hinge plates and striker plates will be fabricated out of a Haynes material and attached to the narrow end of the beryllium shell. These hinge plates and striker plates will mate with a conical aft body which will open to provide access for assembly and checkout.

\section{Electric Connections}

One cable assembly will be utilized for the purpose of connecting all electrical components together between the CIR package and the thermoelectric subsystem. All cables within the interior of the systems will be fabricated in accordance with applicable MIL specifications for wiring harnesses. These harnesses will be fabricated using harness boards which will be provided by tool manufacturing.

\section{Insulation}

This item has been adequately covered under the 3200 task. Also, task 3400 adequately covers the annular insulating rings which will be fabricated and installed to the beryllium shell for the purpose of minimizing heat losses.

Quality

\section{Structure}

Due to the brittle characteristics of beryllium and manufacturing problems anticipated, Quality will prepare inspection instructions (II) for the product inspector to use while the structure is being fabricated. It will describe what inspections to make, when to make them and how. Quality Laboratories will cooperate with the Advance Manufacturing Technology group in a development program for the drilling and machining of beryllium.

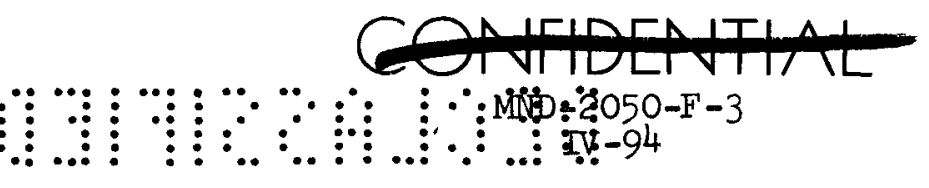




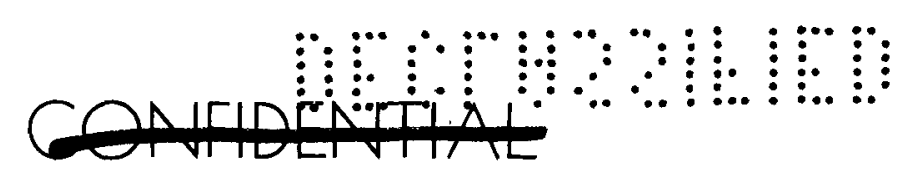

\section{Insulation Rings}

Quality receiving inspection will inspect each shipment of insulation rings received from the subcontractor. This will be in accordance with a Martin prepared receiving acceptance plan (RAP) that lists the verification/documentation review that will be performed by an inspector. It will include:

(1) A review of the subcontractor's test results and certificate of compliance.

(2) First article dimensional and workmanship inspection.

1. 3410--Design And Analysis

The design and development of the radiator subsystem will be based upon a coordinated set of criteria which will define the performance requirements of the subsystem and the imposed environmental factors. A set of baseline criteria will be established immediately upon the inception of the program and will subsequently be developed and modified as the design evolves. The test and material specifications will be drawn up shortly after the program begins. Test liaison and test data reduction and evaluation will be performed under this task.

a. Radiator

The radiator sizing and the thermal analysis effort will be accomplished under control point number 3110. Results from that analysis will be used in additional design and analysis approaches discussed under this control point number.

A complete structural analysis of the radiator shall also be performed under this control point.

The results from the tests performed under the radiator subsystem control point number will be used, where necessary, to modify the analysis being performed on the radiator.

b. Aft cap hinge plates

A stress analysis will be performed on the hinge plate and the interface between the hinge plate and the beryllium.

c. Heat source installation guides

A stress analysis shall be accomplished to determine that the

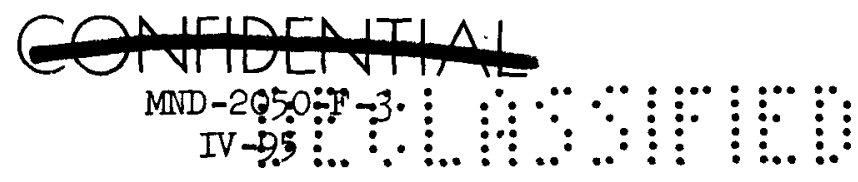




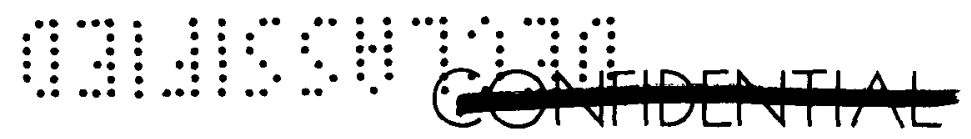

guides are not damaged as a result of contact by the heat source during the fueling operation.

\section{d. Heat source support assembly}

A stress analysis based on the dynamic load factors and the thermal stress due to temperature differences shall be performed on the cones and the spider support. A thermal analysis must be accomplished to determine the temperature gradient and the heat loss between the heat source and the radiator during prelaunch, launch, orbital life and reentry. The locking tube spring must be evaluated to ensure that the heat source loading can be accomplished, yet the locking tube will keep the heat source latch hooks locked into position.

\section{e. Thermal insulation}

An analysis of the heat lost through the insulation will be accomplished under control point 3110. The analysis will be modified if the results of the insulation development tests indicate that this is necessary.

\section{Electrical wiring harness}

The requirements for instrumentation and the wire sizes for the various electrical leads must be established. A layout of the wiring harness can then be accomplished.

\section{g. Electrical connector}

An electrical connector must be designed which will withstand the radiator temperatures during all phases of the mission, and through which all of the instrumentation and power leads must pass.

\section{3420--Component Development}

Testing will be performed on sample components in order to assess their performance and operation in the subsystem. Tests will be concentrated in the following areas.

\section{a. Emissive coating}

At least three different types of emissive coating for the radiator surface will be evaluated at the component level. The objective is to select a coating with a high emissivity and low solar absorptivity that will withstand the environmental conditions of launch, thermal vacuum, solar heating, micrometeroroid scouring, and nuclear radiation. Approximately thirty small samples of each coating material will be 
required for testing. Duplicating the effect of micrometeroids appears to be the most difficult test condition to achieve. A comparison of mechanical adhesion with coatings known to withstand micrometeroid bombardment is one practical approach which will be evaluated.

\section{b. Structural development}

Structural loads are relatively easy to predict for the radiator. At the component level a confirmation of beryllium properties will be made using material which has been subjected to the radiator fabrication process. Elevated temperature properties after exposure to cyclic mechanical loads will be of major interest. Also some testing of mechanical fasteners or joining techniques may be required. The effect of radiation on material properties will be evaluated. At present it is not anticipated that radiation damage will produce a stmuctural problem.

\section{c. Thermal insulation}

Tests will be performed on the two large annular thermal insulation assemblies to determine their ability to function after exposure to elevated temperature and environmental conditions simulating launch and vehicle separations. Results will determine whether additional support structure is required.

\section{d. Electrical quick disconnect}

Development and initial testing of an electrical quick disconnect will be performed. A non-standard design will be incorporated which features a short circuiting of the thermoelectric modules upon disconnection. Performance of the device will be determined after exposure to thermal, launch, and sub-orbital environments.

\section{3. $3430--$ Radiator Sub-System Development}

Tests will be performed on the radiator sub-system to demonstrate its ability to withstand launch, sub-orbital, and re-entry environments. Significant masses such as the heat source will be simulated. Several active thermoelectric modules will be attached to the beryllium shell in addition to a full complement of dummy modules to evaluate structural integrity. Specific vibration levels applicable to module development will be measured at the module-radiator interface. These data will be the basis for vibration test levels imposed on RCA for thermoelectric module qualification. Radiator temperatures, especially those achieved during re-entry will be produced by an array of lamps directed on the radiator surface. Loads associated with acceleration of the spacecraft and vehicle separation will be simulated by static

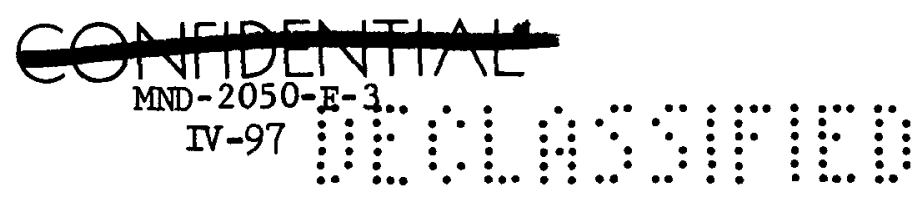




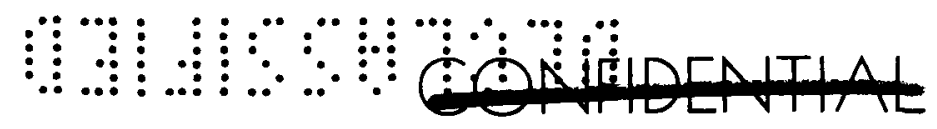

loads and imposed at significant mass locations such as the radiatorheat source interface. The structural integrity of the beryllium radiator shell is of major concern.

4. 3440--Radiator Subsystem Qualification Tests

Four radiator subsystems will be exposed to qualification levels simulating launch, sub-orbital, orbital, and re-entry environments. Due to restraints imposed by the assembly sequence, any thermoelectrics required for future tests or missions will be installed prior to subsystem qualification. Simulation of the heat source with equivalent masses will be permitted. Temperature conditions will be approximated with external lamps and internal heaters if necessary. Qualification test will specifically include exposure to pre-launch conditions of temperature and atmosphere including humidity; dynamic loads associated with launch environment static loads associated with launch and suborbital flight including vehicle separation; vacuum conditions simulating the effects of space of insulation assemblies; heat and vibration environments associated with re-entry.

\section{5. $3450--$ Prototype Acceptance}

In-process fabrication tests will be performed on samples of the radiator material to determine its strength, ductility, and chemical composition. Non-destructive tests will be performed prior to insta1lation of the radiator to ensure its structural integrity.

Ful1 acceptance will be withheld until system acceptance tests performed under CP 3150 are completed satisfactorily.

6. 3460--Flight Acceptance

Flight acceptance tests will be essentially the same as those for the prototype unit and described under CP 3450. System acceptance tests will be performed under CP 3160 . 


\section{Objective}

To design and develop a voltage regulator subsystem which will maintain the RTG output voltage within prescribed limits over the mission lifetime and within the environmental restraints placed on the subsystem by vehicle configurations and launch requirements.

\section{$\underline{\text { Problem Areas }}$}

(1) Effect of radiation levels generated by the RTG on the electronics used in the voltage regulator.

(2) Reliability requirements placed on the regulating system to meet system goals.

(3) Physical constraints placed on location and orientation of voltage regulation package(s).

\section{Approach}

(1) Evaluate, select, and test (if required) components, and subsystems of the regulator to assure mission lifetime and voltage output requirements. Existing Radiation Effects Facilities - (X-Ray - Gamma) may be used to obtain data on components where insufficient information is available. Shielding and package location will be established to minimize detrimental operation due to radiation.

(2) The number and configuration (redundancy) of voltage regulating modules will be evaluated to establish optimum design. A testing and screening program will be established to assure that only proven components will be used. Manufacturing processes will be established and closely monitored to assure that only proven components will be used. Manufacturing processes will be established and closely monitored to assure that only the highest order of workmanship will be used. The unit will be tested at various stages of production and under prescribed environmental conditions to demonstrate that all design goals are met.

(3) Careful consideration will be given to packaging requirements and special housings used to assure proper component heat sinking and to minimize effects of temperature, radiation, vibration, acceleration, vacuum on other environmental conditions.

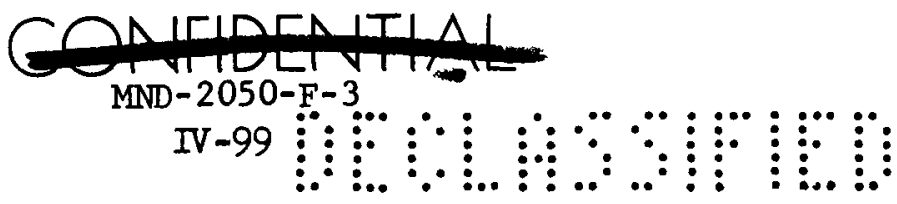




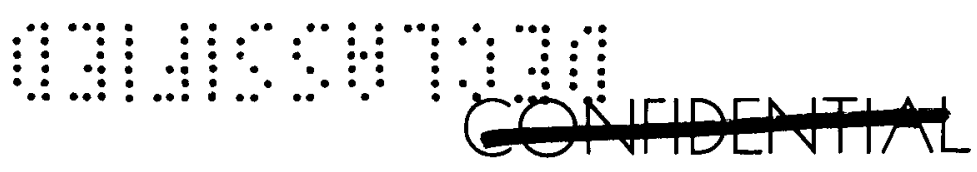

a. Fabrication and assembly

The voltage regulator assembly will be a black box assembly that will be fabricated within the Engineering Power Conditioner section of Nuclear Engineering. It will consist of approximately six transistors, six resistors, and several diode semi-conductors. Manufacturing inputs will only be concerned with the installation of the voltage regulator subsystem and its associated wiring harness. Installation of the black box will be accomplished in the lower portion of the CIR Package System and will be a routine assembly operation. Wire harness fabrication will be accomplished in accordance with the procedure outlined in sub task 2 of task 3400 .

b. Quality contro1

Quality receiving inspection will inspect each shipment of transistors, resistors, diode semi-conductors, wiring, etc. received from vendors. It will be in accordance with a Martin prepared Receiving Acceptance Plan that lists the verification/documentation review that will be performed by an inspector. It will include:

(1) A review of the vendor's test results and certificate of compliance.

(2) Sampling plan for inspection and testing of components.

(3) Perform workmanship inspection.

1. 3510--Design Analysis

A design analysis will be made to establish the components and configuration, both electrical and physical, for all circuits used in the voltage regulator subsystem. A theoretical design of selected circuit concepts will be made and a bread board fabricated to test and prove design analysis. Detailed specifications will be established, following bread board test, which will include interface, (electrical mechanica 1 and therma1) requirements. Subsystem connection and interconnection requirements will be established and drawings made. Packaging requirements will be analyzed and layout and assembly drawings will be made. Modular plug-in construction requirements will be evaluated which will allow ease of replacement of assemblies on subassemblies in the event of failure. A design review will be made to assure correct design and attempt to correct any oversights made in the design analysis.

2. 3520--Component Development

It is anticipated that only proven properly screened, high

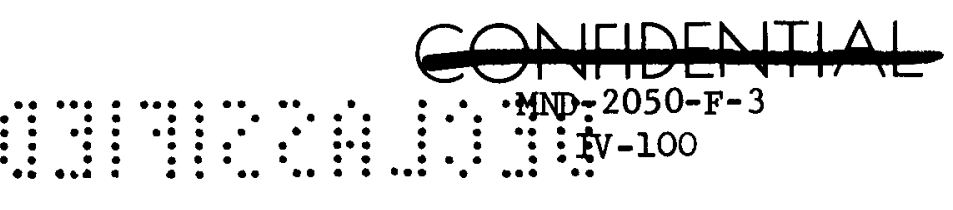




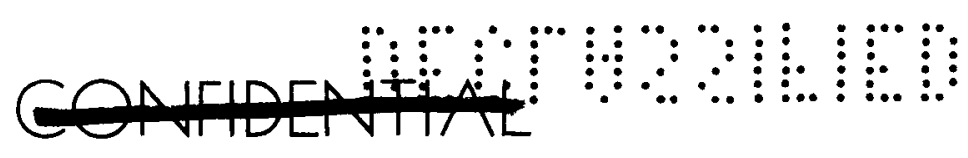

reliable, tested components will be used in all circuits and no new development is required for the voltage regulator subsystem.

3. 3530--Component and Subsystem Development

(1) An engineering development unit will be fabricated in the Nuclear Power Conditioning Development Lab. This unit wil1 be fabricated using drawings prepared under the Design Analysis Task. Revisions in packaging requirements will be made if necessary to allow for simpler and more reliable methods of assembly. A test tool to checkout the subsystem will be developed and used to check out the voltage regulator. This tool will simulate all essential parameters such as input voltage and output load conditions. Provisions will also be made to indicate or record important parameters during the test.

(2) The Engineering Development Unit will be tested under simulated space conditions and all essential parameters closely monitored to determine if all specified requirements are met. Test specifications and procedures will be written for the subsystem to assure a complete test program. Any redesign of the subsystem will be made during this task and sufficient retesting conducted to assure adequacy of redesign. When the performance and configuration have been finalized, a development unit will be placed on life test to demonstrate long term operations. A test report will be written after completed test.

4. 3540--Subsystem Development and Test

a. Fabrication and assembly

The voltage regulator subsystem will be assemblied and married to the generator and a simulated load for system test. An actual physical mockup of the system configuration will be made. Test fixtures will be fabricated and connected to the subsystems. All interconnecting wiring and cabling will be assembled and used to connect a11 required units.

b. Qualification test

A qualification test specification and procedure will be written and the system tested under simulated environmental conditions.

An electrically heated generator will be used for this test. During the qualification test the system will be subject to the vibration, acceleration, and space environments specified to demonstrate subsystem

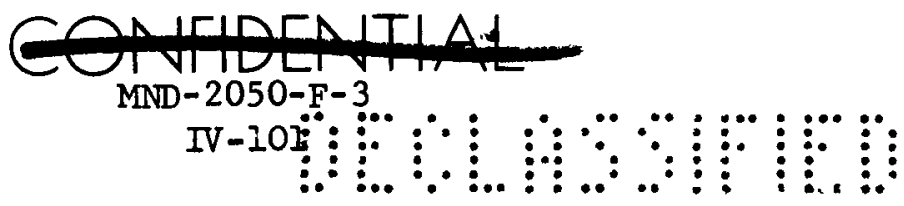




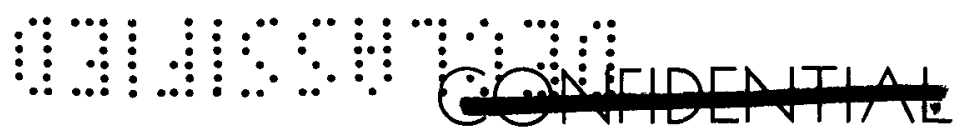

compatibility. EMI (electro magnetic interference) testing will be done on a simulated basis to establish if any shielding requirements are necessary to assure that the generator and its voltage regulator do not generate any detrimental interference on the vehicle. Both conducted and radiated interference measurements will be performed.

Three (3) each of the components in the subsystem will be subjected to the qualification test indicated in Table II.

\section{3550--Prototype Acceptance}

It is not anticipated that a voltage regulator will be included as part of the flight demonstration unit. Therefore no effort is anticipated under this control point.

\section{3560--Flight Acceptance}

Functional tests will be performed on completed voltage regulators prior to their installation in the airborne system. Final flight acceptance tests will be performed at the system leve1 under CP 3160 . 


\section{(9)}

\section{F. 3600--HEAT SHIELD SUBSYSTEM}

\section{Objective}

To develop a heat shield subsystem compatible with all environmental factors associated with the operational life of the complete system and to verify both the ability of the heat shield to be integrated into the overall RTG-RB/CIR package and its integrity under the most severe predicted environmental exposures.

Problem Areas

The selection of materials which will comprise the heat shield subsystem will be in part dependent upon their compatibility with the radiation levels and exposure times related to the generator system fuel source. It will be necessary to evaluate this problem in detail during the design development phase.

Approach

Heat shield subsystem design objectives will be attained by following the basic approach outlined below:

(I) Establish and coordinate a set of design criteria and specifications with affected groups. (Temperature limitations, interface requirements, environmental inputs, other related boundary conditions.)

(2) Perform analysis to identify critical environmental factors. Material selection, structural interactions and heat shield thickness and distribution and structural support requirements will be evaluated.

(3) Appropriate development and qualification testing will be performed as required.

\section{Fabrication}

Although the heat shield involves generally well established plastics and bonding fabrication methods, some of the materials and techniques of fabrication are Martin Company confidential and proprietary information developed during the early years of the Lifting Body concept. The following procedures are, however, a general concept of fabrication.

The heat shield core will be fabricated as a core mat from Martin developed "Hi-Flex Honeycomb." The peripheral edge segments will be preformed by a hot molding process to the desired shape and curvature.

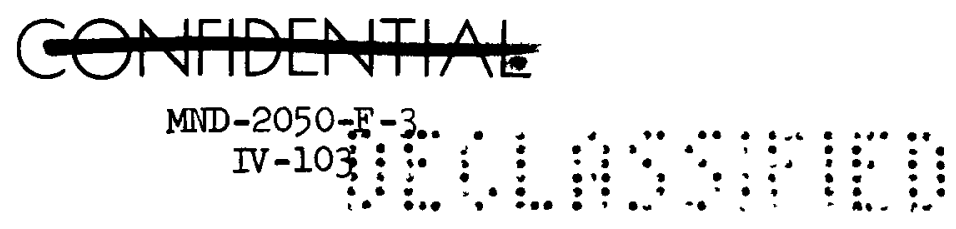




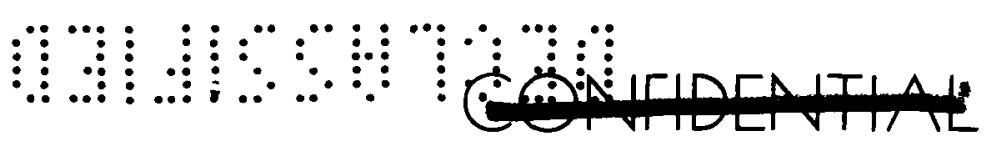

The core mat will be bonded together using HT-424 Adhesive Film.

A riveted subassembly will be made of the ablator support panel and support rings. The bonding surface will then be cleaned and primed and the core mat bonded in place using the HT-424 adhesive system.

The heat shield core subassembly will be packed with pre-mixed Martin developed Ablator Compound (ESA3560) and cured. This assembly will then be machined to proper thickness and contour by the use of master check gages. (Above procedures refer to classified Martin Process MP-60M43.)

Capsule heat shield insulator pads will be made from Min-K 2000, machined to thickness and cut into segments.

The completed heat shield will be assembled to the beryllium shell, drilled and bolted using the Min-K insulation separator pads.

\section{Quality Control}

Quality Receiving Inspection will inspect each shipment of resins, fillers, and HT -424 adhesive film received from vendors. It will be in accordance with a Martin prepared receiving acceptance plan that lists the verification/documentation review that will be performed by an inspector. It will include:

(1) A review of the vendors' test results and certificate of compliance.

(2) Batch chemistry and/or physical test requirements.

1. 3610--Design And Analysis

The design and development of the heat shield subsystem will be based upon a coordinated set of criteria which will define the performance requirements of the subsystem and the imposed environmental factors. A set of baseline criteria will be established immediately upon the inception of the program and will subsequently be developed and modified as the design evolves. Detailed analysis will be performed on existing digital programs relative to the selection of heat shield material and thickness requirements. Heat shield material selection will be based upon consideration of comparative reliability, weight, fabricability and cost for each material which will meet the design criteria. A meaningful heat shield design development effort entails the consideration of both thermal and structural design aspects. Hence in addition to performing analysis in order to optimize the heat shleld from a thermal performance point of view, analytical effort will be 


\section{contomentim}

expended in evaluating the optimum mode of structural support for the heat shield and the related structural interface and interaction problems in terms of load induced and thermal stress.

\section{3620--Component Development}

Candidate heat shield concepts and materials performance will be evaluated in a series of plasma arc facility tests. It is intended that a portion of the materials to be tested will be exposed to radioisotope and $U V$ sources for prescribed periods prior to test in order to evaluate the effect on material behavior. A similar test series will be performed to evaluate the effect on material mechanical properties of prolonged radiation exposure. It is currently planned that all of these tests will be performed on existing Martin Company facilities. Materials involved will include organic ablators, structural organic laminates, and adhesive bonding systems.

\section{3630--Component and Subsystem Development}

Full or sub-scale models of the 2 heat shield/structure subsystem concepts which appear most promising ( 1 prime, I back-up) will be exposed to the predicted re-entry heating environment and evaluated in terms of their overall thermo-structural performance capabilities. Plasma arc size limitations may cause these tests to be performed in either the Martin Hot Gas or Radiant Heat facilities. Shock, vibration and static load capacity of the subsystem assembly will also be evaluated.

\section{3640--Subsystem Qualification Articles and Tests}

Two full scale qualification tests will be performed on the heat shield subsystem. Testing will simulate the critical re-entry heating environment on the heat shield subsystem after it has been exposed to appropriate temperature and radiation levels to simulate a pre-recall environment. Prior to radiation exposure the heat shield will also be subjected to the vibration and acoustic environment associated with the launch flight. Instrumentation will be provided to define the induced stress and temperature fields encountered during the tests.

Sufficient instrumentation will be provided on the heat shield subsystem flight test model (prototype) to demonstrate the temperature histories and stress levels associated with the prototype flight.

\section{3650--Prototype Acceptance}

Acceptance of the demonstration flight heat shield sha1l be on the basis of standard quality assurance techniques to ensure conformance to specifications. In-process testing will include ultrasonic

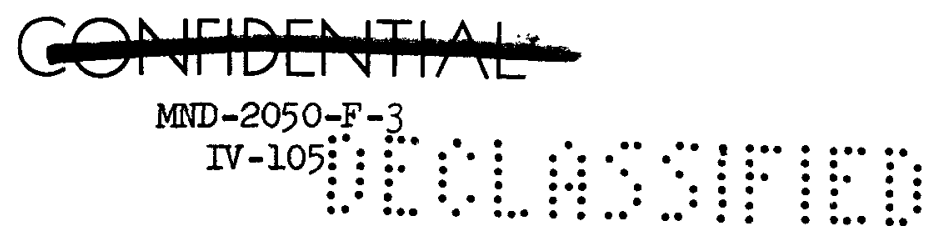




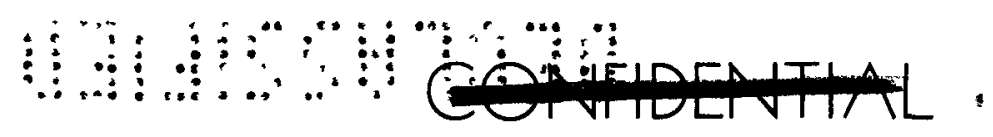

inspection for voids, thickness measurement by eddy current techniques or by means of a depth probe, and batch tests to indicate the tensile strength and ablation characteristics of the material.

No further acceptance tests shall be performed on the heat shield prior to its installation and test in the complete system as covered under CP 3150.

\section{3660--F1ight Acceptance}

Acceptance of flight articles shall be on the same basis as that for prototype articles, as discussed under CP 3650. Acceptance testing of flight articles at the system level is discussed under CP 3160 .

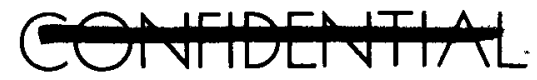




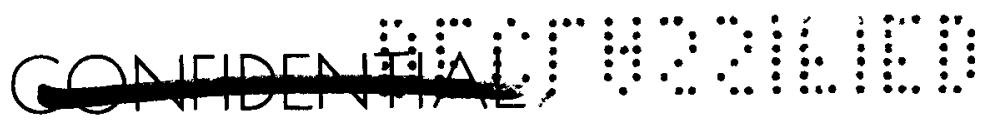

\section{G. 3700--AFT CAP SUBSYSTEM}

\section{Objectives}

The objectives of this task are to optimize the aft cap subsystem concept, to conduct detailed design and analysis on the selected subsystem, to verify the design tests, and to build and qualify the required subsystem. The proper number of subsystem assemblies will then be supplied for the demonstration flights, the prototype systems, and the flight systems.

\section{$\underline{\text { Problems }}$}

The physical configuration of the aft cap is such that the structural requirements are rather simple. Only the potential heating during an abnormal re-entry might affect the structural properties of the body. In order to alleviate this potential problem area, a high temperature alloy (Haynes 25) has been chosen for this structure. Nevertheless, additional protection might be required.

\section{Approach}

After the destabilization requirements have been specified, an aerodynamically oriented design of the aft cap will be achieved. Verifying wind tunnel tests will be conducted. At the same time, invariant hardware items such as the hinges and latches will be developed. Further analysis will be conducted to define the explicit environment that the aft cap has to survive. Any required protection will be supplied.

Interfaces with the fueling operation, the radiator subsystem, and the beacon subsystem will be monitored by the system design analysis and tests. The physical interface with the fairing (through the fairing link) will have to be checked by the total system integrator.

\section{Fabrication}

The aft cap subassembly will be fabricated from Haynes 25 superalloy through conventional fabricating techniques. Hinge plates will be fabricated out of the Haynes material and will be mechanically attached to the aft cap assembly. This subsssembly will be utilized for the purpose of providing an access to the thermoelectric subsystem for fueling and defueling operations. The antenna windows will be 


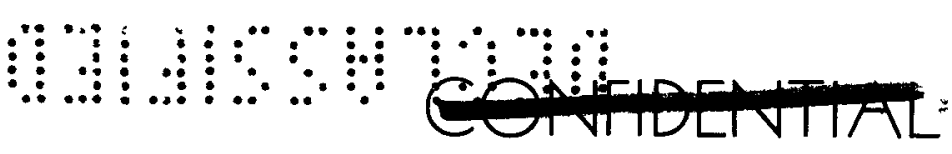

fabricated from pre-molded ceramic reinforced teflon and cut to size. This material will be in accordance with Martin Material Specification MMS -A663.

\section{Quality Control}

Quality does not anticipate any problems in the inspection of this system since it is straight forward type of fabrication. Due to the importance of proper adjustment of the electrically activated spring loaded catches and the control rod between the cap and the payload fairing, Quality will prepare a certification $\log$ which the inspector will follow in the verification of these adjustments.

\section{3710--Aft Cap Subsystem Design and Analys is}

\section{a. Structures}

The Aft Cap is required to extend the $\mathrm{RB}$ geometry beyond the radiator in order to provide the proper C.P.-C.G. relationship, to accommodate a destabilizing surface, to close off the RTG heat source loading opening and to house the tracking beacon subsystem. The selected design permits hinging the cap open and closed for heat source insertion and access to the contained beacon equipment. This structure will be dynamically tested with dummy subsystems which will simulate mass and center of gravity conditions.

A latching system for locking or unlocking the aft cap to the RTG radiator will be designed and dynamically tested.

A thermal insulation system will be designed to protect the tracking beacon subsystem from RTG generated thermal damage as well as re-entry thermal damage.

A nuclear shadow shield will be designed to protect the beacon from RTG generated radiation damage. This shield will be designed commensurate with the shielding dose rate calculations.

Thermal analysis will be performed on the cap. It is important to determine the internal heat balance during the various operational modes to evaluate the effects on the beacon. The thermal analysis is also critical in determining the structural allowables.

The design will make provisions for electrical, thermal, and mechanical instrumentation to verify the analysis data.

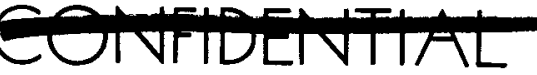


b. Structural analysis

A complete structural analysis of the subsystem components will be performed. A dynamic analysis will be included to determine component and system resonant frequencies and dynamic load factors. The stress analysis will account for dynamic loading, static loading, and differential thermal expansions.

A structural evaluation will be made to determine optimum locations and schemes for mounting the tracking beacon subsystem components in the cap. A dynamic analysis will be performed to determine system resonant frequencies and dynamic load factors, and corresponding loads at the RTG latching points.

This effort necessitates a close liaison with the generator design since a primary structural interface exists between the radiator subsystem and the aft cap. In this regard, permissible attachment points to the generator and the permissible load input to these attachment points must be established early in the program. 


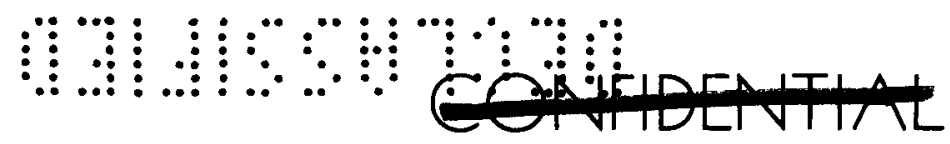

2. 3720--Aft Cap Component Development and Evaluation Tests

The Aft cap hinge and latch mechanisms will be evaluated for structural static and dynamic load characteristics and for positive latch position signal outputs.

The Fairing Release Attachment Mechanlsm will be developed and evaluated by manual release and use of pyrotechnics.

3. 3730--Aft Cap Subsystem Development Tests

Structural static and dynamic load tests will be performed on the Aft Cap hinged assembly as a subsystem and as part of the RTG/RB dynamic tests under CP 3130. The hinged Aft Cap and Fairing Actuator operations will be tested for repetitive type functions and failure mode detection and safety operations by remote control sources. Further tests of this nature will be covered under subsequent system tests.

\section{3740--Aft Cap Subsystem Qualification Tests}

The major qualification at the subsystem level will be performed as part of the RTG/RB system. Qualification at the components level will be performed on critical hardware items such as latches and fairing release pyrotechnics as shown under Table II in CP 3020.

\section{3750--Prototype Acceptance}

Acceptance of the demonstration flight aft cap shall be on the basis of in-process quality control checks and standard structural test techniques. The completed items will be assembled to the system and subjected to system acceptance tests as described under CP 3150 .

6. 3760--Flight Acceptance

Acceptance of flight hardware shall be based on in-process quality control checks and standard structural test techniques. The completed items will be assembled to the system and subjected to system acceptance tests as described in CP 3160. 


\title{
(4)
}

\author{
H. 3800--BEACON SUBSYSTEM
}

\section{Objectives}

The beacon subsystem is required to permit tracking of the RTG/RB during re-entry. The beacon will also serve as a backup to the CIR tracking system while the two vehicles are attached. Its activation will provide automatic notification to the ground that the separation event has occurred and that the second target must be tracked with available $\mathrm{C}$-band radars.

\section{Problems}

The major problems associated with the beacon subsystem will be the temperature and radiation environment of the $R / B$. The radiator temperature will be $500 \mathrm{~F}$ and that of the aft-cap about $200 \mathrm{~F}$. A beacon and power supply capable of withstanding the aft-cap environment and subsequent operation for up to nine hours is required. An antenna system which will provide adequate coverage must be designed.

\section{Approach}

C-band beacons may be procured as off-the-shelf hardware. The initial approach to the environmental problems will be insulation and radiation shielding to maintain temperatures at the $165 \mathrm{~F}$ level to which most present hardware is qualified. A parallel program of investigating possible component development will also be conducted. Active cooling systems and different battery types will be considered. Resistance to the radiation environment will be obtained by hardening the system at the component level. Various antenna designs will be investigated and tested with the aid of a spinning mockup vehicle. Standard manufacturing techniques will utilize in quality control and installation. Vendor control will be exercised through a Martin prepared Receiving Acceptance Plan that lists verification/documentation review that will be performed by an inspector. This will include:

(1) A review of the vendor's test results and certificate of compliance.

(2) Instructions for performance of operational tests.

(3) First article dimensional and workmanship inspection.

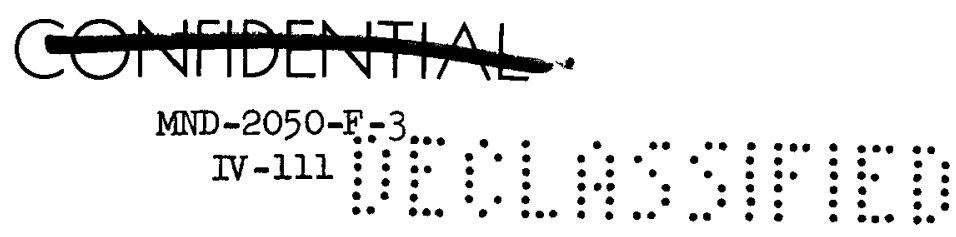


1. 3810--Design And inalysis

It is expected that the beacon will be procured as an of $f$-theshelf item and that it will have been qualified to T-III-C environmental conditions. Remaining problems will consist of insuring compatibility with the $R / B$ system and environmental qualification to the temperature conditions to be expected inside the $R / B$. Antennas will be designed by Martin and high temperature shielded coaxial cable utilized in RF transmission. The battery system proposed utilizes activated $\mathrm{Ag}-\mathrm{Zn}$ batteries which must be insulated to withstand temperatures expected in the $R / B$.

Further investigation is desirable in the area of high temperature, high capacity batteries. Alternatives to the simple solution of insulation for maintenance of a reasonable temperature within the $\mathrm{RB}$ cap include investigation of active fluid cooling systems although this is felt to be undesirable complexity. Another alternative may include use of a fuel cell rather than battery power supply for the beacon. These units are capable of operation at much higher temperatures than the usual $165^{\circ}$ limit if appropriately sealed and designed for the pressures generated.

Antenna design will include selection of an optimum antenna type with consideration of the environment involved. Compatibility with the booster $\mathrm{C}$-band system will be established and interference and coupling established for the antennas. A canvass of vendors will be made for available component parts and/or complete units which may be adapted to requirements of the $R / B$. Wiring harness design and coaxial cable connections will be minimal because of proximity of the beacon to the antennas.

Complete link calculations and estimates of multipath problems for the radars (FPS-16, TPQ-18, MPS-26, etc.) are required. Thereafter, tracking accuracies can be determined and acquisition probabilities specified. The problem of tracking two beacons simultaneously (Transtage and $R / B$ ) will be investigated. Trajectory data will be utilized to determine the areas of ionization blackout and this information combined with similar data from the S-band units of the CIR to provide complete operational sequence of TrC units aboard the vehicle. Spin tracking capability will be determined.

In the area of checkout, the vendor will be consulted as to those functions required to be verified in manufacturing checkout, pre-launch checkout and possible airborne checkout. This area will then be coordinated with digitally controlled automatic checkout design. Further, operational functions such as activation of the beacon will be defined

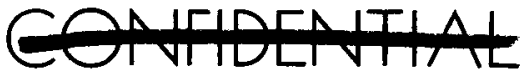

MND-2050-F -3 


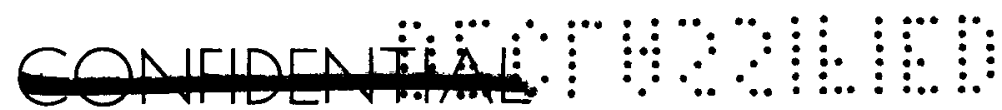

and provided to design of the command and programmer modules. Telemetry functions shall be defined and end instruments provided for in the design.

2. 3820--Component Development

The C-band beacon may be procured as an off-the-shelf item, in which case it will not require component development. However, development tests such as structural, thermal, and antenna pattern tests will be required for other items of the subsystem.

3. 3830--Component and Subsystem Development

Component and subsystem development for the C-band beacon will be devoted to qualifying the beacon at the system level to $R / B$ environment. Several of $f-t h e-s$ helf beacon assemblies are qualified for the Titan IIIC and principal effort will therefore be devoted to tests with regard to temperature, radiation environment and magnetic fields generated by the RTG.' Design and manufacture of antennas and wiring harness for this unit will be carried out during this period. System EMI and RFI tests will be carried out in coordination with those for the S-band TTC system. Both systems will be installed in a mock-up of the $\mathrm{RB} / \mathrm{CIR}$ such that interference and antenna patterns may be determined utilizing the Martin antenna range. The beacon will also be incorporated in a prototype breadboard of the entire electronics assembly which will include the instrumentation. This breadboard will serve to demonstrate physical and electrical compatibility of the electronic systems.

4. $3840--$ Subsystem Qualification

The C-band beacon will be procured as off-the-shelf hardware. As such, it will have been qualified for other space missions which are similar to the CRONUS mission. No further qualification tests are required prior to installing the beacon in the generator system and performing qualification tests on the entire system.

5. $3850--$ Prototype Acceptance

During Phase III primary emphasis will be placed on acceptance tests, installation and assembly and compatibility of the beacon with other electrical and electronic systems for the prototype vehicle. The prototype pre-flight tests will provide initial opportunity for checkout of the beacon in conjunction with corresponding units in the TIIIC transtage. The entire operational sequence of the beacon will be demonstrated with external power under control of AGE stimulus to the programmer. Flight test support will be provided in the form of checkout procedures and monitoring of beacon performance. Verification of beacon performance will be made through analysis of prototype post flight data.

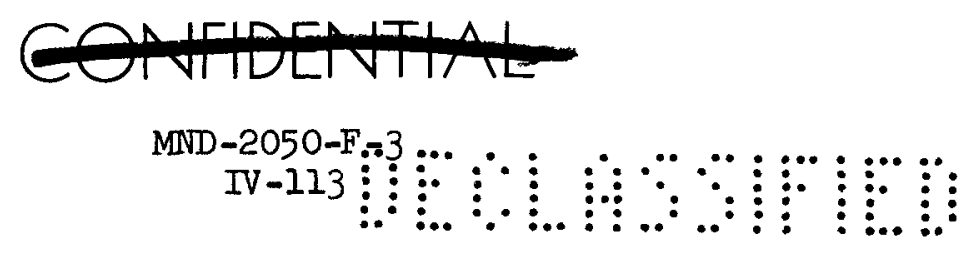




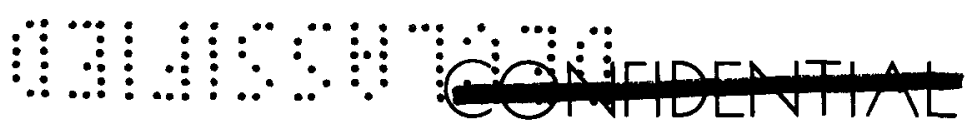

6. $3860-$-Flight Acceptance

Recelving inspection, installation, assembly and checkout will be conducted on operational flight articles in accordance with the schedule for their delivery. Performance will be monitored for operational flights as with the prototype. 


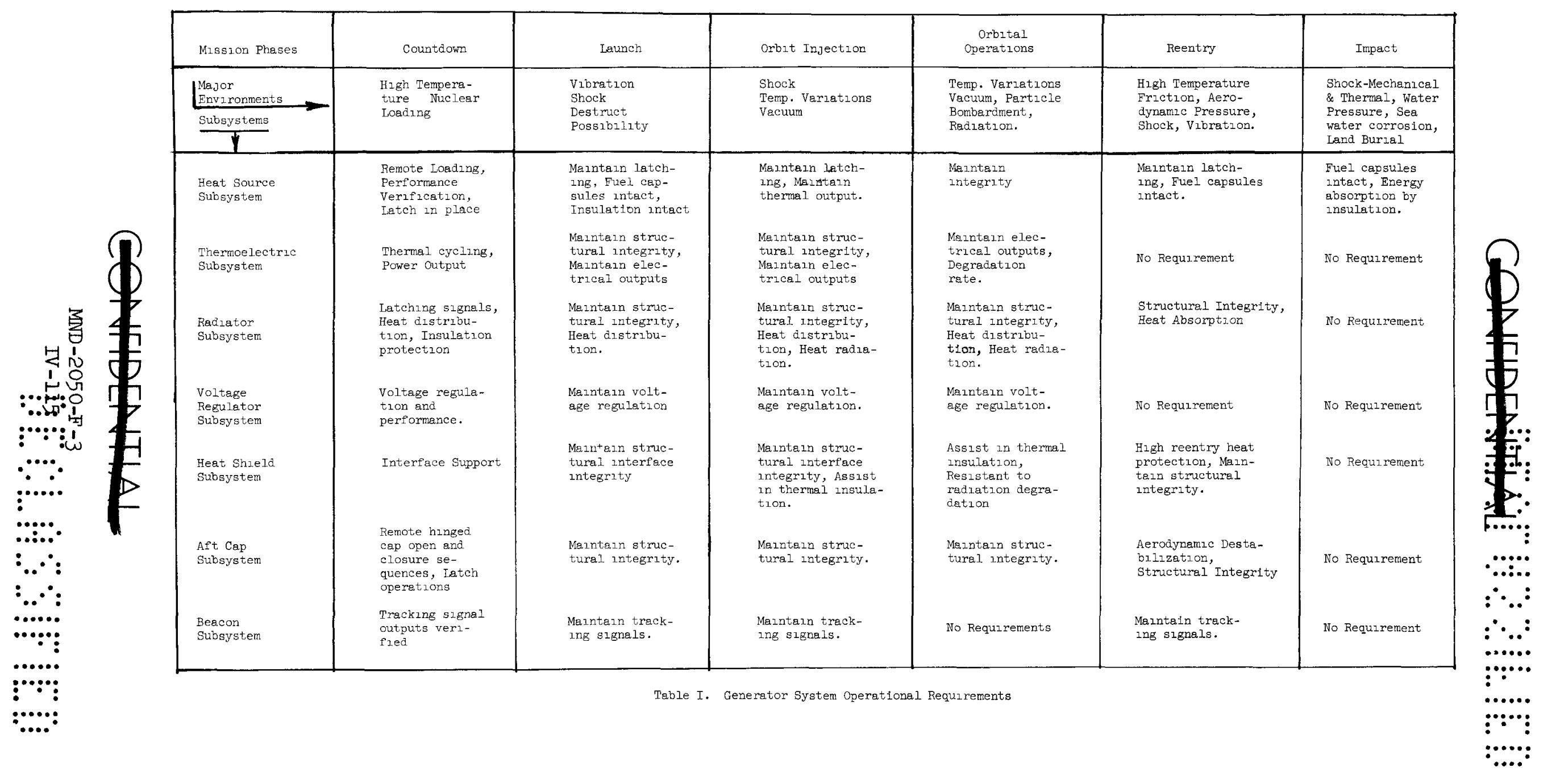


:

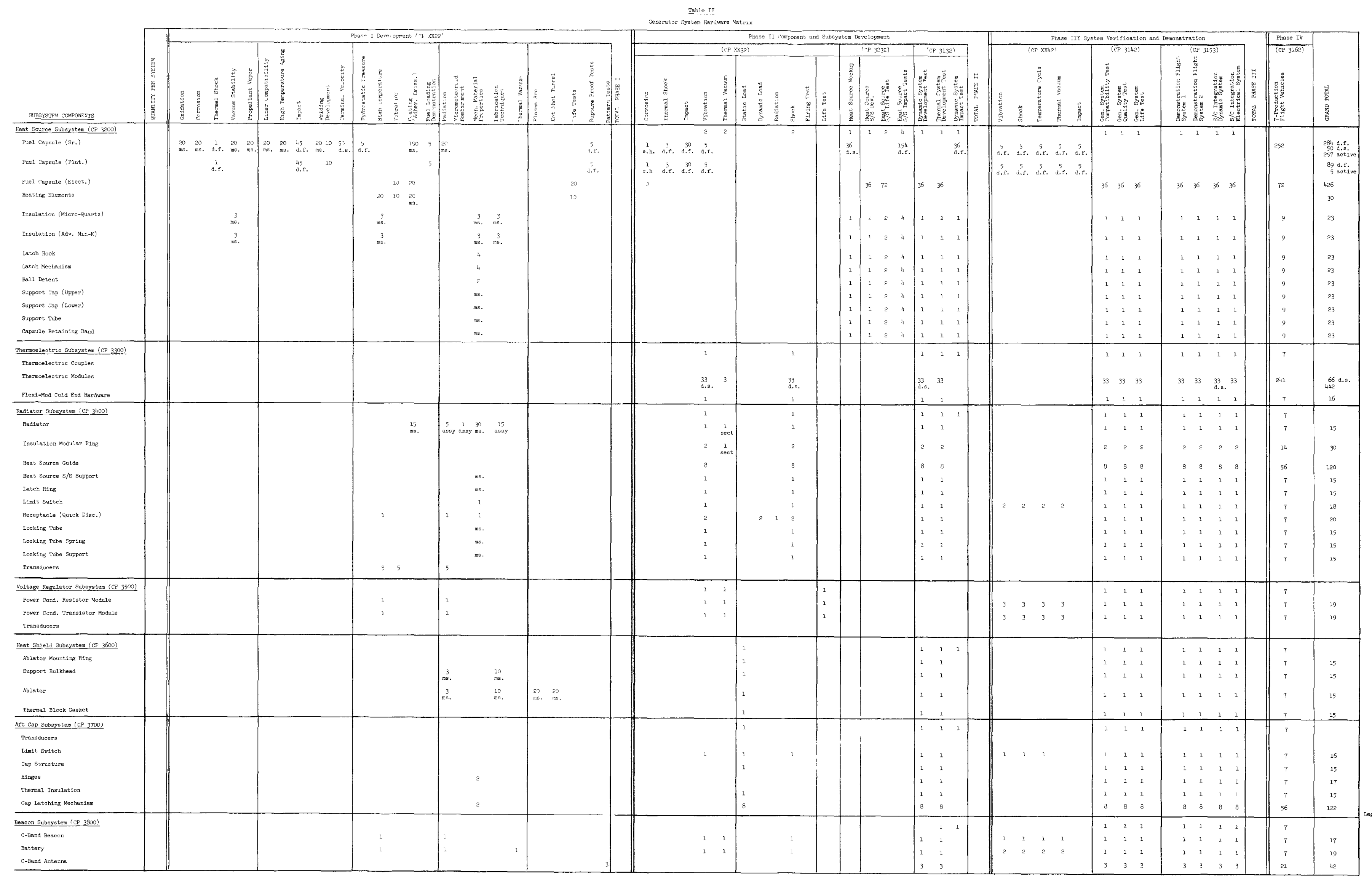


Table III

PROPOSED AERODYNAMIC TEST SCHEDULE RTG/RB

Hypersonic Tests

Basie Configuration

1. Stability, lift \& drag

2. Heat transfer

3. Blast

4. Deorbit rockets

5. Local flow conductivity

Abort Configuration A

1. Stability, lift \& drag

2. Heat transfer

Abort Configuration B

1. Stability, lift \& drag

2. Heat transfer

Supersonic Tests

1. Stability Basic Configuration Lift \& Configuration A

Drag Configuration B

Transonic Tests

1. Stability Basic Configuration Lift \& Configuration A

Drag Configuration B

Subsonic Tests

1. Stability Basic Configuration

Lift \& Configuration A

Drag Configuration B
3

Months

$\overline{\mathrm{M}}$ $\overline{\mathrm{M}}$

$\bar{M}$

$\overline{\mathrm{M}}$

C

C

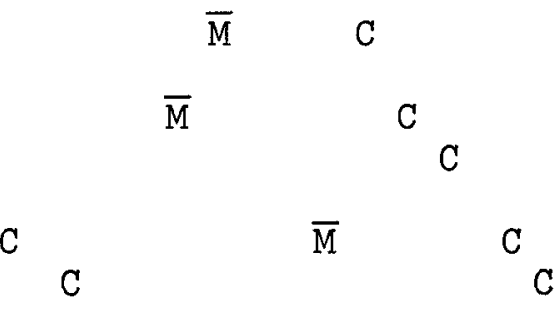

A

A

A

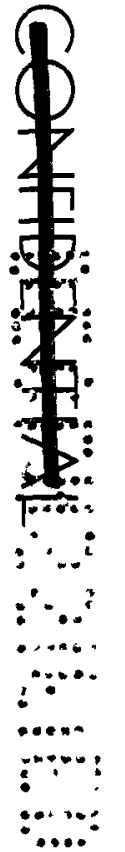




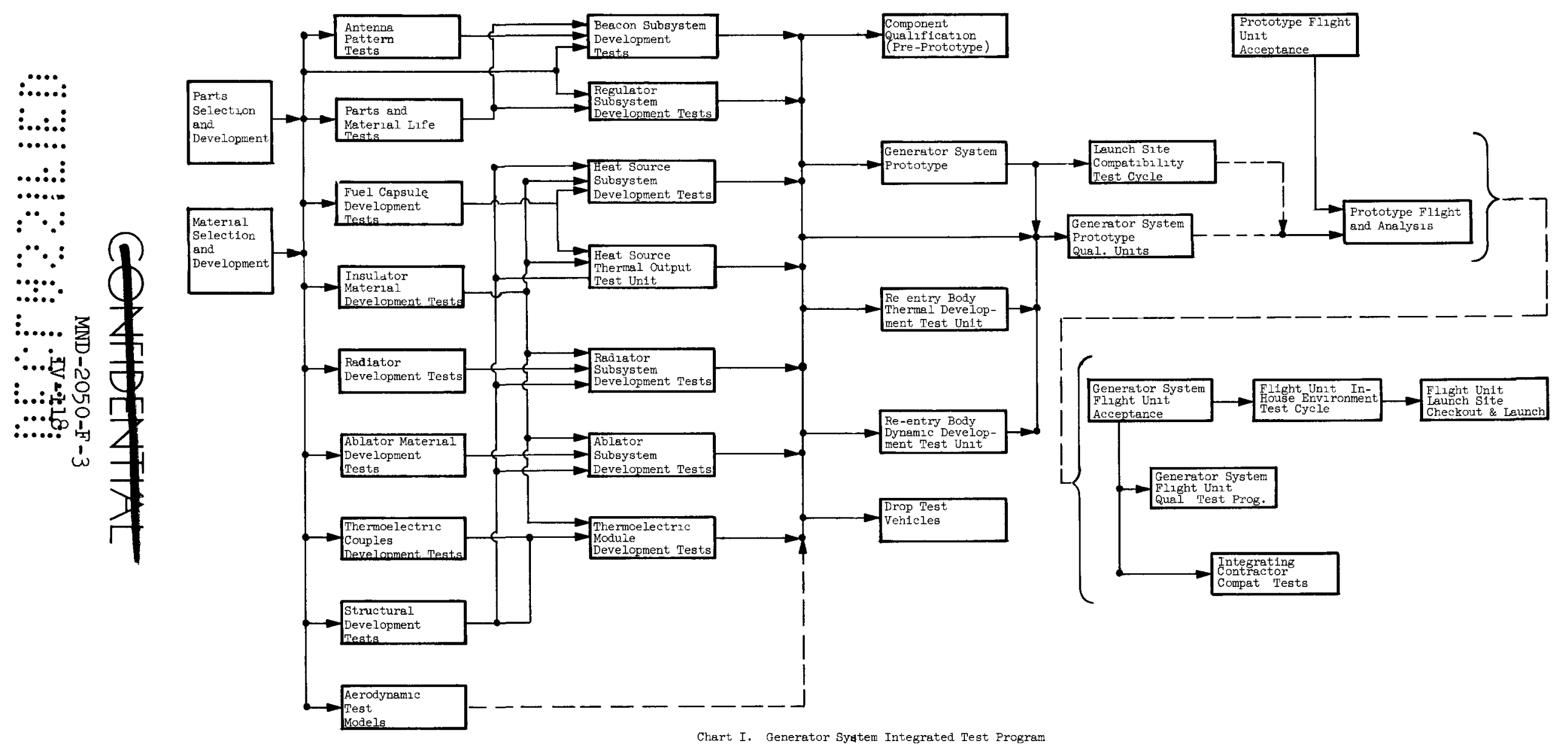

$\therefore . . .:$

:

......

$\therefore$.

$\therefore$

$\because \cdots$ 


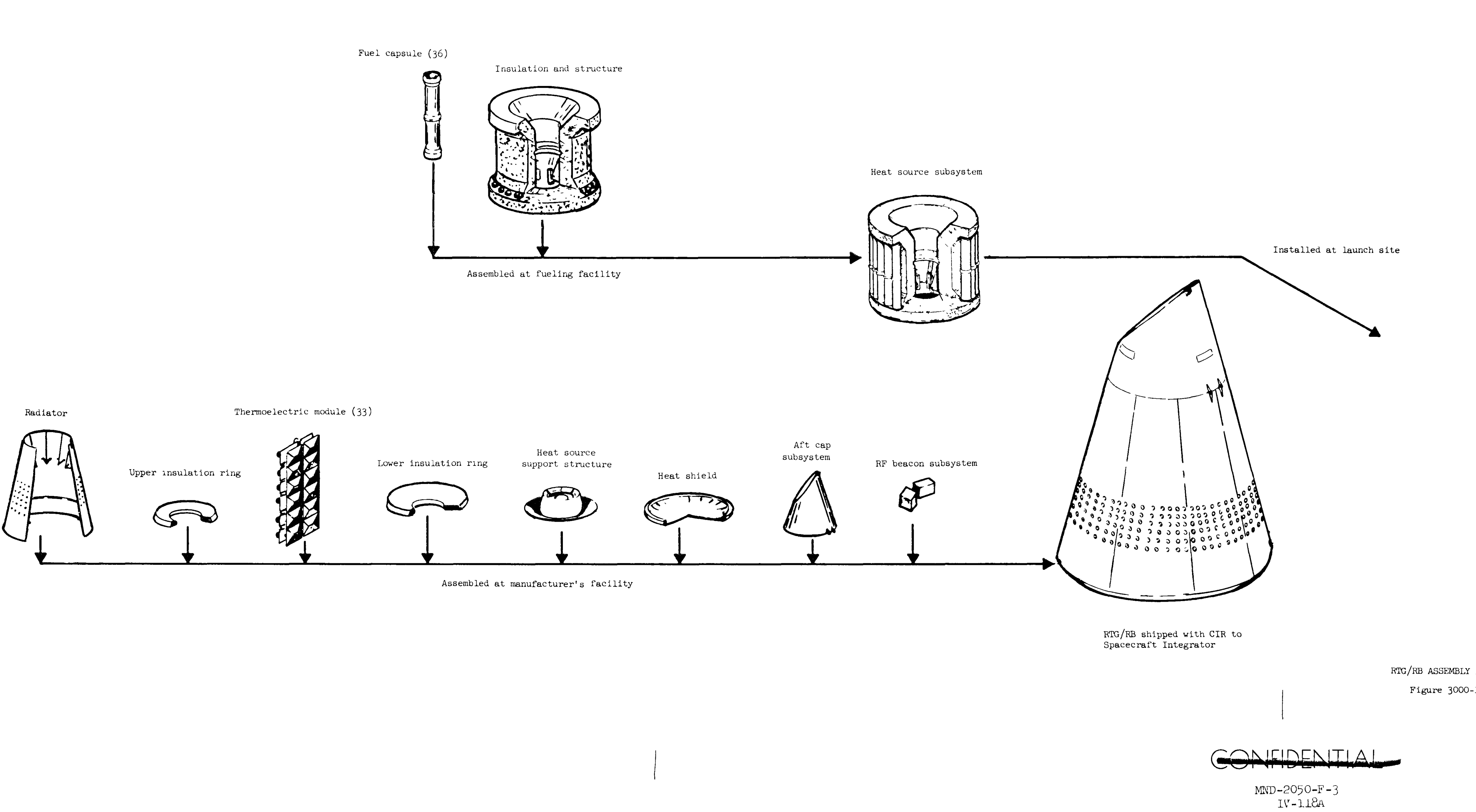




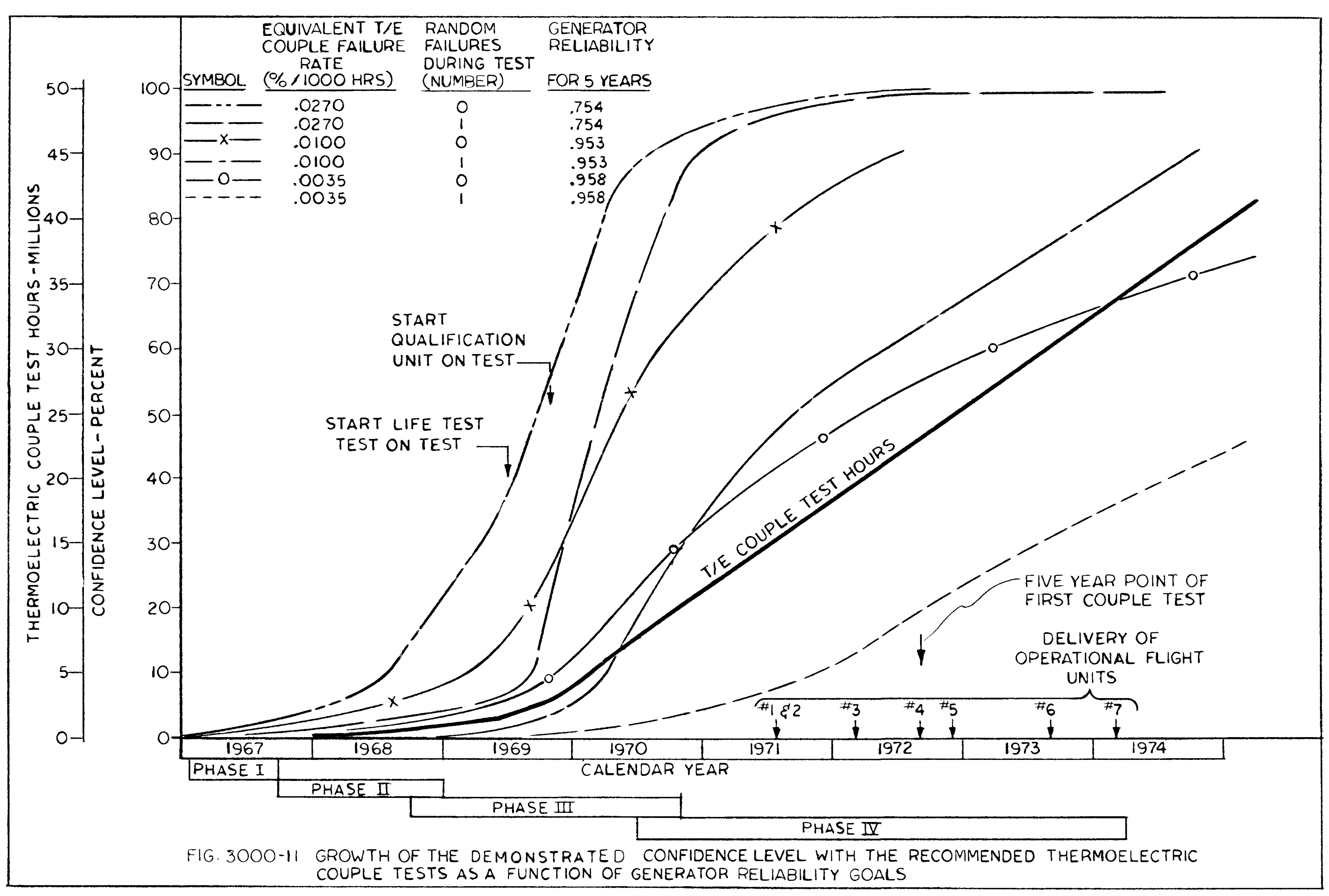
GROWTH OF THE DEMONSTRATE D CONFIDENCE LEVEL WITH THE
COUPLE TESTS AS A FUNCTION OF GENERATOR RELIABILITY GOALS 
4000--CONTROLLED INTACT RE-ENTRY SYSTEM

The objective of this effort is to design, develop, fabricate, inspect and test a system for effecting the controlled intact re-entry of the generator radioisotope fuel in the event of a launch vehicle abort or a failure to achieve a sufficiently long-lived orbit. The CIR system will separate the Generator System from the host satellite, then initiate deorbit by applying a braking thrust and, finally, automatically separate from the generator to leave a clear aerodynamic reentry shape.

Separation from the satellite during ascent may be initiated in either of two ways: manually through ground-based command or automatically by the satellite/launch vehicle Malfunction Detection System (MDS). The deorbit thrust vector assumes the alignment of spacecraft at the instant of separation. The MDS monitors, among other things, spacecraft attitude and angulat rates to the extent that, within limits, separation of CRONUS always can be achieved before deorbit thmust vector orientation tolerances are exceeded. The study ground males specify that spacecraft angular rates can be assumed to be within these limits $(0.3 \mathrm{rad} / \mathrm{sec}$ estimated). In addition, the very low precessional rates of the spin stabilized CRONUS allow for ample time in which to predict the Instantaneous Impact Point (IIP) and manually command deorbit at the proper point in space.

After deorbit thrust termination, CRONUS is despun so that the $\mathrm{RTG} / \mathrm{RB}$ will be rapidly, aerodynamically stabilized with its heat shield forward, during initial atmospheric re-entry.

The CIR system can accomplish these objectives with four functional subsystems with the following individual control point numbers:

$\begin{array}{ll}4200 & \text { Propulsion Subsystem } \\ 4300 & \text { Ordnance Subsystem } \\ 4400 & \text { Electric/Electronic Subsystem } \\ 4500 & \text { Structure Subsystem }\end{array}$

These are combined into the CIR System under Control Point 4100. Under this control point are all combined subsystems and system level efforts. Configuration layouts, dynamic analyses and system tests are examples of "across-the-board" efforts which are performed under this control point.

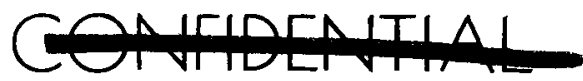

MND $-2050-F-3$

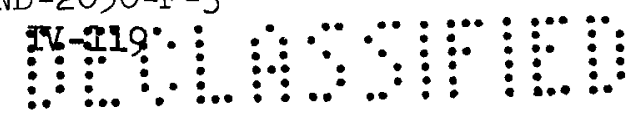




\section{ming}

Because the CIR system furnishes abort-recovery and trajectory alteration "services" to the $\mathrm{RTG} / \mathrm{RB}$ in accordance with the safety requirements determined under the generator system control point, the majority of the trajectory and aerodynamic efforts are performed under that control point. However, that part of these disiplines necessary to design and analyse the CIR System are performed under Control Point 4100.

At the CIR System program level, Control Point 4000, will be efforts such as the program and technical management and Quality Assurance. This includes establishment of reliability goals, apportionment of the goals to various subsystems and determination and demonstration that these goals are being met. Overall efforts of Quality Control, Value Engineering and similar broad functions will be done on this level.

\section{4010--Program and Technical Management}

This effort is essentially the same type as appears under Control Point 1210.

\section{4020--Quality Assurance}

Product integrity will be built into the CIR end items through the integrated efforts of the contractor's functional departments comprising the organizational structure. The primary efforts to be used to provide quality assured products will include:

Reliability

Quality Control

Maintainability

Value Engineering

System Testing

Engineering Controls to assure that the CIR system is designed to meet the contract performance goals.

to ascertain the delivered end items are as specified in the contract and specifications.

to establish and demonstrate maintenance criteria consistent with program goals and reliability.

to obtain specification performance and reliability at minimum cost.

to develop system confidence and demonstrate specification performance.

to ascertain that system development and design data and analysis are reflected in the end product design. 


\section{(2)}

Manuals and Reports

to document system development, operational characteristics and other operational and maintenance use criteria.

a. Reliability

The objective of the CIR System Reliability Program is to assure that the system meets the reliability goals established for it. Because the CIR system is essentially a "service module" for the RTG/RB, the reliability goals will be established under the generator system effort. The apportionment of the goals, between the various CIR components and subsystems, will be done under this task as will all effort necessary to assuring the goals are met.

Appendix A of this volume presents the proposed reliability plan based on specifications DOD MIL-STD-785, "Requirements for Reliability Program for Systems and Equipment" and NASA NPC 250-1, "Reliability Program Provisions for Space System Contractors". During Phase I a comprehensive Reliability Program Plan will be finalized based on the proposed program plan. This plan will identify effort necessary to meet total reliability requirements for the airborne systems and assure that the system components, parts and materials are selected to meet allocated reliability requirements. This plan, is designed to provide criteria to guide system design, part and material selection, test programs and qualification of manufacturing processes.

The reliability program plan will be implemented in all phases to assure designs are evaluated, and that the established integrated test program (Martin and its suppliers) provides the maximum of reliability data to demonstrate compliance with the reliability objectives.

Presented below is a brief summary of some aspects of implementing the proposed reliability plan.

(1) Component level controls and test evaluation for reliability.

(a) Reliability sign off of all engineering drawings, specifications and test procedures a prerequisite to release. This requirement holds also for piece parts, subsystems and systems.

(b) Selection of components in Phase I that are known reliability wherever possible.

(c) Prepare procurement specifications that clearly establish reliability, requirements for the components based on predetermined apportionments of the subsystems.

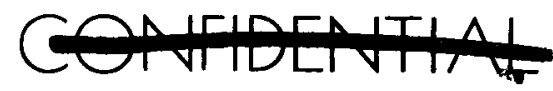

MND $-2050-\mathrm{F}-3$ 
(d) Select suppliers that have produced similar or identical equipment that has demonstrated its reliability through use on other programs.

(e) Monitor supplier activities to assure compliance with specification requirements.

(f) Conduct acceptance testing of supplied hardware (i.e. critical components or piece parts).

(g) Perform in-house qualification testing of the component and monitor subcontractor qualification test programs.

(2) Subsystem level controls and test evaluation

(a) Conduct design reviews.

(b) Assure the finalized integrated test plan contains adequate testing to provide the data necessary to indicate subsystem qualification.

(c) Assure adequate lot testing of one-shot devices (e.g. pyrotechnics and rocket motors) to demonstrate the reliability of the items in that lot. Actual flight unit items, will be selected from the verified lot.

(d) Failure reporting analysis in depth and corrective action loop to assure eliminating modes of failure requiring the corrective action.

(e) Applicable controls defined at the component level also apply.

(3) System level controls and test evaluation for reliability.

(a) Design review at system level.

(b) Conduct complete system test using inert pyrotechnic devices and rocket motors. Install stray voltage detectors to insure no transient signal can trigger an inadvertent operation.

(c) Conduct cyclic life testing of system with inert pyrotechnic and rocket motors to assure reliability and confidence for the system. For example using the binomial confidence 1000 cycles without a failure should demonstrate \& .999 probability with a $50 \%$ confidence.
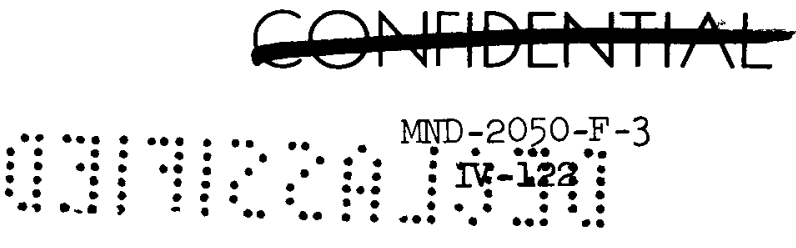


\section{कAll}

A level of testing will be selected to meet or exceed reliability goals.

The above example was not meant to be all inclusive but to describe the intent and approach in implementing the CIR reliability plan.

The proposed CIR mission establishes a relatively short life requirement when compared with the RTG. Thus exposure to space vacuum and/or radiation does not impose a severe restraint. The system is essentially a one cycle operation. Pyrotechnics and rocket motors will be qualified by similarity wherever possible since gaining statistical samples for obtaining reliability data requires testing of large quantities. Procurement of these items will be by lots, with sample sizes, determined by quality sampling techniques sufficient to establish lot characteristics that meet reliability requirements. Tests are described in the integrated test plan.

Electrical connectors will be selected based on prior usage and from manufacturers with known capability for supplying reliable hardware.

Bearings will be evaluated for operation in the space vacuum environment. Lubricants for the bearings will be selected for compatibility with nuclear radiation and space vacuum. The bearing-lubricant combination will be tested to assure uniformity between bearings since spinup velocity is influenced by bearing friction.

Electronic components in the command system, tracking beacon, and switching devices will be selected for compatibility with radiation dosage and space vacuum operation.

These are some of the recognized problem areas and the expected approaches to these problems. A thorough failure mode analyses will be made in phase I based on all expected environments and environmental levels. Trade off studies will be made in order to insure optimal reliability.

\section{b. Quality control}

Quality effort associated with the development of the CIR system will include reviews of specifications, design review, test procedures and processes; preparation of inspection instmuctions and log books to cover detail fabrication, assembly and test operations; and evaluation of procurement plans to determine requirements for vendor surveys, receiving acceptance plans and source inspection requirements. A detail description of the methods to be used in performing these efforts is contained in the Quality Assurance Plan of Vol. VI of this report.

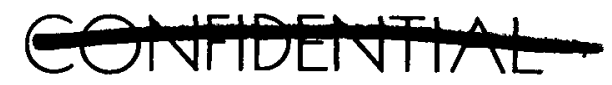


A continuous monitoring and periodic review of the engineering design will be performed to ensure that all quality assurance requirements have been considered. Close liaison will be maintained between quality controls engineering and procurement department to obtain this compliance. All procurement initiated by engineering will be reviewed to determine that the necessary design, test, documentation, quality and delivery requirements are included.

During the period of component and subsystem development, Quality Engineers will monitor test laboratory, vendor and sub-contractor activities in accordance with the approved Quality Assurance Plan to assure full compliance with all test specifications, procurement specifications and data requirements.

Quality Laboratories will support Quality Engineers by performing material and component tests, failed parts analysis, development of new processes, etc. During the period of system development and fabrication of prototype system, qualification test programs and system demonstration. During the period of flight article fabrication and, if required, modification Quality Control will continue the functions described for the previous efforts in addition to shipping inspection and launch site flight support inspection activities.

\section{c. Maintainability}

The object of this effort is to assure that the design and hardware meet the maintainability requirements established by the contract. This will be accomplished by establishing maintainability criteria for the equipment design. The equipment designers will be indoctrinated in the maintainability requirements and goals to be factored into the design. Periodic reviews of the design and trade-off studies related to maintainability items will be conducted. Special considerations will be given to the problem of handling and storing solid propellant rocket motors and pyrotechnic devices. A topical report presenting the incorporated maintainability features, the maintainability trade-off studies performed and the predicted mean-time-to repair will be prepared and submitted to the AEC. A maintainability demonstration will be conducted during the maintenance manual verification.

\section{d. Value engineering}

This effort will be directed toward reducing the cost of providing CRONUS CIR hardware without sacrifice of product performance or reliability. In the performance of this task, the following will be accomplished:

(1) reviews of the design, manufacturing processes, and hardware by a specialist to reduce costs without impairing the 


\section{(4)}

functional design of the equipment. Where Customer approval is granted, such changes shall be incorporated.

(2) the total cost savings (value of re-engineering) will be determined.

e. System testing

The integrated test program plan defines the basic test approaches and test philosophy, the phasing of the test cycles in coordination with the design and fabrication cycles, and the integration and sequencing of individual tests for a well balanced program at a minimum cost and effort. The integration of the various tests is of great importance both for the $C I R$ and the RTG/RB due to the fact that many of the required functions cut across subsystem and system interfaces.

Each phase of the test program will be identified and discussed with emphasis in those areas where variations in test philosophies may be possible. Special test considerations, test fixtures and test facility requirements will be identified. Test and document control practices will be identified and implementation indicated in relation to the various departmental functions.

The basic guidelines for the implementation of the test program plan must be defined in order to provide a uniform frame of reference. The guidelines include the following:

(1) The program plan implemented and approved between the Martin Company and the customer shall be the master document having precedent over all other instructions.

(2) The prescribed mission operational requirements for each assigned mission will be used as a fundamental background for assessment of required hardware system functions by phase of flight and the operational environments to be considered during simulated flight test operations (See Table 4000-1 for format.)

(3) The system design specification and the mission requirements establishes the basic system test requirements specification for the fabricated system. The component and subsystem test requirements and performance serve as building blocks for the combined system and must be compatible to the final system operational performance.

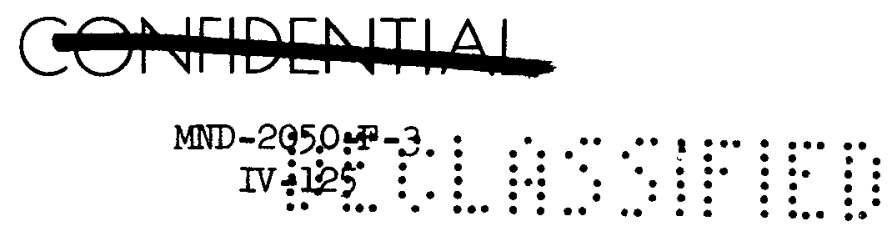


(4) A single functional group will be responsible for the total integrated test program to provide continuity of test efforts and coordination of test activities in the most logical sequence and combination of tests.

(5) The integrated test program as presented represents the types of test to be performed to all phases and levels of test. Since some of these tests are to be performed at a subcontractor or vendor and priced separately, the summary of components used during the test program reflect only the in-house test program quantities.

(6) The design philosophy emphasizes the use of hardware components and designs from previous programs. The test program will reflect this philosophy in two basic areas. Where hardware designs have been previously developed and proven, the development program will stress evaluation performance tests on the hardware to verify that it will satisfactorily meet the system requirements in the operational environments. If the hardware meets the evaluation test criteria and has been perviously qualified, requalification of the new fabrication hardware will be limited to a minimum number of units with major emphasis on critical environments.

Each of the subsystems will be subjected to the integrated test program approach in the fabrication and checkout of each subsystem's hardware from parts and components level to the complete system level. The interface functions and environmental requirements between the major components will also be investigated and verified.

The basic features of the integrated test program are:

(1) Definition of each of the discrete test phases of the program.

(2) Definition of the special problem areas of investigation based on the mission functional requirements of the system (Table 4000-1).

(3) Plan the scope of testing required to demonstrate systems operational capability and development during each of the program phases.

(4) Coordinate or combine tests or series of tests to supplement or complement each other in the most logical and contributory manner. 


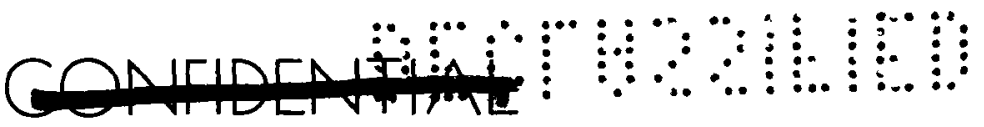

(5) Coordinate interface tests with co-contractor or integrating contractors.

(6) Schedule tests that are consistent with design and delivery committments.

(7) Specify special test equipment and test facility requirements and coordinate their provision with the providing agency.

(8) The accumulation and correlation of test data will be an essential part of the integrated test performance to optimize the system verification. Test reports will be prepared for each test or series of tests to formalize data presentation and to distribute results to all groups requiring the information.

Fig. 4000-2 indicates the test flow of hardware components and system from the preliminary development phase through the final launch check-out of the flight hardware. A summary of each test phase is presented below; more detailed test plans are discussed unde: each subsystem by control point and for the complete system in subsequent sections of the Development Plan.

Tables 4000-2 and 4000-3 indicate the hardware requirements for each test sequence. Table 4000-2 covers the component test program required to provide satisfactory components for the designed system. Table 4000-2 indicates the various subsystem or system test vehicles or configurations with component hardware requirements. The tests are defined in the test writeups under the control point designations in subsequent sections.

The test phases and the major areas of investigation for the CIR System are discussed below following the general breakdown of Chart 4000-1

Development Test Phase. The development tests are performed to assist the design engineer in confirming his design philosophy by hardware fabrication and performance demonstrations. The tests are closely coordinated with the design groups and primarily performed by design personnel or under design cognizance. Test integration will monitor and coordinate these tests to accomplish combined tests between different design groups where possible to minimize duplication of test setups and test objectives.

The prinicple function of the CIR system is to separate the Generator System from the launch or orbiting vehicle in the event of malfunction or faulty orbit acquisition and deorbit the reentry body into a safe earth environment. The development tests will be designed to demonstrate the capability of the design to achieve these objectives with a

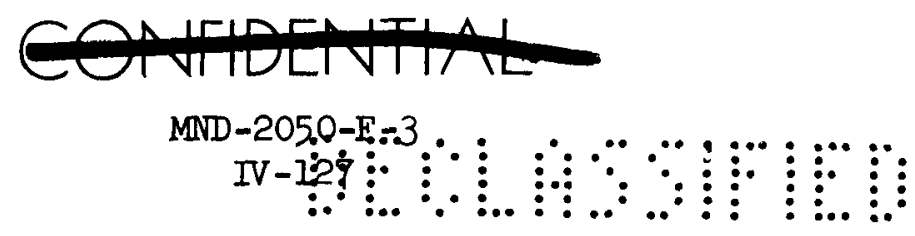




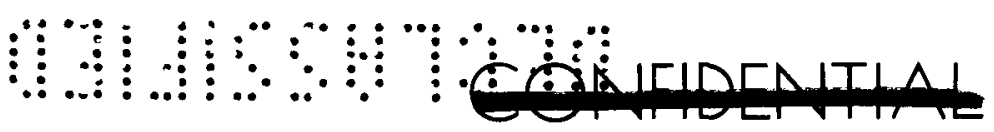

high degree of reliability. Besides the normal performance capability demonstration tests, tests will be performed to investigate this capability under the possible environmental or malfunction conditions which may exist. Discussions on the specific types of tests planned are indicated in the writeup by control point designations in subsequent sections of the Development Plan.

(1) Preliminary Development and Evaluation Phase (Phase I)--The design philosophy emphasizes the use of hardware designs from previous space programs where feasible. In those particular areas, the initial test program will specialize in the evaluation of the prior usage components to new environmental or operational constraints such as the separation shock modes and the nuclear power source radiation environment.

New development areas will require additional tests of parts and materials to the environmental conditions of the mission. Based on the standard tests performed on most parts and materials used in system designs, the major areas of investigation will be radiation exposure and thermal/vacuum affects.

The aerodynamic tests are basically associated with the separation and reentry drag coefficients of the CIR structural body in relation to the $\mathrm{RTG} / \mathrm{RB}$ characteristics. All aerodynamic tests are discussed in Section 3120.

(2) Subsystem and Component Development Phase (Phase II)--This test cycle is concerned with the component and subsystem development and also in direct relationship with the system operational concepts. The tests confirm the operational capability of the components individually and as part of the subsystem functional requirements in the system concepts.

Structural and thermal test models are subjected to static and dynamic structural tests and thermal test profiles along the CIR System design requirements. Interface structural and environmental inputs must be simulated for the RTG/RB and the booster or spacecraft interfaces. Component dynamic and thermal simulation will be utilized where possible in the CIR system. The separation mechanical hardware and component mounting arrangements including heat sinks or insulation are critical features in the development test measurement factors.

The CIR separation development tests includes discrete separation operations, such as manual release of the spin bearing lock, manual spin of $C I R$ and $R T G / R B$ simulator, and movement along the track, and also the sequential operations using the solid rocket motors.
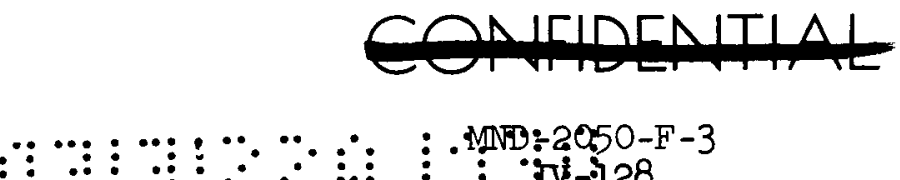


\section{-}

Prototype and Qualification Test Phase (Phase III). The developed hardware will be fabricated into a series of prototype test vehicles. These test vehicles will include system ground test models for design verification, qualification test hardware for operational and environmental tests at a margin of safety above the mission operational requirements, and two flight vehicles for flight demonstration of the short and safe entry of a reentry body containing simulated nuclear power sources.

(1) Prototype Compatibility Test Vehicle - The final system design configuration is verified in the compatibility test vehicle test cycles. All intersubsystem functions and compatibility of operations to mission requirements are demonstrated using simulators for pyrotechnics and rocket motors. Electrical and mechanical interfaces are tested between the CIR and the RTG/RB and spacecraft. Any design changes found necessary are tested on this test vehicle prior to incorporation into the qualification vehicles or delivered hardware. The compatibility test vehicle is also used for preliminary verifications of the AGE and also with the launch complex operations.

(2) Qualification Tests - Component qualification tests on previously proven hardware will be at a minimum with major emphasis on new or critical environments. The pyrotechnics, solid rocket motors, and separation links will be subjected to standard qualification tests as indicated in Table II. A complete CIR system will be subjected to the standard environmental qualification tests. These tests may be repeated if design changes are necessary following the prototype flights.

(3) Reliability Tests - Reliability on the CIR system will rely strongly on the other test phases instead of an extensive reliability test program. This is based solely on the use of many prior usage components and the relatively short flight period involved prior to intended or anticipated use of the system. Additional tests for reliability will be conducted on the pyrotechnics and solid rocket motors in conjunction radiation and thermal/vacuum environmental exposures. Except for a life test mun on a complete CIR system, other reliability evaluations will be based on the development and qualification programs.

(4) Prototype Flight Vehicle Tests - The prototype flight vehicles will be subjected to the standard acceptance test cycle as indicated for the production flight vehicles in Phase IV. Since these flights are advanced development flight programs
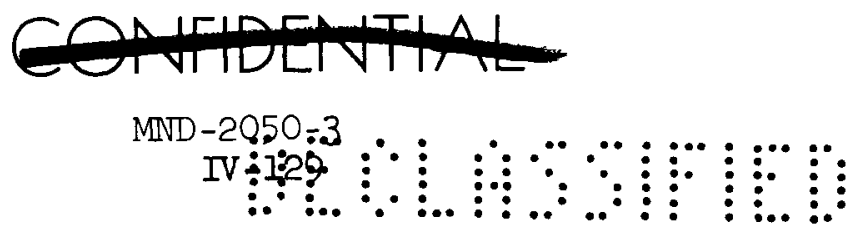
for verification of the separation and reentry sequences, major emphasis on the instrumentation and data measurement systems will be involved.

Flight Hardware Acceptance Test Phase (Phase IV). All flight hardware will be subjected to acceptance tests at the component, subsystem and system levels for performance evaluation to prescribed parameter limits. Environmental tests sequences will be performed for EMI, Vibration, and Thermal Vacuum tests. Since alignment accuracies and weight and balance determinations are critical for the CIR operations, the RTG/ $\mathrm{RB}$ or a precise simulator must be available for the environmental test sequences.

The launch complex operational test sequences are closely involved with the other flight system and operational support equipment. The CIR system functions are monitored and verified prior to integration with the other systems. Alignment accuracies and ordnance installations are the major discrete operations in addition to the system monitoring.

Test Analyses and Reports. Each test performed, during the test program beyond the component breadboard stage, will be planned and documented as to objectives, configurations, procedures to be followed, and the expected test results. At the completion of each test, the performance results will be analyzed and reviewed against previous test results and subsequent test plans to coordinate and incorporate required changes for the best integrated test and program effort. All test results and plans will be documented in a formal report at the end of the test. Where individual tests are a portion of a series of tests, a preliminary quick look report will be issued to provide a data base for program and system performance review. The high degree of safety and reliability requirements of the Generator System necessitates a continuous evaluation and accountability of data to minimize the needs for an excessive number of CIR tests for safety or reliability purposes. These objectives will be stressed under each test plan.

\section{f. Engineering controls}

The functions accomplished by the Engineering Department to assure product integrity are itemized in Fig. 17 of Vol. VI. In particular, Engineering will maintain control of the product specifications and drawings to assure that the program goals are achieved. A system of Engineering Directives will be issued to define areas of responsibility and requirements of each functional groups for achieving these goals.

Specifications will be prepared to establish the requirements for all Contract End Items. These will establish the criteria for acceptable product and enable determination as to whether or not compliance has been achieved. Engineering Process Specifications will be prepared 
for all critical manufacturing requirements. A drafting and checking manual will be used to assure standard illustrations, nomenclature, format, etc. on all program drawings to minimize misinterpretation. All drawings for hardware to be delivered will be subjected to $100 \%$ checking before release for fabrication. Drawing change controls will be used are described in MV-2050-3 of Vol. IV. Resident technical representation will be at all subcontractors to monitor their technical performance. Engineering analys is of the subcontractor products will also be continuously conducted. Engineering will participate in the Configuration Change Board and Malfunction/Discrepancy Automatic Report System (MARS) action meetings.

\section{g. Operating manual}

A set of instmactions will be prepared for the installation, handling, maintenance, checkout and launch of the CIR System. This manual may be combined with those for the RTG/RB and $A G E$ systems to make a single integrated operating manual.

By analysis of the design and liaison with test operations personnel, a topical outline will be developed which will include all operations necessary for use of the CIR. Alignment proceedings, arming instructions, and fueling malfunction recovery instructions will be included in the operations portion of the manual. The preliminary operating manual will then be developed in conjunction with the preparation of the test procedures. The procedures for integration with the spacecraft and launch vehicle contractors will be developed through liaison with the customer and the contractors involved. The operating manual will be verified during the contractor's in-plant tests and checkouts.

A verification copy of the manual will be furnished for the fueling demonstration at the launch site. The manual will be modified to incorporate necessary changes where the demonstration indicates revision is appropriate. An updated verification copy will be furnished for use and further verification during the prototype flight demonstration. A final copy of the operating manual reflecting experience gained in fueling demonstrations and prototype flight tests will be prepared for delivery concurrent with the delivery of the first flight operational hardware. Revisions will be generated and issued as required to keep the manual current through the remainder of the program.

Maintenance Manual. A set of preventative maintenance procedures for assuring operational readiness or timely return to operational status in the event of a malfunction will be provided. Special handling and transportation data will be included. 
The manual will be based on the maintenance concepts as defined in the maintenance plan and the support equipment and spares available. A preliminary maintenance manual will be developed concurrently with the in-plant test operations of the CIR system hardware. Maintainability analysis, failure mode analysis data, refurbishment kit data, spares provisioning, etc. will be factored into the maintenance procedures. The maintenance, handling and transportation procedures will be verified using launch site operations data prior to the preparation of the final manual. Verification and final copies of this manual will be prepared and delivered concurrently with the operating manual.

Reports. Contributions to the AGE program for the monthly, quarterly, and summary progress reports and other topical reports under this control point as required. 


\section{A. 4100--CIR SYSTEM}

The objective of the CIR System design, development, and procurement activities is to create a safe, dependable RTG/RB support and deorbit module.

The CIR can be physically segregated into four subsystems. Although each of these subsystems will be developed individually, the functions that the CIR must perform often cut across subsystem lines. Therefore, the system oriented analysis, development, and integrated tests are of vital importance.

No basic development problem needs to be solved, since the CIR concept and design is based upon current state-of-the-art technology. However, some of the hardware, such as deorbit motors, should be redesigned in order to attain reasonable welght or performance goals. The first problem which has to be solved, therefore, is the optimization of the feasible CIR system. The second problem is the actual design and verification of the design. In order to solve these problems, we need specific criteria, and some information concerning the spacecrafts and missions for which CRONUS is intended.

The criteria to which this system should be designed is, of course, difficult to specify. This is due to the dual nature of the CIR; support the $R T G / R B$ in normal operation and, in an emergency, provide for quick $\mathrm{S} / \mathrm{C}$ separation and controlled deorbit capability. Furthermore, the CIR contains the only physical link, in flight, between the generator and the $\mathrm{S} / \mathrm{C}$. Consequently, variations in the CRONUS mission, or in the spacecraft for CRONUS appear as modifications in the requirements imposed on the CIR.

One additional general problem must be recognized in the development of the CIR namely Nuclear Safety. This requirement implies a need for high reliability both under normal operation and under abnormal environments. Achieving the specified safety goals will require special effort.

The approach to solving these problems will be to initially establish sufficiently broad interface specifications, mission profiles, and detailed spacecraft definitions so as to encompass the most probable, reasonable mission.

Within these constraints, the CIR will be optimized in the first phase of the contract. The proven, feasible reference system approach is the starting point for the optimization. Explicit trade-off ratios between cost, weight, growth potential, etc. will be established. Certain basic long lead items, such as the spacecraft separation functions and the bearing and roller designs, will also be developed in Phase I. The

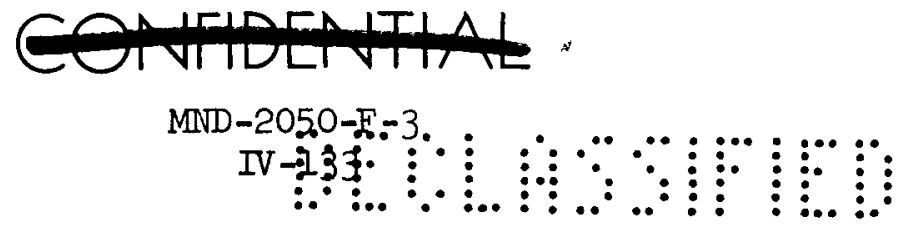




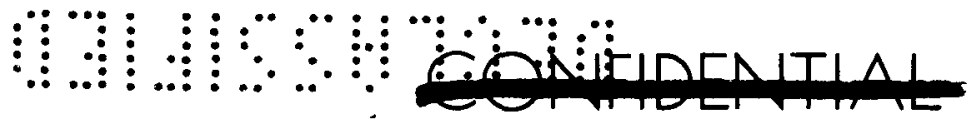

design will be finished about 8 months after go-ahead. The required subcontractor contracts will be let. During Phase 2, the necessary engineering drawings will be prepared so that the required subsystem component and operational tests can be performed.

A prototype will be available for the demonstration flight. It is assumed that this prototype design will also be suitable for the final design. However, allowances are made for reasonable changes in Phase III in the $\mathrm{S} / \mathrm{C}$ and the mission characteristics. Normal engineering and test support will be rendered during the operational period of Phase IV.

In order to assure the nuclear safety requirements are met for CRONUS, an approach akin to man-rating will be used on the CIR. Components that have been qualified and have been flown will, if possible, be used. Even these parts will be requalified for any new or different environment (ex. Radiation). A series of worst case analysis and tests will be performed. Assessments will be made of the consequences of all credible failures, either in the CIR or the launch vehicle MDS system. Parts which are critical to the nuclear safety will be so labeled, and treated with Tender Loving Care. Full records and documentations of all applicable tests (successful or otherwise) will be maintained. Emphasis will be placed upon system orientation analysis and tests--both internally within the CIR and with regard to the $R T G / R B$ and GHE interfaces.

A detailed record will be established for each CIR. During the final phases of the contract, design changes will be carefully monitored and accepted only if they do not adversely affect the nuclear safety. Tested subsystems will be brought together for partial system tests. During the development and qualification phases, after total system tests, the system will be dismantled and the individual components carefully examined and retested. The resulting flight hardware will, therefore, be highly reliable, even under extremely severe and unexpected environmental conditions, and will also consequently be safe for nuclear application.

The assembly and installation of the CIR is illustrated in Fig. 4000-I. The CIR package assembly will be fabricated in accordance with Engineering requirements to meet the overall objectives of the design criteria. All of the general manufacturing knowledge and methods that has been accumulated throughout the years will be utilized in this overall fabrication effort. Martin standards and MIL specifications, where applicable, will be maintained on all hardware items. Additional controls and procedures will be initiated where necessary for the speciflc purpose of increasing the overall reliability effectiveness of this system.
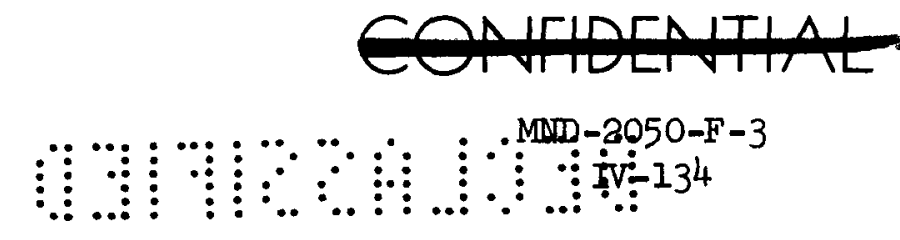


\section{Wuा}

1. 4110--CIR System Design Analysis

The objectives of the design and analysis of the CIR system is to optimize the concept and subsystem to develop a detailed design of the finalized system, and to conduct all the required system and functional analysis required for the engineering of the CIR. Furthermore, the engineering effort required to support the customer; analyze and assess system level component developments, establish interfaces between subsystems, direct and assess functional and system test, are included. The engineering effort required to assess the impact of explicit missions and spacecraft definition is also included.

The basic system problem that has to be analyzed are as follows:

\section{a. Interface definition}

The CIR has a function and structural interface with the $S / C$ and with the RTG/RB. It also has a function interface with the LV (MDS requirements and fairing compatibility). Furthermore, the checkout and handling procedures generated are interfaced with the GHE and AGE. The operational requirement (backup ground command for separation, and ground command for deorbit) creates an interface with the various tracking stations. Furthermore, there is a structural, functional, and electrical interface between the CIR and the RTG/RB.

These interfaces require definition, analysis, and documentation. Most of the required engineering effort will be done as a natural part of the subsystem and system design and analysis. However, some additional effort is required to coordinate the various efforts to carry out functions not specifically oriented to subsystem or normal engineering analyses.

b. $\quad \mathrm{S} / \mathrm{C}$ separation analysis

The spacecraft attachment and separation operation has to be analyzed in detail to determine the kinematic properties as a function of the subsystem description to assess the allowable S/C and LV materials to determine the effects of various reasonable malfunctions in the spacecraft or MDS or RTG/RB and CIR, and to develop and compare the optimum functional sequences.

\section{c. Spin stability analysis}

The spin stabilized operation has to be analyzed in detail to optimize the nominal spin rate, to evaluate the effect of varied tolerances in the propulsion subsystem, to assess the effect of nonrigia body characteristics (stiffness, flexing, loose or non-linear connections, etc.), to evaluate the effects of various reasonable

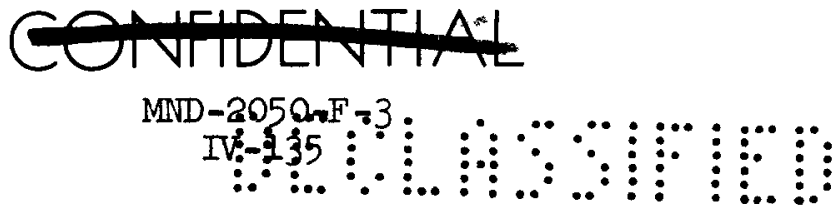




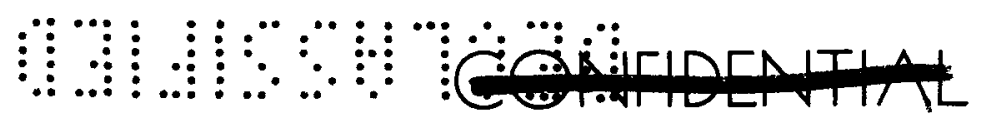

malfunctions, and to assess the system behavior in the presence of aerodynamic forces or blast waves. This analysis will encompass the $\mathrm{S} / \mathrm{C}$ separation, free-fall, deorbit, and despin plans of the CIR operation.

d. Operation and trajectory analysis

An operational analysis study must be conducted to analyze and optimize the ground operation requirements. This includes a trajectory dispersion study to assess the allowable launch vehicle MDS setting and determining launch vehicle ground tracking requirements.

e. Weight optimization

A weight analysis effort must be conducted to monitor and optimize the system weights, to determine the component arrangement compatible with the principle axis and moment of inertia requirements, and to assist in the evaluation and contract of vendors and subcontractors.

f. Thermal analysis

A detailed transient thermal analysis will be conducted to determine overall heat balance in the CIR as well as local temperatures at various critical points, during the different operating modes. This analysis will determine what is required in the way of emissivity coatings and/or thermal control devices for the system.

g. Safety support

A safety analysis will be constructed for the CIR to support the CRONUS safety effort. This work will include the formulation of the various disasters that could occur (ex. Propulsion explosion), and an analysis of the various malfunctions that could lead to the disaster.

h. Mission analysis

A mission and system analysis should be conducted, in the initial phase of the contract, in order to assess the potential or desirable changes in the mission and spacecraft definition.

i. Design

A thorough design effort must be conducted to first assist in determining the optimum concept and configuration, in arriving at the final design, and then in creating the required drawing and documentation effort for testing and manufacturing purposes.

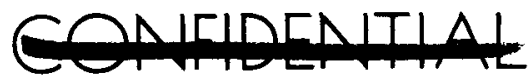


A necessary part of the CIR design and analysis is the production and rework of the eng ineering release drawing. This effort will have to extend over various phases of the program, since the unavoidable changes in the spacecraft mission, and CIR will have to be incorporated into the proper drawings.

The approach to solve the design and optimization problems of the CIR will be to first set up a conceptual design team. This small team will optimize the concept, and finalize the basic choices four months after go-ahead. In parallel to this team, there will be a gradually increasing engineering analysis effort which will conduct the aforementioned analyses to support the optimization providing the analytical tools necessary for the final design; and, when the concept has been finalized, verify in detail the choices. team.

This effort will, as time progresses, absorb the conceptual design

Subsequent activities of this engineering team will include the monitoring and assessment of the component and subsystem development and qualification tests. It will also include the sustained engineering effort necessary to service the customer.

Throughout the life of the program, there will be program reviews, briefing, etc. These activities are considered a normal part of the CIR design and analysis effort, and have been prorated among the various subsystems and systems analysis tasks.

2. 4120--Component Development

The objectives of the Phase I system component and development activities is to experimentally verify the basic functional activities which the CIR must perform, and to estimate by model testing, some of the important physical characteristics (ex. aerodynamic properties).

The basic function that has to be experimentally verified is the $\mathrm{S} / \mathrm{C}$ separation method. There is no doubt about the fundamental feasibility of the rail separation method. However, the behavior of the system in the presence of vibration, track misalignment, elastic body effects, various malfunctions, etc. must be established experimentally. The aerodynamic properties of the CIR (the CIR alone or in the presence of the $\mathrm{RTG} / \mathrm{RB}$ ) also cannot be readily estimated.

The approach to solving problems is to run tests. An instrumentational mock-up of the separation hardware will be made, and various tests made. The tests necessary to develop the bearings, etc. are discussed

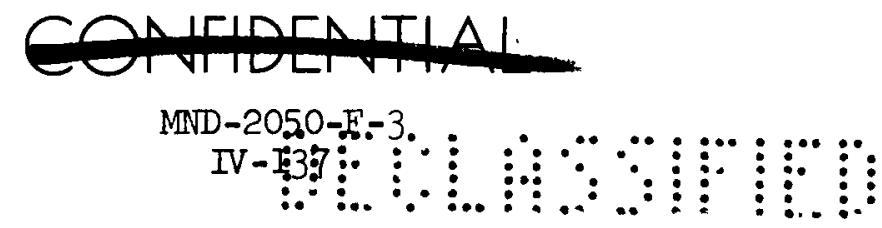


in Section 4520. The model will be scaled so that effects of launch vehicle acceleration, etc. will be reasonably simulated. The model may be mounted on a vibration table. Included in the simulation will be a structural mock-up of the RTG/RB.

A series of wind tunnel tests should be made to determine the gross overall hypersonic aerodynamic characteristics of the CIR. Further tests should be made on the CIR (with RTG/RB attached) to determine the flow and pressure characteristics of a blast. Similar tests will determine some of the aerodynamic properties of a re-entering RTG/RB-CIR configuration.

Development tests are performed to assist the design engineer in confirming his design philosophy by hardware fabrication and performance demonstrations. Test integration monitors and coordinates these tests, including combined tests between different design groups to minimize duplication of tests. The development tests are under design engineering cognizance.

a. Parts/Material selection and development

\section{General System Parts or Materials}

Parts and materials, which are common to more than one subsystem design, will require development or evaluation tests early in the design cycle to determine whether they are adaptable to the environmental and performance requirements. New designs or hardware redesign concepts may indicate that additional tests must be performed which have not been necessary in previous system applications. Results of these performance tests must be analyzed to determine whether new hardware selections must be made.

The affects of nuclear radiation dosage levels on materials such as coatings, insulation, and wiring and on parts such as transistors, resistors, and transducers will be analyzed and/or testing. Other environmental investigations will include temperature levels and cycles, vacuum, and solar radiation spectrums.

b. Aerodynamic test model

Aerodynamic wind tunnel tests will be performed with the CIR attached to a re-entry body model to determine the effect of re-entry and orientation in the event separation does not occur. The aerodynamic tests will also determine the re-entry drag of the CIR when separated for maintaining a distance from the re-entry body. These tests are discussed in more detail under Control Point 3120.
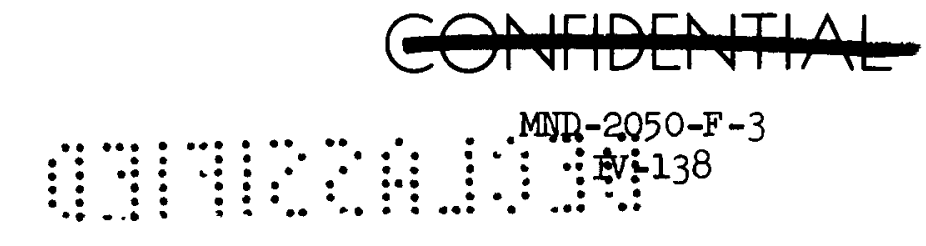


\section{c. CIR mockup vehicle}

A CIR structural mockup vehicle will be fabricated out of wood or thin gauge aluminum. All CIR components, mountings, and interface hardware will be simulated in the same manner and mounted in the structure as per the preliminary configuration drawings.

The mockup vehicle will be used to determine the optimum equipment mounting locations, interconnecting cable runs, access panel locations, and interface compatibility features. Portions of the mockup will be suitable for experimental verification of the spacecraft separation concept. As the vehicle design progresses, the mockup shall be modified to serve as a design configuration tool for the prototype hardware.

\section{4130--Subsystem Development Test}

The component and feasibility demonstration tests of Phase I will be continued in Phase II, with emphasis upon the system oriented subsystem development test.

a. Re-entry body - CIR/Spacecraft separation development tests

The separation events for the CIR/Spacecraft interface separation involve a number of discrete functions which are precisely timed in actual operation. Although each of these discrete operations will be development tested individually a number of times, the coverage here will be sequential with indication of special areas of concentration.

The configuration requires the Re-entry Body and Spacecraft mechanical interfaces, the separation, spin and despin rockets, the spin bearing, tracks, and stops, the rocket igniter circuits, simulated mass and $C G$ of the other CIR and Re-entry Body components, electrical energizing console, and overheat attachment support with freedom of rotation and lateral motion in one direction and with capability of simulating $g$ loads.

(1) Release of Locking Pins and Connector - Squib actuation release of interface connector and pin puller to permit spin operations. Reliability of squib firing and adequate clearance of released mechanisms is critical.

(2) Spin-Up - Firing of spin-up rockets and rotation of CIR and Re-Entry Body on spin bearing assembly. Rotational speed and bearing friction are critical items as well as determining affect of bearing temperature control requirements. The effects of a single spin motor firing will be investigated.

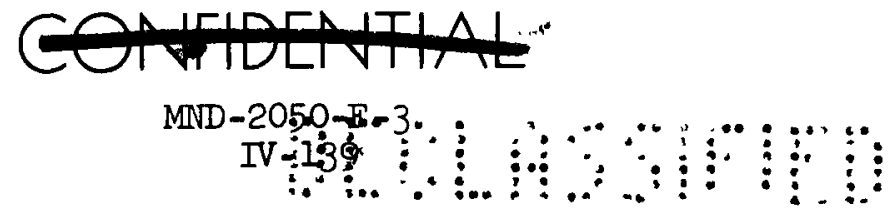


(3) Separation - Firing of separation rocket, movement forces and speed along tracks, separation motor disconnect, and complete separation of two units are major demonstration requirements. Friction, shock, and temperature control affects must be analyzed and verified.

(4) Credible malfunction will be simulated and the effects noted.

b. Despin development tests

Using the same vehicle configuration as for the Separation Tests, the despin rockets will be fired to determine the despin rate and balance affects on the vehicle.

c. $R T G / R B-C I R$ separation development tests

The CIR and Re-entry Body interface structure and connections will be provided with mass and CG of both bodies simulated. Using overhead test rigs and force measurement devices, the separation mode will be demonstrated in a horizontal test position. Squib firing synchronization, separation band release, latch finger disengagement (including interface connector), and separation spring forces will be investigated.

d. CIR thermal test vehicle development tests

A complete CIR, structural and thermally designed, will be provided with thermal output simulated components mounted as per the designed concept. The Spacecraft interface will be simulated with estimated thermal differential provided from spacecraft components. The Re-entry Body interface and temperature differential will be simulated.

This test unit will be installed in a temperature chamber to simulate external temperature profiles during launch pad sequence and early flight mode. The test unit will then be placed in a thermal/ vacuum chamber to simulate external space environments. Extensive thermal recordings will be made.

4. 4140--System Development and Qualification Tests

The development of the Integrated Test is generated based on the mission requirements necessary to accomplish the assigned mission objectives. The majority of the test demonstrations for design capability verification of the designed system will be accomplished during the development and qualification phases of the test program. The acceptance test phase will primarily demonstrate that the fabricated flight systems conform to the proven design in both configuration and

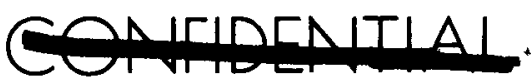


performance. Chart 1 indicates the basic integrated tests program flow for the CIR System from development to the flight launch condition.

a. Electrical and compatibility test vehicle

The initial test vehicle built to the design configuration will be used for electrical, mechanical, and electro-mechanical compatibility test demonstrations at the subsystem and system level. Any required design changes will be factored into this vehicle prior to incorporation into other vehicles. As a design verification vehicle, the results of these tests will be factored into the design and functional requirements of the qualification and prototype flight vehicles. AGE will be used as a joint compatibility test verification.

(1) Mechanical verification and alignment - The CIR assembly is checked for component mounting, tolerances, preliminary alignment measurements, and weight and CG measurement techniques. Latching and release mechanisms are verified.

(2) Subsystem Verification Tests - Each of the CIR subsystems will be tested individually for input and output parameter design verifications with interface signals verified to the interfacing subsystems. Since the electrical power and vehicle cabling will be required for all subsystem tests, these subsystems will be verified initially. Simulators will be utilized for RTG power source, pyrotechnics, and thrust or separation operations.

(3) System Compatibility Test - The complete CIR system will be operated in a simulated mission functional performance run using simulators indicated in the previous section. The instrumentation, telemetry, and malfunction detection subsystems are utilized to provide various possible malfunction modes to initiate $C I R$ separation and deorbit modes. Marginal parameter limit tests will be performed. One of the systems has demonstrated performance to design requirements, electromagnetic interference tests will be run to determine generated interference modes and levels and to determine the system susceptibility to external interference sources. The compatibility tests also include interface signals with the spacecraft and RTG unit.

(4) Launch Site Compatibility - The vehicle will be shipped to the launch site, at the completion of the in-house compatibility tests, for launch complex compatibility tests.

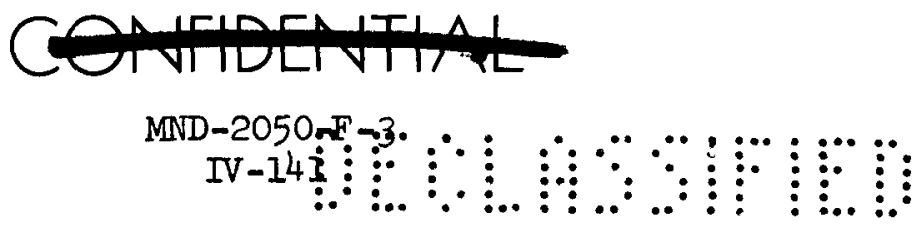


b. Qualification test vehicle

A prototype CIR vehicle will be tested for subsystem and system performance verifications. This vehicle will then be subjected to environmental qualification tests. The tests to be included here are as follows: (The Re-entry Body interface and weight distribution and the spacecraft interface supports must be simulated).

(1) Launch vibration mode to twice the expected launch levels.

(2) Booster separation shock pulses.

(3) Thermal/Vacuum Test simulating heat inputs and cold vacuum for approximately 30 days.

(4) Spin, Despin, and Separation of CIR/SC interface.

(5) Deorbit thrust test.

Vehicle performance monitoring will be required throughout all these tests.

c. Life test vehicle

A prototype CIR vehicle will be tested for subsystem and system performance verifications. This vehicle will then be subjected to a life test program as part of the reliability and qualification program. The test program will be the following:

(1) Launch vibration acceptance levels.

(2) Thermal/Vacuum Test for approximately 10 days as a shakedown space temperature and vacuum test.

(3) Gamma radiation test - An extended test in a gamma radiation test cell at a radiation dose level approximating that of the heat source and space radiation. It is expected that this environment may be the more critical one for extended space flights.

d. Post-prototype qualification tests

Final production hardware will be requalified to the extent required based on re-design.
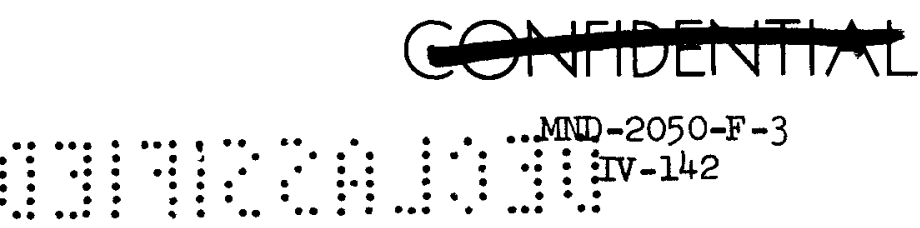


\section{काIII}

(1) Component Qualification - Requalification of production components will be performed on production hardware where any design or configuration changes have been made. Any critical hardware under change will also be subjected to additional life tests.

(2) System Qualification - The CIR system will be reverified for functional performance and subjected to qualification tests as indicated for the Pre-Prototype qualification test vehicle (modified if possible where functions or operations do not require requalification).

\section{e. Combined system tests}

The CIR system must be combined and tested with the RTG/RB, the $\mathrm{GHE}$, etc. These coubined system tests are discussed in section 3140 . 5. 4150--Protosystem Acceptance Tests

This phase of the program covers the test program for the assembled prototype test vehicles for design verification and qualification, the interface contractor test models, and the prototype flight units.

a. Component acceptance tests

All components provided for the test and flight vehicles in the Prototype and Qualification phase must be subjected to specified acceptance tests prior to use in the vehicles. The component tests on the initial prototype test vehicles will provide more definite acceptance parameters for the qualification and prototype vehicles.

b. Integrating contractor test vehicles

(1) Dynamic Test Vehicle - A CIR Prototype Dynamic Test Vehicle will be provided to the Integrating Contractor for a dynamic test program. The test vehicle shall consist of:

- A complete CIR structure including all interfaces.

- A mechanical separation system equipped with separation tracks, track supports, spin bearing, locking studs, and simulated rocket motors (spin, despin, separation).

- Weight and CG simulated components mounted in the CIR structure similar to the flight hardware.

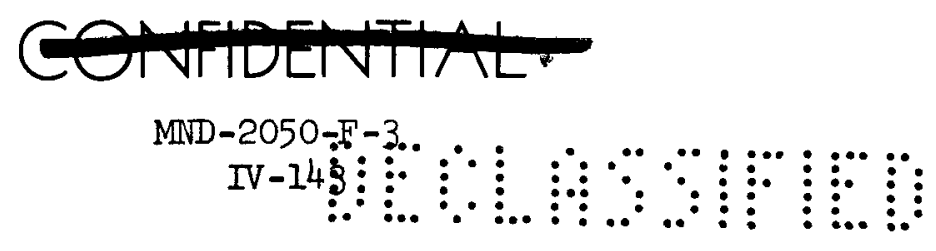




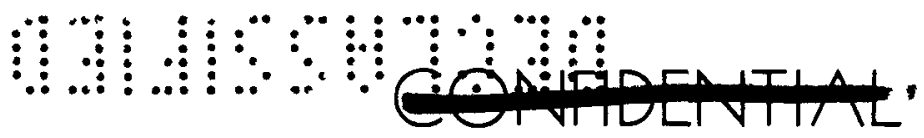

(2) Electrical/Thermal Test Vehicle - Complete CIR Prototype vehicle will be provided to the Integrating Contractor for the electrical and thermal test program. This vehicle will be subjected to the standard acceptance test cycle performed on the qualification test vehicle and the prototype flight test vehicles prior to their delivery to their operational test programs. Dummy rocket motors and simulated pyrotechnics will be provided on the delivered vehicle.

\section{c. Prototype flight vehicle acceptance test program}

Each of the Prototype Flight Vehicles will be subjected to an acceptance test program at the factory and a pre-launch test program at the launch site. The test program will follow the following pattern:

(1) Subsystem and System Performance Tests - A test of each subsystem for verification of all specified functions and parameter performances. A test of the CIR system for intersubsystem performance and complete system mission sequence using simulators for explosive devices or other one shot devices. Tests will be concluded with an electromagnetic interference and susceptibility test phase.

(2) Alighment of critical components.

(3) Weight and CG - Determination of weight and center of gravity parameters and aajustments to proper relationships. Re-entry Body must also be available or simulated for weight and CG.

(4) Systems Vibration Test - Three (3) axis vibration inputs simulating launch environment at CIR/Launch Vehicle adapter or spacecraft interface will be applied to the CIR and simulated Re-entry Body.

(5) Systems Thermal Vacuum - Operational performance test in a thermal vacuum chamber under simulated space environments. Test is designed to detect major seal defects, material outgassing, and thermal control patterns. Test exposure should be limited to from 3 to 7 days.

(6) Spacecraft Checkout Facility Tests - System performance tests are rerun for verification of parameters and sequences. Interface tests are performed with other portions of the space operating vehicle.

(7) Thrust Rocket Installation and Alignment - The solid propellant rockets are installed (with igniters removed) and 


\section{L}

alignment operations performed.

(8) Assembly, Weight and CG Operations - The CIR is mated to the other space operating assemblies and a final weight and center of gravity adjustment made.

(9) Launch Pad Checkout - After the CIR and other space operating assemblies are mounted on the booster, operational or monitoring functions are performed. When operations near completion where personnel must clear the pad, the igniters are installed and connected and final circuits verified. Luunch GO given.

d. Combined system tests

See Section 3150.

6. 4160--Operational Flight Acceptance Test

Each of the production Flight Vehicles will be subjected to the acceptance tests prescribed in the final Integrated System Test Plan. The test sequences are similar to those specified for the Prototype Flight Vehicle Acceptance Test Program covered previously (Control Point 4150).

7. $4170--F 1$ ight Test Support

A well founded development plan factors into its design consideration the support requirements of the end items of hardware. When these support considerations are not evaluated early enough in the design and hardware development phases much redesign is ofter required after the product is developed. This redesign effort is time consuming and costly. Thus, the Technical Support Services are incorporated to provide the effort that will lead to lowest life-cycle cost, and result in a product that is ready for immediate field use during Phase IV of the development plan.

The task of technical support contains several subtasks that will be accomplished concurrent with and integrated into the design and hardware development. The essential support items to be developed are: a) An Operations Plan; b) a Maintenance Plan; c) an Onerating Manual; d) a Maintenance Manual; e) Training; f) Spare Parts Provisioning; and g) Support Facilities.

The operations and maintenance plans are discussed in Section 1230 of this report. The operating and maintenance manuals are discussed in Sections 4030 of this report.

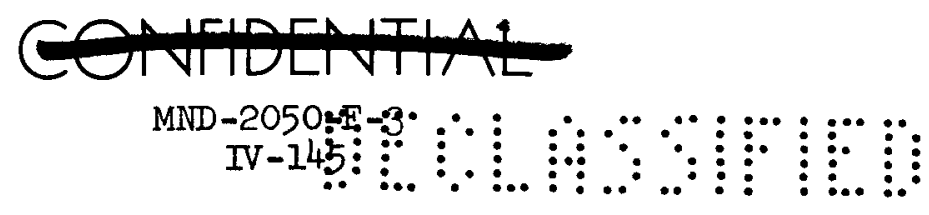


a. Training

The objectives are to provide a highly skilled and competent team of personnel to test, checkout, maintain and launch the complete CRONUS system and, in addition, to provide orientation and familiarization training to all levels of contractor personnel. In order to maintain skilled personnel during the span of the program, instructional film and/or sound-slide presentation which can be used as a device for training new personnel and retraining personnel will be employed. Furthermore, demonstration mock-ups and models for the purpose of maintaining skills will be used.

b. Spare parts provisioning

Spare parts provisioning lists will be generated for the CRONUS System hardware user so that the user can select and order the spares required to support Phase IV and to support the tests, checkout, and launch operation of Phase III. The residual span of Phase III will be delivered to the user at the end of the phase.

Delay in approval and functioning of spare parts provisioning list item will hold up placing of spares on order. This means that approval is required in a timely matter to insure availability of spare parts for the support of Phase IV operations. Early identification of problem areas, and interim approval, is desirable on long lead time procurement items.

\section{c. Support facilities}

The government furnished equipment and facilities required at the launch location for support of the CRONUS Systems hardware will be identified, and their availability verified.

d. Equipment maintenance and repair

Provisions will be made for timely maintenance and repair of CRONUS System hardware during Phase III operations. This maintenance and repair will become the responsibility of the user during Phase IV operations. 


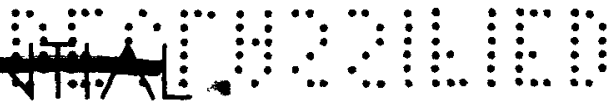

\section{B. 4200--PROPULSION SUBSYSTEM}

The development and qualification program discussed herein is applicable to the development of the deorbit rocket, the spin-despin rocket and the separation rocket. This plan assumes that new $\mathrm{CFE}$ rocket motors will be developed by selected subcontractors for each of the 3 specified functions. Should an off-the-shelf rocket motor be selected for a specific function during the design phase, the status of that rocket motor will be examined with respect to the requirements herein and the development program suitably modified.

The propulsion system contractor will be responsible for the development of all components associated with the structural and operating aspects of the rocket motor(s) for which he is contracted. Component and subsystem development will be accomplished concurrently with the development of the rocket motor.

The basic rocket will be developed through a series of full scale proof firing tests of the propellant grain design, ignition system and performance, in prototype hardware. The prototype hardware tests will be followed by flight-weight hardware tests consisting of structural (hydrostatic) tests and full scale rocket tests. Complete rocket motors representative of the production configurations, will be subjected to a sufficient sampling of typical environmental tests (temperature cycling, vibration, drop and shock, etc.) to indicate that the propellant, grain design, structure and igniter system will perform as intended and that the rocket motor system is ready to pass into the flight certification and qualification phases which preceed production.

Firings will take place at sea level and under vacuum conditions. In addition to the development motors, the selected propulsion system contractor will provide a specified number of motors to the systems contractor. These motors, some of which will be loaded with inert propellant, will be used in CIR system tests.

It is vitally important that the type of propellant, propellant formulation, structural materials and other major design criteria be established as firmly as possible prior to any deep involvement in the development test program in order that the background data on the development configuration tested and fired will be based on a sufficiently similar configuration, to warrant confidence in the configuration that will go into flight certification. That is particularly important because the short period available for development of the rocket motors may require that the initial flight test be conducted before the rockets can be fully qualified.

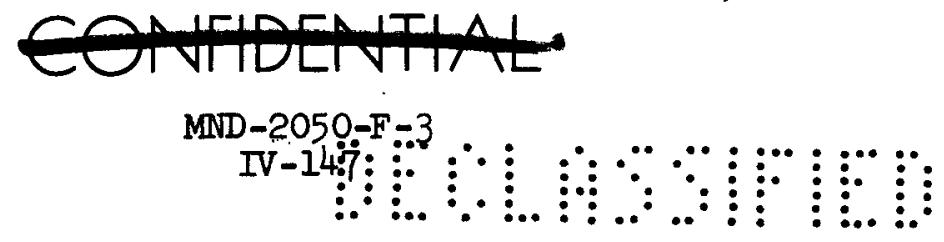


Documentation shall be furnished which will describe test methods, results and associated data such as motor physical characteristics, performance and environmental conditions. Reports shall be submitted periodically in the form of: Progress Reports, Summary Reports, Static Test Reports, Summary Stress Reports, Reliability Reports and Final Reports.

In order to ensure that the reliability requirements for the system will be met, Quality will monitor the development and qualification test programs at the subcontractors' plants in accordance with Engineering prepared Test Specifications. Source inspection of each shipment of rockets and ordnance subsystems will be performed prior to leaving the subcontractors' plants. This will be in accordance with a Martin prepared contractor acceptance plan (CAP) that lists the verification, documentation review that will be performed by an inspector. It will include:

(1) A review of the subcontractor's in-process and assembly inspection results.

(2) A review of the rocket component and subsystem test results. 1. 4210--Design and Analysis

The Systems Contractor shall conduct analyses to establish propulsion system requirements for CIR operation. Preliminary design studies shall be performed and individual rocket motor specifications for the separation rocket, the spin-despin rocket and the deorbit rocket shall be prepared.

Following AEC approval of the specifications, subcontractor bids will be solicited. Evaluation of proposals will result in subcontractor selection. The subcontractor shall perform a detail rocket design study and submit final rocket design engineering drawings for approval to the System Contractor.

The Systems Contractor shall maintain a propulsion system engineering liaison force to perform the following functions:

(1) Provide liaison between the System Contractor and the rocket subcontractor with respect to integration and compatibility aspects of the rocket with the CIR, problem areas, design changes, etc.

(2) Represent the Systems Contractor during rocket motor firings and other critical subsystem test.
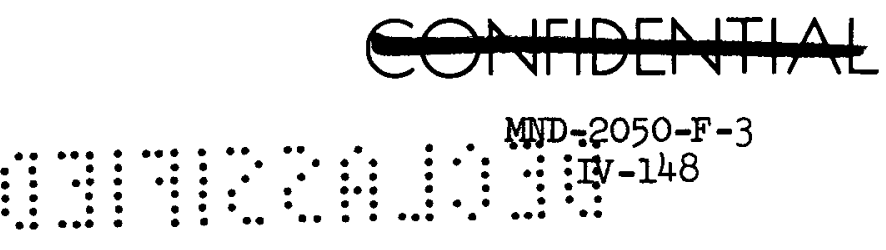


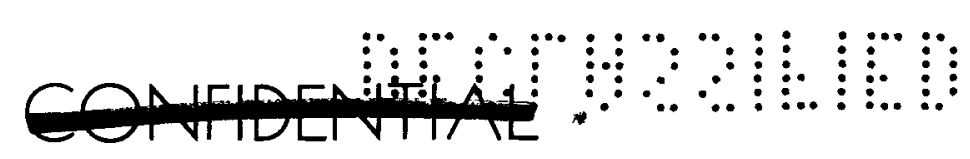

(3) Evaluate subcontractor test reports, progress report, etc.

(4) Perform detail analyses associated with the system application of the rocket motors.

(5) Maintain documentation on the entire propulsion system development and qualification program.

(6) Provide Iiaison between the System Contractor and the AEC as well as other pertinent Government Agencies.

(7) Provide flight test support at the launch site.

2. 4220--Component Development

Since the subcontractors will be let at the end of Phase I, there are no Phase I component development activities.

3. 4230--Development Program

The development program will consist of selection of materials and propellant, fabrication of prototype components, testing of these components individually and proof testing of the complete assembled rocket motors.

a. Propellant

(1) It is assumed that an existing basic propellant formulation will be suitable although slight changes in the additives may be necessary to provide the propellant characteristics needed to match the grain configuration and performance required. If possible, the formulation will be one or similar to one that has previously been tested for nuclear radiation effects. A laboratory test program shall be conducted to confirm the modified propellant formulation characteristics. Such tests will provide data on processability, density, tensile strength, elongation, elastic modulus, strand burning rate, etc.

(2) The propellant shall be subject to specified nuclear radiation (gamma and neutron) levels based on accelerated dosage rates for short periods of time. The radiation program will utilize the selected propellant in 5-inch diameter CP motors.

(3) The five-inch diameter CP motors containing the selected propellant shall be test fired in order to verify laboratory data (radiation effects, performance, mechanical and physical properties). 


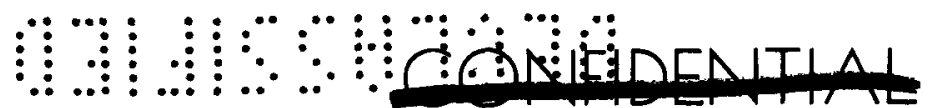

b. Rocket chamber and nozzle

(1) Tolerances and material thicknesses will be checked and the hardware X-rayed.

(2) The first three chambers will be hydrotested to burst. All following development chambers will be hydrotested to proof pressure.

(3) Nozzle hardware will be X-rayed and a structural test will be performed.

(4) Nozzle to chamber assembly tolerances will be checked.

c. Igniter

(1) "Open air" tests shall be performed to evaluate the ballistic performance of the igniter (pressure vs. time, delay times, gas ejection pattern or heat profile, power requirements).

(2) Igniters shall be subjected to shocks, vibration and temperature cycling and test fired.

(3) The igniter design will be checked out with actual firings of test motors containing the selected propellant.

d. Rocket system tests

(1) A specified number of heavy walled prototype rockets shall be static fired for evaluation of the grain design, ignition characteristics and performance. The adequacy of the insulation, liner and pressure release boot (if any), and the errosion characteristics of the nozzle will also be evaluated. The rockets will be fired at ambient temperature.

(2) The external metal parts temperature profile will be determined for purposes of CIR equipment location and external insulation.

(3) A specified number of flight weight hardware motors shall be fired to evaluate the effects of basic environmental requirements as well as to provide additional data on performance, ignition characteristics, internal design characteristics, and nozzle characteristics. The test criteria are as follows:

(a) Temperature cycle - fire at high temperature

- fire at low temperature

- fire at ambient temperature

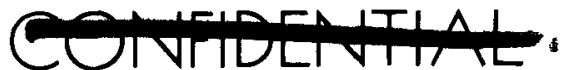




\section{- आIIII}

(b) Drop test at high and low temperature to satisfy specified handling characteristics

(c) Vibration test of dropped motors to be performed at specific grain ambient temperatures.

(d) Shock tests simulating the flight environment. These tests shall be performed on motors that include drop tested and shock tested motors.

(e) Altitude tests will be performed to obtain vacuum performance data and ignition system data.

At the conclusion of this limited number of development or proof tests of the finalized design, the rocket motor design will be ready for preflight qualification. While the reliability of the motor will not be computed on the basis of development tests, the degree of success in this part of the program can contribute to the overall confidence in the design.

4. 4240--Qualification Program

The Qualification Program will be designed to provide a motor qualified to the extent necessary for the initial flight test, with complete qualification being completed at a later time. The Qualification test program will consist of structural tests, tests relating to launch vehicle dynamics and tests relating to storage, shipping, and the operational environment. The effects on propulsion system design produced by these tests will be measured by performance evaluation and inspection of physical changes or damage. The following tests shall be conducted:

\section{a. Ingition system}

A specified number of igniters shall be fired to confirm that specification requirements are met.

(1) Drop Test - A specified number of igniters shall be subjected to MIL SPEC drop tests. After the test, the igniters need not function, but shall be safe to handle.

(2) Temperature-Humidity Test - A specified number of igniters shall be subjected to MIL SPEC temperature and humidity conditions to evaluate igniter seals during storage. After the test, the igniter will be tested to confirm performance and ignition requirements are met. 


\section{mine}

(3) Jolt and Jumble Tests - A specified number of igniters shall be subjected to MIL SPEC rough handling tests to assure safety under such conditions.

(4) Performance and Reproducibility - A specified number of igniters will be fired in open air tests and under vacuum conditions to establish performance data and standard deviations.

b. Rocket system

The igniter will be installed in all rockets to be tested except in such cases where a definite safety hazard exists. In these few cases, an inert igniter will be used for the test and replaced by a live igniter for subsequent rocket motor firing. A specified number of rockets will be tested to satisfy qualification program requirements. The following tests are anticipated:

(1) Weight - Each rocket shall be weighed before each test and after each firing.

(2) Statistical Firing and Thrust Alignment - A specified number of motors shall be fired at the high, low, and ambient temperature conditions. A specified number of these motors will be static fired at simulated altitude conditions to obtain statistical vacuum performance data.

(3) Thermal Cycling - A specified number of motors shall be subjected to three full temperature cycle limits established for space operation. Some portion of these rockets will be fired under maximum temperature gradient conditions. Another portion of these motors shall be subjected to a specific vibration environment (cycling and resonance). A smaller number of these same rockets shall be drop tested and then subjected to acceleration tests simulating the flight environment. The motors shall be inspected after each test and fired in relation to the combination of tests for various groups. In this manner, individual and cumulative effects can be evaluated. Acoustics tests simulating boost vehicle conditions will be performed on specified motors in these groups, as required.

(4) Rain, Fumidity, Salt Spray, Sand and Dust tests - A specified number of motors shall be subjected to MIL SPEC environmental tests after which they will be temperature conditioned and statically fired.
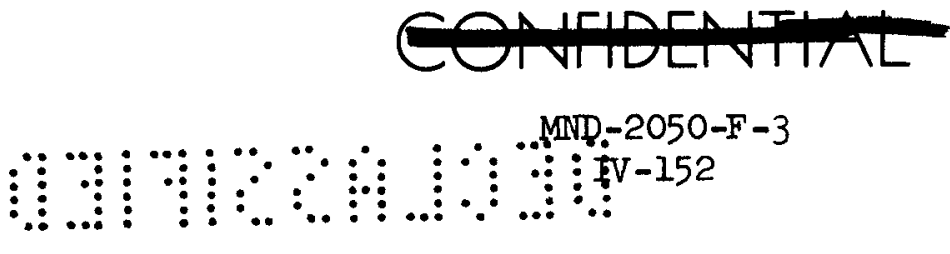
(5) Rough Road Test - A specified number of motors shall be tested under conditions which simulate handling and transportation conditions.

(6) Hydrostatic and Burst Tests - A specified number of rocket chamber assemblies shall be tested to destruction. Pressures causing initial yield and failure shall be recorded. Sections of destructed chambers shall be examined for proper metallurgical grain structure.

(7) Storage Tests - Concurrent with the basic qualification program, a specified number of complete rocket motors and igniters shall be stored. These motors will serve 3 distinct purposes:

(a) A portion of these motors shall be stored at elevated temperature for accelerated aging studies under ambient conditions.

(b) A portion of the motors shall be stored under simulated space storage conditions to determine the need for internal pressurization and the leakage characteristics of sealed motors.

(c) A certain number of the motors stored under the conditions of (b) above will also be subjected to a low dose rate of neutron radiation over extended storage periods. The motors will be removed and static fired at periodic intervals to determine the combined effects of long-term storage in an atomic radiation environment.

(8) Autoignition - A specified number of motors shall be exposed to a continuous heat source simulating the fireball of a booster explosion. The time required to ignite the propellant or otherwise destroy the rocket motor will be determined. This data in combination with anticipated durations of the rocket under such a booster malfunction condition, will be used to establish the degree of additional protection required for the motor.

5. 4250--Acceptance Tests

Acceptance tests shall be performed by Subcontractor Quality Control throughout the fabrication and assembly phases of production motor manufacture. Acceptance tests during this period will involve visual inspection of materials and components, propellant sampling, hardware hydrostatic tests, dimensional checks, ignition system electrical checks, tolerance checks, assembly checks and manufacturing inspections.

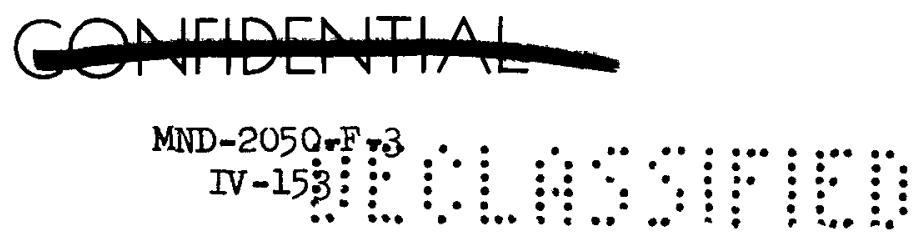




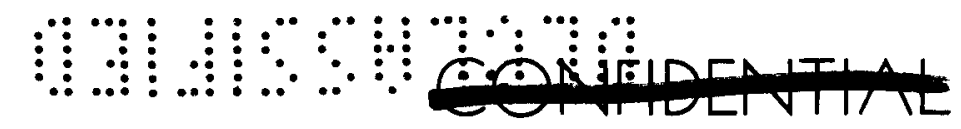

The assembled rocket motor shall be thoroughly visually inspected, followed by non-destructive testing (such as radiographic evaluation of the grain, liner and insulation for voids and apparations). Finally, the subcontractor shall demonstrate that specification limits for rocket internal pressurization leakage rates are not exceeded and shall submit computed performance characteristics based on propellant statistical control data (data on burning rate, pressure, etc., obtained from sampled propellant firings in small test motors).

a. Delivery of prototype

The rocket propulsion subcontractors shall fabricate and deliver five groups of rocket motors. The number of rockets per set and the utilization of these motors is as follows:

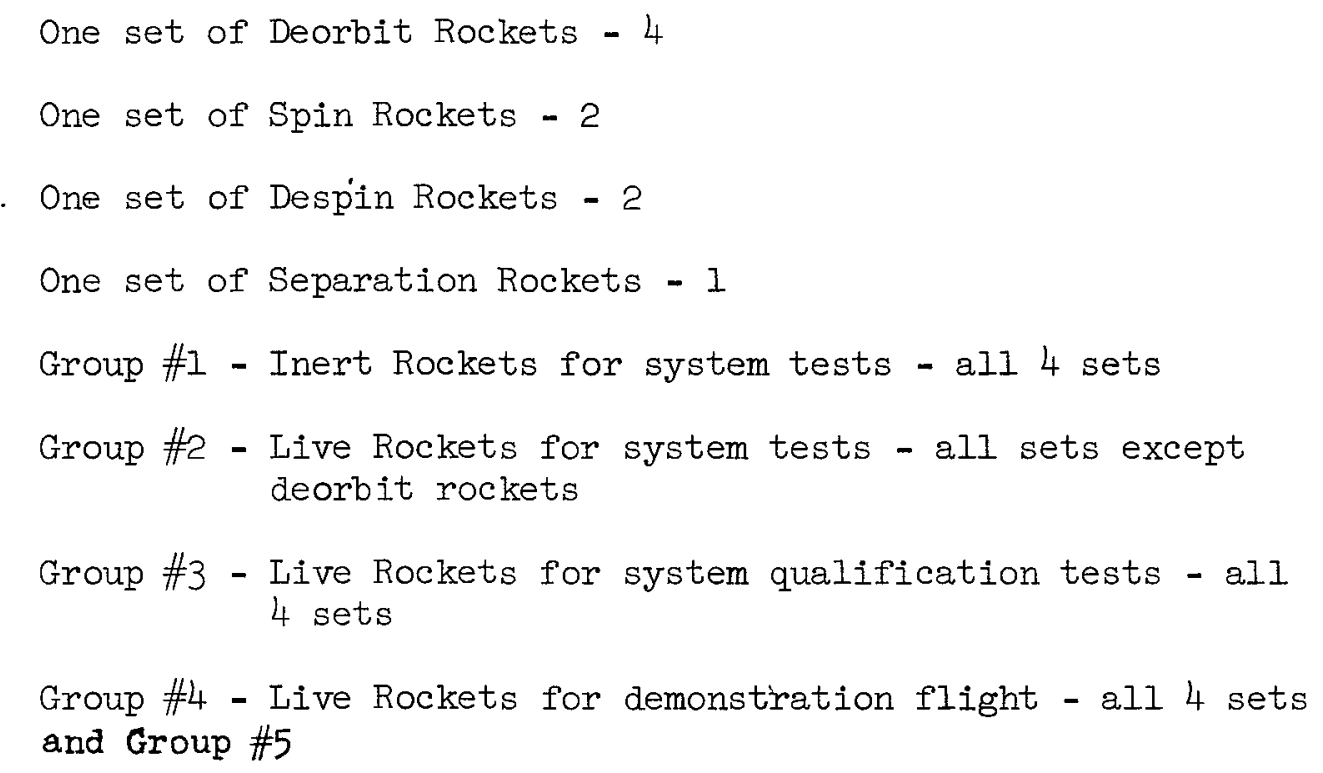

Group \#4 - Live Rockets for demonstration flight - all 4 sets and Group \#5

The subcontractor shall deliver Group \#1, Group \#2, and Group \#3 to the Systems Contractor. Group \#4 and Group \#5 rocket motors will be shipped directly to the launch facility.

\section{Flight article acceptance tests}

Acceptance testing of the flight articles will be identical to that for the prototype system flight units (described in Section 4250).

\section{c. Flight articles delivery}

The rocket propulsion subcontractor shall fabricate and deliver seven sets of each type of rocket motor (the term "set" is defined in Section 4250). These rocket motors will all be live units and will be shipped directly to the launch facility.
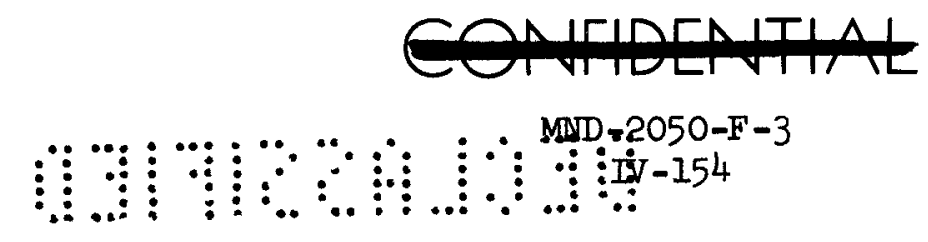


\section{4300--ORDNANCE SYSTEM}

The development and qualification program discussed herein is applicable to the ordnance devices and electrical components required to sequence and execute separation of the $R / B-C I R$ from the spacecraft, ignition of all rockets, and separation of the $R / B$ from the $C I R$.

The ordnance devices will be integrated into a single subsystem that must perform 6 separate functions. Since the various ordnance devices must, of necessity, be located at widely separated positions in the CIR, packaging of the system must be accomplished by the CIR systems contractor. The ordnance network and its operational characteristics can be developed and tested by a subcontractor.

The basic ordnance system network development shall be subcontracted as a single package. The subcontractor shall be responsible for integration of the ordnance devices into an electrical network, including sequencing equipment. The subcontractor interfaces will be with the electrical power system and the propulsion system igniters, the latter being provided by the propulsion system subcontractor.

The ordnance system subcontractor shall make or buy the ordnance devices based on a Specification generated by the CIR contractor, develop the complete electrical system and qualify the entire system. The CIR contractor shaII provide the CIR electrical wiring required to install the ordnance system in the CIR. Close coordination between the Ordnance System subcontractor and the CIR contractor is essential to assure compatibility between installation electrical wiring requirements and ordnance system electrical characteristics.

Subcontractor breadboards and test articles shall utilize CIR contractor specified wiring. follows:

Existing ordnance system devices of the type required are as

(1) Pin Puller - hi-shear Corporation - Pt. No. SP 1200

(2) Clamp Separator - hi-shear Corporation - Pt. No. SC 1002-6

(3) Initiating Command Module (S \& A) - hi-shear Corporation Pt. No. HE 350

(4) Pyro Switches - Atlas Corporation

(5) Solid State Switches - Used on Titan III

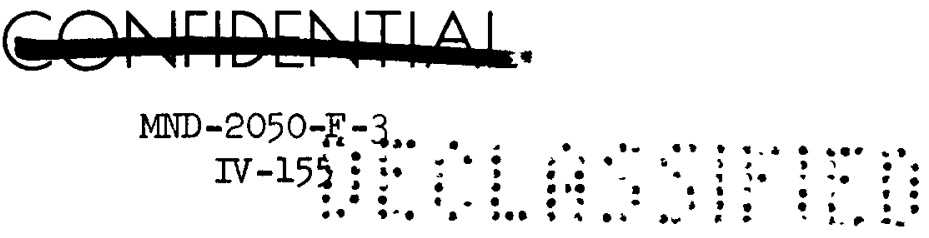




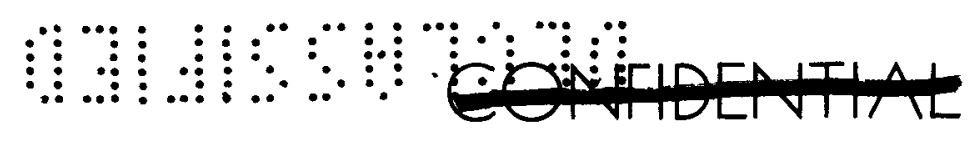

The status of these components shall be compared with the ordnance system specification requirements and the development program described herein modified, as required.

The ordnance subsystem will consist of one pin puller, two band separators, six delay devices for sequential operation, twelve safe arm components and twelve solid state switching networks. Of these component items only the twelve solid state switching devices are yet to be developed items. These switching devices will be fabricated with semiconductors and will become a black box installation item. All of the other components that have been mentioned as part of the ordnance subsystem will be procured by the subcontractor. Manufacturing effort will, therefore, be reduced to mounting detail fabrication and wire harness fabrication. These required mounting details and wire harnesses will be fabricated in accordance with standard type manufacturing techniques.

In order to ensure that the reliability requirements for the system will be met, Quality will monitor the development and qualification test programs at the subcontractors' plants in accordance with Engineering prepared Test Specifications. Source inspection of each shipment of rockets and ordnance subsystems will be performed prior to leaving the subcontractors' plants. This will be in accordance with a Martin prepared contractor acceptance plan (CAP) that lists the verification, documentation review that will be performed by an inspector. It will include:

(1) A review of the subcontractor's in-process and assembly inspection results.

(2) A review of the ordnance component and subsystem test results. 1. 4310--Design and Analysis

The CIR contractor shall conduct analyses to establish ordnance system requirements in terms of functions, sequencing and activation time. A specification shall be prepared which will reflect one set of integrated requirements common to the electrical power system, the propulsion ignition system and installation.

Following AEC approval of the Specification, subcontractor bids will be solicited. Evaluation of proposals will result in subcontractor selection. The subcontractor shall perform a detail design study and select specific ordnance devices, although it is intended to specify qualified designs currently in service wherever possible. This design study shall incorporate installation data provided by the CIR contractor.
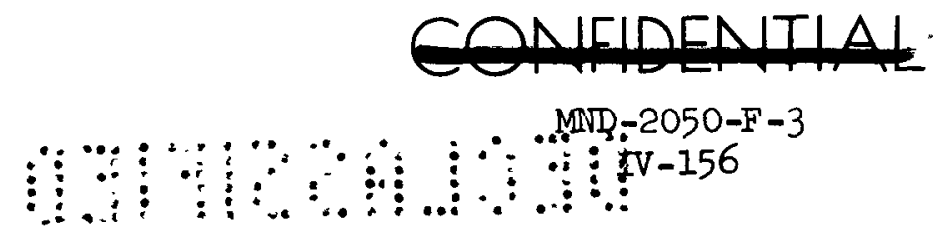


\section{(4)}

The recommended ordnance system design shall be submitted to the CIR contractor for approval.

The CIR contractor shall maintain an ordnance system engineering group including ordnance engineers, electrical engineers and installation engineers. The ordnance engineers shall perform the following functions :

(1) Generate the ordnance system specification.

(2) Provide liaison (coordination) between the CIR contractor, the subcontractor, the AEC and other pertinent Government agencies.

(3) Represent the CIR contractor during critical system or component tests.

(4) Maintain documentation on the entire subsystem development and qualification program.

(5) Evaluate subcontractor test reports, progress reports, etc.

(6) Provide flight test support at the launch site.

2. 4320--Component Development

a. Ordnance devices

Selected ordnance devices shall be tested individually against specification requirements (performance, environmental and electrical characteristics). Statistical analysis (Bruceton Tests) will be conducted on all initiators for all fire-no fire conditions, as required. The components to be tested or have their characteristics verified are:

(1) Initiators for igniters, separation clamps and pin puller

(2) Time Delay (gas pressurized type)

(3) Initiator Command Module (safe-arm function)

(4) Pin Puller

(5) Clamp Separator

(6) Sequence Controller

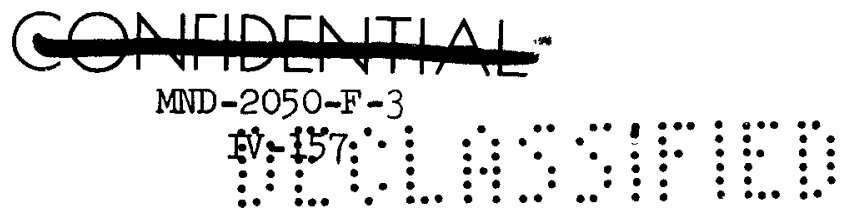




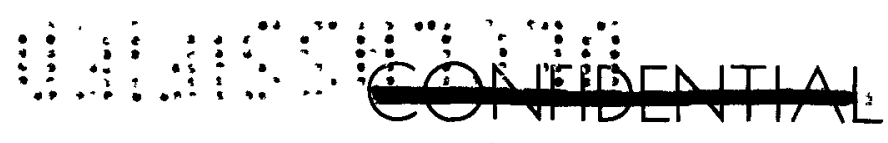

b. Switches

The solid state switches will be based on a design for the Titan III program. Performance will be verified against the Specification requirements and additional testing will be performed, as required.

\section{4330--Subsystem Development}

The entire ordnance subsystem shall be breadboarded and operated repeatedly with ordnance simulators in the circuit. Circuit parameters and sequencing parameters will be measured under environmental conditions (vibration, shock, humidity, vacuum, etc.) required by the specification. Wiring will be identical to that to be used in the CIR. Reliability and reproductibility will be determined as will standard deviations. Functional operation of the sequencer shall be demonstrated.

These tests shall be repeated using live ordnance devices including igniters. The adequacy of the checkout procedures will be evaluated. sources.

The circuit shall be tested for no-fire under directed RF energy

At the conclusion of these tests, the subsystem will be considered proof tested and ready for qualification.

4. $4340--Q u a l i f i c a t i o n$ Program

A specified number of complete subsystem tests shall be performed on a developed subsystem configuration. During these tests, statistical data shall be obtained and evaluated for specified environmental conditions-singly and in specific combinations. Performance, safety, reliability and reproducibility shall be demonstrated. Fifty to one hundred subsystem tests are anticipated to be required to satisfy qualification requirements.

\section{4350--Acceptance Tests}

The ordnance subsystem subcontractor shall test $20 \%$ ( $10 \%$ if device previously qualified) of the ordnance item lot, for each ordnance device used in the subsystem. The types of acceptance tests to be performed or demonstrated are:
(1) Workmanship
(2) Weight
(3) Attachment fittings (if applicable) 
(4) Dimension verification

(5) Electrical parameters (resistance, continuity, no fire current, etc.)

(6) Vibration (non-operating)

(7) Static discharge

(8) Operation (lot testing)

a. Delivery

The Ordnance System subcontractor shall deliver five Ordnance subsystems, less CIR wiring, to the CIR contractor. These systems will include the following items:

(1) 1 sequencer

(2) 12 solid state switching devices

(3) 12 initiator command modules

(4) 6 gas operated delay devices

(5) 2 clamp separators

(6) 1 pin puller

(7) 1 associated set of wiring, exclusive of CIR wiring used to bridge the spaces between major components of the ordnance subsystem

Two of the subsystems shall be used in CIR system tests and two subsystems shall be incorporated in the Demonstration flight vehicle and its back-up vehicle. The fifth system will be utilized for tests in which complete simulation of the CIR is required.

6. 4360--Flight System Acceptance Tests

Acceptance testing of the Phase IV flight articles will be identical to the prototype subsystems (described in Section 4350) for the Demonstration flight. 


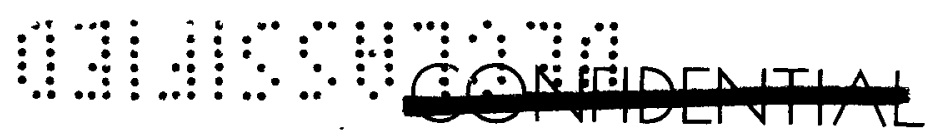

a. Delivery

The Ordnance System subcontractor shall deliver seven Ordnance subsystems, less CIR wiring, to the CIR contractor. The systems will be identical to those delivered for the Demonstration flight. 


\section{4400.--ELECTRICAL/ELECTRONIC SUBSYSTEM}

The development and qualification program described herein is required to establish a reliable electrical/electronics subsystem capable of providing adequate power and communication channels to the airborne system.

The Systems contractor will be responsible for the acquisition and integration of existing, proven basic equipment into an airborne electrical/electronic subsystem that will operate reliably in the unique environment imposed by the $R / B-C I R$ system. Furthermore, the airborne system must be integrated with one of the existing ground based systems operated by the Government.

The Systems contractor will first evaluate and select a ground based communication system (Air Force SGLS or NASA USBS) based on the anticipated operational characteristics, performance capabilities and environmental conditions associated with the CRONUS and the spacecraft to which it potentially applies. The major basic equipment; i.e., s-band and C-band systems will be procured. However, telemetry requirements, power supply requirements and checkout requirements will be analyzed, and new and/or existing equipment specified accordingly. The analysis will include all vehicle subsystems for which power and measurement data will be required. Specifications for qualification of new equipment will be prepared as required.

The operational sequence of events will be established through coordination of the requirements, capabilities and limitations imposed by the CRONUS System Integrator, the launch vehicle manufacturer, the spacecraft manufacturer and Range Safety. A data management plan for flight evaluation will also be developed.

Subsystem performance and qualification tests will be conducted prior to the first flight and will require integration and calibration of the entire airborne and ground based electrical/electronic systems. The telemetry system will be reevaluated and modified as required, after the first flight.

It is also proposed to analyze and develop a unique vehicle attitude and spinning vehicle control concept during Phase II. While this capability is applicable only to a PU-238 system (circular orbit recall capability), a test of this concept will be devised for inclusion in the current flight test program.

The major portion of the electric/electronics subsystem is made up of purchased black box items. Manufacturing effort in this system will be mainly concerned with the interface wiring that will tie the battery,

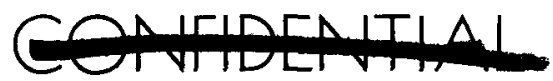

MND-2050-F-3

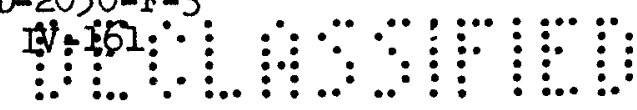




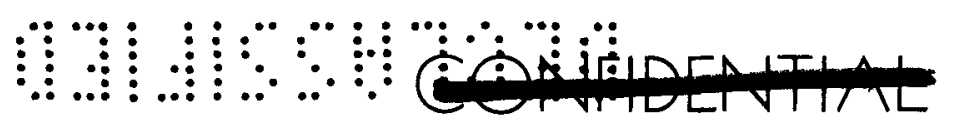

communications, telemetering and command units, and instrumentation together. The instrumentation area is of primary concern to manufacturing inasmuch as there are 256 channels which include microphones, sensors, and accelerometers. A number of mounting detail type brackets will be fabricated and installed within the CIR package for the purpose of mounting these purchased items. A quantity of four turnstile antennas will be fabricated in accordance with Engineering specifications. Fabrication effort on these antennas will consist of conventional type techniques that are standard for this type of hardware. Harness boards will be manufactured for the fabrication effort involved in the wiring harness requirements. All of the prefabricated harnesses and mounting brackets will be assembled within the CIR package in the $1 / 2$ inal assembly position fixture.

Quality does not anticipate any problems in this area. A decision will be made during the design effort as to whether the purchased components will be source inspected or in-house inspected but whichever decision is made, the inspector will have a document (CAP or RAP) which will direct him in the proper acceptance of components.

1. 4410--Design And Analysis

The Electrical/Electronics Subsystem of the CIR will be required to provide TTC services to both the CIR and R/B. It will further supply the command interface with the TIIIC Malfunction Detection System and also with the satellite vehicle. For purposes of the feasibility study, both the Air Force SGIS system and the NASA USBS system were considered adequate for these functions. Equivalent systems may be composed of individual units from other manufacturers. As with the $\mathrm{C}$-band beacon, the $\mathrm{S}$-band system is expected to be procured as a fully qualified off the shelf unit. In particular, USBS is being qualified as part of the Apollo Program and SGLS as part of MOL. Design and analysis is required to specify in detail requirements for the CIRS. These problems include link calculations, tracking accuracy, acquisition probabilities, ionization sheath and skin tracking capabilities, and ground coverage definition. Environmental requirements must be specified and telemetry lists and functions compiled for electronic systems as well as ordnance and structure. The prototype vehicle will be instrumented for failure in the sense that diagnostic telemetry will be incorporated in the space otherwise to be occupied by the RTG and a fast playback system will be implemented.

The power supply must be defined. In particular, growth into a single vehicular system will require investigation of high temperature power sources as backup power for the reentry phase. These may include other types of batteries such as liquid sodium/sulfur and lithium/chlorine systems. The command programmer must be specified and included in
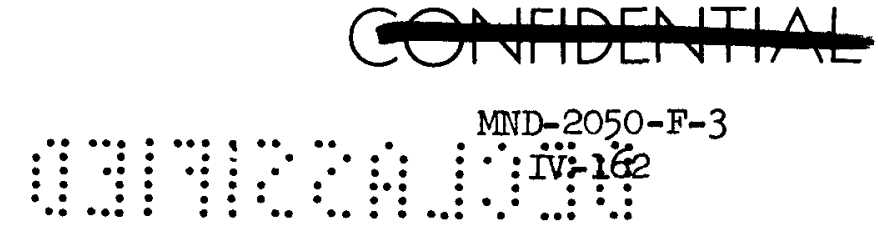
definition of the S-band system.

Automatic checkout equipment is planned to consist of stimulus generating modules controlled and monitored by a sequential processor such as the Telemetrics 670 . Where these modules are not available as part of procured equipment, they will be designed and manufactured by Martin. Ordnance and other systems (including the RB/RTG) will have their functions integrated into an overall automatic checkout program which will serve for prelaunch checkout of the entire CRONUS system. These activities will lead to a coordinated design criteria which will form the basis for procurement specifications. The concluding activity of Phase I will consist of "make-or-buy" decisions and requests for bids from qualified vendors for major items of equipment. Response will be evaluated and suppliers selected in readiness for contract awaras at the beginning of Phase II.

\section{4420--Component Development}

It is desirable to develop a technique for attitude determination of a spinning vehicle from the ground. This attitude determination may enable the deorbit of the $\mathrm{R} / \mathrm{B}$ after extremely long time periods since the spinning vehicle may be precessed to a proper orientation for deorbit by ground command without requirement for low reliability instrumentation. Such a system could be mechanized utilizing S-band CW doppler techniques. A minimum of three antennas (diode corner reflectors) may be used to return the up link signal with the two way doppler shift. Alternatively, the frequency of the up link may be measured within the satellite and transmitted to the ground via the telemetry link. In either case, the antennas on the satellite must be identifiable since they will alternately rotate into the beam as the vehicle spins. The sequence of rotation and the doppler shift identified with each antenna may then be utilized to establish vehicle attitude with respect to the illuminating beam and therefore relative to the earth. Ambiguous situations such as head on spin may be avoided by use of more than three antennas providing omnidirectional coverage.

This system may be investigated in the analysis phase of CRONus by generating a digital program which will be utilized in real time processing of the signals. Physical verification of feasibility will be accomplished by utilization of the Martin antenna range with a rotatable model and S-band doppler link. The model will be placed on an X-Y mount capable of rotation at rates up to three revolutions per second about the spin axis. The model will simulate the CIR/RB system in respect to shielding and antenna ground plane, thereby serving as an antenna. development tool for the prototype system. Experiments will be performed with respect to doppler shift determination and threshold noise levels which may be expected to set a limit to the accuracy with which attitude

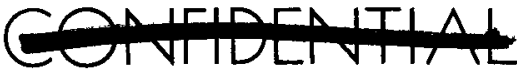

MND-2050-F-3

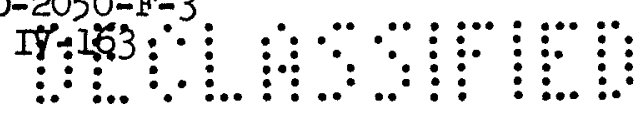




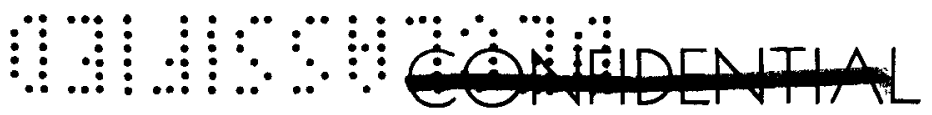

can be determined. The digital program will be directly applicable to the mechanization of the SGLS ground station computer. The experimental work will establish the modifications required to SGLS signal processing for accomplishment of the attitude determination objective. Antenna patterns generated will provide experimental data for final antenna design under CP 4430.

There is a further requirement for capability of attitude control of a spinning vehicle which may have been separated from its host satellite in orbit. Such a system should be capable of reorienting the vehicle for deorbit within a reasonable time. Power available from an operational RTG may be presumed and the earth's magnetic field operating upon a coil wrapped around the satellite for generation of a magnetic moment provides control forces. Such a system has been utilized reliably with the TIROS meterological satellite for control of its spin axis with respect to the celestial sphere. In conjunction with passive (or active) attitude determination via S-band tracking, a reliable system may be developed for deorbit of the plutonium fuel capsule over a five year period.

One further development item may be considered. Space systems containing RTG power supplies as their primary source will inevitably be saddled with providing an alternate backup power source. The only convenient answer to this problem is battery power supplies which, however, are unreliable in themselves. In particular, the thermal environment generated by the RTG precludes use of the more common cells (lead-acid, Ni-Cd, Ag-Zn) without insulation. Some of the more unusual combinations such as LiO-Cl which are being developed by Gulton and the liquid sodium-sulphur type recently announced by Ford offer promise of high temperature operation without degradation. An investigation of these types of batteries will be carried out to determine their suitability for space application.

\section{4430--Component And Subsystem Development Phase II}

The various design and analysis effort of Phase I will have produced instrumentation requirements for the RTG/RB systems as well as those of the CIR system. This will include measurements to monitor performance, status of systems and verification of significant events during the mission. During Phase II, selection and procurement of end instruments for the prototype design must be accomplished. The design of signal conditioning modules for $\mathrm{S}$-band equipment must be carried out in conjunction with the subcontractor. Instrumentation component development will include qualification of end instruments to the environmental specifications of the operational system as well as to the limits of fallure tests designated for each subsystem and component. Thus, the design effort will comprise selection of space proved hardware which is
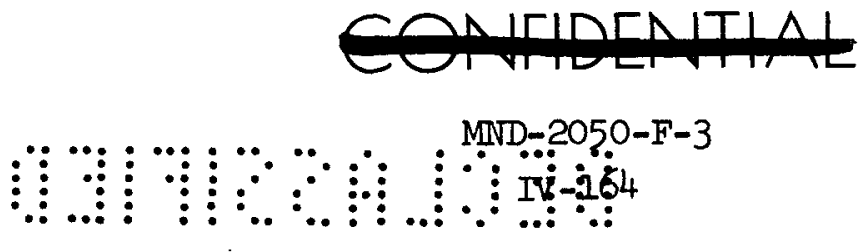
also capable of withstanding radiation and thermal conditions peculiar to the RTG. Coordination of the entire test and qualification program into a single measurements program for the entire project will be accomplished. Interconnecting wiring for these instruments will also be designed for the prototype vehicle as well as for each component and subsystem test performed. Breadboards of each system will precede final design.

The programmer for the CIRS system must also be designed in conjunction with the S-band subcontractor. MDS requirements will be transmitted to the booster contractor and coordinated with the booster guidance vendor. An operational sequence of events coordinated with booster and $\mathrm{T} / \mathrm{V}$ system contractors must be generated and cleared with the specific range for tracking and command coverage. Range user documents should be initated during this phase because of special safety requirements of RTG missions.

Another function which must be accomplished during this phase is coordination of a data management plan for flight test purposes. This will include definition of data processing required for each measurement to provide useful output for the prototype flight. Utilization of the Telemetrics Model 670 Telemetry Processor for this purpose will materially reduce the effort involved in generating these programs. The results of the antenna studies being accomplished under CP 4420 will be utilized in the final design and manufacture of S-band antennas and their interconnections. These units will undergo full component qualification tests and tests of the full S-band system conducted at the subsystem level. Further EMI/RFI tests will be conducted with the entire system including operation in conjunction with the C-band beacon. Acceptance tests, installation, manufacturing and checkout will be required for test systems and for the prototype.

4. $4440--$ Subsystem Qualification

Reevaluation of the telemetry system will be undertaken for operational flight vehicles. Experience gained in the development phase and in flight of the prototype vehicle will permit reduction of the number of measurements for housekeeping purposes. A priority rating for each measurement will be established with only those measurements necessary to assure a successful mission considered. At this point, the operational satellite vehicle shall have been defined and its command, tracking and telemetry capabilities established. It will then be possible to ascertain whether the TIC functions may be shifted to the satellite in whole or part, thereby reducing the modular capacity or eliminating telemetry within the CIRS. A simple programer, communications and tracking system may suffice for the operational vehicle.
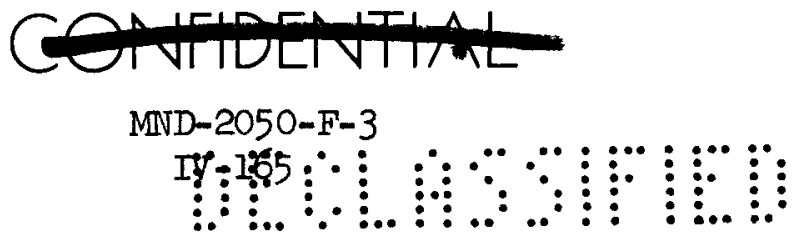


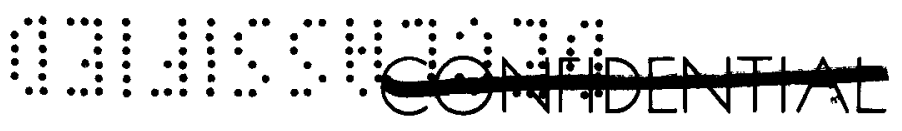

At this point also, an evaluation of passive attitude control will have established its feasibility for long time control of deorbit.

Design additions for such a system include the coils required to establish a magnetic moment and corner reflector antennas necessary for shifting the signals in an unidentifiable manner.

The activities for the prototype and flight hardware have been covered in Section 4100. 


\section{E. 4500--STRUCTURE SUBSYSTEM}

The objectives of this effort are to develop a structural configuration compatible with all environmental factors associated with the operational life of the complete system and to verify its integrity under the most severe predicted environmental exposures.

Development and verification of the functional capability of the separation spin bearing in a space environment must be accomplished early in the program. Similarly the design of the roller/track separation system must be evaluated in the early phases.

The structure subsystem design objectives will be reflected in a set of criteria and specifications which will be generated at the initiation of the program. Studies will be performed to determine combinations of material and structural configuration which will meet the design objectives most efficiently. Where applicable, development testing will be performed on a component as well as a subsystem level in order to define and resolve critical design problems. The final configuration will be exposed to a series of qualification tests which will represent critical combinations of environmental design factors.

The Controlled Intact Re-entry Structure will be fabricated in accordance with conventional fabrication practices. The configuration of the CIR details permits the use of conventional shop practices and facilities in conjunction with standard tools and special tools where required. Forming methods will utilize the hydro-press, slip rolls, brakes, and stretch form machines. Any required aluminum weldments will be accomplished in accordance with Martin Process P-55013 using certified welders.

\section{Main Frame}

The main frame will consist of a conventional aluminum frame interior with aluminum stringers exterior. The frame details will be located and clamped in a tree-type wood and masonite assembly fixture. Rivet holes will be laid out and drilled. The details will then be disassembled and holes deburred. Riveted subassemblies of stringers and reinforced gussets will be fabricated prior to final assembly and riveting. Support rings will be fabricated, clamped and riveted in place. A honeycomb instrument mounting shelf will be fabricated as a conventional honeycomb structure and will be bonded using a $250^{\circ}$ fahrenheit curing adhesive technique. The completed honeycomb instrument mounting shelf will then be riveted or bolted in place.

A second position assembly fixture will be utilized to hold the

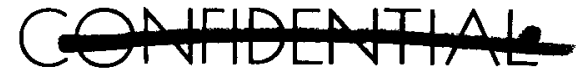

MND-2050-F-3

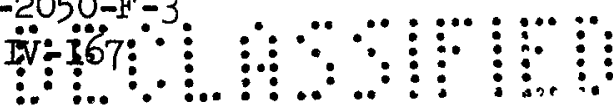




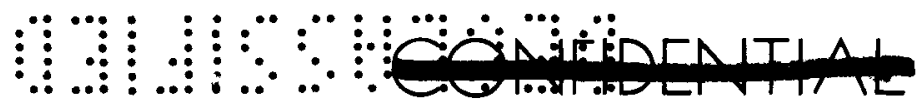

above fabricated subassembly. Mounting and support brackets will be located and clamped in place. Bolt holes will be drilled from pilot holes in the brackets and fixture drill plates. Upon completion of all drilling operations, the details will be disassembled and all holes deburred. Reassembly and bolting of the detail parts will then be accomplished.

\section{Propulsion Mounts}

Manufacturing effort required for the propulsion subsystem is limited to detail type manufacturing items such as angular bracket mounts with which to mount the four deorbit thrust rockets, the two despin rockets, and the two spin-up rockets to the exterior of the CIR package. Also, mounting provision details will be manufactured with which to mount the separation rocket on the track and carriage mechanism. This detail type manufacturing will be accomplished in accordance with standard conventional type fabrication practices that exist within our manufacturing sections. These details will be completely predrilled to engineering specifications so that assembly of these fabricated articles will be a standard process. The brackets for mounting the deorbit rockets must have provisions for adjustment of the deorbit rocket alignment. The same is true for the spin and despin rockets. All mounting brackets will be assembled on the final assembly position fixture. Wire harness fabrication will be prefabricated on wire harness boards and installed within the CIR package for propulsion subsystem connections.

\section{Heat Shield Support and Hold Down Fingers}

The heat shield support will be fabricated in three individual ring assemblies. The honeycomb support panel will consist of premolded and cured $2 \mathrm{ply}$ phenolic fiberglass faces bonded to a $3 / 16$ cell 5.5\# density honeycomb core using the HT-424 adhesive system. A silicon rubber seal will be bonded to the honeycomb support panel which will receive the heat shield assembly. The bolting assembly operation will take place prior to the bonding of the silicon rubber seal.

The silicon support cushion will be fabricated from premolded corner segments and sheet stock.

A quantity of eight hold down fingers will be fabricated as aluminum details and bolted to the exterior portion of the heat shield support panel. Cementable teflon pads will be cut to suit for cementing to the hold down fingers.

The retention band will be fabricated out of stainless steel sheet material. Two splice fittings will be manufactured with which to attach

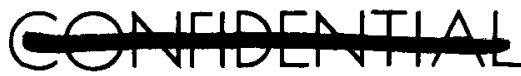


the pyrotechnic release mechanism.

The track assembly will be fabricated in three separate "U" channel details. Four separation track struts will be fabricated out of aluminum material and attached to the track assembly.

The carriage assembly will consist of three individual pieces of aluminum channel which will be formed to correspond to the required contour. A set of rollers will be attached to the carriage frame.

A spin bearing will be purchased and installed within the carriage assembly and attached to the CIR package.

\section{Tools}

The following tools will be required for manufacturing the structure subsystem:

(1) Forming and stretch blocks for heat shield support assembly.

(2) Forming and bonding tool for heat shield support honeycomb fabrication.

(3) Forming block for gusset development within heat shield support.

(4) Drill templates for latch fingers and hinges.

(5) Forming blocks for stringer development.

(6) Tooling for rocket bracket mounting.

(7) Christmas tree type assembly fixture for stringers, frame, and skin fabrication.

(8) Final assembly fixture for wire harness and black box installation.

(9) Forming blocks for carriage development.

(10) Assembly fixture for carriage.

Quality will review and sign all tooling drawings verifying that they have the necessary quality assurance provisions incorporated in them to perform the task for which they were designed. The first part fabricated from each tool will be inspected against the engineering requirements. If all requirements are met, the tools will be approved

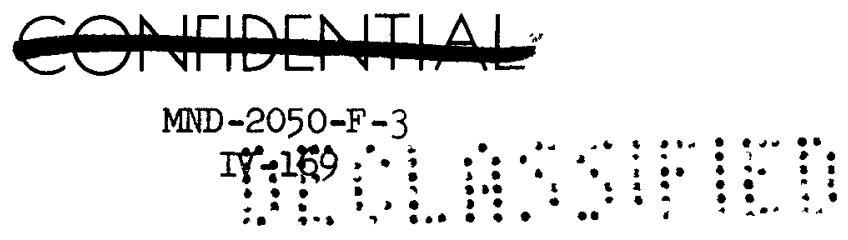




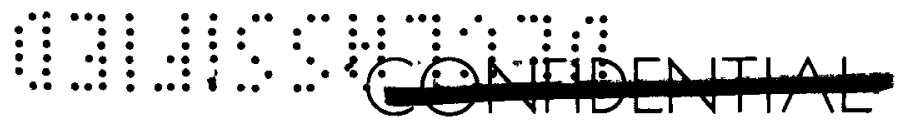

by Quality and subsequent parts will be allowed to be fabricated. If the parts are rejected, no further parts will be fabricated until the tools have been satisfactorily reworked.

\section{Testing}

Manufacturing will perform those tests deemed necessary on the subsystem level. These tests will be accomplished in accordance with engineering specifications during the fabrication cycle sequence. Quality will approve and monitor all test procedures required for adequate testing of the Re-entry System. Manufacturing will provide the necessary test procedures and tools that will be required to meet the engineering specifications.

Quality control of the structure is not expected to be a problem since this subsystem is straight forward type of fabrication with which Quality has had considerable experience.

Quality will in-plant acceptance inspect all phenolicfibre glass silicon rubber, adhesive film and honeycomb used in the fabrication of the instrumentation shelf and heat shield support. Receiving inspection plans (RAP's) will be prepared by Quality to be used by the inspector for acceptance purposes. These plans will include:

(1) Review of the vendors certificate of compliance and test results if required.

(2) Performance of dimensional integrity checks.

(3) Performance of chemistry and physical tests in the Quality Laboratories.

(4) Workmanship evaluation.

1. 4510--Design and Analysis

The design and development of the structure subsystem will be based upon a coordinated set of criteria which will define the performance requirements of the subsystem and the imposed environmental factors. A set of baseline criteria will be established immediately upon the inception of the program and will subsequently be developed and modified as the design evolves. Parametric studies will be performed to enable the selection of the materials and structural concepts which will perform most efficiently. Detailed analysis will be performed on the most promising design concepts in order to determine the single best design. Subsequently, the selected design will be optimized in order to meet all design criteria.
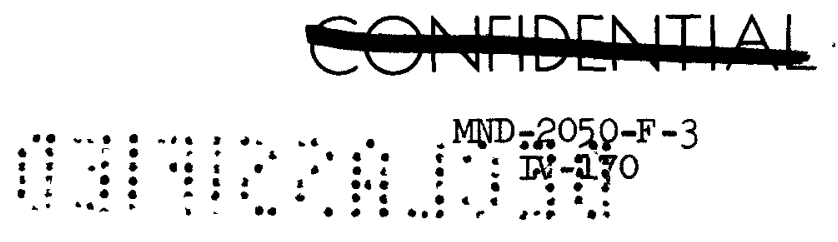
2. 4520--Component Development Tests

Structural Material Tests Material selection for structural hardware and mechanical parts may require early development test to determine material stress loads, elestic body effects under temperature variations, and effective coatings on operating surfaces. The critical operating surface areas include the spin bearing assembly, the separation carriage and track, and the latch fingers and retention band.

Tests to determine bearing friction forces in the spin bearing and track roller bearings must be accomplished early in the development effort since these values will be involved in selecting the thrust levels of the spin up and separation rockets. The film coatings on these same items must be subjected to environmental tests of various types to determine their life potential under the anticipated conditions. Though no serious problems are expected in this area, rates of degradation must be established so that coating thicknesses can be determined.

Although the final spin bearing and track roller design will be expected to function without binding, tests must be performed on the hardware while under load and while exposed to the simulated expected environment to establish that proper operation will occur.

3. 4530--Component and Subsystem Development

CIR Structural Test Vehicle Development Tests

A complete CIR structural unit will be provided with interface structural configurations for both spacecraft and re-entry body. All components not considered part of the structural support in the CIR can be simulated for mass and CG with the designed mounting connections utilized. The mass and CG of the Re-entry Body will be simulated as part of the structural interface. Structural development tests of the following types will be performed:

(I) Static load tests on structural members and mountings.

(2) Shock tests simulating launch shock mode and separation shock. (Spin, Despin, and Retro-thrust firing shocks will be verified during separation and firing tests).

(3) Vibration tests simulating launch and acoustic environments to margin of safety limits.
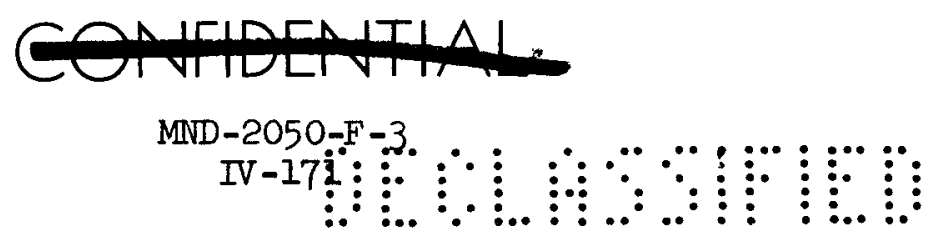


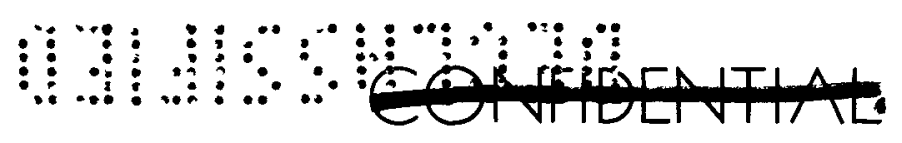

4. 4540--Subsystem Qualification Articles and Tests

Full scale static load, shock, vibration and acoustic tests will be performed on the complete structure subsystem article in order to verify the adequacy of the design. The test articles will be complete including actual equipment items or simulated masses.

5. 4550--Prototype and Flight Article Subsystem Assembly

The number of subsystems to be built for the test and flight hardware has been discussed (Section 4020). The acceptance tests for this subsystem are considered to be portions of the system tests. 


\begin{tabular}{|c|c|c|c|c|c|c|}
\hline MISSION PHASES & COUNTDOWN & IAUNCH & ORBIT INJECTION & SPACE FILGHT OPERATIONS & $\begin{array}{l}\text { CIR/SPACECRAFT } \\
\text { SEPARATION }\end{array}$ & $\begin{array}{l}\text { RTG-RB/CIR } \\
\text { SEPARATION }\end{array}$ \\
\hline EISION & $\begin{array}{l}\text { Temperature } \\
\text { Nuclear Loading } \\
\text { RFI }\end{array}$ & $\begin{array}{l}\text { Vibration } \\
\text { Shock } \\
\text { Destruct Possibility }\end{array}$ & $\begin{array}{l}\text { Shock } \\
\text { Temperature } \\
\text { Vacuum }\end{array}$ & $\begin{array}{l}\text { Temperature } \\
\text { Vacuum } \\
\text { Radiation } \\
\text { Particle Bombardment }\end{array}$ & $\begin{array}{l}\text { Shock } \\
\text { Iaterial Ácceleration } \\
\text { Spinning }\end{array}$ & Shock \\
\hline $\begin{array}{r}\text { PROPULSION } \\
\text { SUBSYSTEM }\end{array}$ & $\begin{array}{l}\text { Continuity Loop } \\
\text { Verification }\end{array}$ & $\begin{array}{l}\text { Maintain Thrust Rockets } \\
\text { and Circuit Integrity }\end{array}$ & $\begin{array}{l}\text { Maintain Thrust Rockets } \\
\text { and Circuit Integrity }\end{array}$ & $\begin{array}{l}\text { No Requirement Except } \\
\text { No Fire }\end{array}$ & $\begin{array}{l}\text { Spin Motor Operation } \\
\text { Separation Motor Firing } \\
\text { Retrothrust Firing } \\
\text { Despin Operation } \\
\text { Precision Sequences }\end{array}$ & No Requirement \\
\hline $\begin{array}{l}\text { ORDNANCE } \\
\text { SUBSYSTEM }\end{array}$ & $\begin{array}{l}\text { Continuity Checks } \\
\text { Arming }\end{array}$ & $\begin{array}{l}\text { No Fire } \\
\text { Maintain Firing } \\
\text { Capability }\end{array}$ & $\begin{array}{l}\text { No Fire } \\
\text { Maintain Firing } \\
\text { Capability }\end{array}$ & No Fire Protection & $\begin{array}{l}\text { Pin Puller Release } \\
\text { Interface Connector } \\
\text { Pyro Release } \\
\text { Propulsion Motor } \\
\text { Firing Charges }\end{array}$ & $\begin{array}{l}\text { Separation Band } \\
\text { Pyro Release }\end{array}$ \\
\hline $\begin{array}{l}\text { ELECTRIC/ELECTRONICS } \\
\text { SUBSYSTEM }\end{array}$ & $\begin{array}{l}\text { Power Distribution } \\
\text { Telemetry Performance } \\
\text { Command Verification } \\
\text { Instrumentation Output } \\
\text { Parameters } \\
\text { Malfunction Detection } \\
\text { Loops } \\
\end{array}$ & Telemetry Transmission & $\begin{array}{l}\text { Telemetry Transmission } \\
\text { Command Reception } \\
\text { Capability }\end{array}$ & \begin{tabular}{|} 
No Requirement Except \\
No Separation Signals
\end{tabular} & $\begin{array}{l}\text { Telemetry Transmission } \\
\text { Command Reception } \\
\text { Separation Sequences }\end{array}$ & Separation Sequence \\
\hline $\begin{array}{l}\text { STRUCTURE } \\
\text { SUBSYSTEM }\end{array}$ & $\begin{array}{l}\text { Final Alignments } \\
\text { Latch Mechanisms } \\
\text { Verified }\end{array}$ & $\begin{array}{l}\text { Maintain Structural } \\
\text { Integrity }\end{array}$ & $\begin{array}{l}\text { Maintain StructuraI } \\
\text { Integrity }\end{array}$ & $\begin{array}{l}\text { Particle Bombardment } \\
\text { Protection } \\
\text { Thermal Protection }\end{array}$ & $\begin{array}{l}\text { Release Mechanisms } \\
\text { Spin Bearing and Track } \\
\text { Operations } \\
\text { Shock Protection }\end{array}$ & $\begin{array}{l}\text { Release of Separation } \\
\text { Band, Holddown Fingers } \\
\text { and Electrical Connec- } \\
\text { tor } \\
\text { Separation Spring Force } \\
\text { Non-Reentry Interferenc } \\
\text { With RTG/RB. }\end{array}$ \\
\hline
\end{tabular}

Table $4000-1$

Controlled Intact Reentry System Requirements Vs. Major Mission Phases 


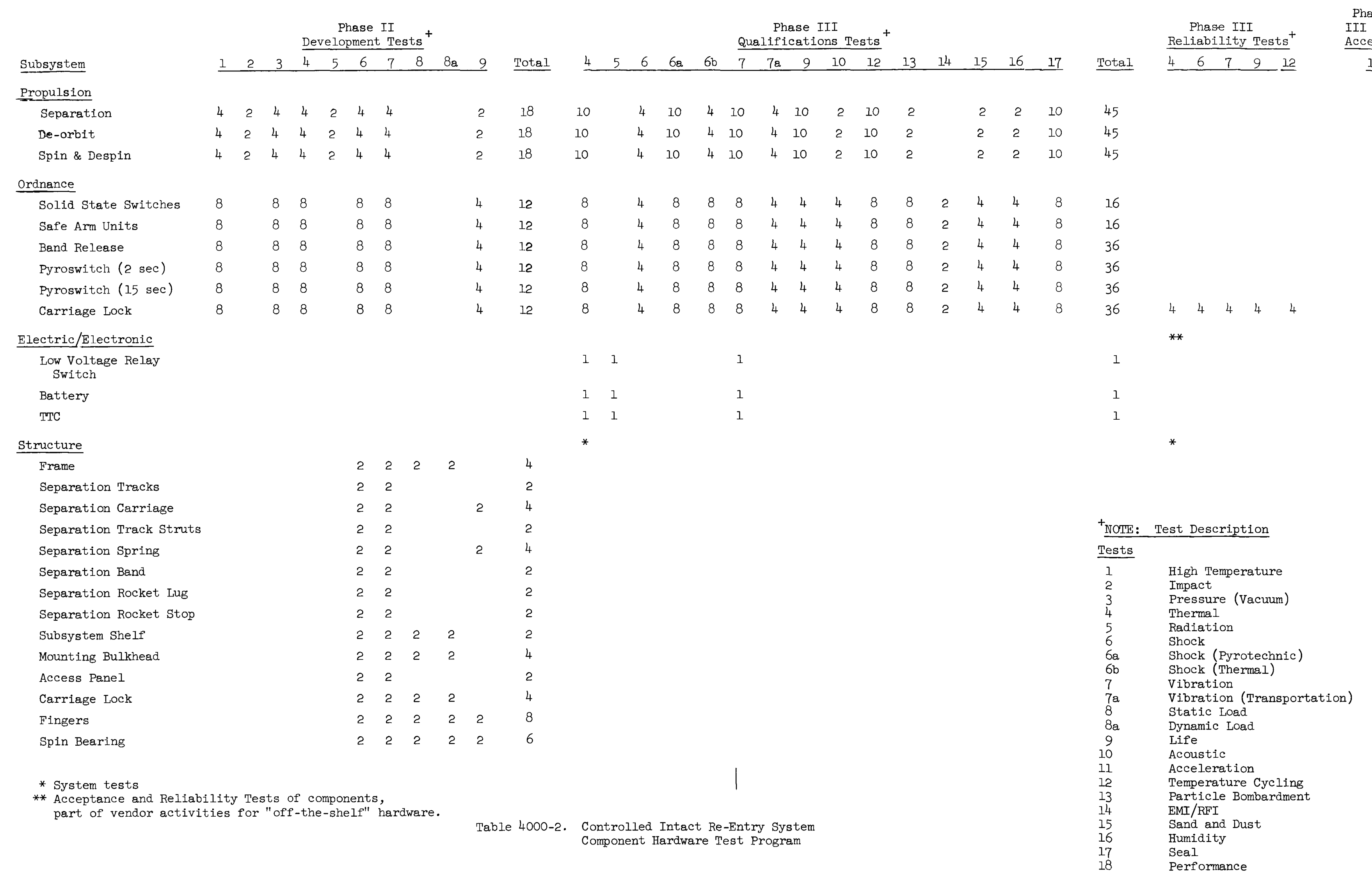

COIVIDETIATL 


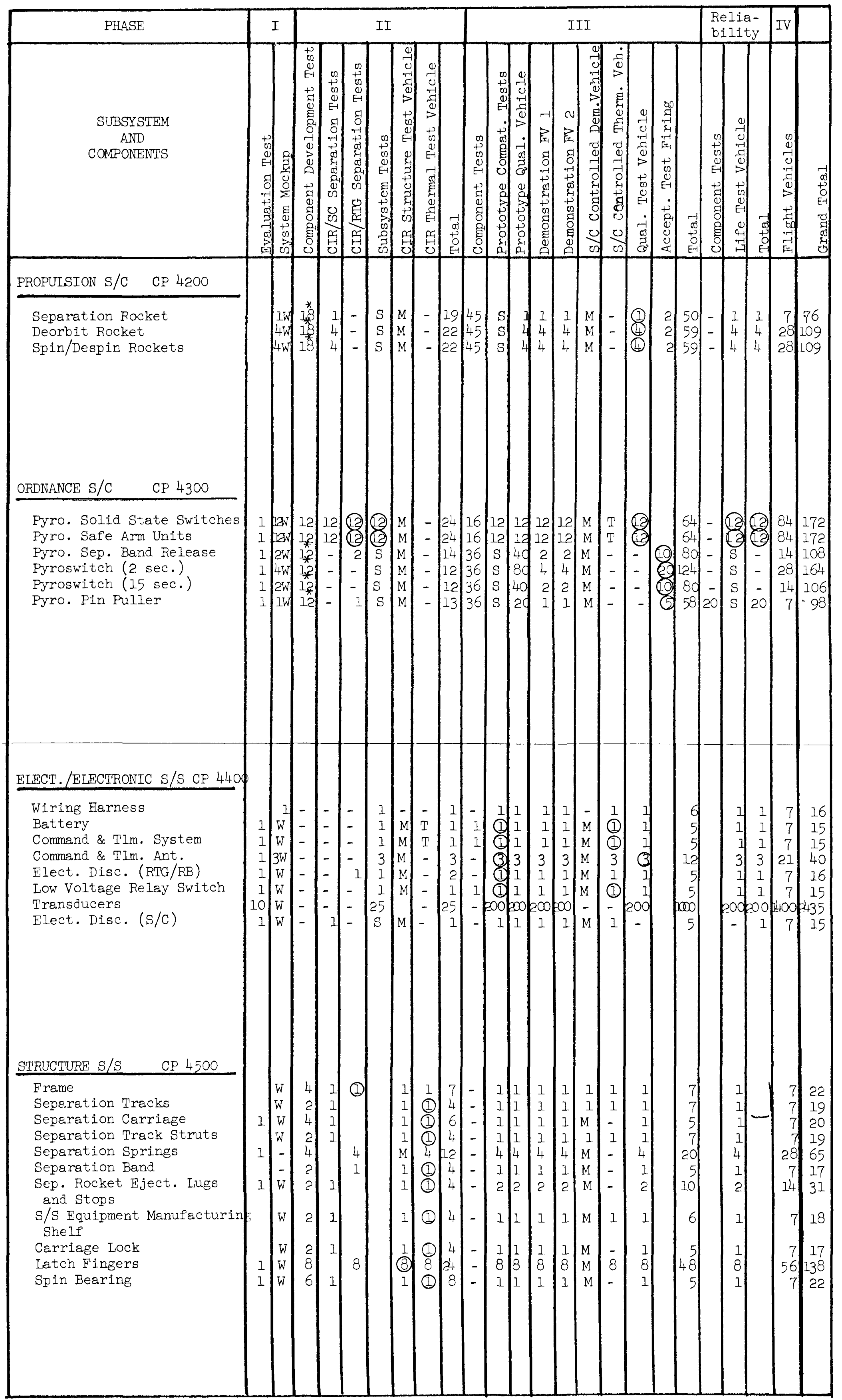

$\begin{array}{lll}\text { NOTES: } & \mathrm{S}=\text { Simulators } & W=\text { Wooden } \\ \mathrm{M}=\text { Mass Simulation } & *=\text { Part of Supplier Tests } \\ \mathrm{T}=\text { Thermal Simulation } & \end{array}$

Table 4000-3. CIR Hardware 


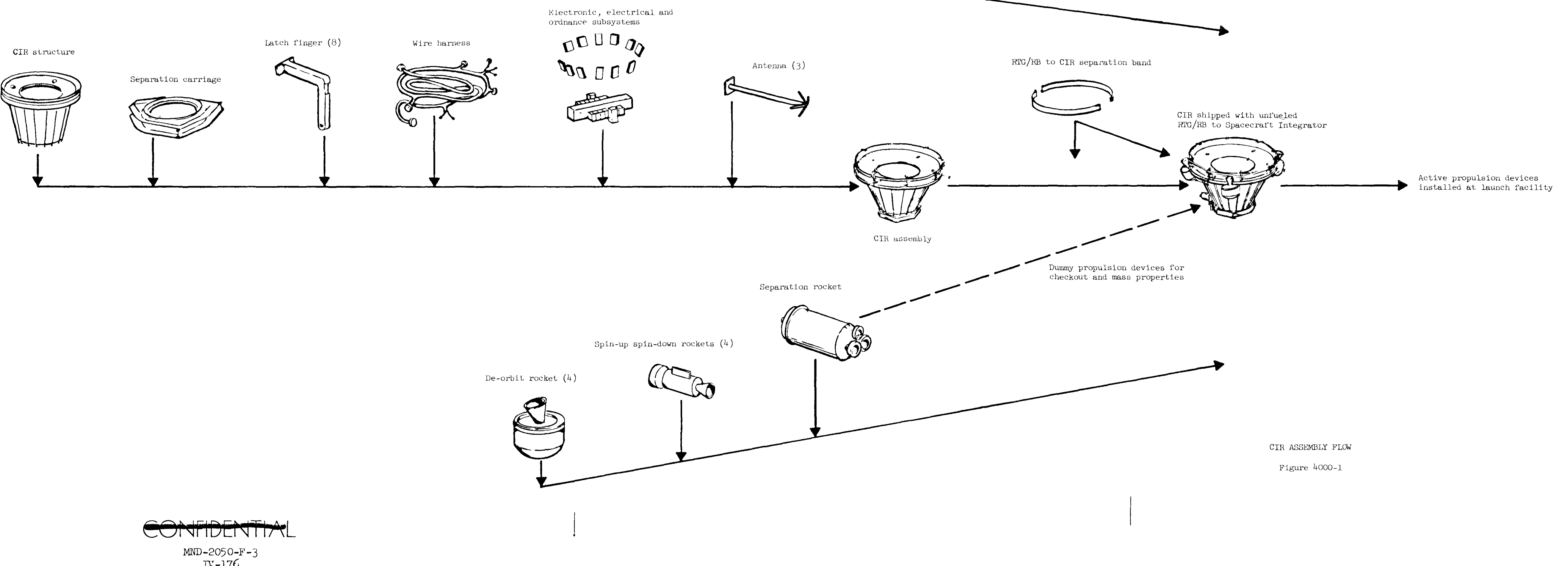




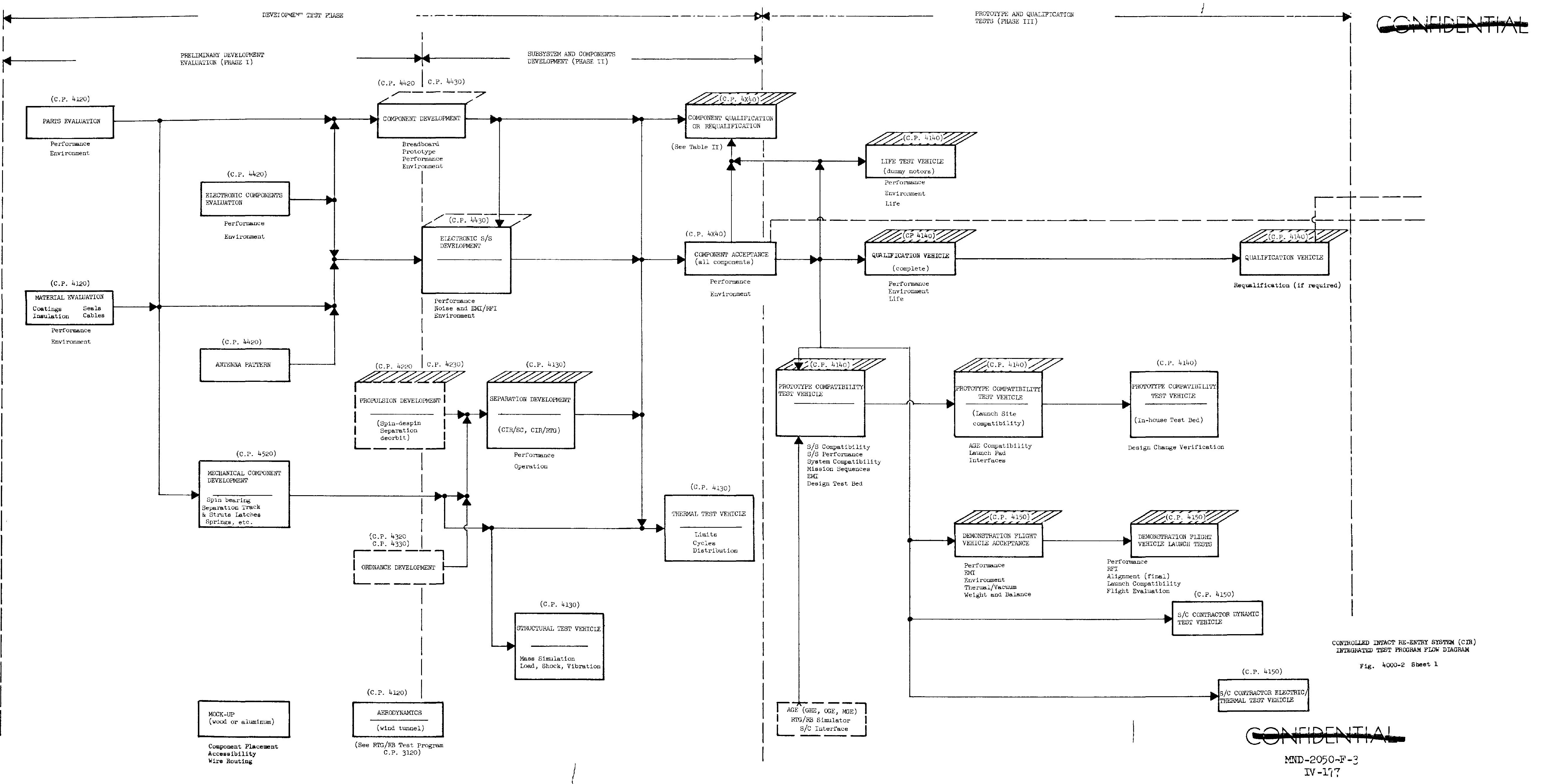




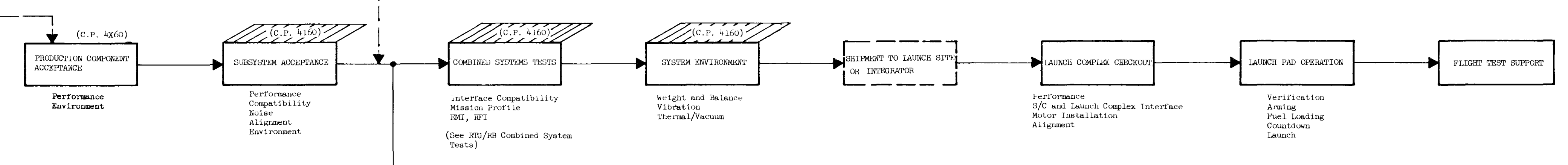

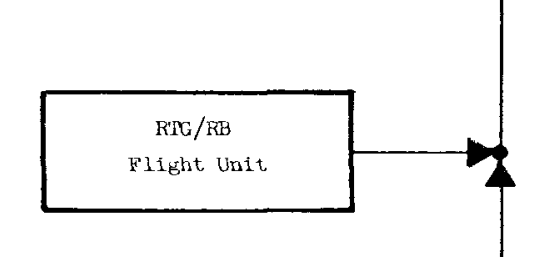

.

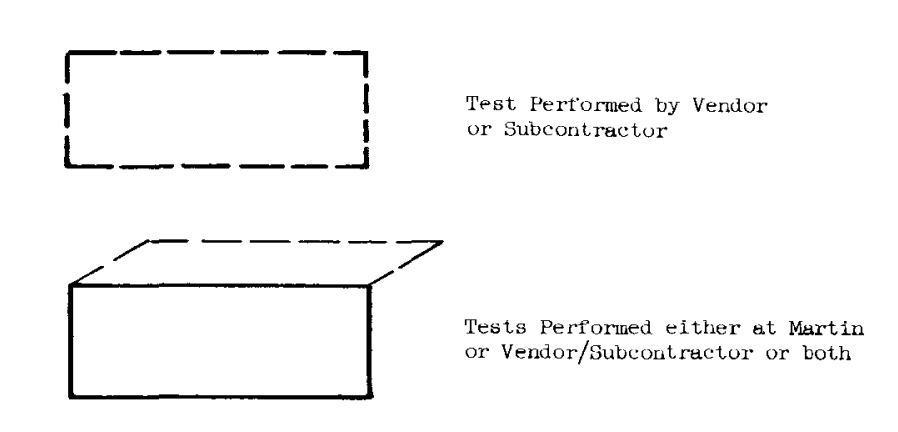

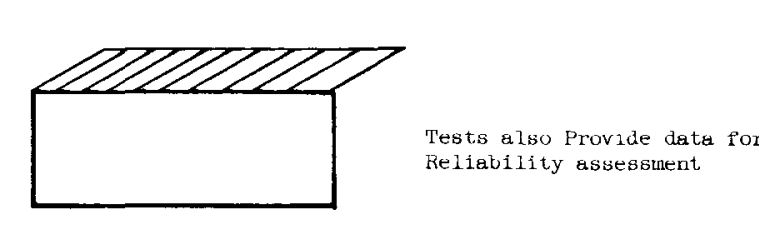




\section{Con}

\section{0--AEROSPACE GROUND EQUIPMENT PROGRAM}

The development program for the aerospace ground equipment has as its objective the identification, design, development, test and delivery of a system necessary for handling, fueling, checkout, servicing and monitoring of the CRONUS airborne svstems. The development program for an AGE system consists of three equipment groups which have been assigned separate control points:

5100--Ground Handling Equipment (GHE)

5200--Operating Ground Equipment (OGE)

5300--Maintenance Ground Equipment (MGE)

All efforts which relate to the total AGE system are included under Control Point 5000. This includes configuration layouts, intrasystem design studies, analysis and test, program and technical management and Quality Assurance. This last activity includes establishment of reliability goals, apportionment of the goals to various subsystems and determination and demonstration that these goals are being met. Overall efforts of Quality Control, Value Engineering and similar broad functions will be done on this level.

The GHE consists of:

(1) A fuel cask for transporting the fuel to the launch site and storing it there until the $\mathrm{RTG} / \mathrm{RB}$ is fueled.

(2) The mechanical portion of a loading system for remotely placing the fuel into the RTG/RB

(3) Auxiliary mechanical equipment such as slings and special tools.

The OGE consists of the control and checkout consoles necessary to verify the launch operational status of the airborne systems (RTG/RB and (IR), and to operate the GHE loading system.

The MGE includes equipment necessary to keep the entire CRONUS system operational or restore it to operational status after a prolonged period of inactivity.

The Sr-90 fuel block has a very high radioactivity level and, therefore, presents an extreme biological hazard if it is not under control. Consequently, the GHE fuel loading system must be designed not only to accomplish the loading while it is remotely controlled but it must be

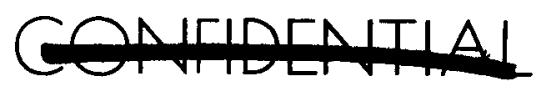

MND - 205. - F. -3

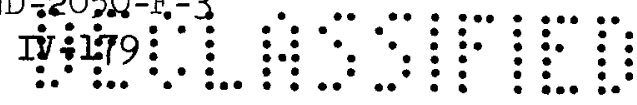




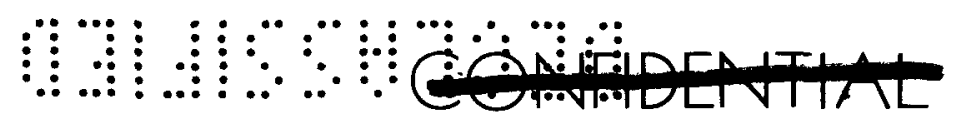

demonstrated to a high degree of reliability that it will not malfunction. Furthermore, if it should malfunction, then it must be capable of remotely controlled recovery. Reliability, then, is a primary requirement of the fuel handling portions of the GHE and OGE.

A complete set of AGE will be furnished to the launch site, portions installed and operational for the fueling demonstration and the remainder for the demonstration flight. Part of a second set of the equipment, consisting primarily of the OGE and MGE, will be provided for the Contractor's Acceptance Test Facility (ATF), and part of a third set will be furnished to the spacecraft Contractor's Integration Facility.

1. 5010--Program and Technical Management

This effort is essentially the same as Control Point 1210 and is described in detail under that Control Point.

2. 5020--System Studies and Analyses

The objective of this effort is the determination of the areas of interface between the airborne and ground-based portions of CRONUS and intrasystem interfaces within the AGE system. The baselines established as a result of this work will form the basis for the interface specification, the guide lines for AGE configuration, delineate intercontractor areas of responsibility and other boundaries on the necessary efforts.

The apporach to this effort will be to accomplish a technical review of the spacecraft, launch vehicle and launch complex engineering to establish the base existing configurations of these systems, within which the RTG/RB, CIR and AGE systems must function. Preliminary identification of any modifications necessary to these GFE or other contractor facilities will also be accomplished. Safety constraints by and for the equipment will be established.

a. Interface analysis and definition

All areas of interface between the AGE and the airborne and facility systems capabilities will be identified. An analysis of the AGE requirements within the capabilities of the interfacing launch complex will be accomplished. Maximum use of existing equipment capabilities will be the goal.

Requirements in excess of existing launch complex capabilities and equipment modifications will be identified. Interface meetings with the customer, spacecraft and payload integrating contractors and other organizations will be attended for purposes of establishing the interface requirements. From these efforts the necessary interface specifications will be prepared.
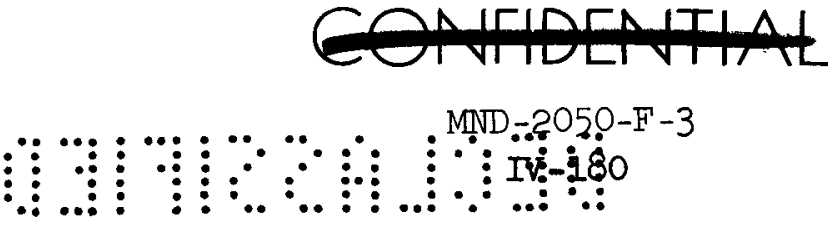


\section{(2)}

b. Safety studies

Safety studies will be accomplished and reports will be prepared, as required, to substantiate issuance of required licenses for the nuclear heat source transportation cask. These reports will include shielding test results and the analyses performed to prove container integrity for the types of accidents which can occur during transportation, the effects of such accidents on the source and cask and the resulting hazard.

A launch site nuclear safety evaluation will also be conducted. Storage and handling facilities will be evaluated to identify potential accident areas and resultant hazards. Recommendations for limiting personnel exposure will be generated based on the CRONUS dose rate characteristics and the procedures for heat source storage and handing. Launch site nuclear safety requirements will be documented in operating instruction manuals.

3. $5030--Q u a l i t y$ Assurance

Product integrity will be built into the AGE end items through the integrated efforts of the Contractor's functional departments comprising the organizational structure. The primary efforts to be used to provide quality assured products include:

Reliability---to assure that the AGE is designed to meet the contract performance goals

Quality Control---to ascertain that the delivered end items are as specified in the contract and specifications

Maintainability---to establish and demonstrate maintenance criteria consistent with program goals and reliability

Value Engineering---to obtain specification performance and reliability at minimum cost

System Testing---to develop system confidence and demonstrate specification performance of the system

Engineering Controls---to ascertain that system development and design data and analysis are reflected in the end product design

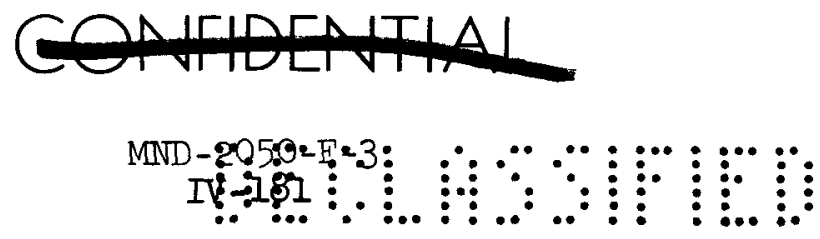




\section{आII)}

Manuals and Reports---to document system development, operational characteristics and other operational and maintenance use criteria

\section{a. Reliability}

The AGE reliability program has four goals:

(1) To assure that the probability of release of the fuel due to a failure of the GHE will be less than 10-6 (including the probability of losing fuel capsule integrity),

(2) To assure the probability that a failure of the GHE which would prevent the fuel from being returned to the cask will be as low as practical in terms of time and/or cost,

(3) To assure that human engineering factors have been fully employed to minimize improper operation of $\mathrm{AGE}$ equipment,

(4) To assure that the OGE and the MGE equipment is designed and fabricated to aerosapce requirements for this type of equipment.

Appendix A of Volume 3 presents the proposed reliability plan based on specifications DOD MIL-STD-785, "Requirements for Reliability Program for Systems and Equipment" and NASA NPC 250-1, "Reliability Program Provisions for Space Systems Contractors". During Phase I, a comprehensive Reliability Program Plan will be completed using the plan in Appendix $A$ as a base. The plan will identify the effort necessary to meet the total reliability requirements for the $\mathrm{AGE}$ system, and assure that system components, parts and materials are compatible with operational environments.

Reliability Engineering will review the proposed AGE design and operating procedures to ensure that the final design will function with a minimum of delays and that the final procedures for operational sequences will be clearly defined to minimize the possibility of human errors. Reliability Engineering will work with safety and design personnel to establish design and test criteria necessary to assure that reliability goals will be attained. For example:

(1) Pressure-containing components will be designed and tested in accordance with working, proof and burst pressures as defined in MIL-P-5518C.

(2) Design and test factors for stmetural components will be as defined in MIL-S-8512B. 


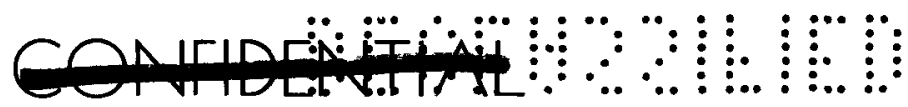

(3) Appropriate derating factors will be applied to other components to assure adequate margins of safety.

Selection of piece parts, components and subsystems will be made on the basis of prior usage, and compatibility with the unique environments of this equipment. Generic failure rates will be utilized where equipment can be shown to be compatible with its operational environments and environmental levels. Where malfunction of a component or piece part could cause a safety hazard the parts will be fully qualified by test.

The theory of reliability by safety margins will be employed to ensure reliability. The approach will be to establish a "reliability boundary" that will encompass the distribution of environmental levels that the component can experience. This distribution is usually the upper $3 \sigma$ level since this includes $99.8 \%$ of all expected environmental levels. A $10 \Leftarrow$ margin of safety will then be established between this reliability boundary and the mean strength of the component based on experimental data (e.g structural material will utilize American Society of Testing Materials or manufacturers'test data). Where there is a wide spread in the distribution of the environmental strength, a larger margin of safety will be required between the reliability boundary and the strength mean. These margins of safety and predicted probabilities based on this technique will be established in Phase $I$.

The effect of a failure of the fuel handling equipment can have an effect as significant as an airborne equipment failure. Therefore, the critical systems of this equipment will be evaluated and its components controlled to the same reliability levels as the critical airborne equipment. A mission analysis will be performed on the fuel handling equipment to determine environmental stress levels, operating times/cycles, effects of countdown holds, and the potential number of countdown holds permissible. Previous launch histories will be reviewed for length and number of holds in order to establish test criteria for the AGE. Fueling procedures will be reviewed to assure that all steps are included in the sequencing. All defueling sequences will be fully documented and evaluated for various failure modes and credible events that might require defueling.

The integrated test program (Control Point 5036) presents the types of tests to be conducted on the AGE during each phase of the program. Performance data resulting from this testing will be factored into AGE reliability assessment. An operational demonstration program will be conducted on the complete GHE system to demonstrate the capability of the equipment and to evaluate written operational procedures. Failure modes will be simulated to evaluate the fail-safe and redundant features and the procedures for the use of these features.
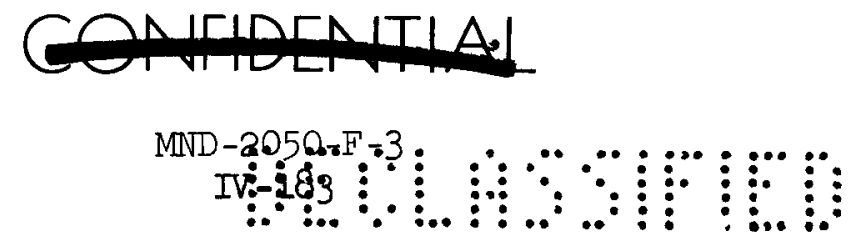


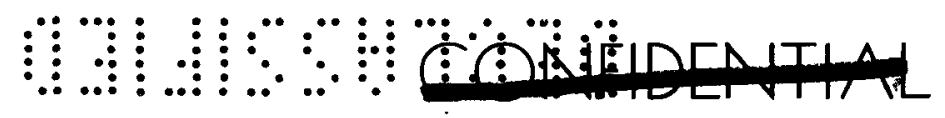

The fueling/defueling operation can be envisioned as a series of cyclic actions of the GHE components, thus the confidence in a given reliability level can be continually increased each time a fueling/ defueling cycle is successfully completed. A .99 probability of successful completion of the next operation will be demonstrated to a $50 \%$ confidence after 70 consecutive successful operations. The fuel handling machine will be cycled this number of times prior to the first loading with radioactive fuel. The demonstrated probability for completion of the next fueling operation is a demonstration of the probability that a series of events successfully occur. Thus, each element of the series, such as the fueling probe, would have at least that high a demonstrated probability of success.

The OGE and MGE systems will be analyzed for capabilities of performing the required functions. These systems are not considered unique and considerable experience has been attained on other programs with similar equipment and operating techniques. Reliability will be attained by monitoring design, operational procedures and participating in reviews of calibration data for this equipment to assure tolerances for all parameters are met. Reliability assurance tasks such as design reviews, parts selection and control, configuration control and corrective action shall be implemented.

b. Quality control

Quality effort associated with the development of the AGE system will include reviews of specifications, designs review, test procedures and processes; preparation of inspection instructions and $10 \mathrm{~g}$ books to cover detail fabrication, assembly and test operations; and evaluation of procurement plans to determine requirements for vendor surveys, receiving acceptance plans and source inspection requirements. A detail description of the methods to be used in performing these efforts is contained in the Quality Assurance Plan, Volume VI of this report.

A continuous monitoring and periodic review of the engineering design will be performed to ensure that all quality assurance requirements have been considered. Close liaison will be maintained between quality control, engineering and procurement departments to obtain this compliance. All procurement initiated by engineering will be reviewed to determine that the necessary design, test, documentation, quality and delivery requirements are included.

During the period of component and subsystem development, Quality engineers will monitor test laboratory, vendor and subcontractor activities in accordance with the approved Quality Assurance plan to assure full compliance with all test specifications, procurement specifications and data requirements. 


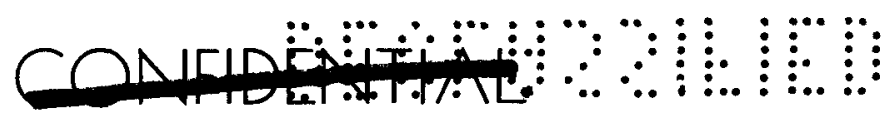

Quality laboratory activities will support Quality engineers by performing material and component tests, failed parts analysis, development of new processes, etc. During the period of system development and fabrication, Quality engineers will concentrate their efforts on the fabrication of prototype systems, qualification test programs and system demonstration. During the period of flight article fabrication and, if required, modification, Quality Control will continue the functions described for the previous efforts in addition to shipping inspection and launch site flight support inspection activities.

\section{c. Maintainability}

The objectives of this effort is to assure that the design and hardware meet the maintainability requirements established by the contract. This will be accomplished by establishing maintainability criteria for the equipment design. The equipment designers will be indoctrinated in the maintainability requirements and goals to be factored into the design. Periodic reviews of the design and tradeoff studies related to maintainability items will be conducted. A topical report presenting the incorporated maintainability features, the maintainability tradeoff studies performed and the predicted mean times to repair will be prepared and submitted to the AEC. A maintainability demonstration will be conducted during the maintenance manual verification.

\section{a. Value engineering}

This effort will be directed toward reducing the cost of producing CRONUS AGE hardware without sacrifice of product performance or reliability. In the performance of this task, the following will be accomplished:

(1) Review of the design, manufacturing processes and hardware by a specialist to reduce costs without impairing the functional design of the equipment. Where Customer approval is granted, such changes shall be incorporated.

(2) The total cost savings (value of re-engineering) will be determined.

\section{e. Engineering controls}

The functions accomplished by the Engineering Department to assure product integrity are itemized in Fig. 17 of Volume VI. In particular, Engineering will maintain control of the product specifications and drawings to assure that the program goals are achieved. A system of Engineering Directives will be issued to define areas of responsibility and requirements of each functional group for achieving these goals.

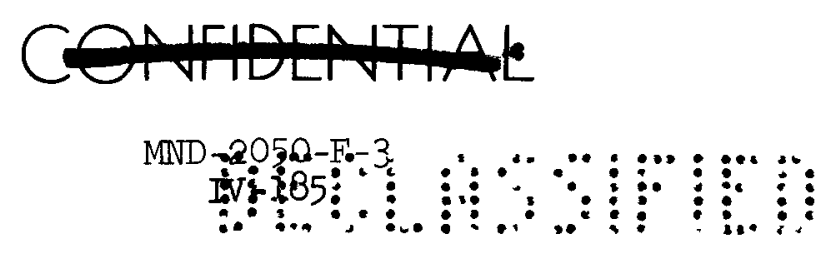




\section{min:}

Specifications will be prepared to establish the requirements for all contract end items. These will establish the criteria for acceptable products and enable determination as to whether or not compliance has been achieved. Engineering Process Specifications will be prepared for all critical manufacturing requirements. A Drafting and Checking Manual will be used to assure standard illustrations, nomenclature, format, etc., on all program drawings to minimize misinterpretation. All drawings for hardware to be delivered will be subjected to $100 \%$ checking before release for fabrication. Drawing Change Controls will be used as described in Volume VI. Engineering will participate in the Configuration Board and Malfunction/Discrepancy Automatic Report System (MARS) action meetings.

\section{f. System test plan}

The objective of the AGE integrated test program will be to demonstrate that the AGE will satisfy program criteria and specified requirements of the contract and applicable specifications. The test program will supplement the analyses and available test data and equipment usage histories. The planned test program for the system of AGE is outlined by phase in Figure 5000-1. Details of system and equipment testing are described under subsequent control points.

The development tests to be performed during Phases I and II will assist in formulation of the design by establishing the performance capabilities of critical subassemblies. Breadboard electrical/electronic circuit tests will be used for both design and component selection. Environmental tests will be accomplished where equipment performance is influenced by these conditions. Subassembly tests will be performed to provide component marriage performance data. The test articles will be equivalent to, or represent the end item configuration and will be subjected to selected environments and stresses in excess of that anticipated in operational use.

GHE qualification testing in Phase III will increase the system confidence established earlier in Phase I and II testing, design and analysis.

Performance development testing of the AGE in Phase III is nondistructive in nature and will be performed on the first deliverable items. The GHE functional operational adjustments will be made during these tests. The performance tests of the OGE and MGE will provide checkout of electronic circuit design and fabrication prior to formal acceptance of the chassis and consoles.

AGE testing in Phase III will result in a complete performance check, applicable proof check and combined systems tests prior to
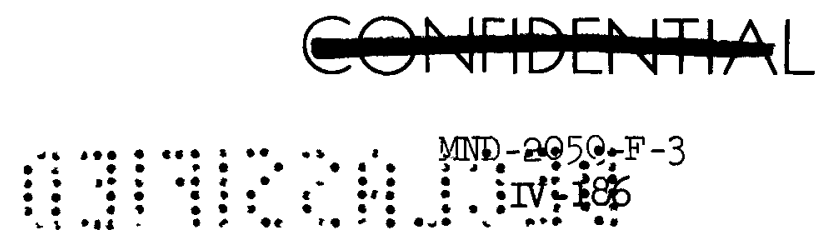
delivery. A demonstration fueling performed with a $5 r-90$ heat source will be accomplished by the Contractor at the launch site, using all of the GHE and applicable OGE in an operational sequence prior to the scheduled flight test.

\section{g. Manuals and reports}

Operating Manual. A set of instructions will be prepared for the erection, handling, maintenance, checkout and operation of the AGE system. This manual may be combined with those for the RTG/RB and CIR systems to make a single integrated Operating Manual.

By analysis of the design and liaison with test operations personnel, a topical outline will be developed which will include all operations necessary for the use of AGE. Fueling malfunction recovery instructions will be included in the operations portion of the manual. The preliminary operating manual will then be developed in conjunction with the preparation of the test procedures. The procedures for integration with the Spacecraft and Launch Vehicle Contractors will be developed through liaison with the customer and the contractors involved. The operating manual will be verified during the Contractor's in-plant tests and checkouts. Fueling procedures will be verified at the Contractor's plant by conducting a simulated fueling operation.

A verification copy of the manual will be furnished for the fueling demonstration at the launch site. The manual will be modified to incorporate necessary changes where the demonstration indicates revision is appropriate. An updated verification copy will be furnished for use and further verification during the prototype flight demonstration. A final copy of the operating manual reflecting experience gained in fueling demonstration and prototype flight test will be prepared for delivery concurrent with the delivery of the first flight operational hardware. Revisions will be generated and issued as required to keep the manual current through the remainder of the program.

Maintenance Manual. A set of preventative maintenance procedures for assuring operational readiness or timely return to operational status in the event of a malfunction will be provided. Special handling and transportation data will be included. The manual will be based on the maintenance concepts as defined in the maintenance plan and the support equipment and spares available. A preliminary maintenance manual will be developed concurrently with the in-plant test operations of the AGE system hardware. Maintainability analysis, failure mode analysis data, refurbishing kit data, spares provisioning, etc. will be factored into the maintenance procedures. The maintenance, handing and transportation procedures will be verified using launch site operations data prior to the preparation of the final manual.

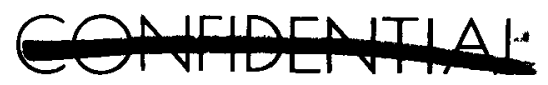




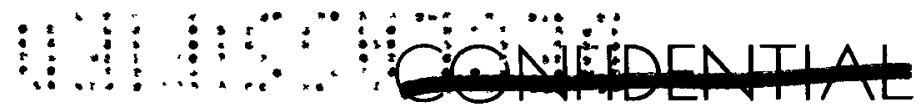

Verification and final copies of this manual will be prepared and delivered concurrently with the operating manual.

Reports. Contributions from the AGE program into the program monthly, quarterly and summary progress reports and other topical reports will be accomplished under this control point as required.

\section{A. 5100--GROUND HANDIING EQUIPMENT (GHE)}

The objective of this effort is the design, development and verification of launch site fuel handling equipment having a high probability of completing generator fueling operations. Components for this equipment are considered within the present state-of-the-art.

The basic problems which are encountered in loading the fuel are the radiation levels which prohibit personnel being in the immediate vicinity of the bare fuel and the relative motion between the launch vehicle and the fuel loading system support structure. These result in the need for:

(1) A transfer cask with acceptable surface temperatures and adequate shielding material,

(2) Remotely controlled engagement of the fueling machine and launch vehicle,

(3) Remotely controlled transfer of the fuel from the cask to the RTG/RB and locking them together

(4) Remotely securing all openings and hatches in the RTG/RB and launch vehicle $(\mathrm{L} / \mathrm{V})$.

The approach to these problems is to provide the following:

(1) A cask design consistent with applicable regulations and system considerations of the concept

(2) A remotely operated fuel loading system with sufficient safety features and redundancy built into the system to prevent entrapment of the bare fuel

(3) Equipment capable of automatically engaging and locking onto the $\mathrm{L} / \mathrm{V}$ fairing

(4) A friction-free compliance device to compensate for the relative motion 


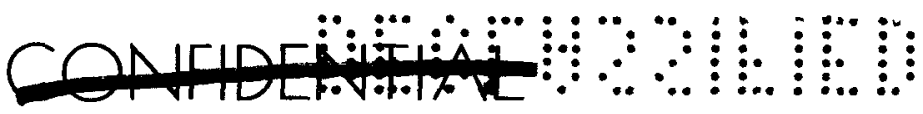

(5) A simple carriage transfer system to move the fuel block from the cask to the RTG

(6) Definition of the access requirements for fueling through the $\mathrm{L} / \mathrm{V}$ aerodynamic surfaces and the performance requirements for the latching devices and operating mechanisms.

1. $5110--D e s i g n$ and Analys is

A fuel cask will be designed to transport the fuel block (generator heat source) to the launch site. The cask in conjunction with the loading system will be designed to permit remotely operated transfer of the fuel from the cask to the RTG/RB within the launch vehicle. These will be analyzed for structural, thermal, mechanical actuation or motion, safety, reliability and radiation characteristics to assure compliance with the system specifications. The system designs will be reflected in production drawings prepared in accordance with the applicable military specifications.

The major groups of equipment to be designed and analyzed within this control point are:

(1) Launch site fuel transfer equipment

(2) Transportation cask and skid

(3) Fuel block loading probe to be used at the hot laboratory facility

(4) Slings, special tools and miscellaneous items of handling equipment.

\section{a. Interface definition}

To establish firm interfaces between the responsibilities, activities, and equipment which are within the purview of the Contractor and those of others, a detail specification(s) will be prepared defining the interfaces between the GHE and the facilities, equipment, electrical and pneumatic services and modifications required to integrate the GHE into the existing facility. Similar documentation will be prepared for the launch vehicle/GHE interface, and the interface between the RTG/RB and the GHE. In addition, specifications for the GHE will be prepared delineating the equipment to be supplied, its physical requirements, the design environments, equipment functional requirements, test requirements, equipment quality, etc., as necessary for complete definition of the equipment to be delivered. 


\section{आII)}

Preliminary versions of the specifications to be prepared are contained in Volume IV of this report. It is intended that these initial specifications will form the base for liaison, coordination and evolution of mutually acceptable program specifications.

b. Preparation of Engineering

Layouts to determine clearances will be prepared of the launch site structures and the launch vehicle in the areas of the fuel loading system installation. Design layouts will be made of the subsystems comprising the fuel loading. system such as the compliance device, fueling probe, position locators, cask, retractable platform for cask installation, boom hinge fittings, etc. Design layouts will then be made of the fuel loading system integrated with the launch site support structures and other interfaces.

Drawings will be prepared to fabricate a fuel loading system mock up constructed from aluminum and wood. Procurement drawings and specifications will be prepared and released for components and subsystems to be procured from equipment suppliers. Detail and assembly production drawings, reflecting applicable military specifications, will be prepared for the manufacture and assembly of the fuel loading system. Test procedures defining proof-load testing, as applicable, and acceptance tests for the fuel loading system and subsystems will be included as part of the drawing package release.

Analyses in support of the design will be accomplished. An analysis will be made of thermal conditions and radiation attenuation of the cask necessary to satisfy government regulations. Stress analysis will be performed on all major structures, such as the cask, transportation skid, slings, support structure pallet, boom and fuel handling machine. All mechanical actuation systems will be analyzed to establish the design parameters for actuators and drive motors. The air bearing system will be analyzed to determine bearing sizes, system gas pressures and flow requirements. A man/machine analysis of the fuel handling equipment for optimization of the man/machine interface will be conducted.

\section{c. Manufacturing support}

Technical personnel will support the manufacturing phase of the fuel loading system. Assistance will be provided to interpret drawings and approve acceptable drawing changes to facilitate manufacturing. Technical assistance during proof load testing, functional testing and acceptance testing of parts, components, and the complete fuel loading system is included in this effort. 


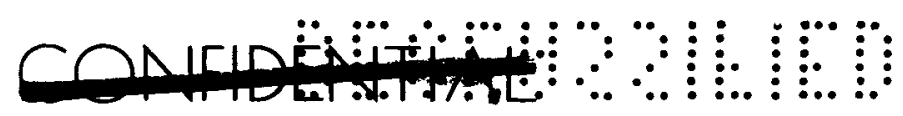

d. Field support

Technical assistance and coordination will be provided during site modification and system installation phases of the program. Technical personnel will assist in specification and drawing interpretation and to evaluate on-site deviations and modifications as required. Coordination and technical support will be accomplished as necessary to expedite the launch site activities.

\section{5120--Component Development and Verification}

Selected components will be tested to establish component, subsystem and system functional confidence. For example, the fueling probe is provided with a primary and backup method of extension and retraction. Development tests will be used to facilitate the integration of the primary and redundant systems into a single actuator. Development tests will also be used to optimize the design of the air bearing compliance device. Selection of porous or annular cut bearings will be based on tests. Influences of geometric tolerances, pressure and flow variation will be established and adjusted by applicable test.

Loads and non-nuclear environments anticipated during operations will be imposed and their influence on certain components evaluated by tests. Fixtures and loading devices will be designed for the support and loading of the components in test. Components used in the development test will not be used in subsequent production equipment.

\section{5130--Subsystem Development}

\section{a. Design verification and proof tests}

Development and design verification tests will be performed on all critical subsystems. Subsystem responses as a function of a variation of system parameters in the expected ambient environments will be determined. Adjustment procedures, operational characteristics and effects of geometric tolerances will be evaluated. Test fixtures and instrumentation necessary for these tests will be provided.

Design verification tests will be accomplished on the production GHE prior to delivery. These tests will be part of the acceptance test program. Fixtures and a dummy fuel block will be required for the special tests. Each major subsystem will be structurally proof tested to twice the design load, as specified in MIL-S-8512. Test fixtures and instrumentation setups will be designed, as required, for the proof loading of the GHE.

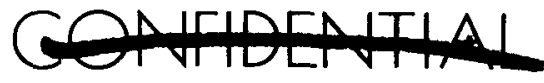




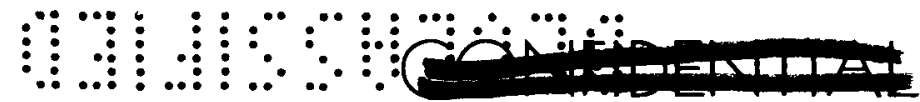

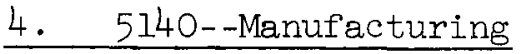

The major portion of manufacturing effort for ground handling equipment will be in the fabrication of the launch site fuel handling equipment and the transportation cask. These are discussed in the following groups:

(1) Structural support pallet

(2) Fuel boom and retraction mechanism

(3) Fueling machine and support structure

(4) Transportation cask.

a. Structural support pallet

The structural pallet of the fuel handling equipment will consist of a conventionally fabricated structure of aluminum or steel. Conventional welding processes and mechanical bolting are employed throughout this structure assembly. AlI aluminum weldments will be manual, inert shielded and will be welded by certified welders. Interface mounting holes, brackets and accessory-type detail hardware will be provided in accordance with Engineering drawings and specifications.

b. Fuel boom and retraction mechanism

Attached to the structural support pallet will be a box beam-type structural boom. This assembly will be fabricated of structural aluminum shapes and will have U channel tracks assembled to its sides. An air motor actuated mechanism with a series of rollers will be fabricated and installed within these track assemblies. A pinion gear drive will be installed along the bottom of the boom assembly which will engage with a rack assembly. It is anticipated that the rollers and pinion gear drive assembly will be purchased items and will require installation only. Stop plates, fabricated out of aluminum or steel, will be welded to the track assemblies to prevent overtravel of the fuel machine mechanism.

\section{c. Fueling machine and support structure}

It is anticipated that the most complex portion of the fueling equipment fabrication will be in the fueling machine and support structure. This consists of the following components:

(1) Primary cylindrical bearings and secondary cylindrical bearings

\section{-}

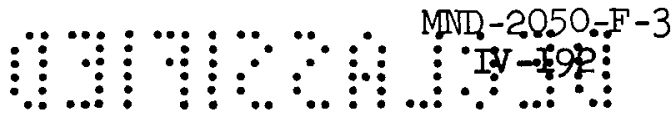




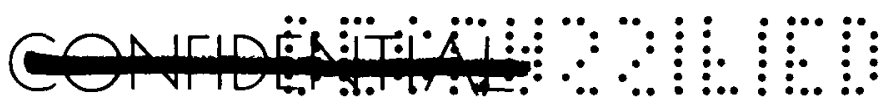

(2) Spherical thrust bearings

(3) Position locators and position index components

(4) Fuel block shroud

(5) Fueling probe with locking mechanism

(6) Fueling machine support structure

The compliance mechanism, Items (1) and (2), will consist primarily of machined parts:. System descriptions indicate that machining tolerances will be critical throughout the entire assembly. It is anticipated that this mechanism will require a development phase during which proper tolerances for hole diameters and restrictor mechanisms will be jointly determined between both Engineering and Manufacturing. This development phase will utilize a step-type development approach. One air bearing mechanism will be developed first and then an assembly of two air bearings will be mounted to a support structure. The purpose of this second step is to identify problems in holding the critical dimensions of the paralleled assembly. A spherical thrust bearing assembly will be developed in a similar manner.

A pair of position locators will be fabricated of metal and mounted to the fueling probe mechanism. The locators will be machined to provide a recess for the installation of the necessary sensors and switches.

The fuel probe mechanism will primarily involve machining and assembly type operations. This probe assembly includes the spherical thrust bearing assembly discussed earlier. One specific area of fabrication effort in this assembly is highlighted because of its critical design parameters. This is the ball detent mechanism. This portion of the probe assembly will be subcontracted to a vendor specializing in developing this type mechanism. Assembling this mechanism into the fuel probe can be accomplished by the Contractor. The entire probe assembly, including the compliance mechanism, will be tested as part of the equipment development tests.

The purpose of the fuel block shroud is to provide containment for an inert atmosphere that will be required for the fuel block. This shroud will be mounted on the bottom of the compliance mechanism and is itself open on the bottom. It will be fabricated of aluminum and presents no apparent fabrication problems.

The fueling machine support stmucture interfaces with the fueling machine. This structure will be fabricated out of aluminum or steel. An air motor-driven pinion gear assembly is installed on the underside of the support structure. This mechanism will interface the rack on the

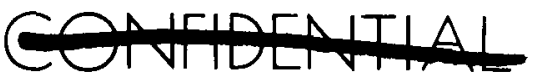




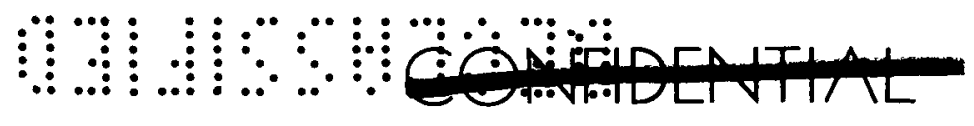

underside of the boom assembly. The pinion gear and rack will be procured as matched items and will require only installation and alignment. Rollers are utilized for support structure movement.

\section{d. Electrical requirements}

Electrical circuits will be installed on the fuel handing equipment in accordance with engineering specifications, including applicable MIL specifications. Wiring harnesses will be prewired on harness boards and installed on the equipment. A closed circuit television system will be installed on the machine and linked by appropriate wiring to the launch control center (through to $O G E$ ). A purchased rewind reel will be installed on the machine to retract and extend the electrical and pneumatic lines.

\section{e. Transportation cask}

A cask will consist of depleted uranium, clad internally and externally by stainless steel shells. The radiation shield is approximately four inches thick and will be subcontracted for fabrication. The labyrinth radiation seal will be machined to required tolerances. The lid assembly will have an integral welded arm assembly to enable the fuel handling machine operator to remotely operate the cask lid.

A steel transportation skid will be fabricated using conventional type fabrication techniques. A protective cage will be fabricated out of a woven screen material and will be attached to the skid. This screen cage will completely enclose the cask and will be attached so it can be removed when access to the cask is required.

\section{f. Manufacturing testing}

Testing of the fuel handling equipment will be accomplished by Manufacturing in accordance with test specifications released by Engineering. Manufacturing will provide the necessary tools and procedures with which to accomplish this task.

Subsystem testing will be performed during the fabrication cycle prior to the completed assembly test. These subsystem tests will consist of:

(1) Boom assembly for proper operation

(2) Cask support platform for proper movement on track assemblies

(3) Fueling machine support structure for proper operation

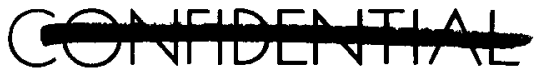




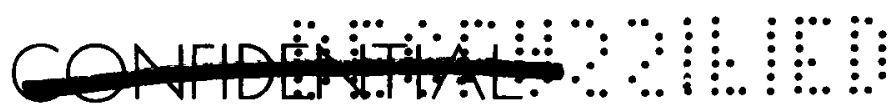

(4) Functional operation of the fuel handing machine.

An overall test will be conducted in accordance with Engineering specifications for final acceptance of the GHE. The acceptance test program includes performing tests to demonstrate functional compliance of the equipment with all applicable specifications.

g. Manufacturing tooling requirements

The tooling requirements for manufacturing tooling are:

(1) Welding and holding fixtures

(2) Drill templates for detail mounting

(3) Sophisticated machining and holding fixtures for the compliance mechanism

(4) Fixtures to perform subsystem tests

(5) Special clean area for assembly and checkout of the compliance mechanism (air conditioned, humidity controlled)

\section{5150--Quality Control}

Quality will apply the experience of past programs and similar configurations to the CRONUS GHE system.

a. Structural support pallet

Since this portion of the system is of a conventional welded design, no problems are anticipated by Quality during inspection. Quality will require that the welds be checked using current methods applicable to similar use equipment.

b. Fuel boom and retraction mechanism

The fuel boom is of a conventional welded design and no inspection problems are anticipated by Quality. All welds will be checked to current standards. Components attached by mechanical fasteners will be checked for proper placement.

c. Fueling machine and support structure

Due to the criticality of the fuel handling machine and support structure, special attention will be directed by Quality to the reliability requirements of this subsystem. Quality will spotlight these requirements throughout design, fabrication, test and delivery.

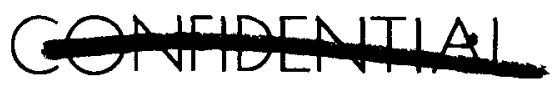




\section{mbั4}

Since the majority of the components which make up the fuel handling machine are close tolerance machined parts, Quality will prepare inspection instructions and/or certification log books to highlight the critical characteristics. Inspectors will use these documents when inspecting piece parts. Quality will participate in the development of the air bearing and fuel probe configurations.

The traversing motor, drive mechanism and other purchased or subcontracted items will be acceptance inspected when delivered. Receiving acceptance plans (RAP) will be prepared by Quality to be used by the inspector for acceptance purposes. These plans will include:

(1) A review of the vendor's certificate of compliance and test results.

(2) Performance of dimensional integrity checks.

(3) Performance of operational tests in the Quality Laboratories.

(4) Workmanship evaluation.

All inspections will be in accordance with a prepared subcontractor acceptance plan.

\section{d. Transportation cask}

Quality will concentrate its effort on the safety aspects of the cask design, fabrication and handling. A certification log book will be prepared describing the critical characteristics of the cask. Items such as dimensional check, radiographic inspection of critical weld joints, performance of laboratory and operational tests, radiation emissivity checks, etc., will be included in the log book. The inspector will inspect the cask for each characteristic described. The subcontracted shield will be source inspected. A Martin-prepared contractor's acceptance plan (CAP) will be used by the source inspector to inspect each shield prior to its leaving the subcontractor's plant. This plan will include as a minimum:

(1) A review of the subcontractor's in-process and assembly inspection results.

(2) An examination of radiographs produced for shield weld evaluation, if applicable.

(3) A review of the vendor's certificate of compliance and test results. 
(4) Workmanship evaluation.

e. Surveillance of tests

Quality will review test procedures to ascertain adequate tests and testing levels. All tests will be monitored by Quality as they are performed.

\section{f. Tool inspection requirements}

Quality will review all tooling drawings to verify that the necessary Quality Assurance provisions required to perform the tasks for which they were designed have been incorporated. The first part fabricated using each tool will be inspected against the engineering requirements. If all requirements are met, the tools will be approved by quality and subsequent parts may then be fabricated using the tools.

\section{6. $5160--F u e l i n g$ Demonstration GHE}

The fueling demonstration unit will be the first production article. Prior to shipment of the demonstration unit by the Contractor, the unit will be erected in a simulated launch site demonstration setup at the Contractor's facility. A simulated loading with an inert heat source will be accomplished to verify the operation of the complete loading system. Customer operating personnel will witness the equipment use for instructional purposes. The system will then be shipped to the launch site.

Design modifications as a result of the fueling demonstration will be accomplished in accordance with the recommendation and conclusions of the engineering report summarizing this operation at the launch site.

\section{a. Packaging and delivery}

The system will be reviewed and special handling and packaging requirements identified. Special packaging and shipping instructions will be incorporated into a pack and ship drawing which will be released as part of the production engineering package. The degree of disassembly for shipping and other special preservatives applicable to the equipment will be included.

\section{7. $5170--F l i g h t$ Operational GHE}

The production fuel loading system will consist of the fueling demonstration unit plus installed refurbishment kits per the recommendations of the test summarizing engineering report. It will be installed at the launch complex and connected to the facility services under

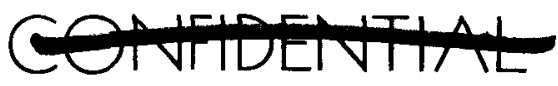




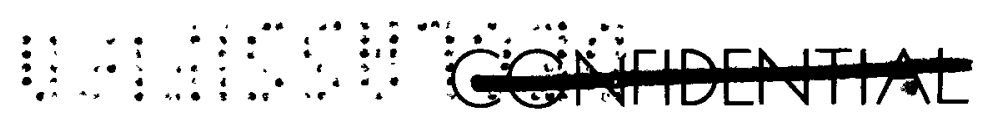

Contractor engineering supervision. A fuel loading operation using a dummy fuel block and approved loading procedures will be conducted for purposes of hardware verification by Contractor personnel. Engineering will support the installation and operation of the equipment by customer personnel for subsequent flights and will continue the training of customer personnel on a level-of-effort basis.

A refurbishment kit will be provided for replacing components and subassemblies expected to be degraded as a result of an operational fueling and launch of the airborne system. Hardware verification tests will be mun after the installation of the refurbishment hardware.

\section{8. $5180--$ Site Support}

The contractor will provide engineering, supervisory and operating personnel to conduct the fueling demonstration, the demonstration flight, the operational flight fuelings and normal equipments maintenance and repairs. In addition, consultation services will be provided in equipment trouble shooting, evaluation of proposed design and procedural changes, etc.

a. Technical support service

Technical support services for the GHE paralleling that effort outlined in 3170 will be accomplished as applicable.

b. Fueling demonstration

The ground handling equipment (GHE) will be erected in the umbilical tower at the launch site. A dummy fuel block will be used to perform the fueling demonstration. The demonstration will make use of all the handling equipment in the system, i.e., fuel transfer equipment, cask, slings and special tools and the nuclear GHE control and monitor console (an OGE item). The fuel loading will he accomplished in accordance with a loading procedure manual. Simulations of the airborne equipment and the launch vehicle, to the extent necessary to provide a functionally realistic fueling demonstration, will be included.

Engineering personnel will supervise the operation of the equipment and indoctrination of customer personnel at the launch site. Contractor personnel will perform actual fueling demonstrations. Engineering will critique the operation and equipment and an engineering report will be prepared summarizing the operation.

\section{c. Flight fueling operations}

The Contractor will provide the operating, supervisory and instructing personnel for the fueling operation which will occur prior to the
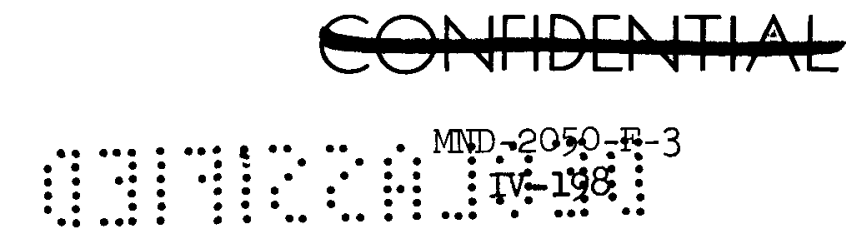
demonstration flight. This operation will be similar to the fueling demonstration except for any modifications to the system which may have occurred between the two operations. Adequate simulation of the RTG/ $\mathrm{RB}$ interface will be provided if the demonstration flight does not have provisions for the fuel block. This fuel loading operation will use a prototype fuel block containing Sr-90.

After each launch and after each long-term storage period, the GHE will be refurbished using a kit supplied for that purpose. The acceptance test for the GHE will be rerun after each such refurbishment. Proof load tests will be remun periodically and after any major structural modification.

The Contractor will provide personnel for the Sr-90 fueling for the operational flights.

d. Equipment maintenance and repair

Maintenance and repair of GHE system equipment will be accomplished substantially as described for the generator system under Control Point 3170. However, the Contractor will conduct routine maintenance of GHE articles during fueling operations by Contractor personnel.

\section{e. Equipment spares}

Spares will be provided for the AGE to support the Phase III launch site demonstrations and launch operations. Selection of spares will be consistent with the maintenance concept and the maintenance plan and will be based on analysis of the Engineering drawings. The type and quantity of supporting spares will be consistent with the requirements for a prototype system. Only those items of long-lead procurement which may cause costly program delays will be considered for spares provisioning. Repair parts, when determined to be available locally or within a short period of time, will be furnished on an as-required basis.

An AGE spare parts provisioning list will be supplied to the customer for customer selection and ordering of spares to support Phase IV of the program.

\section{f. Licensing}

The technical effort, analyses and documentation necessary to license the fuel transportation cask will be accomplished. The Contractor will obtain the necessary licenses for using the cask to ship fuel. 


\section{MINOH}

g. Support of nuclear safety

The technical effort and analyses necessary to the documentation and data needed for certification of nuclear operations at the launch site will be accomplished, i.e., site health physics requirements and then personnel protection requirements. Actual certification Health Physics operations and other safety operations are the responsibility of the Customer.

\section{B. 5200--OPERATING GROUND EQUIPMENT (OGE)}

During the checkout and countdown of the launch vehicle, the fuel is remotely loaded into the spacecraft and certain parameters of the RTG/RB and CIR must be monitored. The objective of this effort is to design and furnish the means by which these functions can be performed and monitored.

The problems associated with these functions are:

(1) Assuring reliable control and monitoring of the fuel handling equipment

(2) Matching the requirements of the parameters to be measured with equipment capable of meeting these requirements

\section{(3) Identifying facility interfaces}

(4) Achieving compatibility between components and subsystems within and between the systems.

The approach to providing the proper equipment is to select components and equipments which have been developed and qualified for similar applications and have documented histories of reliable performance. As nearly as possible, commercial equipments which match the requirements of the parameters to be controlled or monitored will be selected. Components and equipment will be assembled into the consoles which make up the various systems. The data displays and controls on these consoles will be arranged in accordance with MIL-STD-803. Emphasis will be placed on go, no-go displays to simplify the countdown operation and provide rapid identification of operational problems. Demonstrations of performance and equipment compatibility will be performed at the component, subsystem and system levels. 


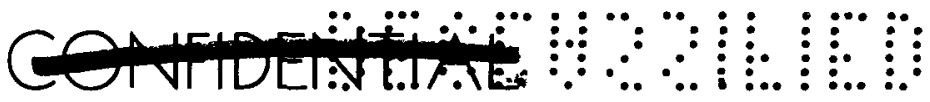

1. 5210--Design and Analysis

The requirements of the $\mathrm{RTG} / \mathrm{RB}, \mathrm{CIR}$ and GHE performance and control will be analyzed to identify the operating parameters to be controlled and monitored. A set of consoles will be designed, specifications prepared and procurement items identified within this control point. The major items of $O G E$ equipment are:

(1) Launch and checkout controls console

(2) Nuclear GHE control and monitor console

(3) Go, no-go analyzer

(4) C band $\mathrm{C} / \mathrm{O}$ set

(5) Interconnecting equipment

(6) Twenty-eight volt dc electric power supply

a. Interface definition

A detail specification will be prepared defining the respective interfaces between the OGE system and the RTG/RB, CIR, GHE and the facility. This specification will define the structural and power requirements of the OGE as well as the electrical, electronic and control interfaces. Physical requirements of the equipment to be supplied, the design environments, equipment functional capabilities, test requirements, quality requirements, etc., will be defined to form a complete description of the equipment to be supplied.

b. Preparation of engineering

Layouts, configurations and schematics of the various contract end items (CEI) of OGE will be prepared. Component and subsystem drawings and specifications will be released to procurement.

Control panel layouts will be accomplished in accordance with MILSTD-803 and reviewed for application of good human engineering practices. A mockup of the console panel displays will be made and the interrelations of equipment placement will be evaluated.

Production engineering will be prepared in accordance with applicable military specifications and released for fabrication. Breadboarding of equipment for functional optimization of components subsystems will be accomplished. Mockups will be made to optimize the system packaging. Test procedures and equipment operating instructions will be released as part of the production engineering package.

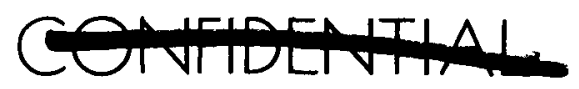




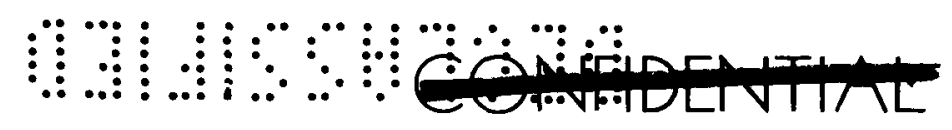

Stmuctural analysis of the chassis and consoles will be performed to the applicable environmental criteria.

c. Manufacturing support

Engineering liaison will be maintained with subcontractors and Manufacturing to aid in specification and drawing interpretation and to evaluate drawing changes to facilitate fabrications. Engineering will accomplish the preparation of the acceptance specifications and the performance of the acceptance testing.

d. Field support

Engineering support at the launch site and to the Spacecraft Contractor will be provided. Layout of equipment within the specified areas, environmental requirements, access to installations, etc., will be analyzed and specified in the interface specifications. Technical support to the installation effort will be performed.

2. 5220--Component Development and Verification

Review and evaluation of systems using similar equipment will be used to select components and subsystems for the OGE. Critical system components undergo development tests and will be evaluated to increase system confidence.

These components will not be used in subsequent production equipment but may be used for breadboard and simulation tasks.

3. 5230--Subsystem Development and Design Verification

Critical components and equipments will be breadboarded into subsystems and operated to demonstrate subsystem functional performance and equipment compatibility. The selected components and tested circuits will be incorporated into the design of the delivered equipment.

4. $\quad 5240--$ Manufacturing

After fabrication and inspection, the operating ground equipment will be installed within a designated test area and an operational checkout will be performed. The equipment will be grouped in consoles according to the system requirement.

a. Control console for fuel handling equipment

A multibay console will be fabricated from purchased racks. The racks will contain fabricated chassis and panels of conventional 
electronic components such as sequential light indicators, switches, solenoids, relays, temperature indicators and closed circuit television monitors. Electrical harnesses will be fabricated to provide a matching interface between the console and the umbilical tower mounted equipment. All wiring will be accomplished in accordance with Contractor standard procedures and applicable MIL specifications.

\section{b. $R T G / R B$ system}

Another control console will be fabricated for the purpose of the $\mathrm{C}$ band beacon checkout. This console will consist of fabricated chassis and equipment necessary to perform the checkout. Antenna connectors and hats will also be provided in accordance with engineering specifications. The rack assembly itself will consist of two standard vertical racks with writing tops.

A launch and checkout controller's console will be fabricated in accordance with Engineering specifications for the purpose of controlling and monitoring various functions of the RTG, RB and CIR. This console will consist of three purchased racks and those electrical components necessary to accomplish this task. Fabricated electrical chassis will establish an interface with which to control and check status indication and RTG/RB circuitry.

Interconnecting cables and junction boxes will be fabricated to conduct a complete integrated ground test checkout of all systems. Junction boxes will be fabricated with sheet metal enclosures containing electrical connectors, bus bars and terminal strips.

\section{c. CIR system}

A purchased go, no-go analyzer will be required with which to verify telemetering system outputs. This system will be a purchased item and will only require a cabling interface between it and the ground station complex. Only cabling requirements are anticipated as manufacturing items.

A purchased 28-volt dc power supply will be included in the OGE system. This power supply will require cables with which to accomplish a total system interface.

All of the operating ground handling equipment requiring fabrication will be accomplished in accordance with applicable MIL specifications and Contractor procedures. All wiring will be accomplished by qualified and certified electronic workmen. 
5. 5250 --Quality Control

The operating ground equipment, which consists of consoles, go, no-go analyzer, 28-volt dc power supply, etc., used for the RB, RTG/RB and CIR systems checkout will include many purchased components and subsystems. During the design effort, each component will be reviewed to determine which will be source inspected and which will be in-plant acceptance inspected. Contractor acceptance and receiving acceptance plans will establish the acceptance criteria.

Contractor fabricated subsystems and end item assemblies will be inspected in the same manner as indicated in Control Point 5150.

6. 5260--Fueling Demonstration and Other Units

The OGE (nuclear GHE controls and monitor console) necessary to operate the GHE during the fueling demonstration tests will be installed and used to operate the fuel loading equipment during the demonstration at the launch site.

Prior to the delivery of the equipment to the site for the fueling demonstration, the GHE and selected $O G E$ will be married and checked out as a system in the factory. Acceptance of the selected item of OGE will be verified in this manner.

The remaining OGE equipment will be acceptance tested as individual end items and as an interconnected system. This system will be delivered and installed at the site and checked out to an acceptance procedure prior to the use of the equipment in the demonstration flight. For that flight, the OGE will be operated by Contractor personnel.

A similar set of OGE will be acceptance tested and installed in the Contractor's acceptance test facility (ATF) for subsequent acceptance tests of the RTG/RB and CIR. That OGE associated with the operation of the GHE is not included in this set. Simulation of signals from the GHE will be provided where interaction of the equipment is necessary.

A third set of OGE, less the GHE control console will be delivered to the Spacecraft Contractor's facility.

a. Packaging and delivery

This is the same as Control Point 5160. 
7. $5270--F l i g h t$ Operational Unit

The installed OGE at the Iaunch Complex, Contractor's ATF and Spacecraft Contractor's facility will be operationally supported by Engineering through acceptance tests of the RTG/RB and CIR systems at these facilities. Installation of modification kits to the launch site equipment, support of customer operating personnel and assistance in system trouble shooting will be accomplished on a level-of-effort basis.

8. 5280--Site Support

Engineering liaison at the site will be provided on a level-ofeffort basis for customer personnel training, operation of the OGE to aid in emergency trouble shooting, evaluation of proposed design and procedural changes, etc. The nuclear GHE control and monitor console will be operated by contractor personnel.

In addition, support of the fueling demonstration, demonstration flight, equipment maintenance and repairs, spares, assistance in procedure approvals and other technical services will be provided.

a. Technical support services

Technical support services for the OGE paralleling that effort outlined in Control Point 3170 will be accomplished as applicable.

b. Fueling demonstration

The contractor will provide the OGE operator for the fueling demonstration at ETR.

c. Fueling operation

The contractor will provide the operating, supervision and instructing personnel for the OGE during the demonstration fueling operation and countdown immediately prior to the demonstration filight.

d. Equipment maintenance and repair

Maintenance and repair of OGE system equipment will be accomplished as described under Control Point 3170.

e. Equipment spares

The procedures used here are the same as for Control Point 5180.

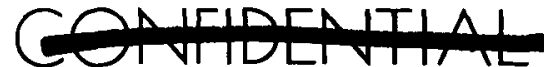


f. Procedure approval assistance

The technical and related efforts necessary to obtain approval for $O G E$ and $O G E$ site operating procedures will be supported.

\section{5300--MAINTENANCE GROUND EQUIPMENT (MGE)}

Preparatory to checkout and countdown of the launch vehicle, certain maintenance functions must be performed on the RTG/RB and CIR systems. The objective of this effort is to design and supply the means by which these functions can be performed and the serviced systems can be evaluated.

The problems associated with these functions are:

(1) Matching the requirements of the functions to be performed with equipment capable of meeting these requirements,

(2) Analyzing measured parameters such that trouble shooting can be performed and corrective action taken without undue delay or additional testing,

(3) Identifying facility interfaces,

(4) Achieving compatibility between components and subsystems within the system.

The approach to these problems will be to select components and equipments which have been developed and qualified for similar applications and have documented histories of reliable performance. As nearly as possible, commercial equipments which match the requirements of the parameters to be performed or measured will be selected. Components and equipments will be grouped and packaged together to make up the required systems. Demonstrations of performance and equipment compatibility will be performed at the component, subsystem and system level.

1. 5310--Design and Analysis

The CRONUS maintenance requirements will be analyzed to identify the maintenance, calibration, adjustments, etc., to be performed. Systems of equipments will be designed, specifications prepared and procurement identified within this effort. The major items of equipments identified as MGE are:

(1) Alignment kit

(2) Ordnance checkout set 


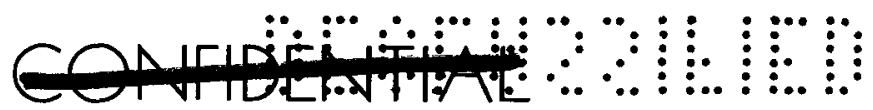

(3) Battery checker

a. Interface definition

A detail specification will be prepared defining the interfaces between the MGE systems, CRONUS and the facility. This specification will also define the stmuctural and power requirements of the MGE and the RTG/RB-CIR and facility. Physical requirements of the equipment to be supplied, the design environments, equipment functional capabilities, test requirements, quality requirements, etc., will be defined as necessary to form a complete description of the equipment to be supplied.

b. Miscellaneous

The efforts for Preparing of Engineering, Manufacturing Support, Field Support, Component Development and Subsystem Development.

2. 5320--Component Development and Verification

This is the same as Control Point 5220.

3. $5330--$ Subsystem Development and Design Verification

This is the same as Control Point 5230.

4. $\quad 5340-$-Manufacturing

The maintenance ground equipment will include an alignment kit for the purpose of installation the retro motors, the spin motors, and the separation motor. This kit will be a purchased item.

An ordnance checkout set will be required to perform continuity checks on the ordnance delay devices, the clamp separators, the pin puller and the solid-state switching devices. Again, this instrument will be a purchased item.

A battery checker will be fabricated in accordance with engineering design releases. This piece of equipment will consist of a metering device with several electrical components. No manufacturing problems are anticipated in the fabrication of this checker.

\section{5350--Quality Control}

It is expected that the rocket motor alignment kit and ordnance checkout set will be purchased items while the battery checker will be contractor fabricated but will include purchased components. This equipment, like that of the Operating Ground Equipment, will be evaluated during the design effort to determine which components will be source

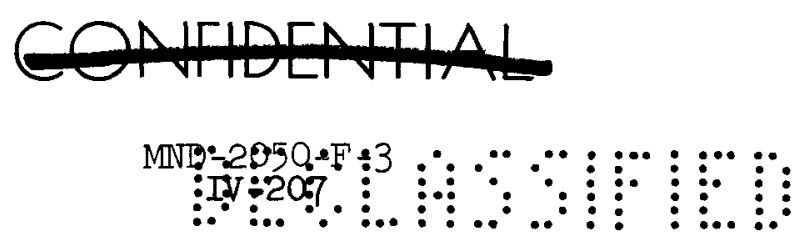




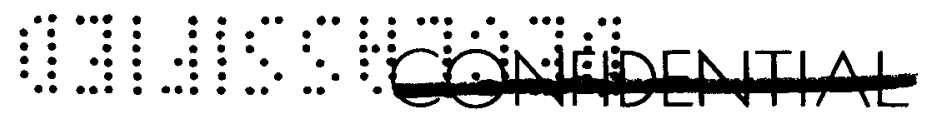

inspected and which will be accepted in-plant. Contractor acceptance plans and receiving acceptance plans will establish the acceptance criteria.

\section{6. $5360--F u e l i n g$ Demonstration and Other Units}

The MGE will be acceptance tested as individual end items and as an interconnected system. The system will be delivered and installed at the launch site and checked out to an acceptance procedure prior to the use of the equipment in the demonstration flight.

A similar set of MGE will be acceptance tested and installed in the Contractor's ATF for subsequent acceptance tests of the RTG/RB and CIR systems. facility.

A third set of MGE will be delivered to the Spacecraft Contractor's a. Packaging and delivery

The requirements for packaging and delivery are the same as those of Control Point 5160 .

\section{7. $5370--F l i g h t$ Operational Unit}

The installed MGE at the launch complex, the Contractor's ATF and the Spacecraft Contractor's facility will be operationally supported by Engineering through acceptance tests of the RTG/RB-CIR at these facilities. Installation of modification kits to the ETR equipment, support of customer operating personnel and assistance in system trouble shooting will be accomplished on a level-of-effort basis.

8. $5380--$ Site Support

The Contractor will provide support of the demonstration flight, equipment maintenance and repairs, spares, assistance in procedure approval and other technical services.

In addition, Engineering liaison will be provided to customer personnel at the site on a level-of-effort basis to aid in emergency trouble shooting, evaluation of proposed design and procedural changes, etc.

a. Technical support services

Technical support services for the MGE paralleling that effort outlined in Control Point 3170 will be accomplished as applicable.

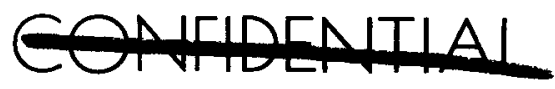


b. Fueling operation

Contractor engineering personnel will provide the operating, supervisory and instmucting personnel for the operation of the maintenance equipment during the demonstration flight.

c. Equipment maintenance and repair

Maintenance and repair of MGE system equipment will be accomplished substantially as described under Control Point 3170.

d. Equipment spares 5180 .

Equipment spares will be handled as described under Control Point

e. Procedure approval assistance

The technical and related efforts necessary to obtain approval for the MGE and MGE site procedures will be supported. 


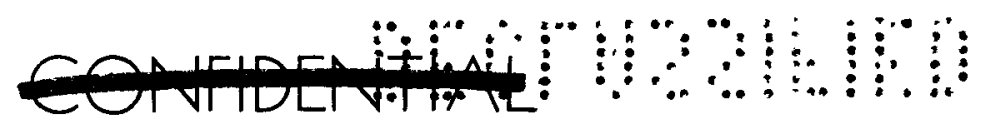

\section{DETA ILED PROGRAM SCHEDULES}

This chapter contains the detail schedules for the CRONUS program. These detail schedules support and expand upon the summary schedules shown in Chapter II. The detail schedules are based on the control point structure contained in the development plan and document the span times for the description of effort contained in the previous chapters. Noteworthy milestones within the detail schedules are listed below.

Phase $I$ is eight ( 8 ) months in duration and includes completion of design layouts, basic analysis and functional plans for all three systems. During Phase I, long lead procurement will be initiated for the prototype systems.

Approximately two (2) months after program go-ahead, complete definition of the space mission will be required. Approximately 8 months after go-ahead, the GHE mockup will be delivered and preliminary design review of all three systems will take place. Also during this phase, component development will be initiated, including aerodynamic wind tunnel tests, capsule development and separation tests employing equipment mockups.

Phase II is of 15 months duration and includes finalization of design, the release of production drawings, and a critical design review in the fourteenth month after go-ahead. During this phase, all long lead procurement for the prototype units will be released by the fourteenth month and subsystem development will be initiated, including dynamic and structural tests, thermal profile tests, separation, despin and spin performance tests and component qualifications.

Phase III is of 25 months durationand includes the fabrication and assembly of qualification test units and the demonstration flight units. During the phase, the GHE will be delivered to the launch site for the fueling demonstration which is scheduled for twenty-nine months after go-ahead. OGE and MGE will be delivered along with the demonstration flight equipment for the flight demonstration occurring in the thirtyfourth month. A spacecraft and launch vehicle integration effort will take place during this phase and two models of the CRONUS system will be delivered to the User's spacecraft integrator in the forty-thirty and forty-fourth months.

Phase IV spans three years and eight months and includes the production of the operational flight CRONUS systems. The first and second of which will be delivered in the fifty-fifth month and the remaining five at six months intervals thereafter.

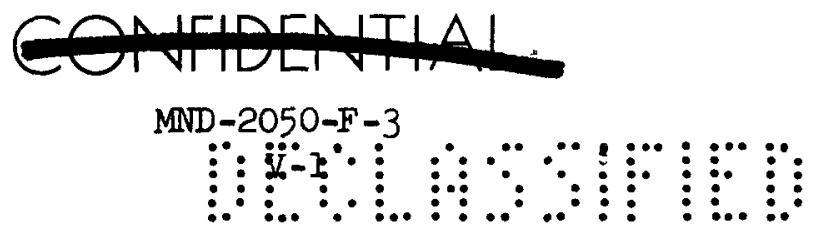




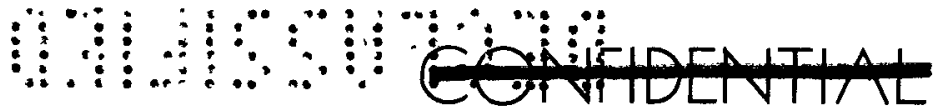

This chapter includes a Management Summary PERT Network containing the major milestones of the program laid out on a time scale and banded according to the first level of control points. The network is at a summary level. During Phase $I$ of the program, detail and supporting PERT networks will be developed to expand the summary network and provide a proven technique for program control. 
CRONUS DETAILPD PROGRAM SCHEDUIES

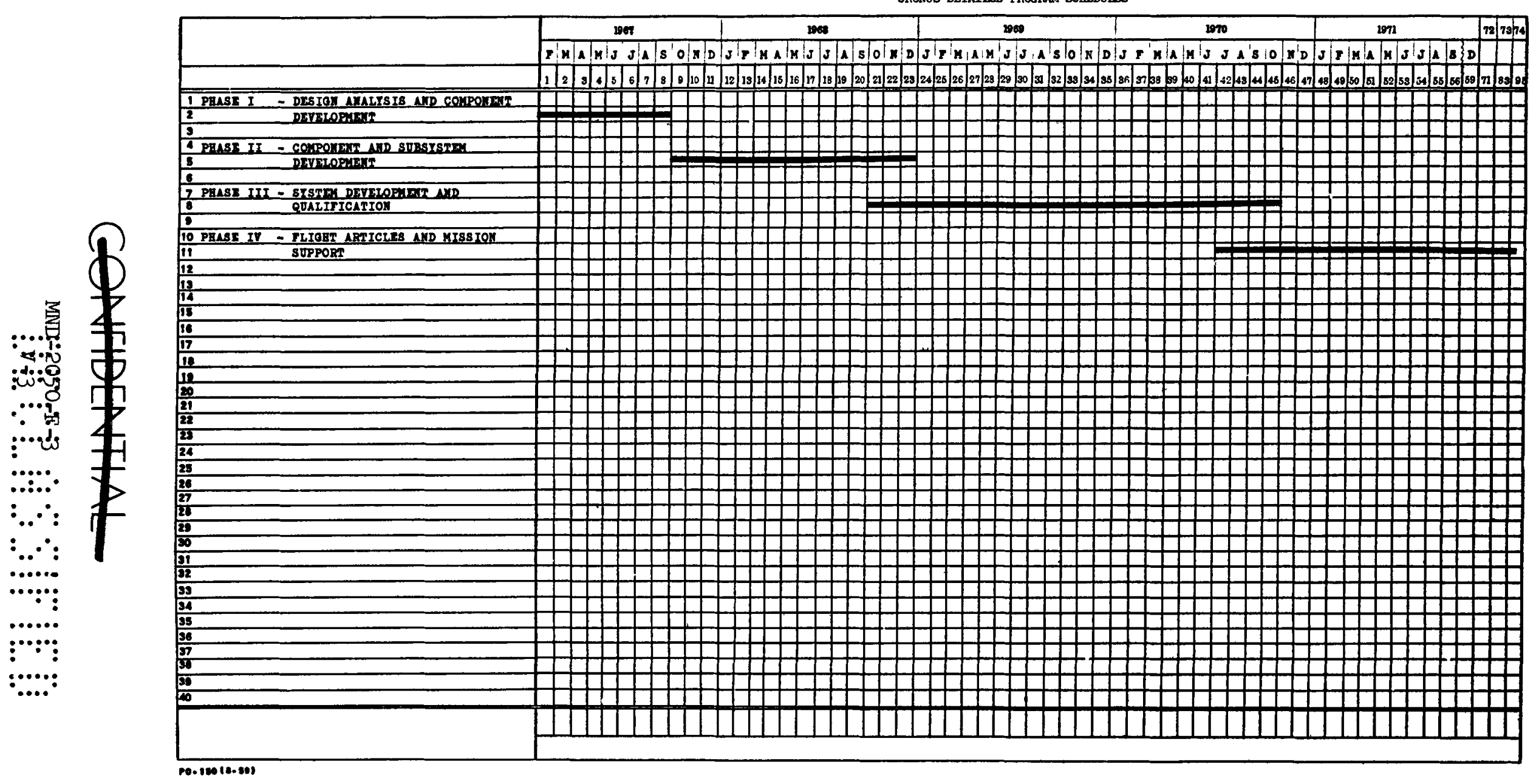

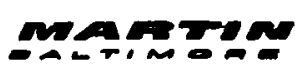

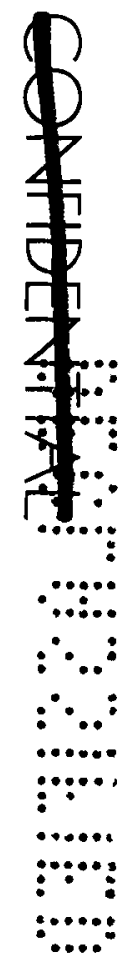


…...

¿...:.:

.......

....:

......

:

$\because \because$

$\ldots:$.

$\vdots$.

:

.

$\because:$

w

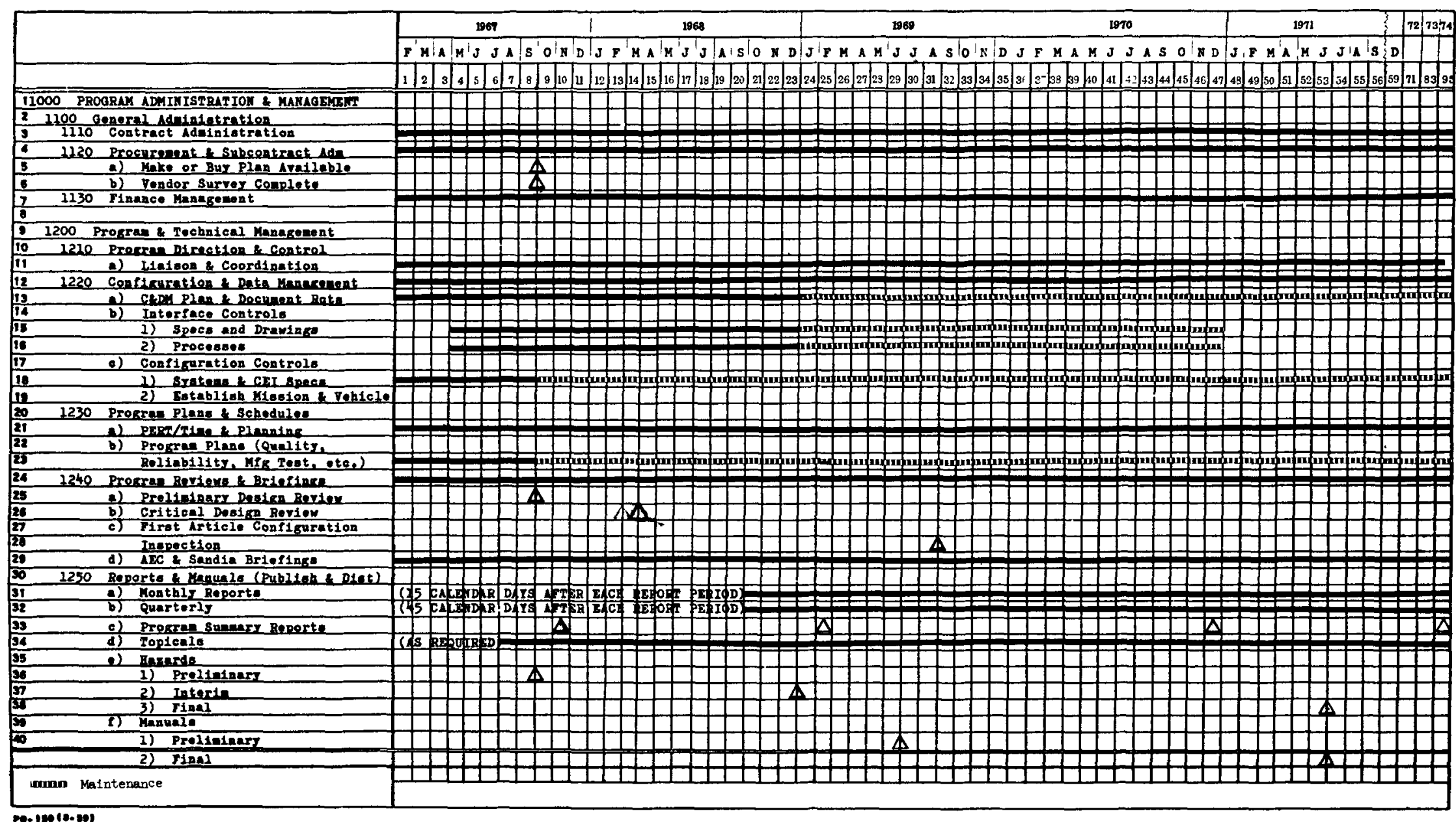

:...:

$\vdots: . .$.

.....

$\vdots . .$.

$\because \because$

$\because \because$

$\therefore$

$\because:$

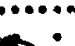




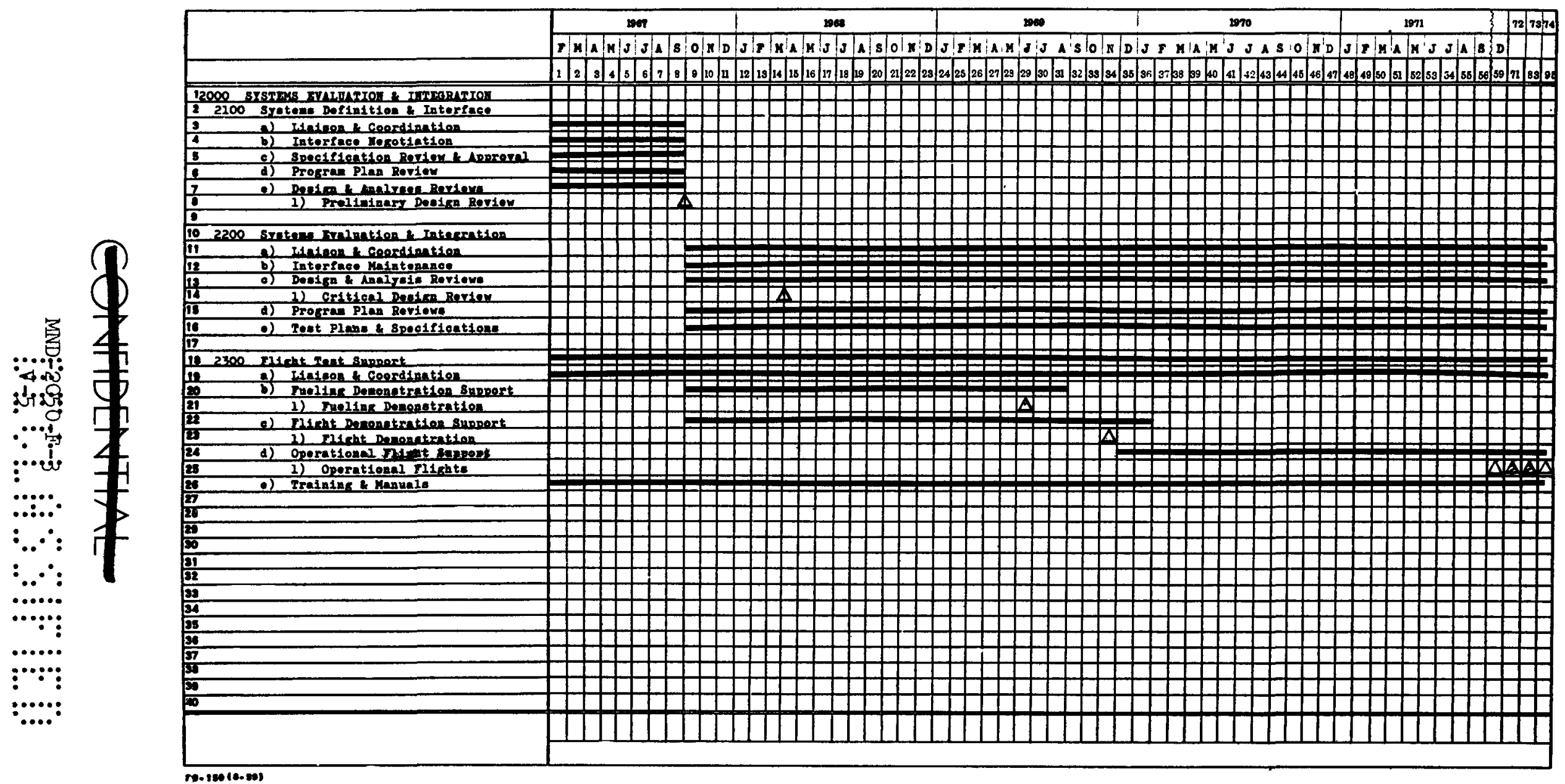


:....:

¿...:.

......

....::

$\cdots$

$\because \because$

$\because \because$

$\because \because .:$

$\therefore$

$\because .$.

:

$\therefore$

它

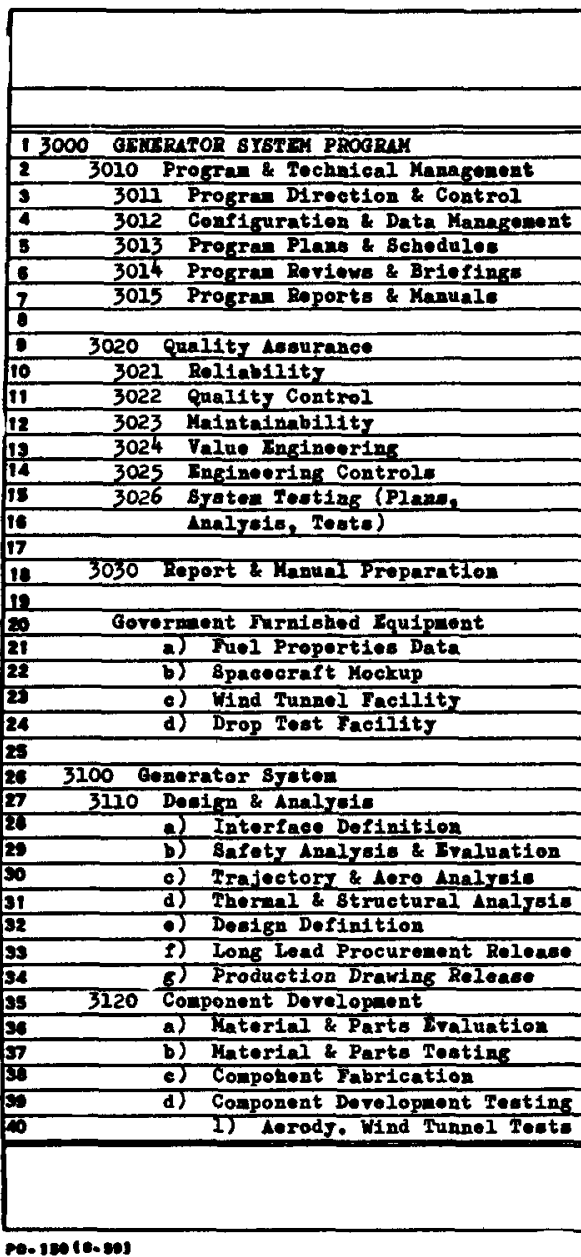

$\operatorname{sen}$

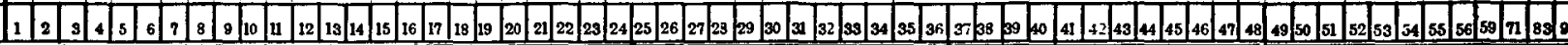

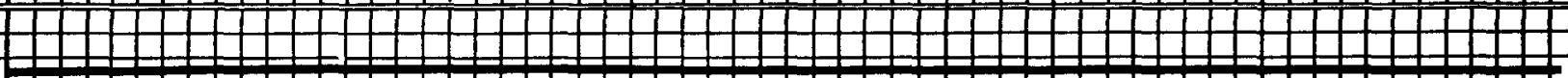

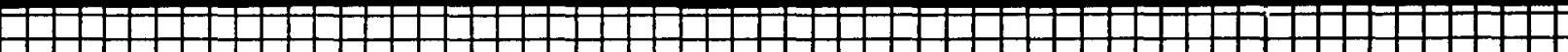

$\mathrm{H}$

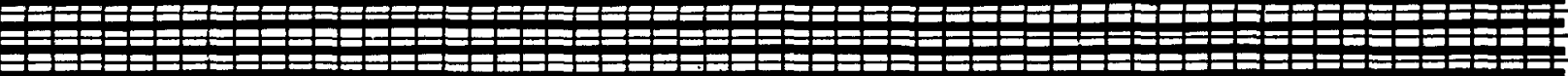

1011

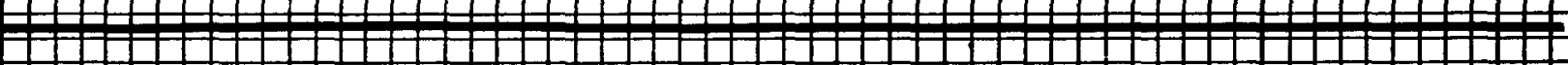

1 O 101

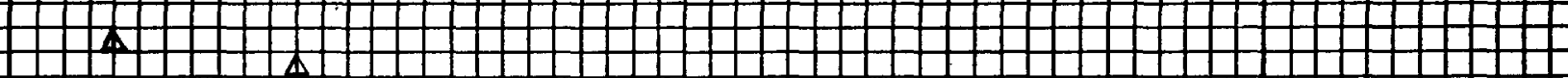

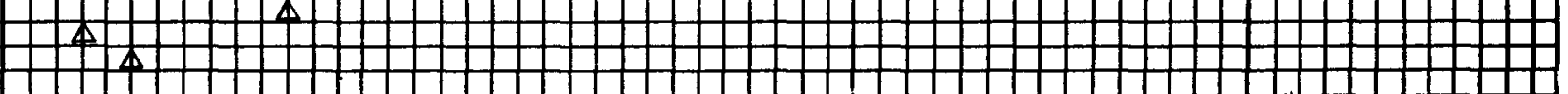

III

1 IPI

4 +

IIIIIII

2 -

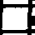

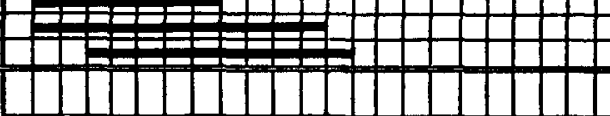

$\therefore . . .:$

$\vdots . . .:$

$\vdots . .$.

$\because \cdots$

$\because \because$

$\therefore \because$

$\because \because: 0$

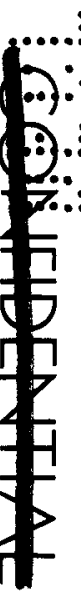




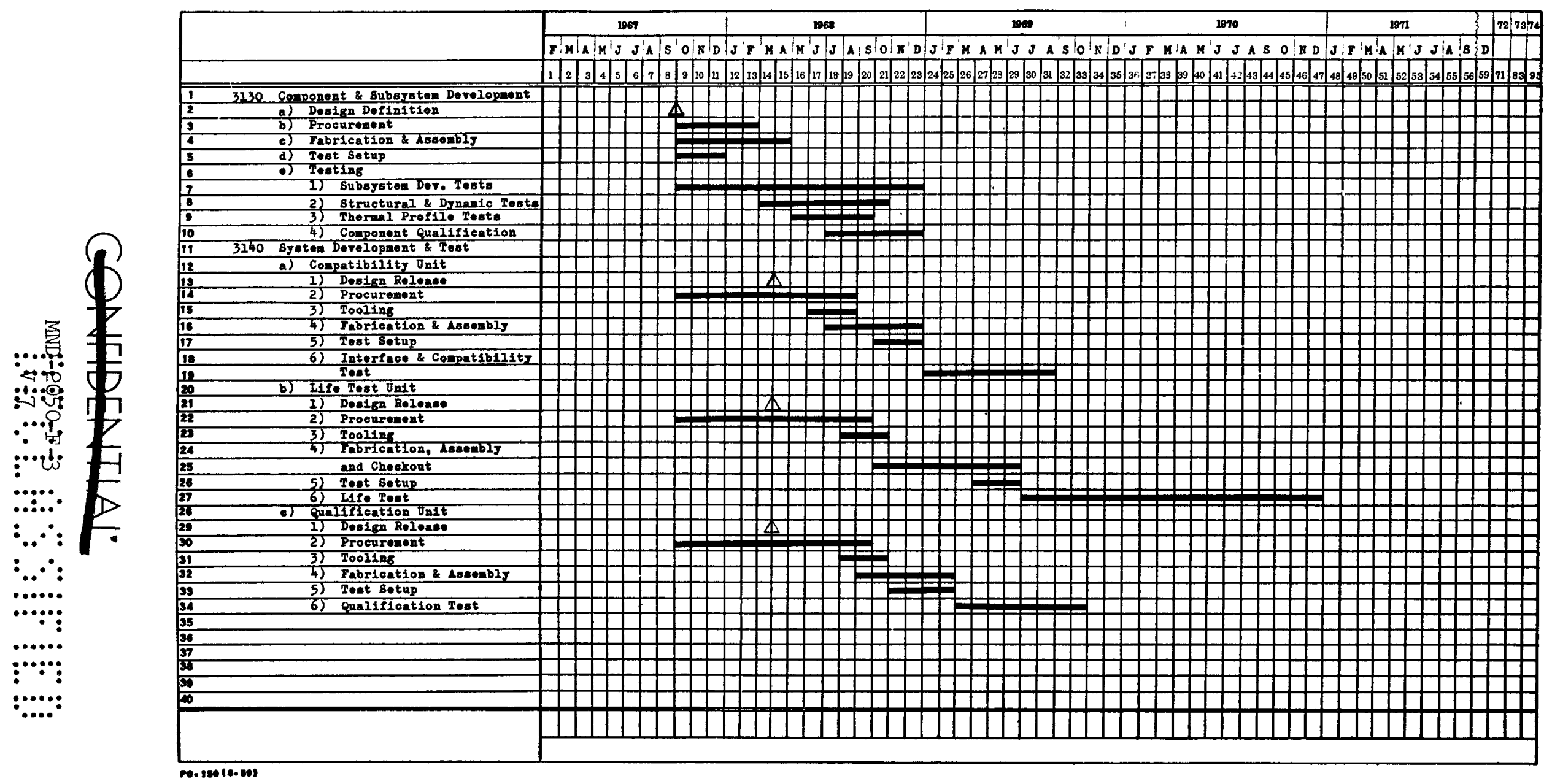

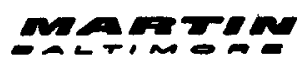




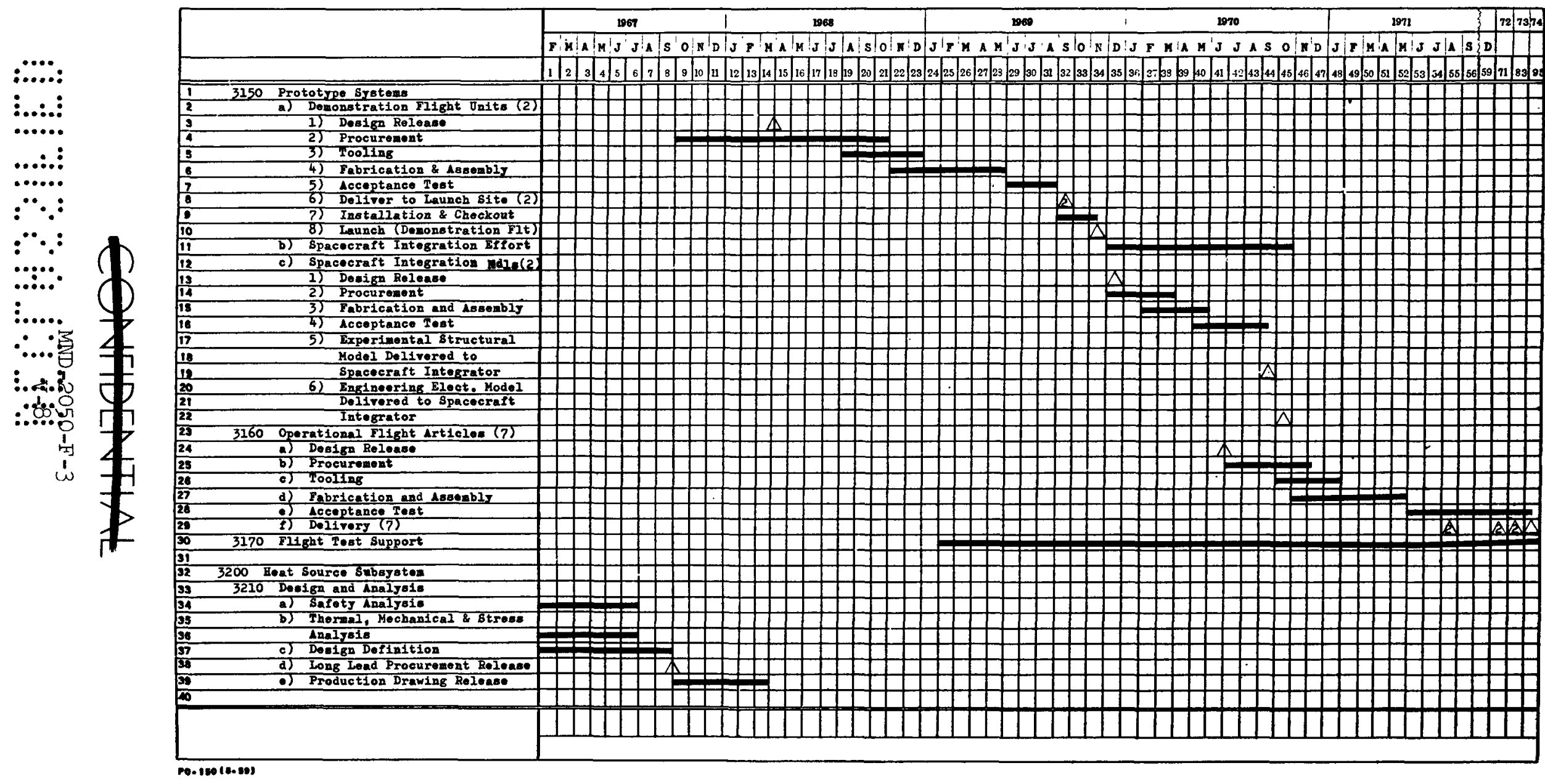

$\therefore: . .:$ :

$\vdots . . . . \vdots$

-.....

$\vdots . . .$.

$\ldots$

$\because \because$

$\because \cdots$

$\because \because:$.

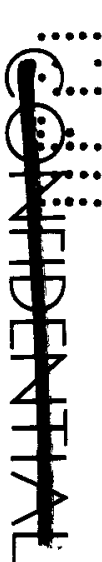




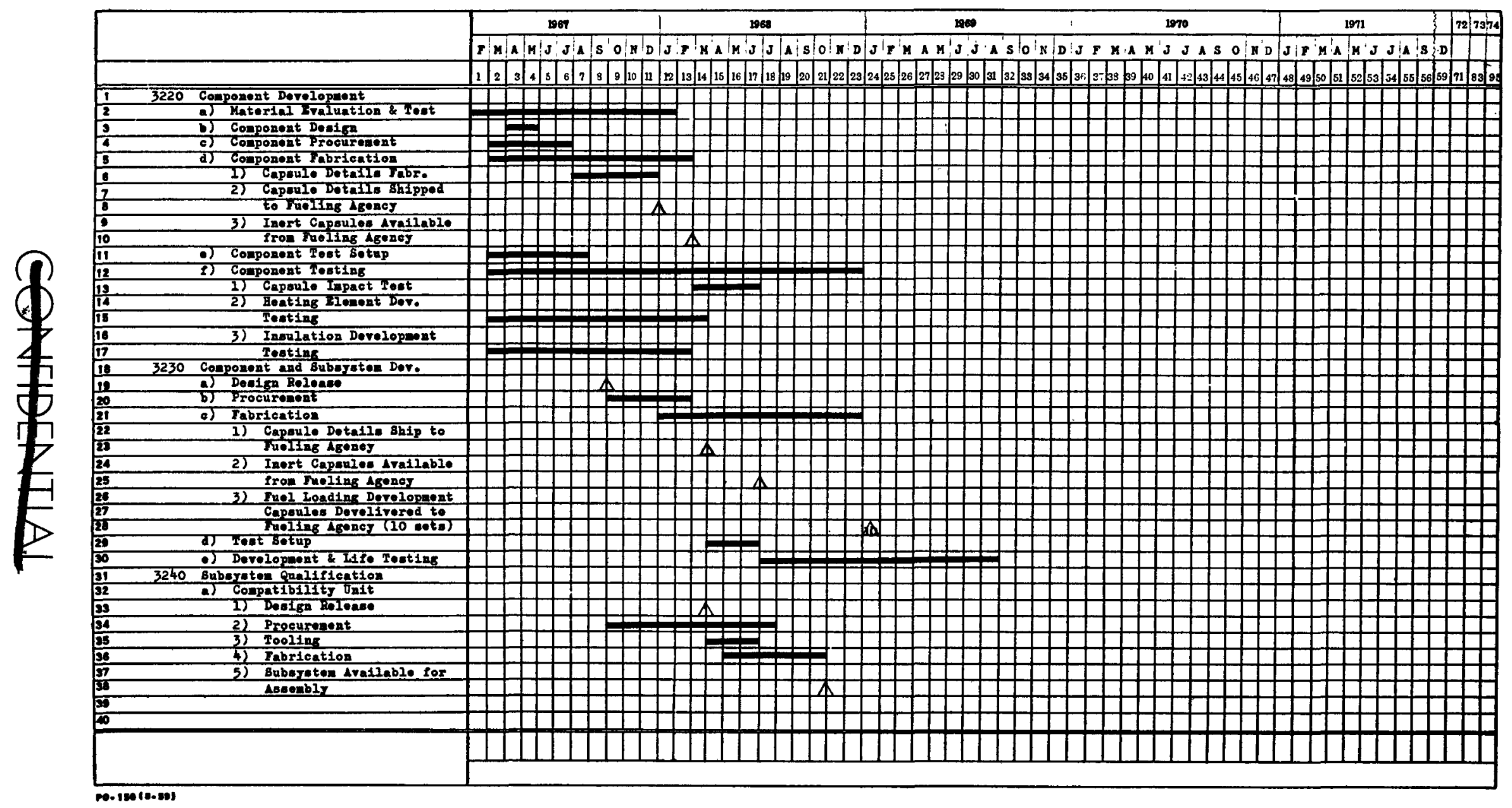




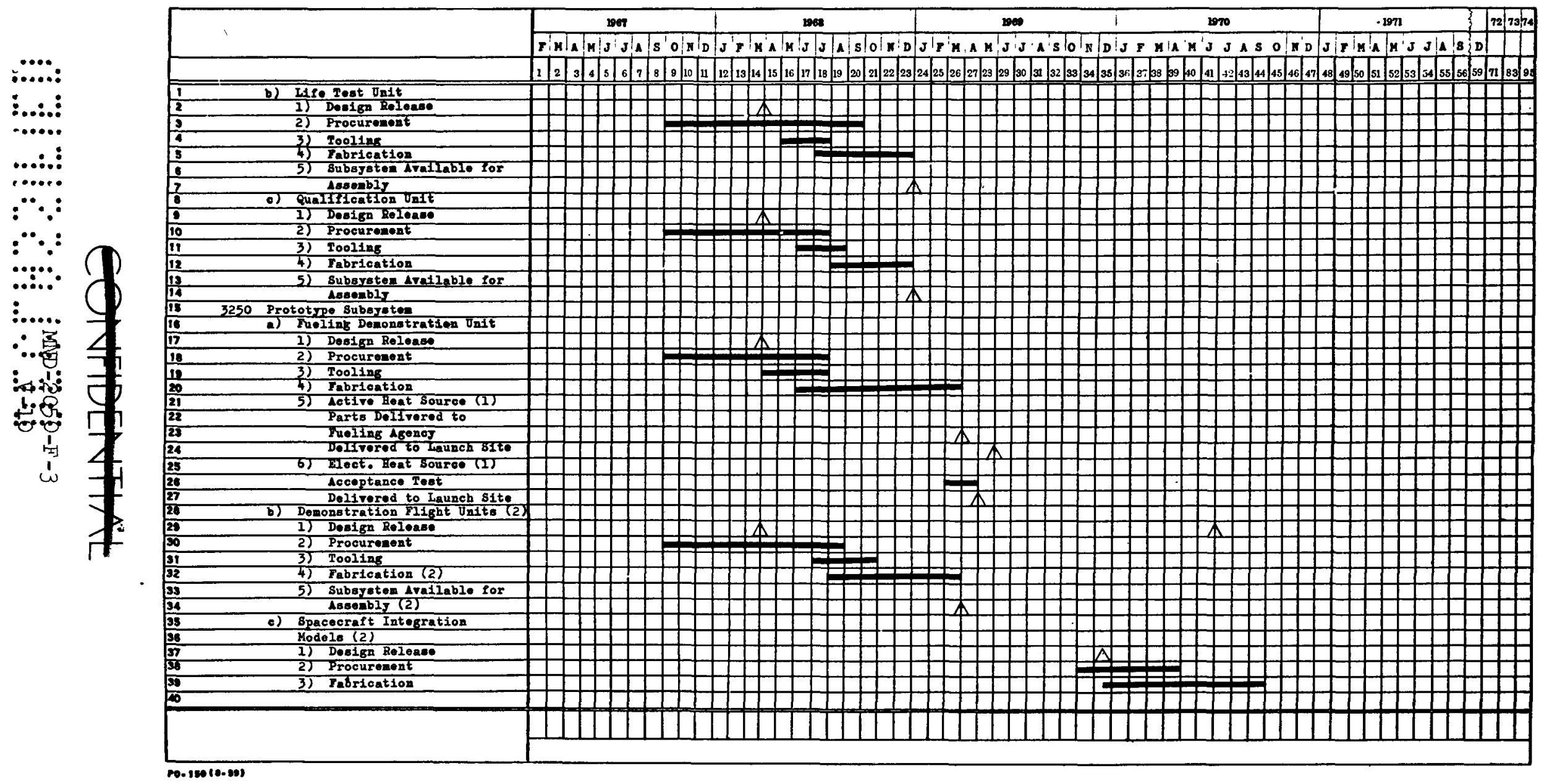

:.....

$\vdots . . . . \vdots$

¿.....

$\because \because$ :

$\because \because$

$\because \because$. 


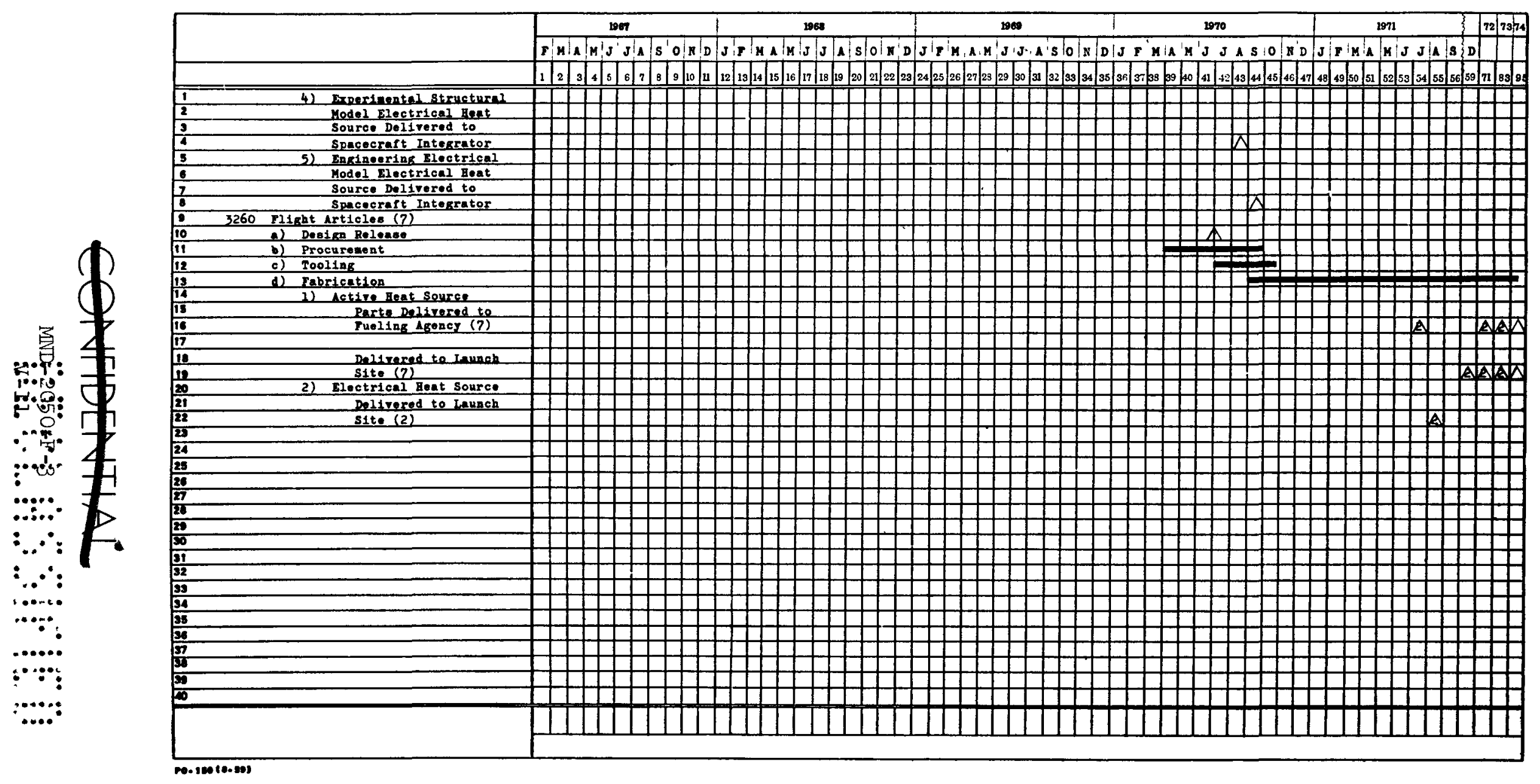




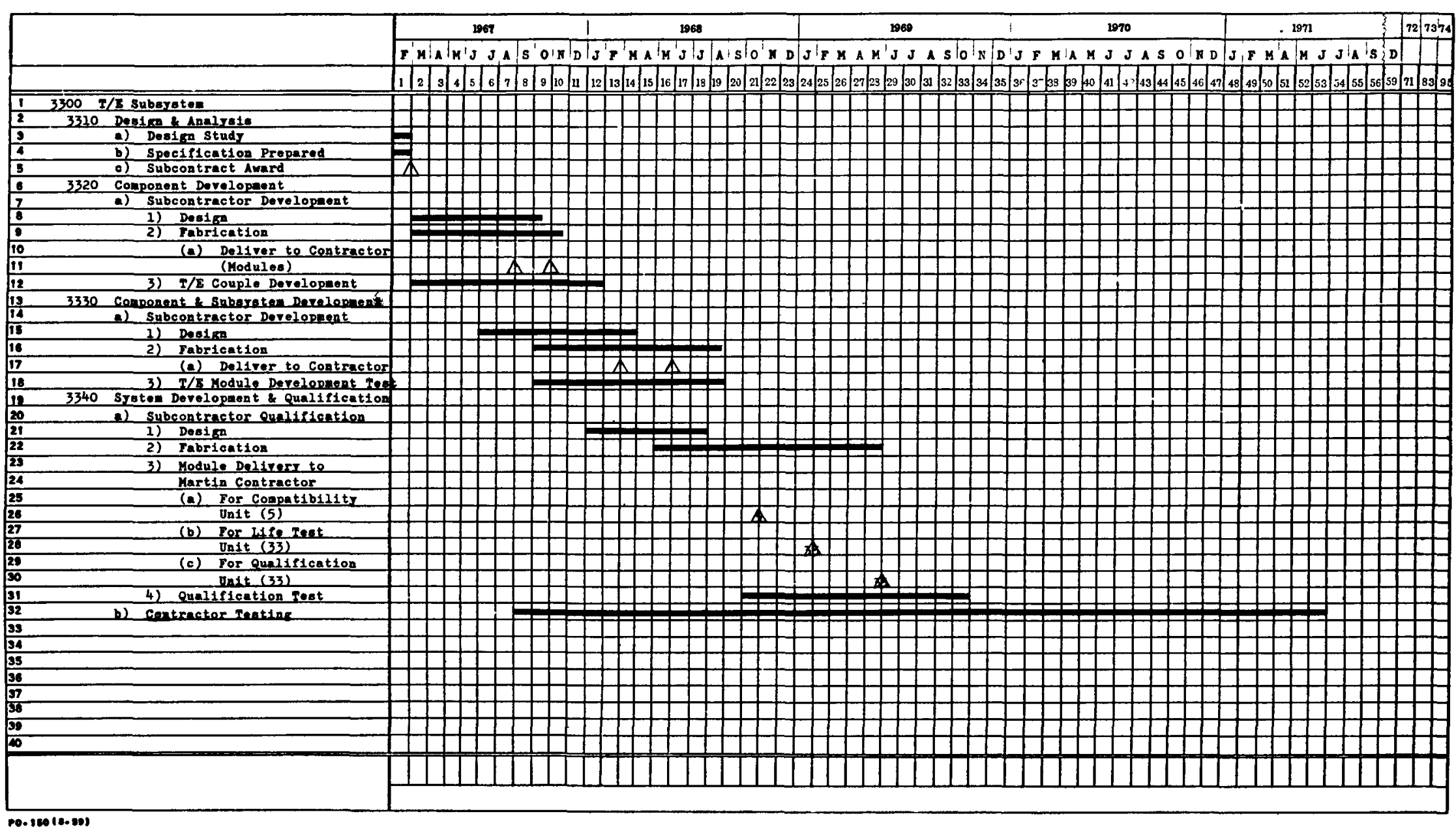




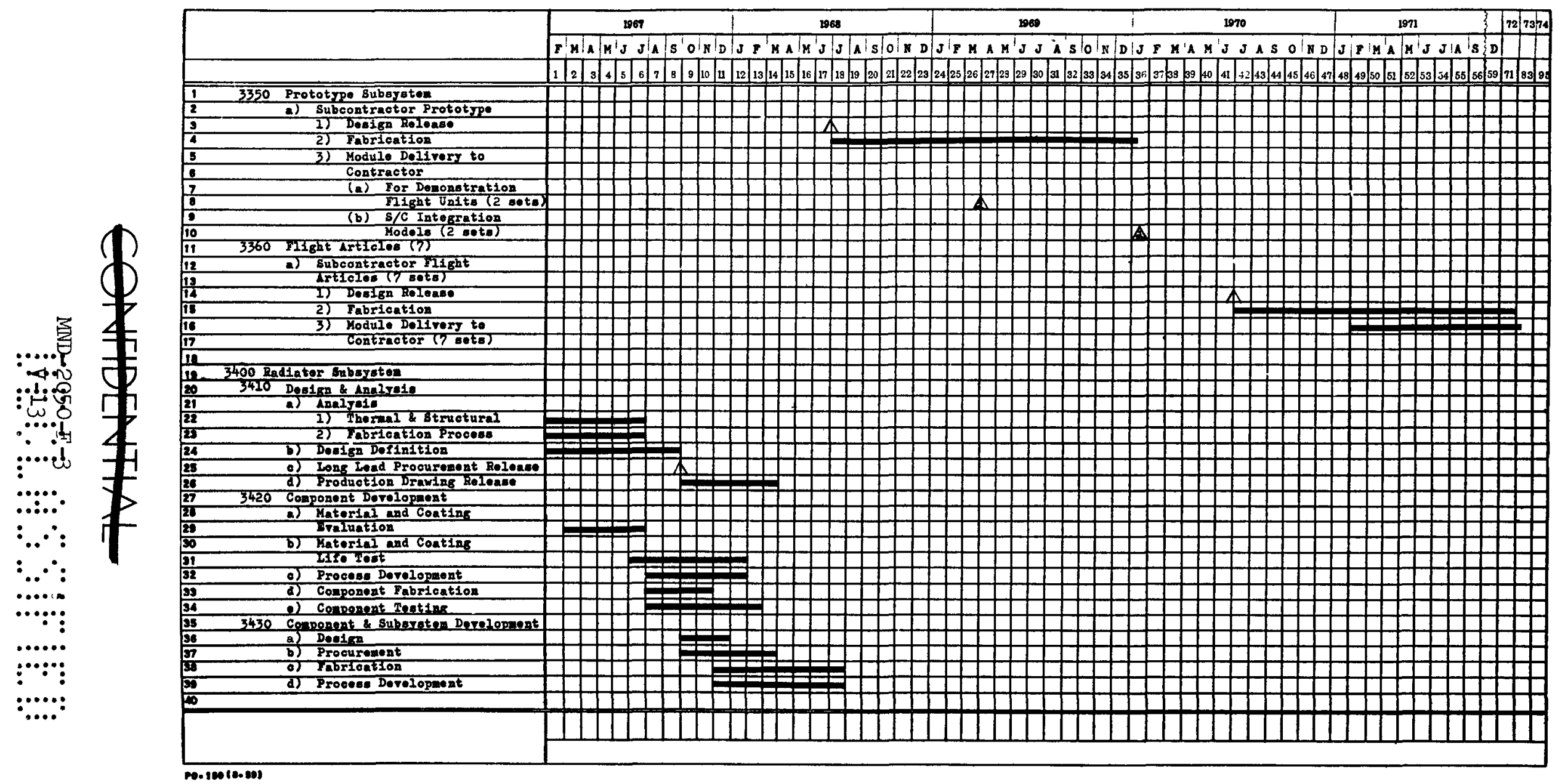

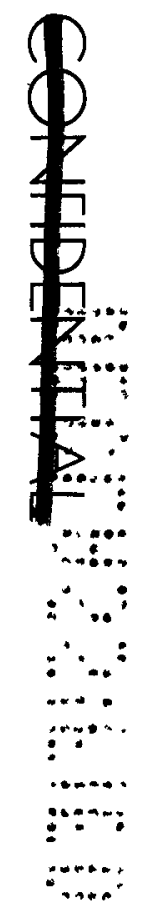




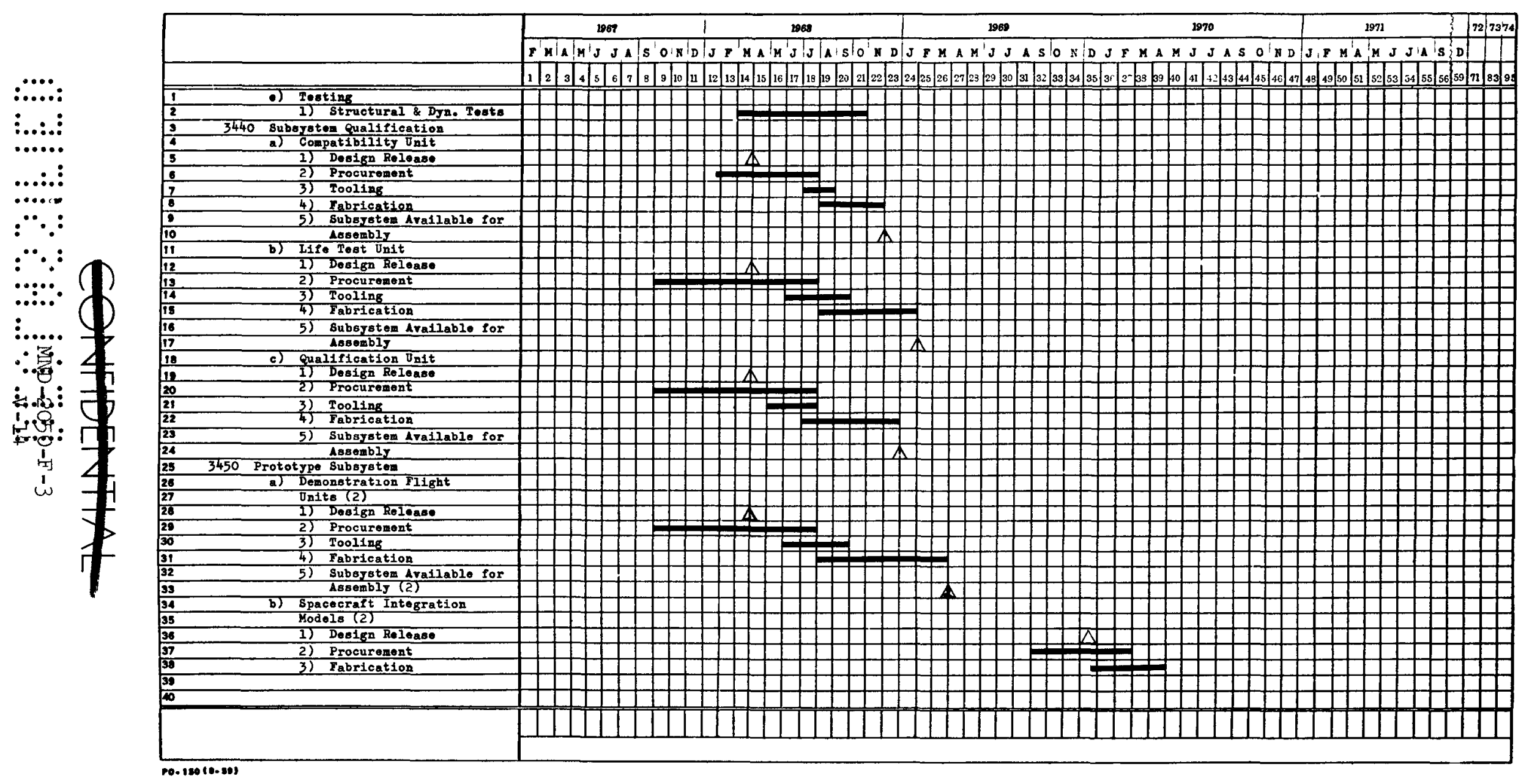




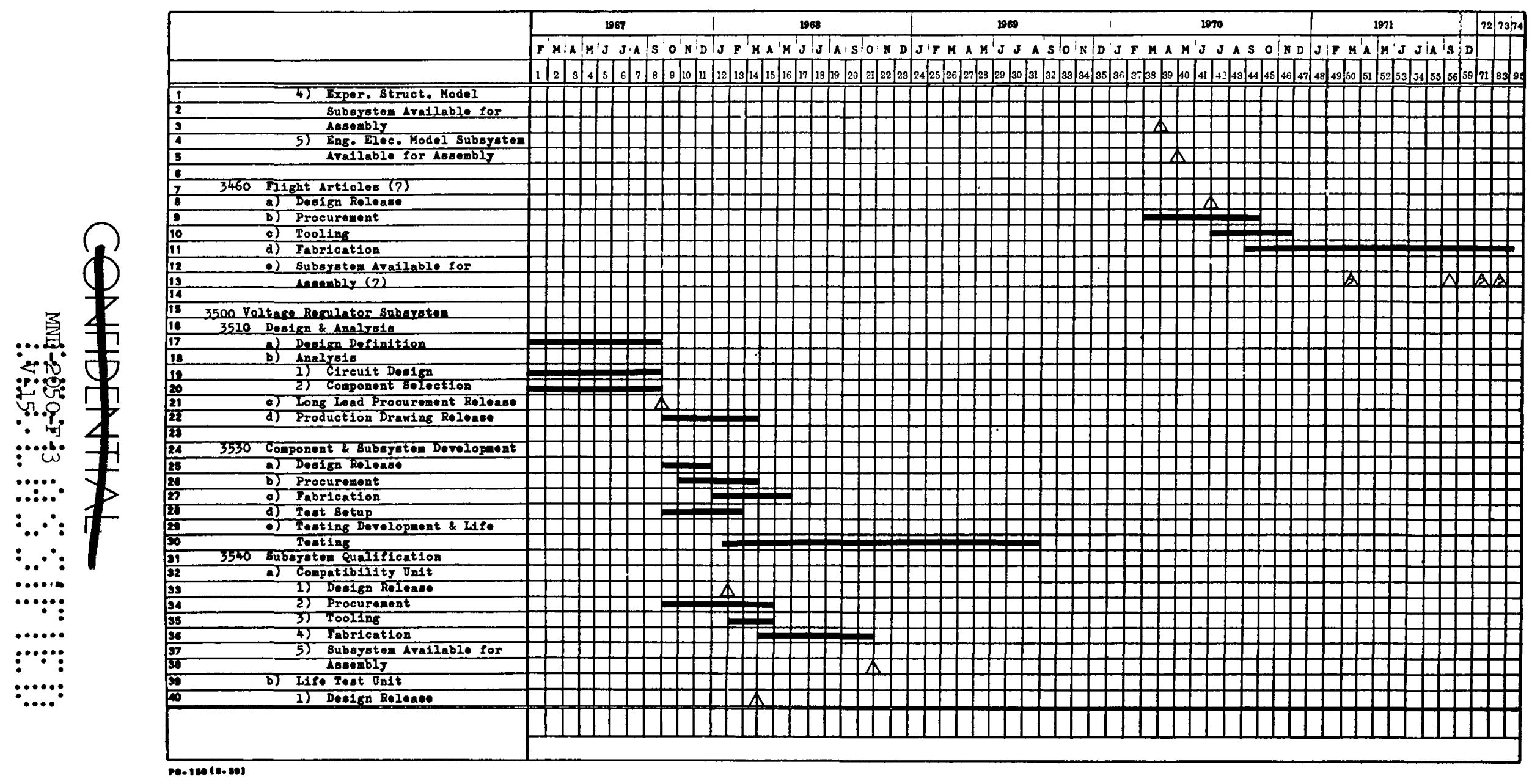

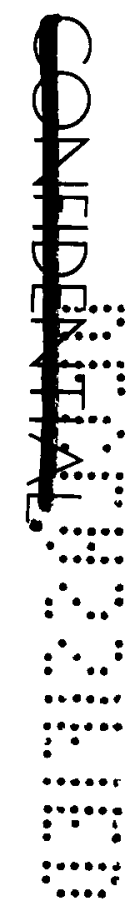




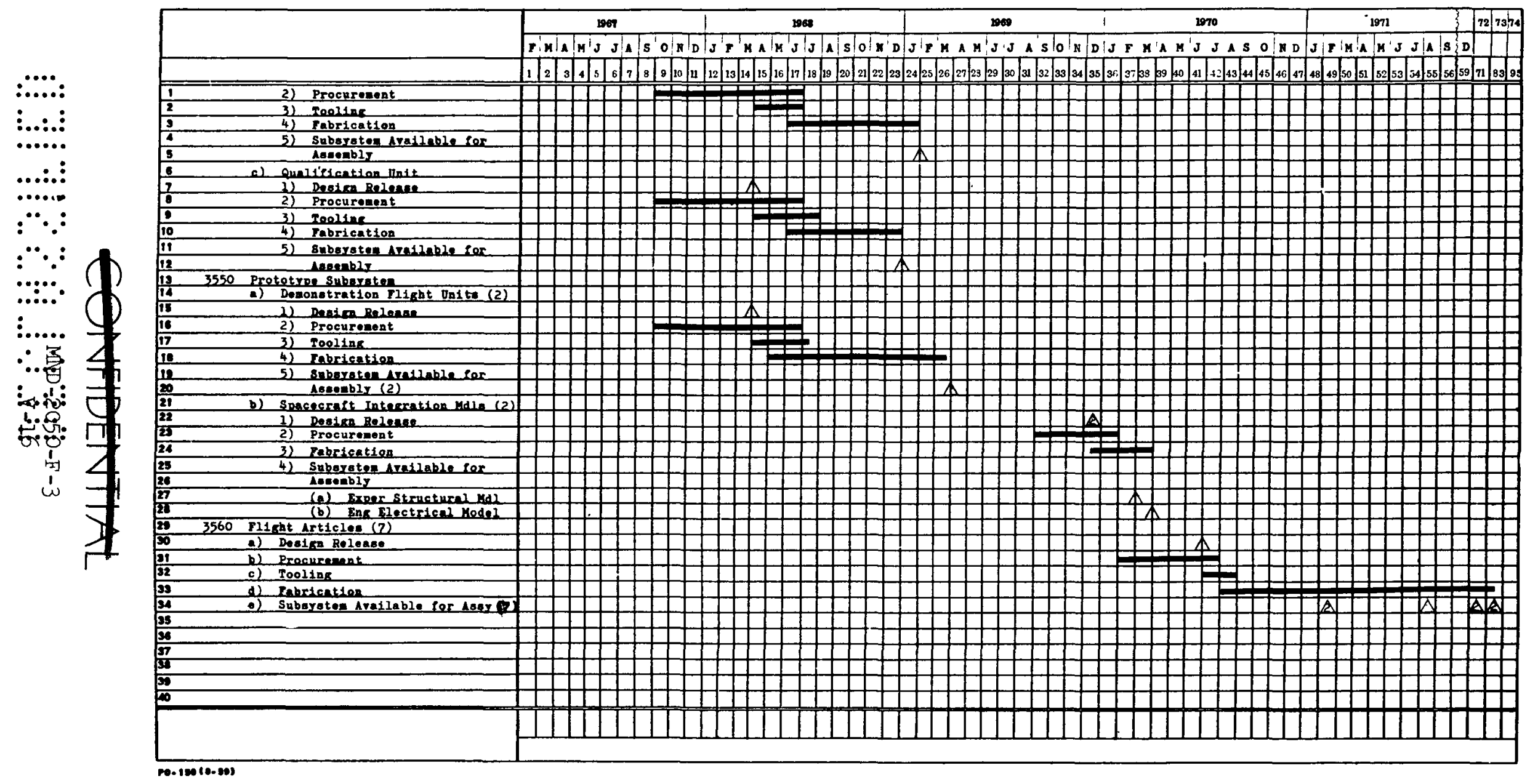




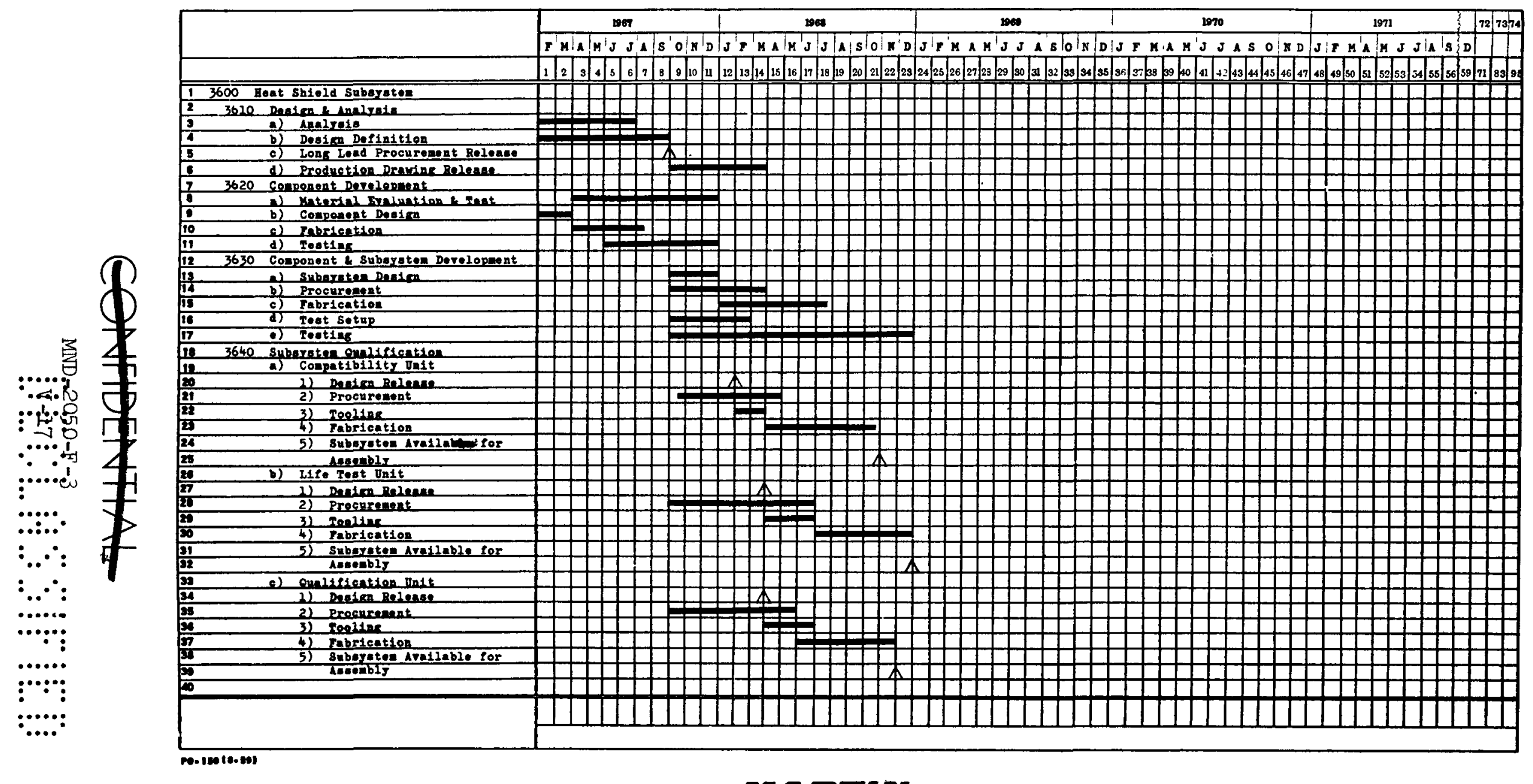




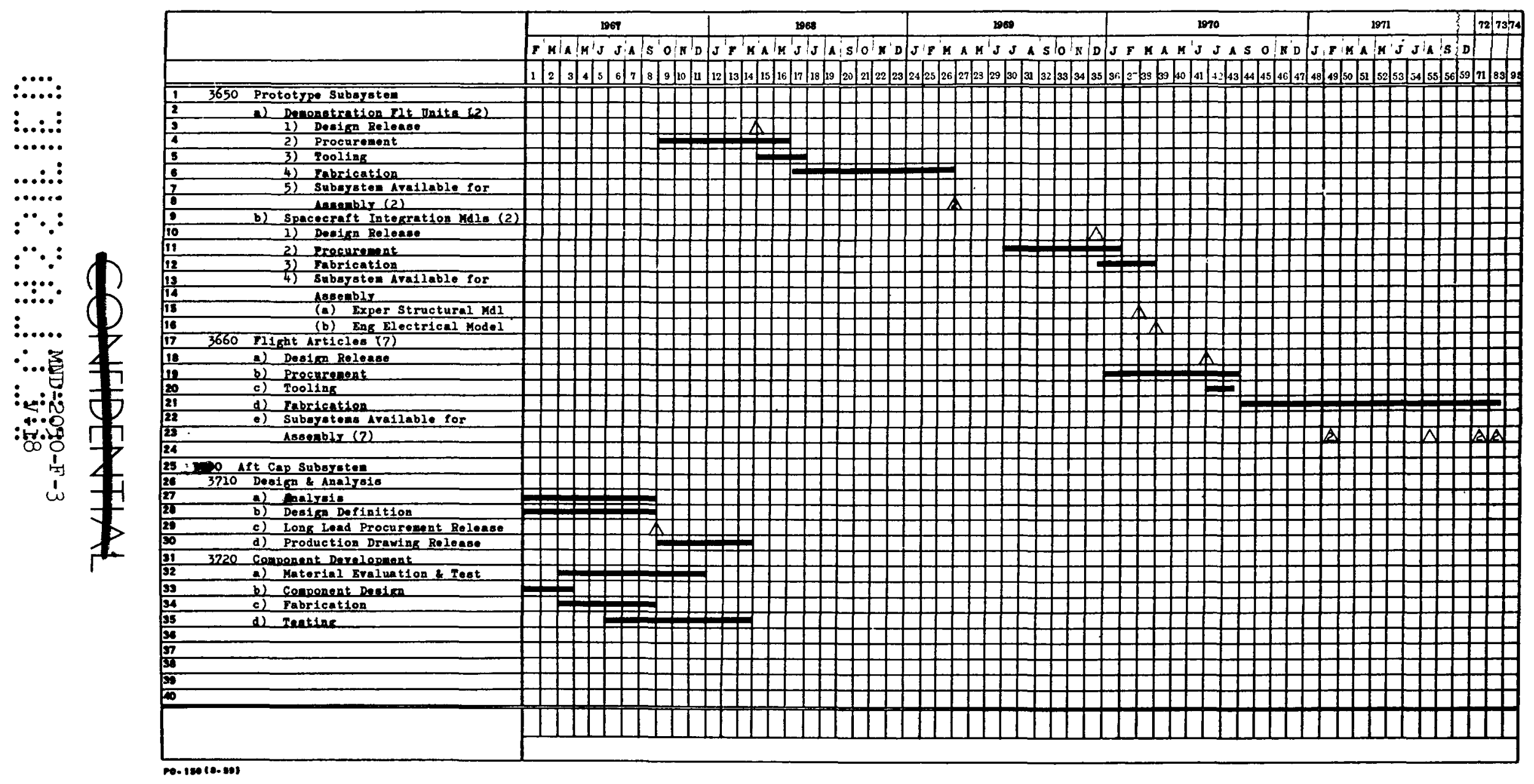

$\therefore: . .:$

$\vdots \ldots . .$.

......

$\vdots \therefore$

......

$\because \because$

$\because \because:$

$\because \ldots$

1....:

年 


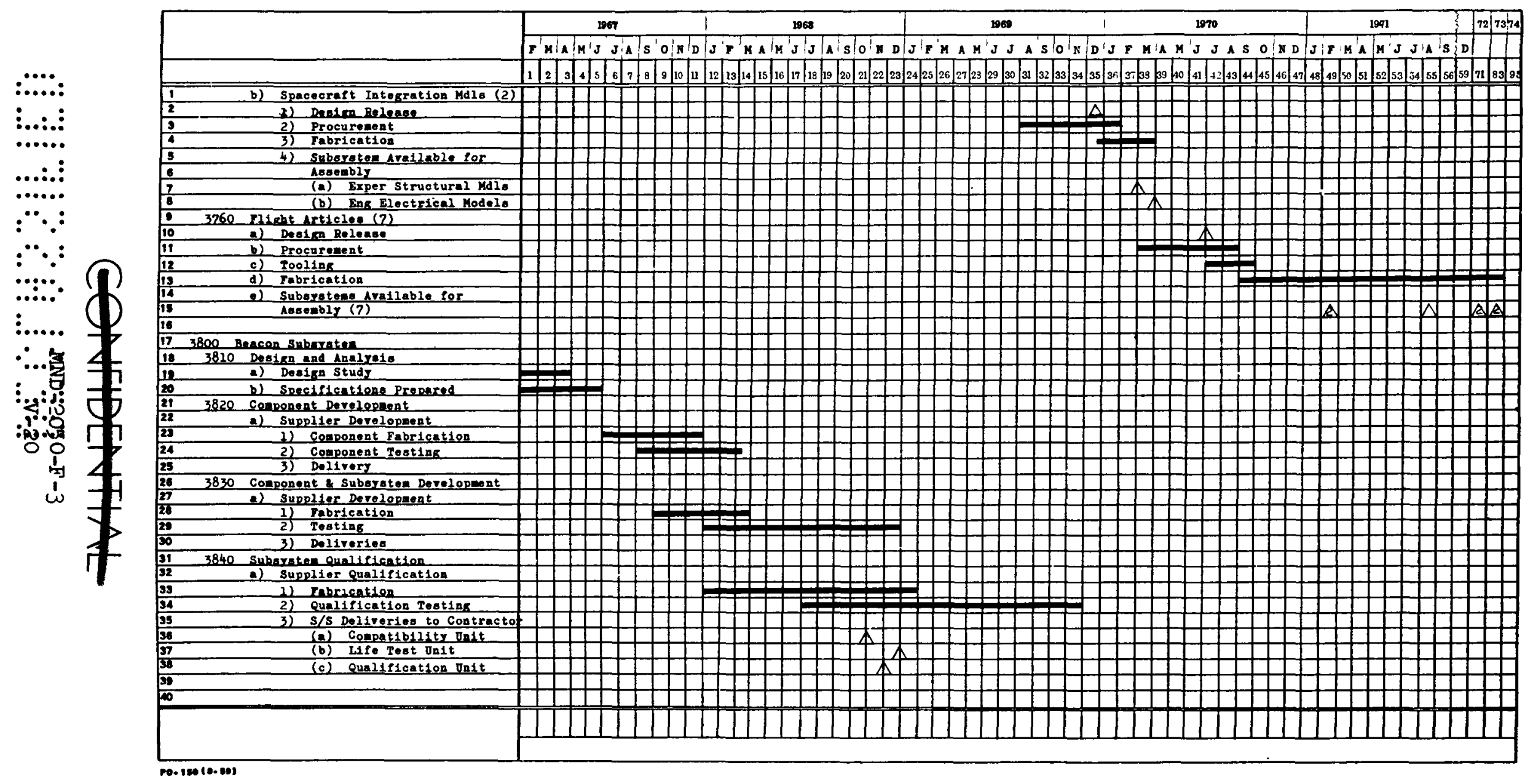

$\therefore: \cdots:$

$\vdots . . . . \vdots$

.......

$\vdots: \ldots$

$\because \because$

$\because \because$

$\because \because$

$\because:$ 


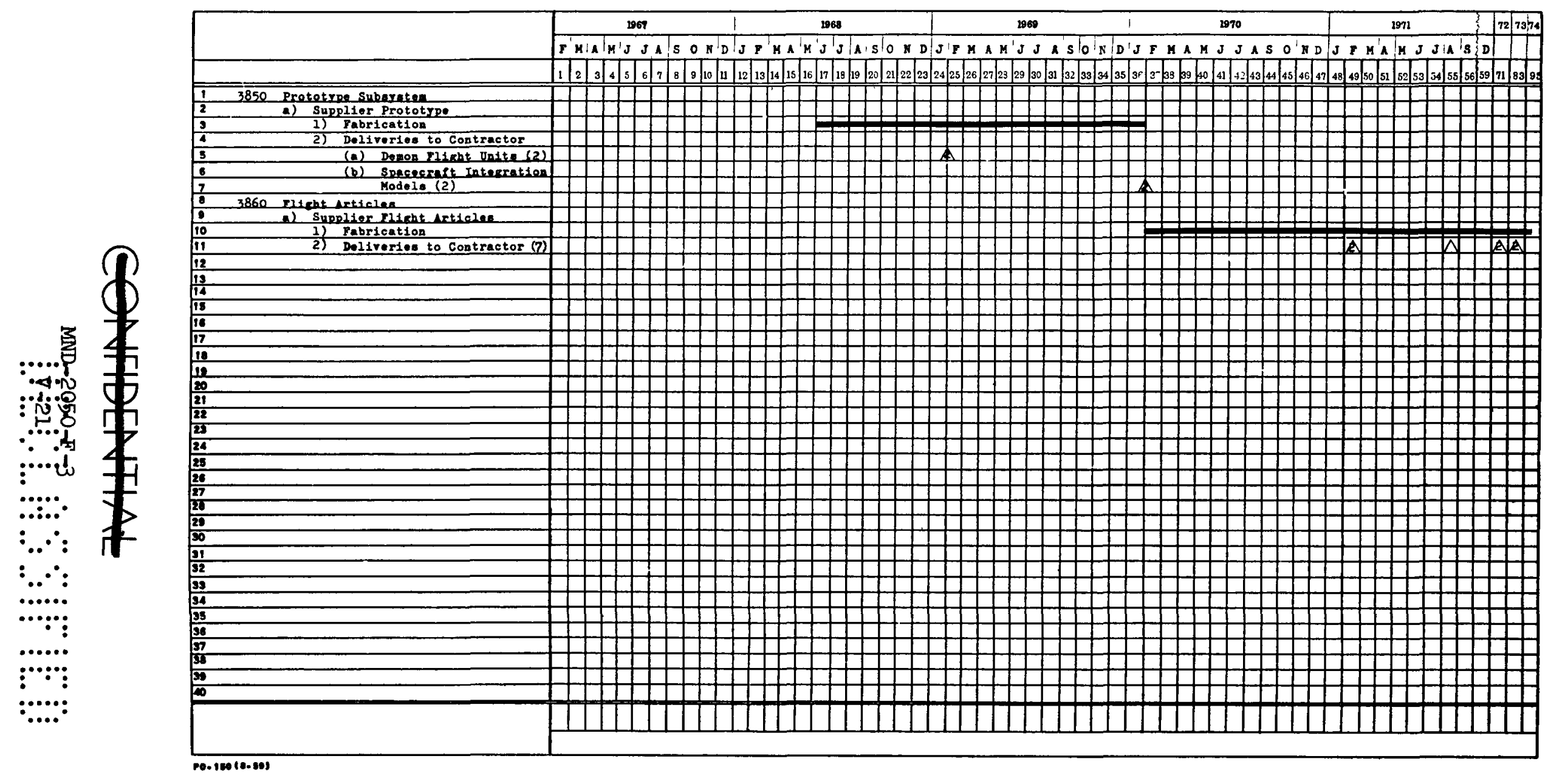

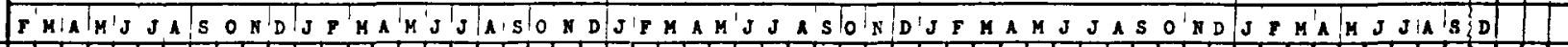

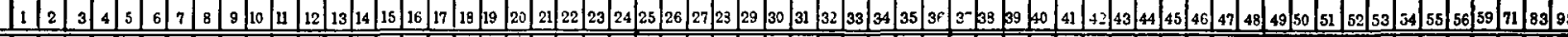




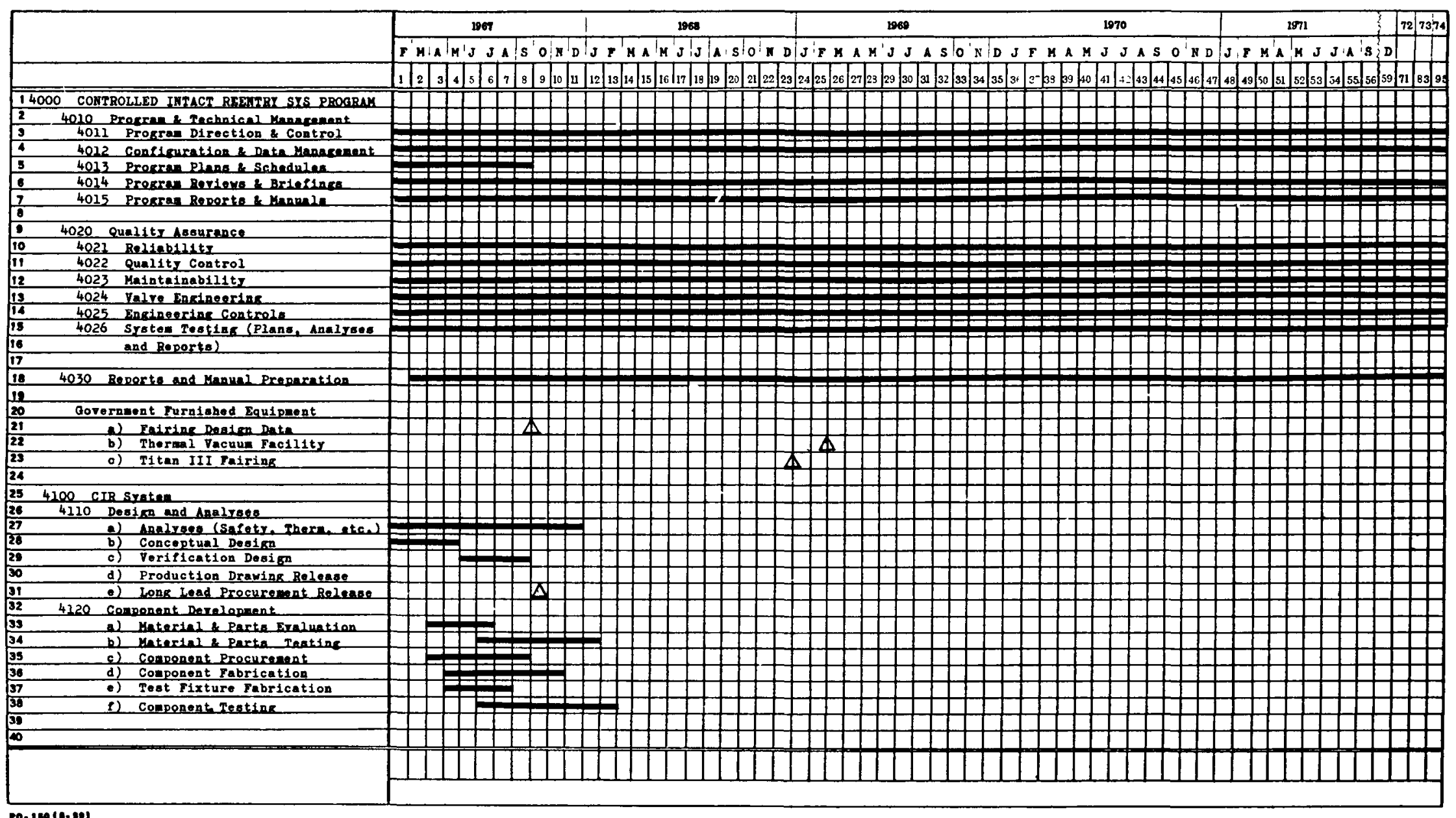




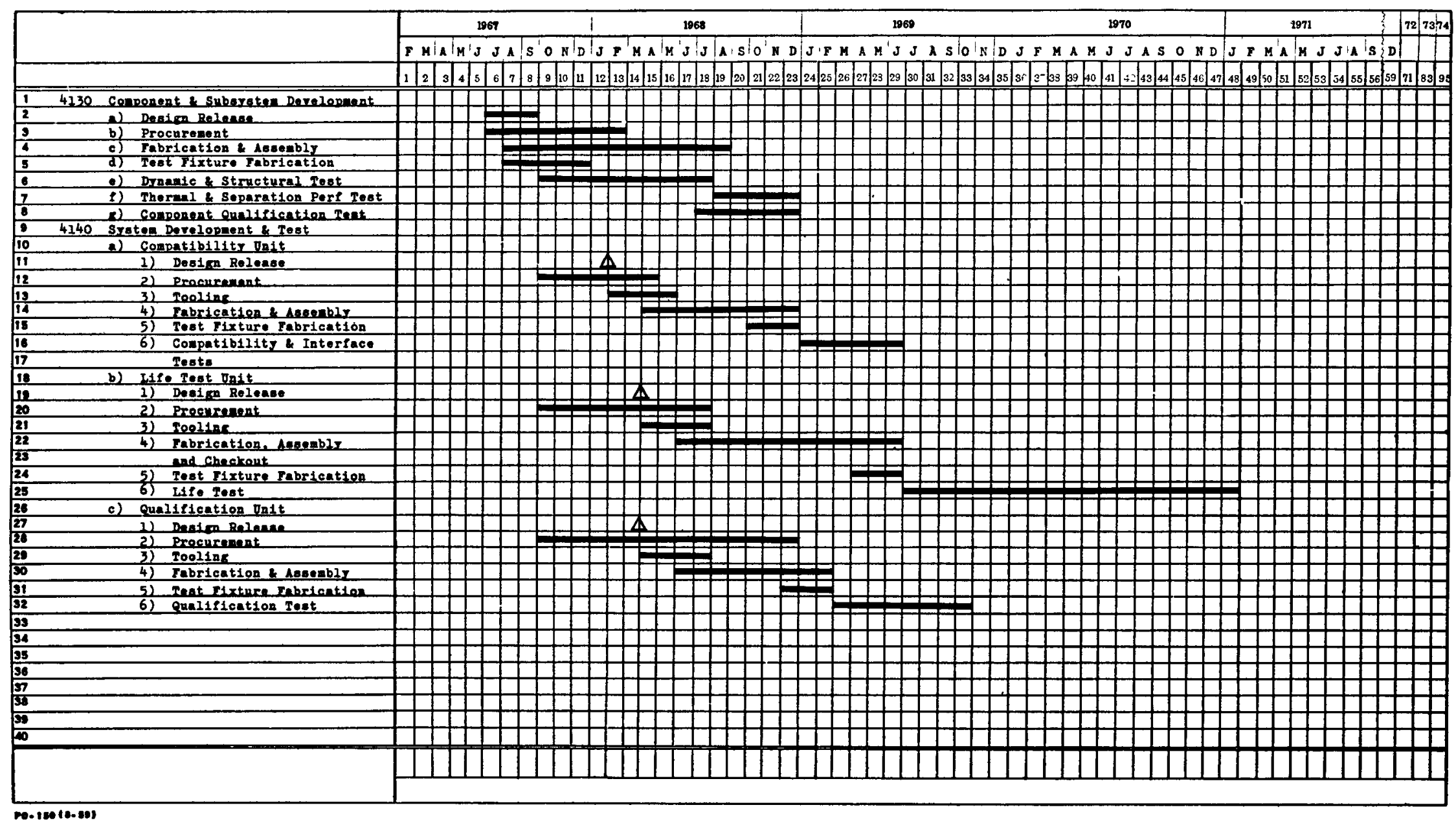

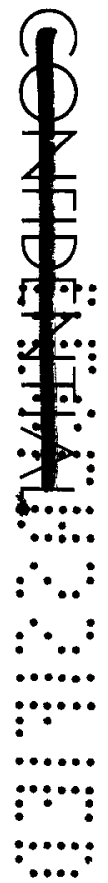

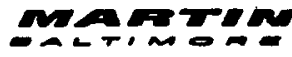




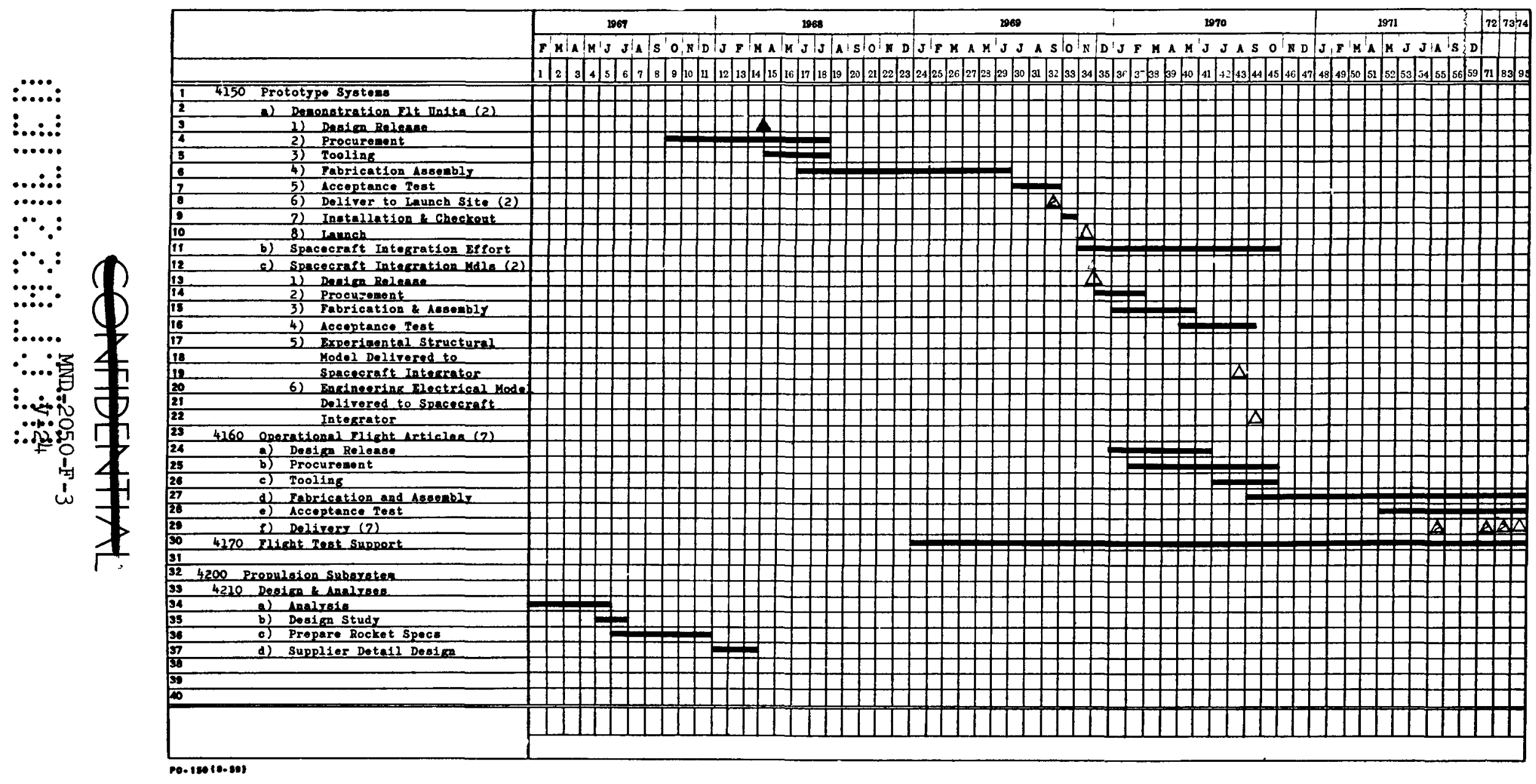



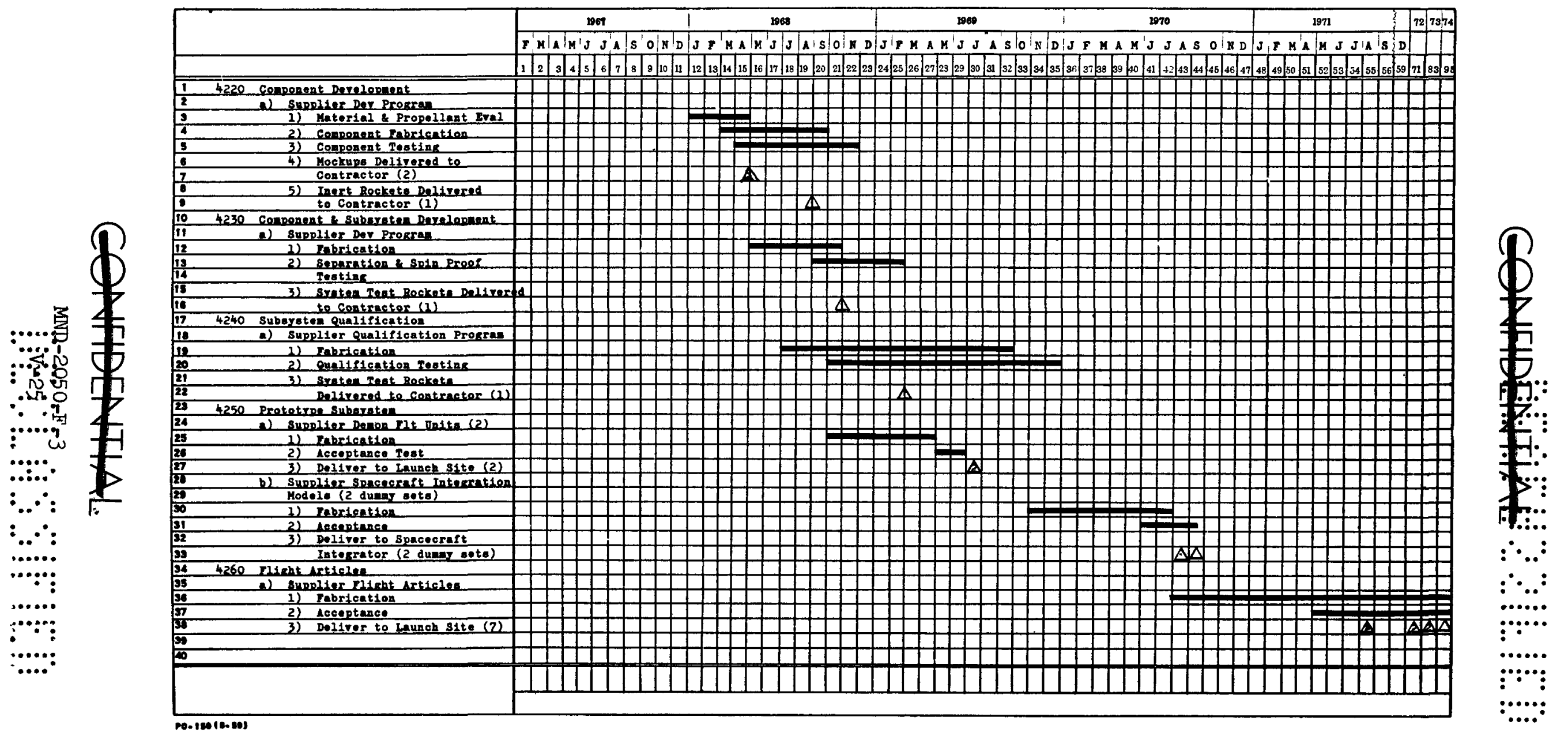


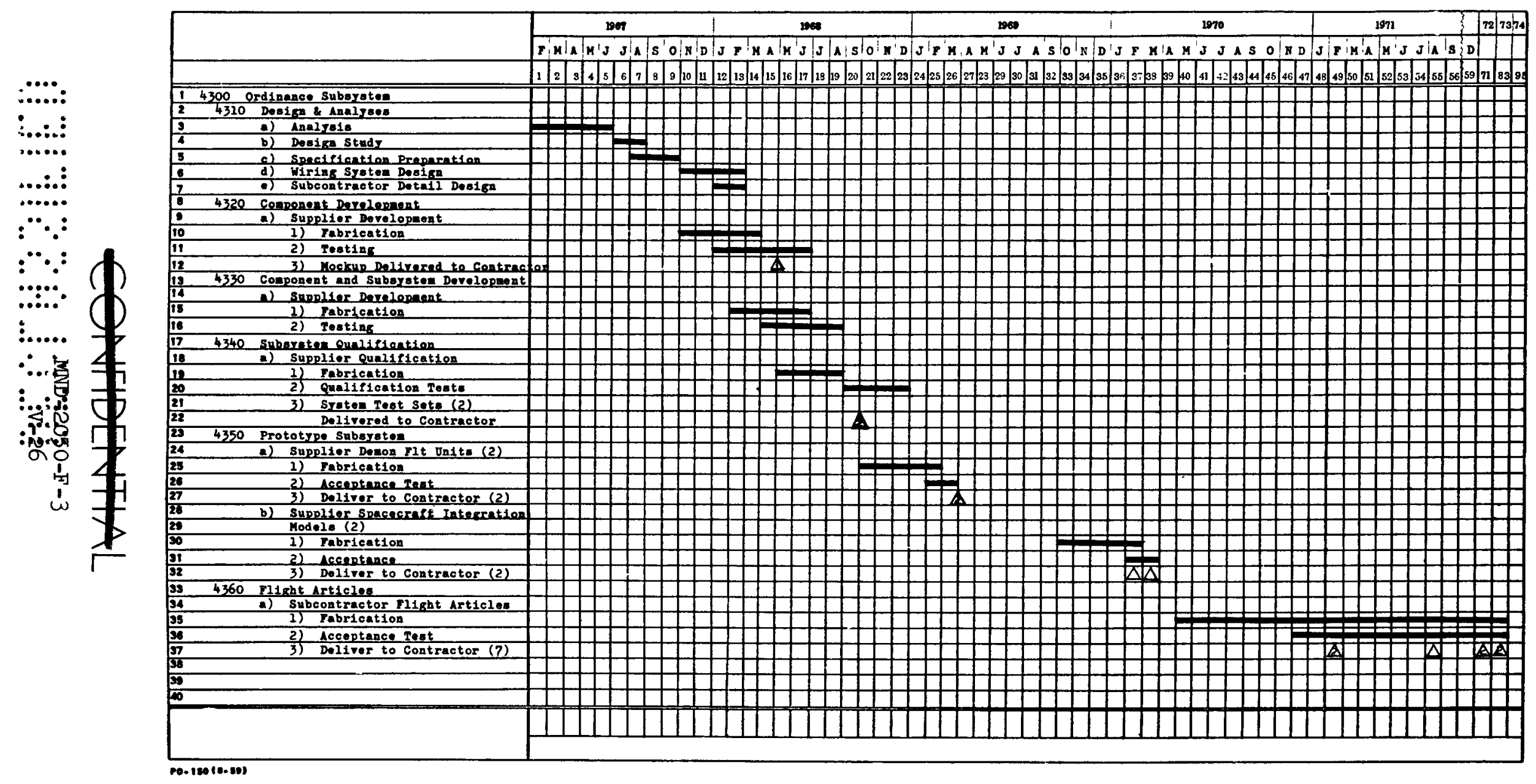

$\therefore: \cdots:$

:.:..:

$\vdots . .$.

$\because$

$\because \because$

$\because \cdots$

零

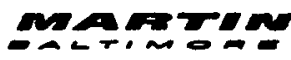




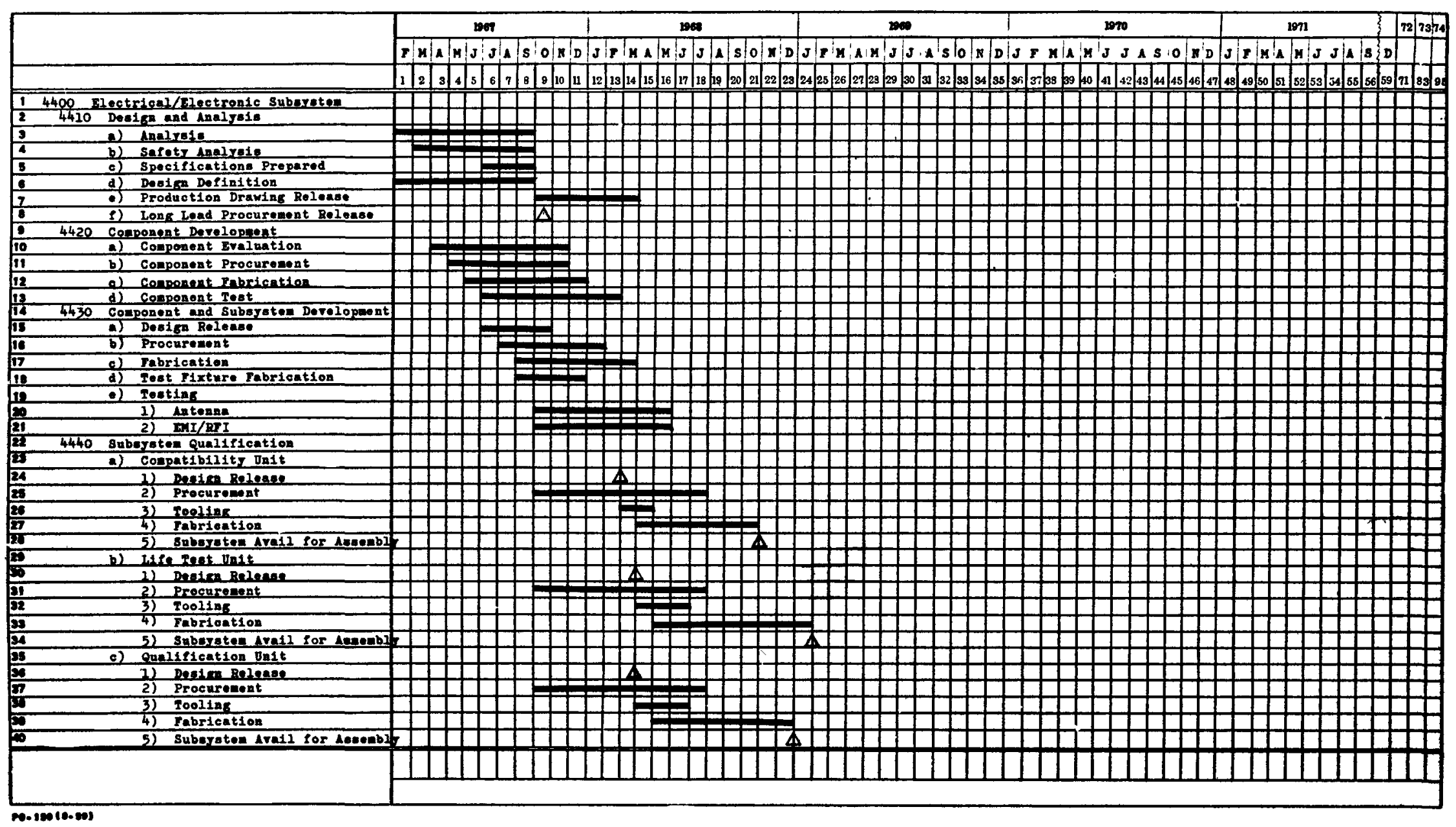

$\$$
事:
$\vdots$
$\vdots$
$:$ 


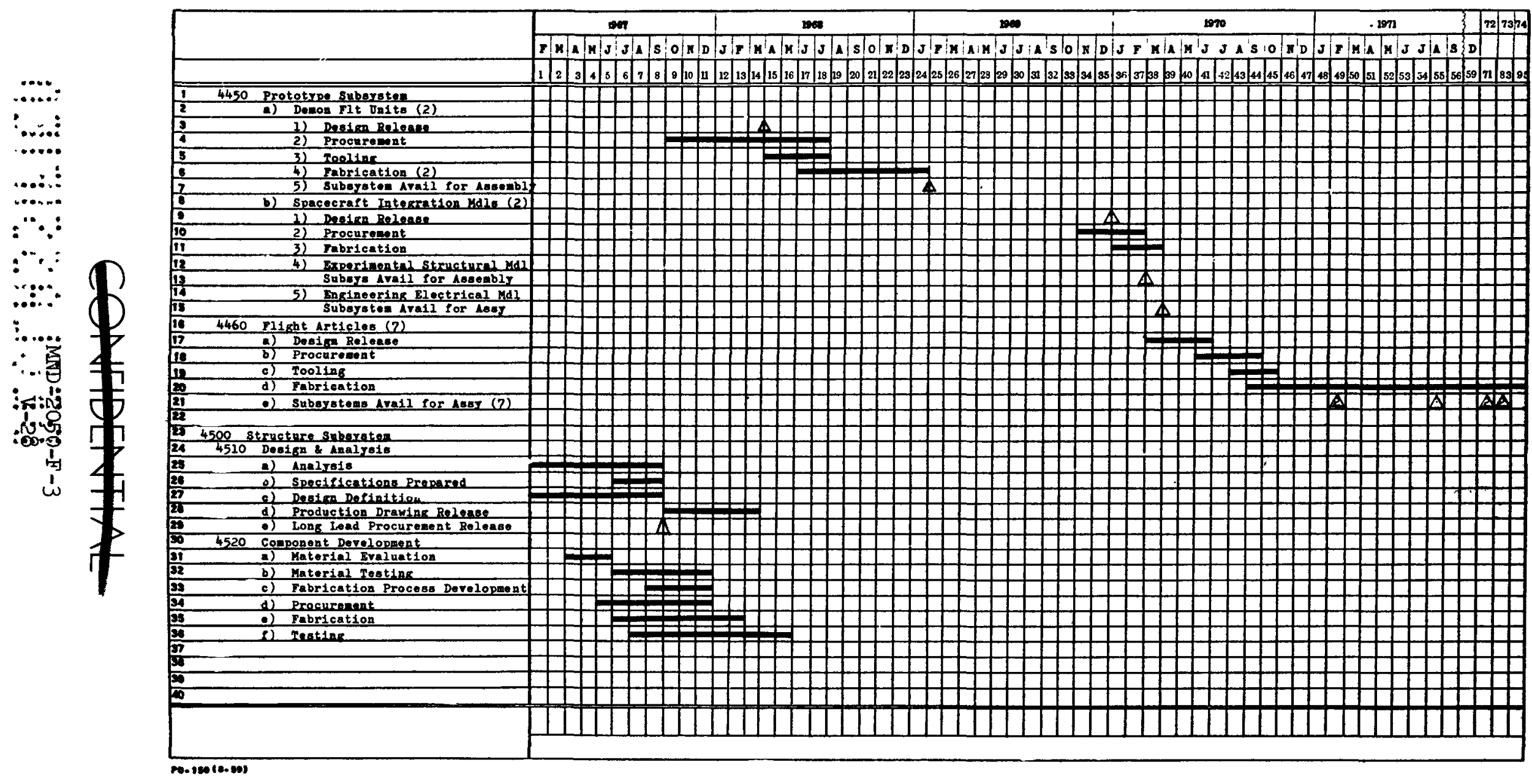

$\therefore: \cdots:$

$\vdots . . . .:$

.......

¿.:....

$\because \because:$

$\because \because$

80. 


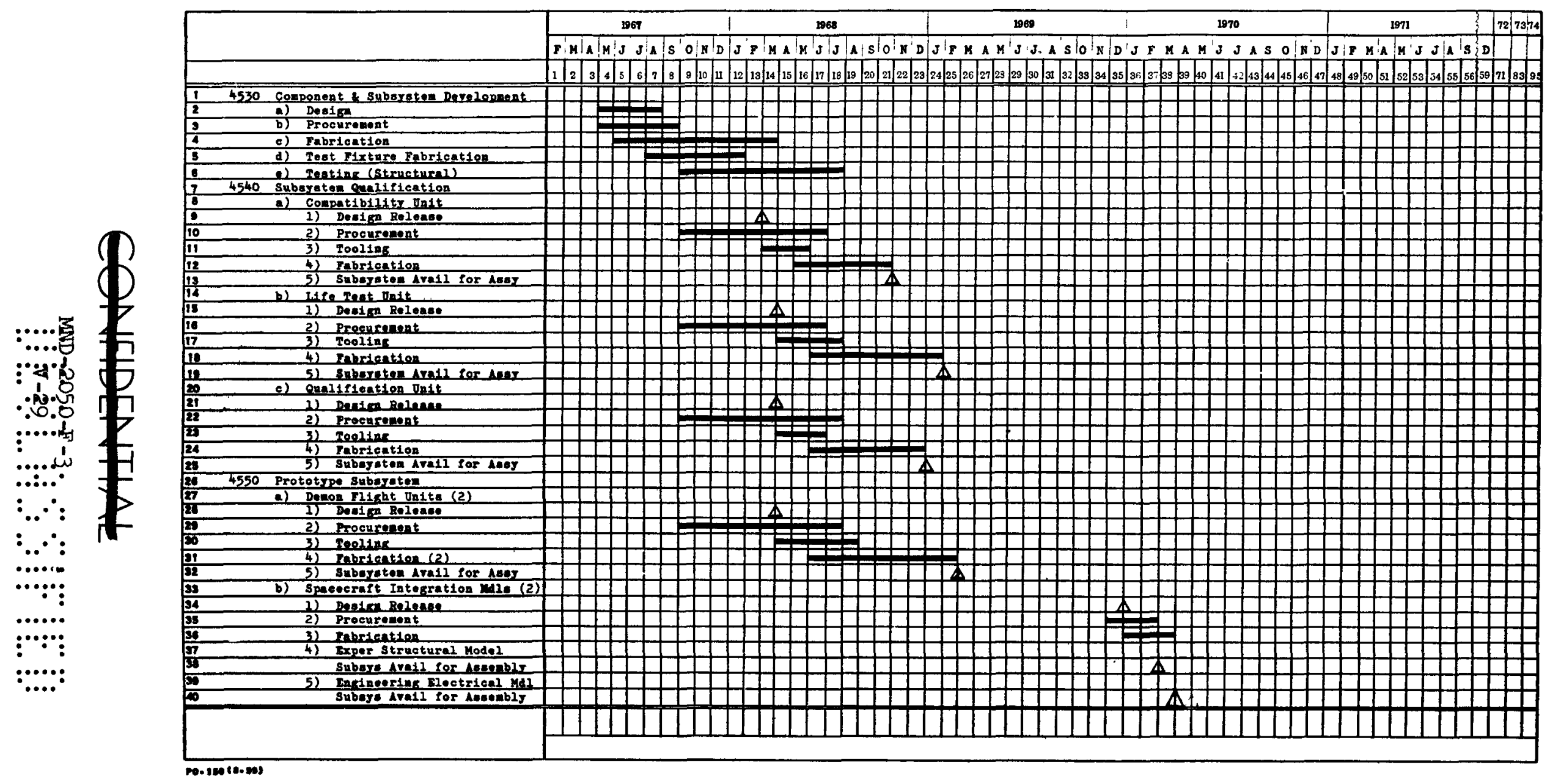




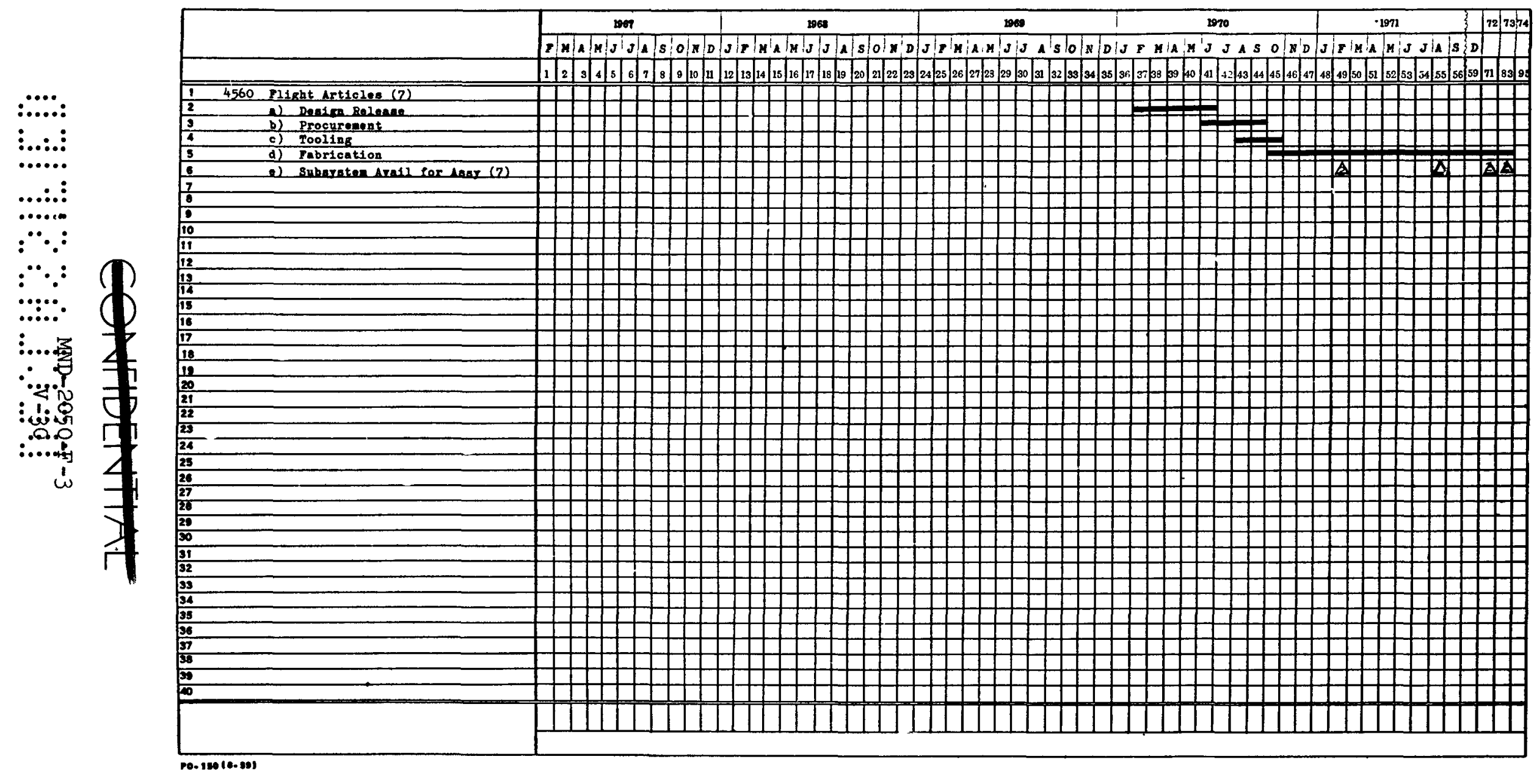

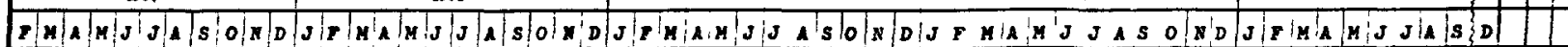

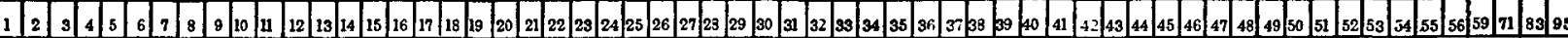

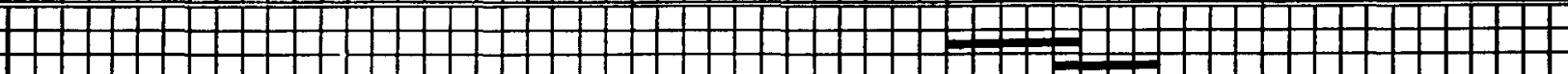

$\therefore \cdots$

$\vdots \ldots$

$\ldots$

$\therefore$

$\because$ 


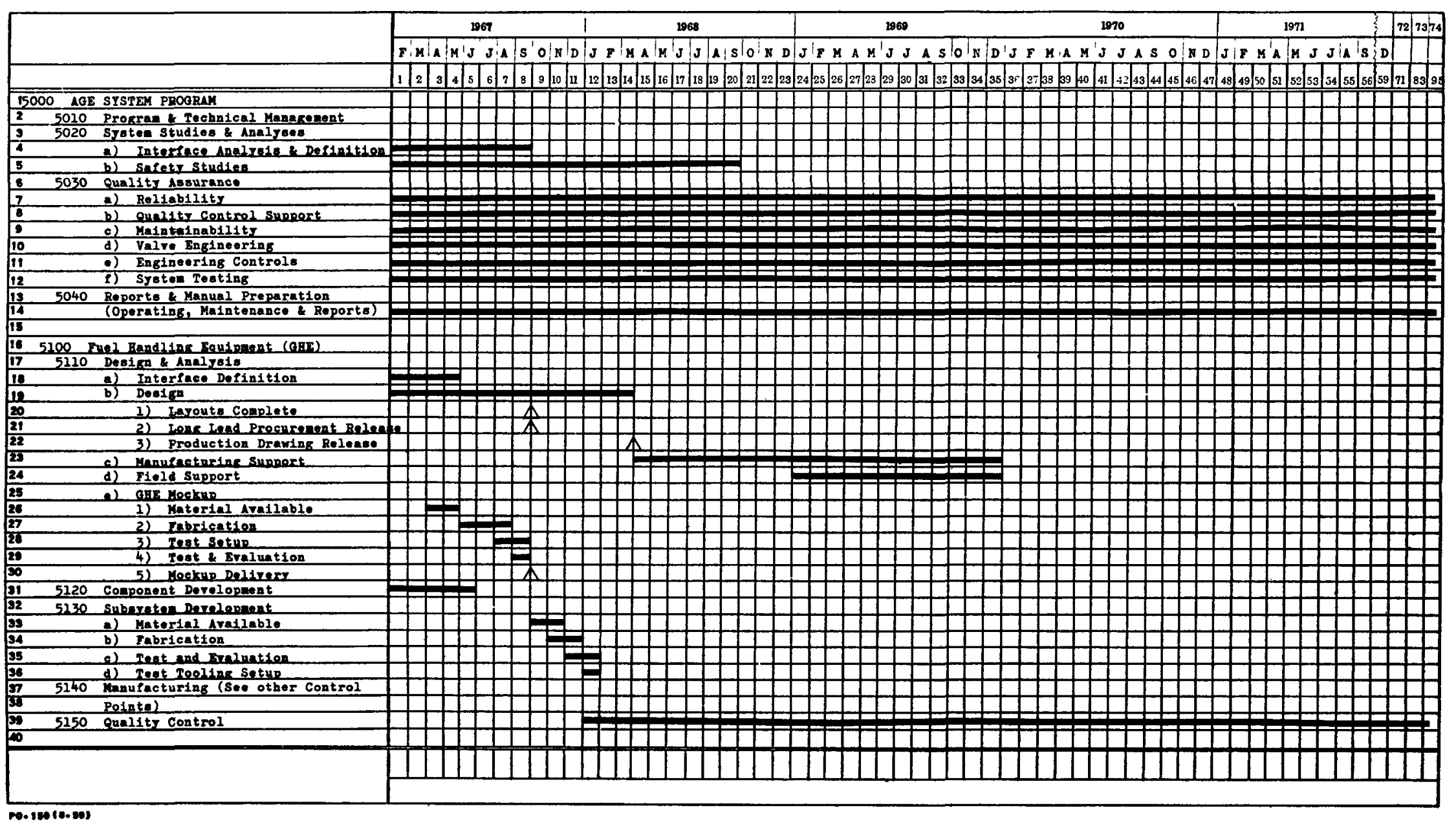

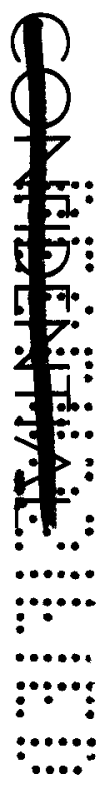




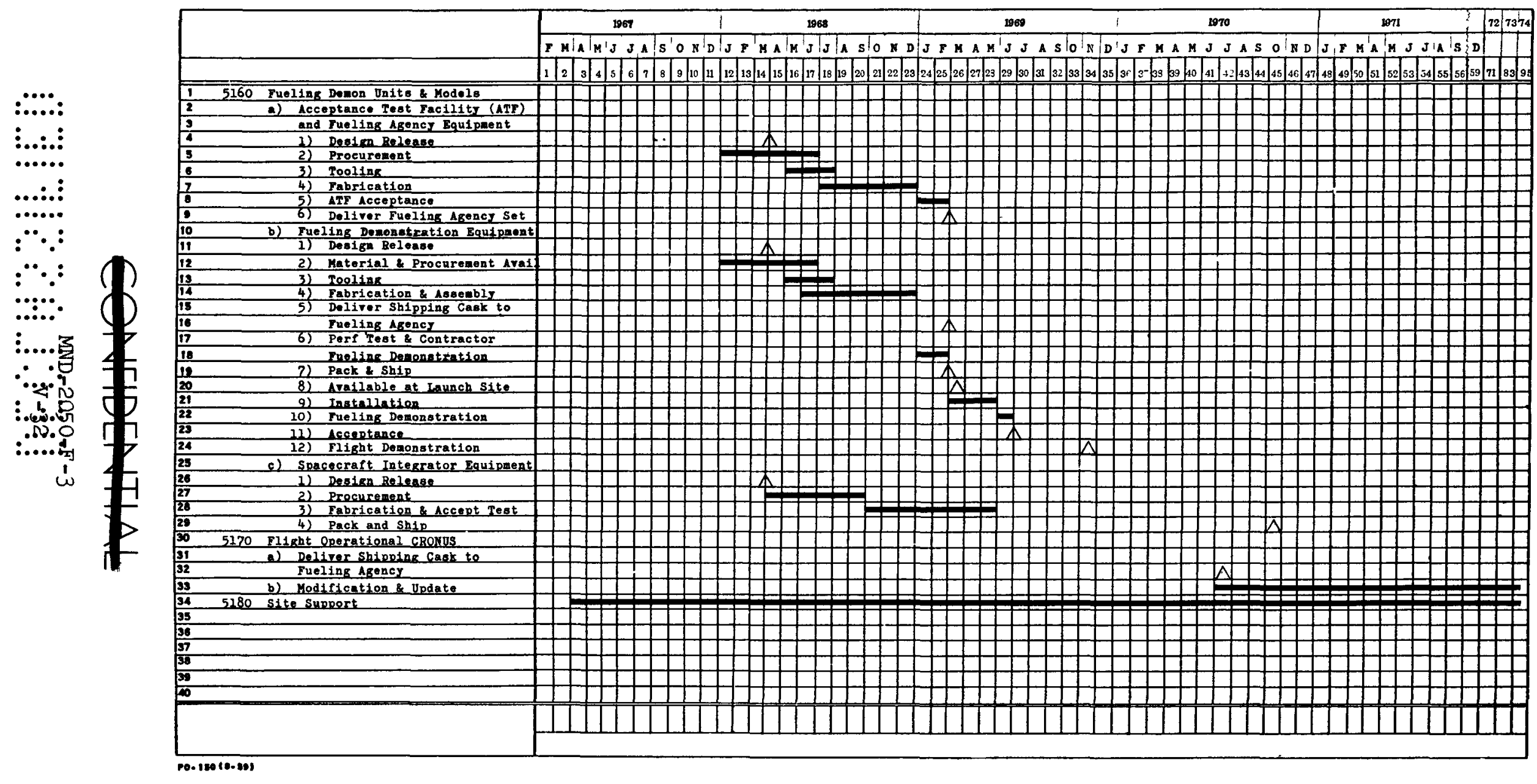




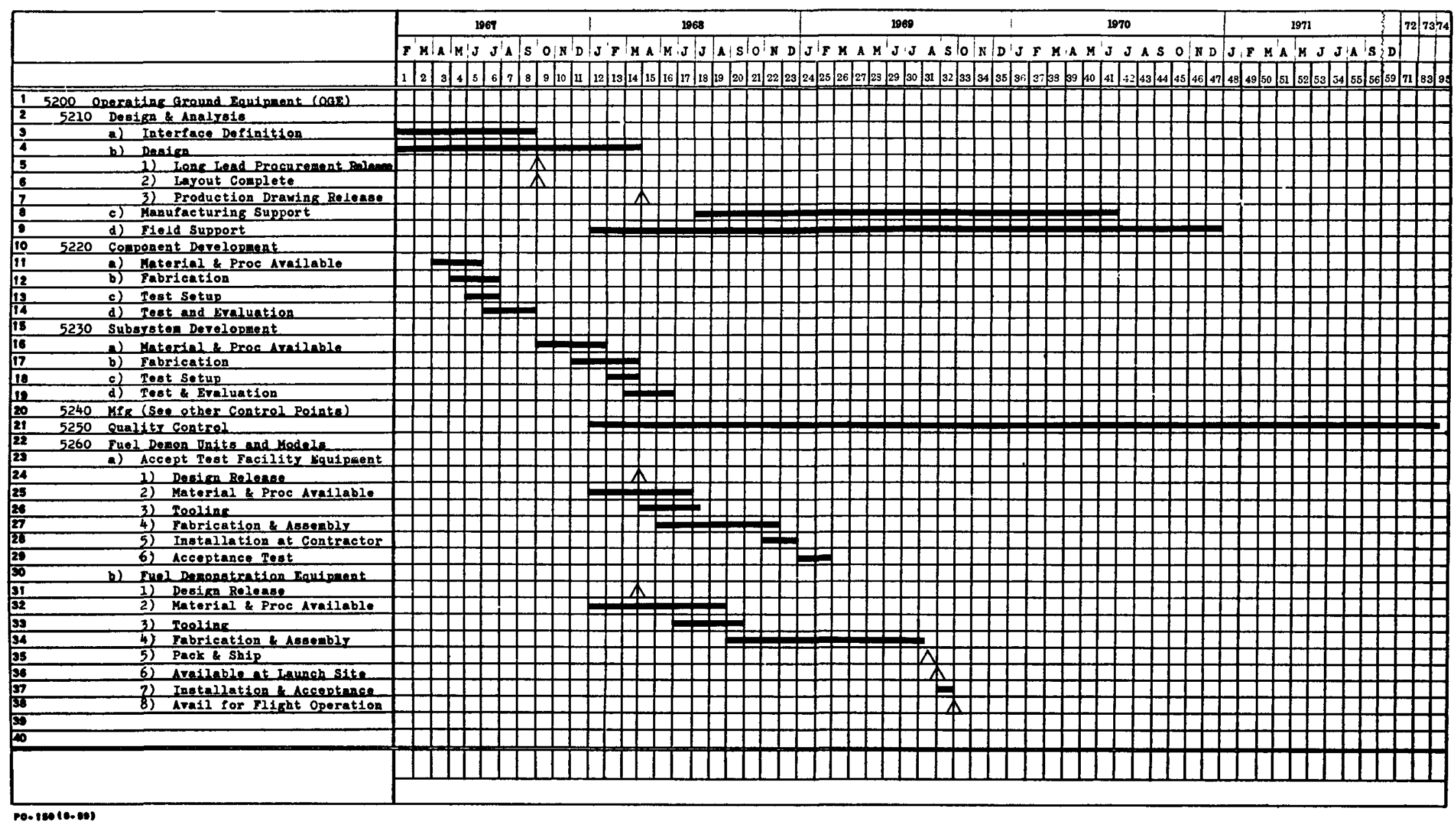




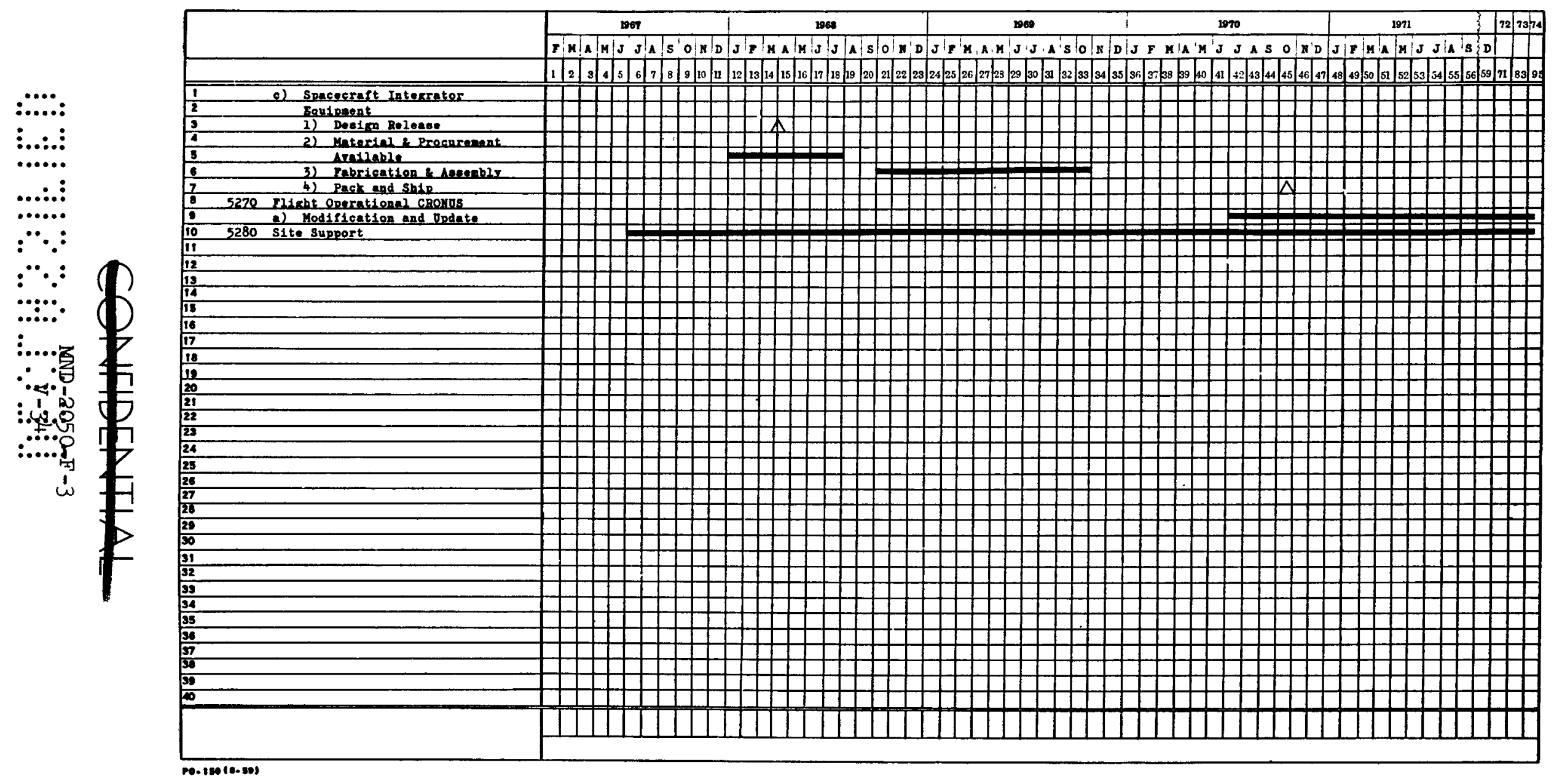

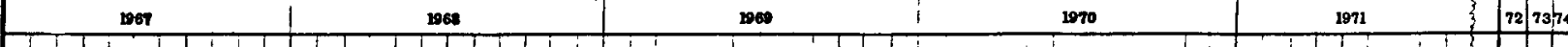

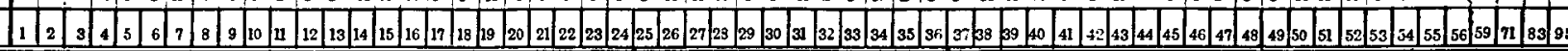

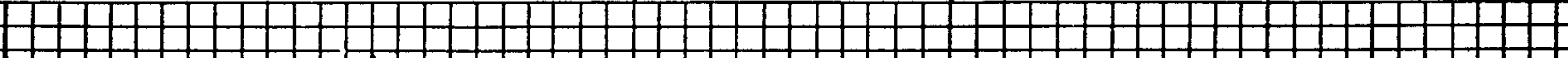

$\therefore \ldots:$ :

$\vdots \ldots: \vdots$

(......

:.n.

$\because \cdots$

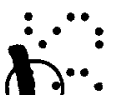

: 


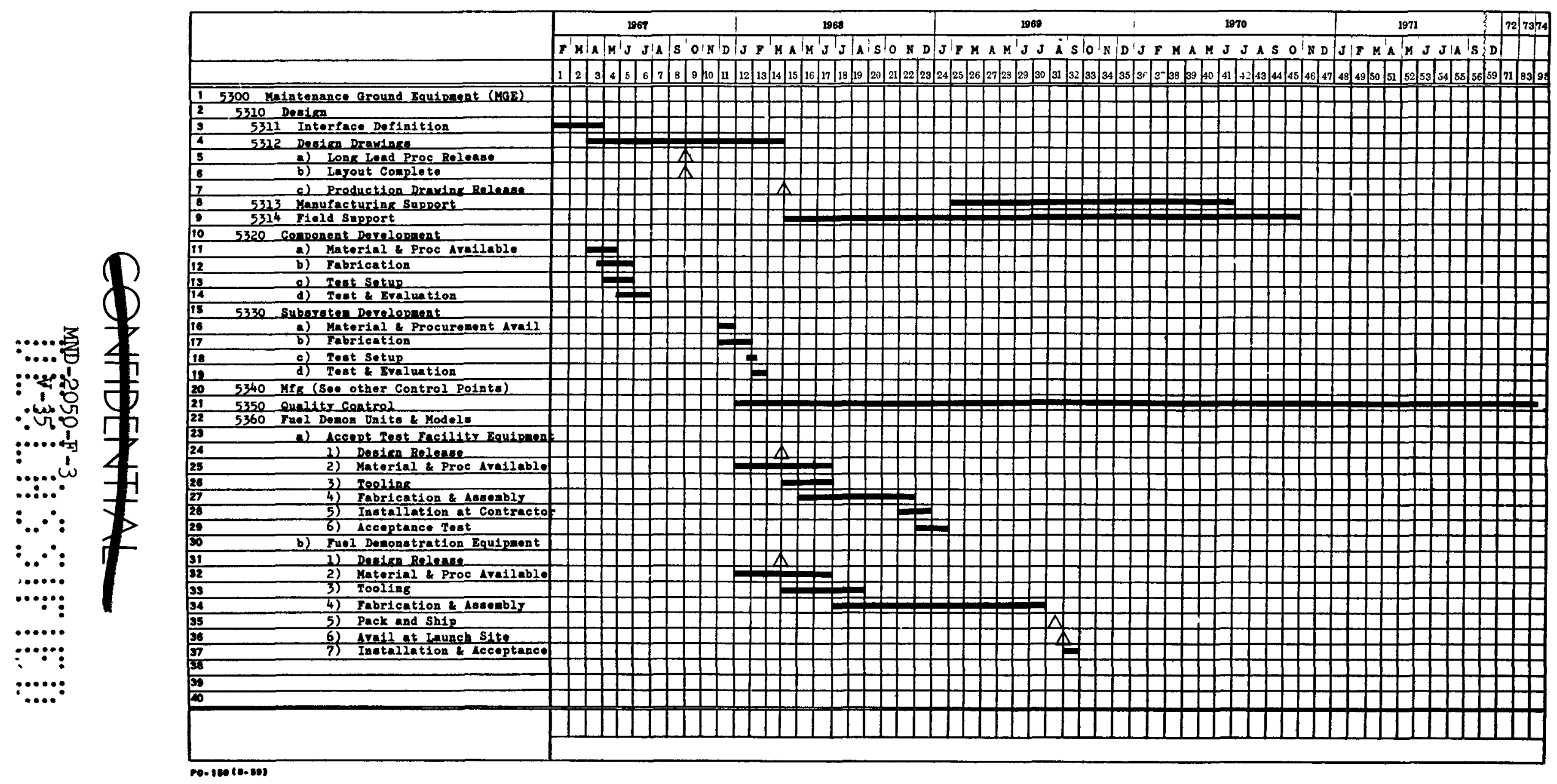




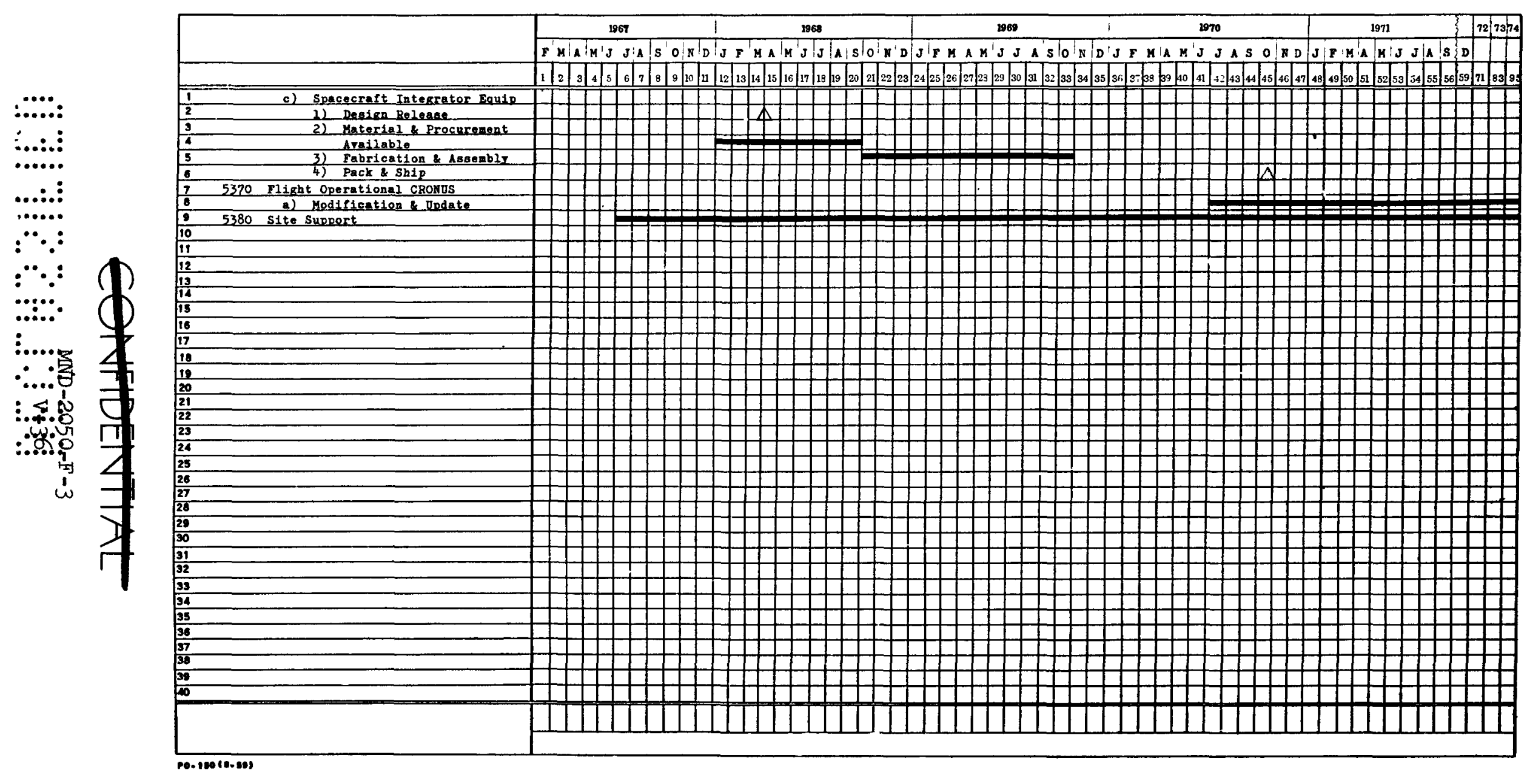




\section{APPENDIX A}

\section{REIIABILITY PROGRAM PLAN}

\section{A. INTRODUCTION}

There are three major facets that significantly contribute to the reliability of any product or system;

(1) the inherent reliability designed into that hardware,

(2) the degree to which that design is truly fabricated into the product, and

(3) how strictly that hardware is operated within the performance and environmental limits to which it was designed.

In any project where quantitative values for reliability are established a method of demonstrating reliability to some confidence level must be determined. Under a long-term, mass production type of program, the demonstration of reliability is readily accomplished. Many units can be tested to failure under normal and elevated stress conditions, the data analysed statistically, and probability of mission success established. However, in limited production programs demonstrations of reliability must be of different form, due to economic considerations. The Martin Company proposes to "demonstrate" reliability by assessment techniques, particularly during the period prior to early Cronus flights. This technique combines the use of valid data obtained from specific Cronus system testing (reference Integrated Test Program) with data resulting from design analysis and established generic type failure rate data. Further reliability assurance is provided through tight controls over the design, fabrication, and use of the products from a parts level up through complete system level.

The Reliability Program Plan in conjunction with the Quality Program Plan' (Vol. VI), and the Integrated Test Plan present the major elements of Quality Assurance. It should be recognized that the degree of implementation of each facet of the Reliability Program Plan for the RTG,

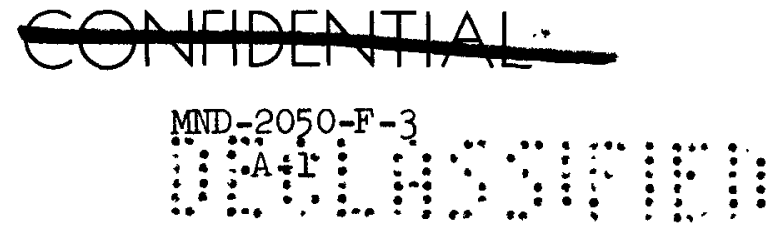




\section{mil}

CIR/RB and AGE Systems will vary, depending upon the specific contract reliability goals established for that hardware. The aspect of the program related to management, controls, design reviews, analysis, parts selection, and reporting will be maintained at a high level in all cases. Tasks such as reliability prediction, assessment, and reliability testing will show the greatest variance in depth of scope. It is anticipated that in the area of RTG performance and system safety items the effort will be high.

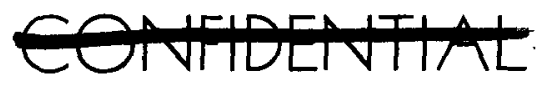




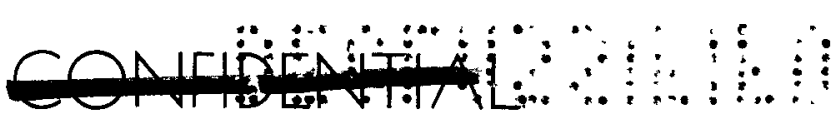

\section{B. PRELIMINARY RELIABILITY PROGRAM PLAN}

The objective of the Preliminary Reliability Program Plan is to present the direction that the Reliability Program will take in order to achieve the reliability requirements for the Cronus System. The plan is of necessity a preliminary one because the exact mission and specific reliability requirements are not yet formally established. This plan meets the general intent of both MIL-STD-785 "Requirements for Reliability Programs for Systems and Equipment" and NASA's NPC 250-1 "Reliability Program Provisions for Space System Contractors". The program plan is divided into the following major categories:

(1) Management and Controls

(2) Documentation Reviews and Approvals

(3) Reliability Design Analysis

(4) Parts, Components and Materials

(5) Reliability Testing

(6) Failure Data Collection, Analysis and Corrective Action

(7) Reporting

1. Management and Controls

a. Company reliability organization

The reliability policy of the Martin Company is established by the Director of Reliability, who is on the staff of the Vice President of Research and Engineering. The Director's responsibilities include the development and application of technical and management disciplines to assure attainment of reliability requirements, and the auditing of Operating Division reliability effectiveness. The Director of Reliability provides a direct channel of communication to the President of the Martin Company.
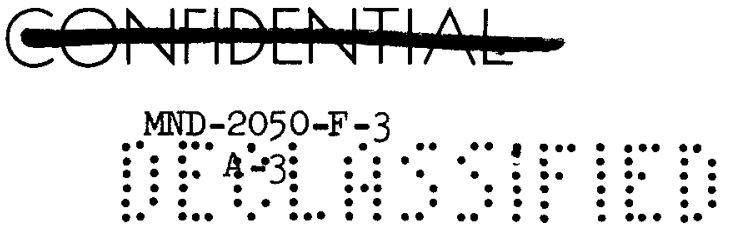


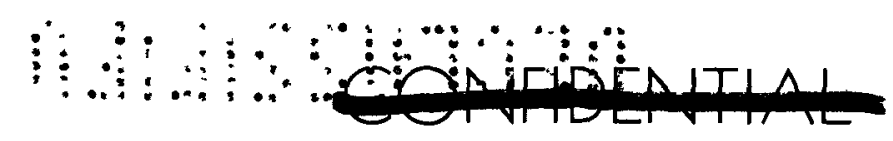

Nuclear Engineering Reliability activities are conducted under the auspices of the Director of Nuclear Engineering and Research, who has established a Reliability function to develop, conduct and coordinate the engineering reliability activities. Quality Engineering monitors the implementation of reliability activities of all departments responsible for executing prescribed reliability tasks. Each Program Director is responsible for the management of his Reliability Program and for resultant reliability achieved by the product.

b. Cronus reliability organization

The Reliability Program organization is shown in Figure 1. The Reliability Lead Engineer reports to the Engineering Technical Director. Specialists in the fields of engineering reliability, and reliability test and evaluation are assigned to the Reliability Lead Engineer to assist in implementation of the Reliability Program and the performance of the prescribed tasks.

\section{c. Final program plan}

A final Reliability Program Plan will be prepared under Phase I of the contract and will become part of that contract. The plan will serve as the master planning and control document for implementing the Cronus reliability program effort. The plan will include:

(1) Identification of the Reliability organization, and its associated responsibilities and authorities.

(2) Relationship between line, service, staff and policy organizations.

(3) Reports, method of reporting and frequency of reporting will be specified.

(4) The specific reliability tasks to be executed, with associated primary and secondary responsibilities for task implementation, task start and completion dates, and a brief description of the work scope, methods of implementation and control procedures, where appropriate.
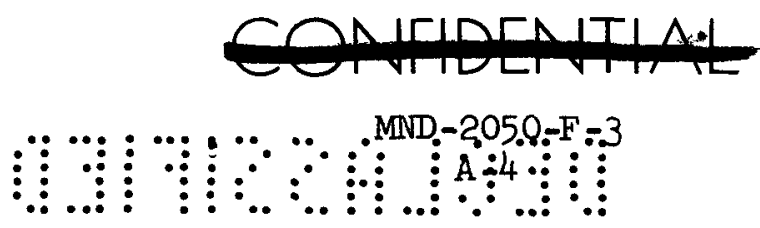
d. Reliability program controls and review

A management control system will be established to assess the performance of Reliability Engineering in meeting its program tasks. The control would be in the form of reporting, PERT scheduling and audits.

(1) Reliability program reporting will be partly accomplished through maintenance of a series of charts which will show the status and progfess of the major elements of the program. The charts will be updated periodically and in sufficient time to take remedial action. The following control charts, as a minimum, will be maintained and displayed in a chart room:

(a) Reliability program task status and
problems

(b) Reliability program review and action status

(c) Design review summary and action status

(d) Reliability apportionment and assessment

(e) Reliability test program status

(f) Problem summary and corrective action status

(2) The reliability tasks are keyed to the program schedules in Chapter V, (Detailed Program Schedules).

(3) Reviews (audits) of the reliability program will be conducted to ascertain conformance to the Reliability Program Plan. These audits will consider all facets of the effort and may be held in conjunction with AEC.

e. Reliability orientation program

To achieve the reliability goals, all project team members, from top management to shipping personnel, must understand the program reliability goals. Each will be made aware of how those goals are to be achieved and the

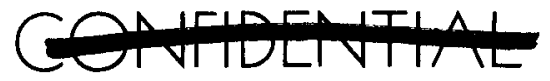


specific part he plays in that achievement. A program task defining the scope of such an orientation program will be included in the program plan.

f. Subcontractor reliability control

Subcontractors will have hardware reliability requirements assigned and reliability programs imposed on them by contract to ensure compatibility with Cronus requirements.

(1) Selected subcontractors will be required to maintain a formal reliability program and to submit the required documentation on test procedures, failure reports, analysis of failed hardware, corrective action, operating time data, critical parts lists handling data, etc., as required by the statement of Work.

(2) Subcontractor performance will be monitored by Reliability and Quality representatives during visits to assure that the required level of reliability is being maintained. Manufacturing techniques, contamination control, quality inspection procedures, and compliance with latest documentation will be recorded. Formal audit reports will be prepared after each visit and submitted to the subcontractor.

2. Documentation Review and Approvals

a. Design reviews

(1) Formal design reviews will be conducted to provide a comprehensive critical audit of all pertinent aspects of the design with particular emphasis on reliability.

Reliability will prepare a design review plan for Cronus defining responsibilities, method of control and reporting procedures within the confines of the specifications and Martin Operating Procedures. Design reviews will be conducted in accordance with Company procedures. A chairman will be appointed for each design review to head a team composed of members from all pertinent departments. The Project Relia-

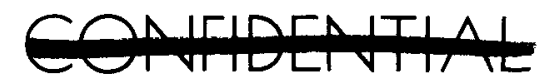




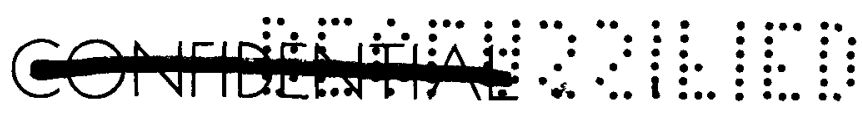

bility Lead Engineer will act as the Design Review Team Secretary, prepare minutes of the meetings, account for all actions directed by the team and maintain a file on reviews. Design reviews will be held at key milestones during evolution of the design to provide a comprehensive critical audit of all pertinent aspects of the design by competent personnel. These reviews will include an evaluation of the achievement of reliability relative to the level established for each major phase and review point of the contract.

(2) In general these reviews will include:

(a) Conceptual - A feasibility evaluation of proposed system blocks, with the purpose of guiding development and design towards the best approach prior to a firm detailed design.

(b) Pre-release - A critical evaluation of developmental studies, analyses and tests, the detailed design, the complete set of drawings and parts list essentially in their final form, and the detailed outline of the design results which led to final item selection, for each part, to the lowest level.

(c) Post Qualification - A final evaluation before shipment to the customer to assure that operation is in consonance with specifications, that recommendations made and agreed upon either in previous reviews or by other sources were satisfactorily implemented, and to provide a detailed review of all items that have been added or altered since release.

b. Engineering drawings, specification and procedures

(1) All engineering drawings will be reviewed, and the approval signature by Reliability will signify that:

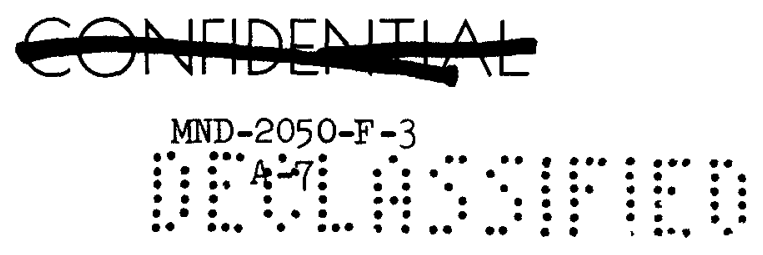


(a) Reliability allocations and predictions for all parts and components have been checked and found to be satisfactory.

(b) Part application analysis, environmental requirements, load factors, derating factors, tolerances and stresses have been checked and found to be satisfactory.

(c) Theory of circuitry or layout is adequate, that modes of failure have been investjgated, and that satisfactory means have been instituted to overcome, counteract or resist the critical modes.

(d) Qualification of every component and part has been reviewed and has been found to be satisfactory, or that adequate qualification tests have been prescribed for unqualified parts.

(e) Reliability tests for designated critical parts and components have shown them to be satisfactory, or that adequate reliability tests have been prescribed.

(2) All proposed design changes affecting the Cronus will be reviewed and approved by Engineering Reliability. The review will encompass all documentation relative to the proposed changes in engineering, inspection and test procedures, and manufacturing and procurement specifications. Reliability will evaluate the effect of the change upon performance and reliability of the component or subsystem, and the analysis will be documented and included in the Engineering Design Change System (EDCS) records.

Configuration control in accordance with Martin Nuclear Programs procedures includes subcontractors; therefore, all subcontractororiginated changes after the qualification tests will be subject to Martin Engineering
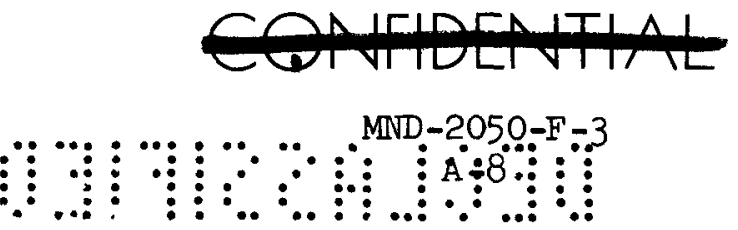


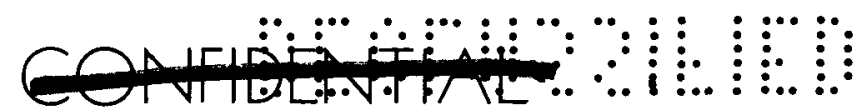

approval. Proposed changes must be submitted to Engineering with substantiating data for evaluation of the change before any action may be taken by the subcontractor.

\section{Reliability Design Analysis}

The design analysis effort is closely allied with the engineering documentation review because it aids in establishing the criteria for review and approval.

Under the analysis task, failure mode and effects analysis and the quantitative aspects of reliability form the bulk of the effort.

a. Failure modes and effects analysis are performed to:

(1) Determine possible modes of failure.

(2) Determine the effect on mission success.

(3) Ascertain the probability of such a failure occurring.

(4) Determine the capability of the component to resist such failure or the system capability to compensate for the part failure.

(5) Provide data to support trade-off studies.

(6) Establish criteria for specifying testing of components and systems.

(7) Establish a listing of parts that are critical to mission success, so that adequate selection, screening, and controls may be provided.

b. Quantitative aspects of the design analysis involves reliability apportionment, reliability prediction and reliability assessment.

(1) The basic reliability apportionment for the Cronus System will be in three areas: a) RTG, b) CIR/RB and c) AGE. This assignment of a quantitative reliability value can either be stipulated by contract or developed under

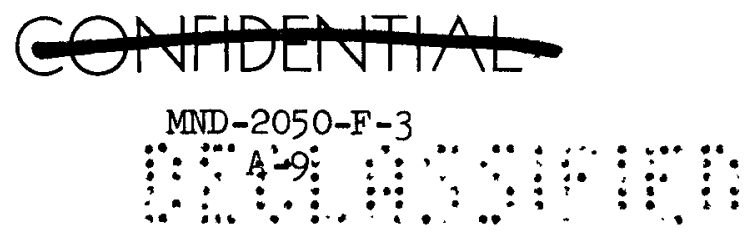


contract during Phase I. Once the basic apportionment is made, the individual values will be subdivided into subsystem, component and part levels. Initial sub-apportioning can be made on a best-judgment basis. After a preliminary reliability prediction is made, reapportionment of the values can be made. These would then be quantitative goals for the individual subsystem, components and parts.

(2) Reliability Prediction involves the development of appropriate math models for each system, ascertaining of valid failure rates, applying proper mission time intervals, and then calculating the predicted reliability for the system and its subsystems.

(3) Reliability Assessment will be accomplished on a continuous basis. It involves a continual updating of the reliability prediction based on data acquired as a result of testing accomplished under the integrated test program. Certain of the tests are specific reliability tests that will provide failure rate data; other tests will yield data that can be converted to reliability values.

Reliability mathematical models, failure mode analysis, reliability prediction and reapportionment are the tools that will be applied in the evaluation of design trade-off factors, such as system weight, costs, scheduling, etc., versus the probability of completing a successful mission.

Throughout the design and development of the bread board, preprototype, prototype and operational models, Reliability will evaluate the systems, subsystems, components and test results for the purpose of guiding design decisions involving design trade-offs.

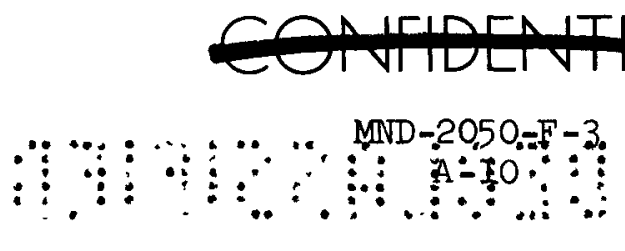


c. Other facets of design analysis involve review for adequate design consideration in the areas of human factors engineering, maintainability, and safety engineering to minimize the possibility of degrading the reliability through human error.

4. Parts Control and Qualification

The design of a highly reliabile system starts with the proper selection and application of parts having inherently high reliability. To aid in assuring that proper selection and application are accomplished, the following parts program is essential.

a. Parts and components selection

(1) Components and parts will be selected in accordance with MIL-STD-143 (or NASA's Preferred Parts Lists) from suppliers with a history proven to be satisfactory by the Company-supplier evaluation system.

(2) Where the design requires the use of parts from suppliers with unknown performance histories, a survey of those suppliers will be made by Quality and Reliability personnel to evaluate their capability of producing reliable parts. In addition to these surveys, a procurement specification will be made part of all purchase orders. The procurement specifications for parts and materials are an important part of Martin-supplier control.

(3) Surveillance and control of suppliers are exercised by Quality Control in accordance with practices outlined in the Quality Program Plan.

b. Parts and components qualification will be accomplished thru use of:

(1) Military standards and NASA preferred parts that have successfully passed qualification tests to environmental levels equal to or greater than the environmental levels prescribed for this program.
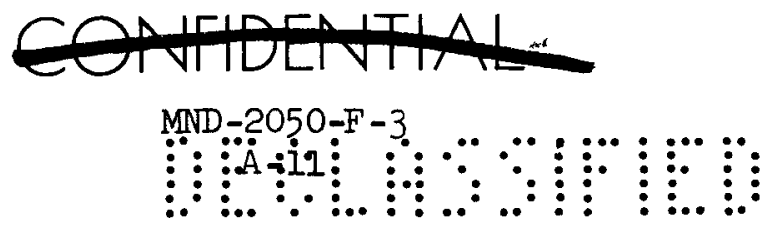


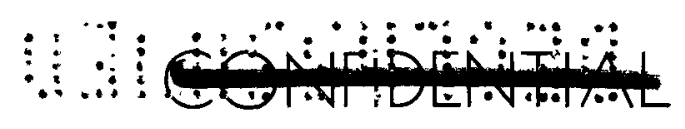

(2) Prior usage of functional components and parts having known histories of successful operation at environmental levels equal to or greater than the levels prescribed for this program.

(3) Functional components and parts not having operational experience will be qualified by test as part of this program.

c. Controlling critical parts

The program for controlling parts deemed critical to Cronus mission success will be planned, integrated and developed to identify those components and parts which require special consideration during design, fabrication and field operations. The importance of each functional part within the Cronus will be assessed for its effect on reliability in specific applications.

The program is implemented by a controlled parts list and a limited-life parts plan.

The purpose of identifying certain functional components as "critical" or "controlled critical" is to insure maximum components inherent reliability and mission success. This is accomplished by establishing special controls over the components throughout the design conception, development, manufacturing, test and operational use stages. These controls will be documented in phase $I$.

Criteria for selection of critical components are:

(1) Failure modes associated with component design and application will result in mission failure or a safety problem.

(2) Failure modes associated with components design and application will significantly decrease the probability of mission success.

(3) Failure of the component during countdown will result in a hold or kill and failure to launch as scheduled, or result in a hazard to launch personnel. 
(i4) The component is a design unique to the Cronus and has no previous similar operational experience.

A limited-life part is defined as one which has a maximum allowable operating, nonoperating or storage time, beyond which its use would jeopardize reliable performance. The requirements for test, overhaul or scrapping of parts, as well as the maximum amount of testing time or cycles permitted, are included for each item.

A record of total accumulated operating time or cycles will be maintained for limited-life parts throughout tests and functional operation.

d. Screening and burn-in requirements will be specified on parts where such techniques weed out early failures and latent defects. The levels of screening and burn-in that will be established will be consistent with current acceptable practices. This technique is particularly applicable to electronic/ electric parts. Data is continuously being collected and evaluated on parts that have been selectively screened. Failure rate data on many of these parts are significantly lower than those of the nonscreened and non-burned-in parts.

5. Reliability Test Plan

a. The primary objective of the Reliability Test Plan is to identify those tests of the integrated test program that will yield valid statistical data to be employed in making the reliability assessment.

b. The secondary objective is to assure that the operational hardware has achieved the design maturity required to accomplish its mission. Three areas are involved: assurance that engineering design and manufacturing processes will meet the requirements; assurance that equipment will perform satisfactorily in the operational environments encountered during its life; and assurance that latent defects, not detectable by normal quality techniques, are eliminated by conducting low level environmental tests.

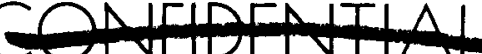




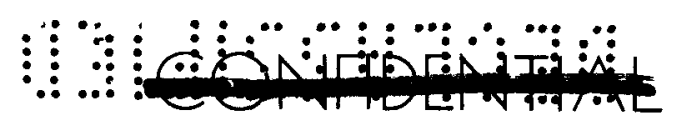

c. The integrated test program provides data for evaluation from development, design verification, qualification, reliability, and production monitoring or acceptance test phases. These test phases are briefly defined below.

(1) Development Tests - These tests are engineering evaluation tests performed on hardware built to preliminary design concepts. They are used to provide further design development information based on operational performance under laboratory and/or environmental stress conditions.

(2) Design Verification Tests - These tests are engineering verification tests performed on hardware built with the development design improvements incorporated and fabricated into the proposed packaging configuration. The tests include functional performance operations and pre-qualification environmental exposure tests.

(3) Qualification Tests - These tests are a series of functional tests performed on a limited number of articles, identical to flight hardware, to verify that the articles as designed and fabricated meet the operational and environmental requirements of the assigned mission. The qualification level requirements, where feasible, are established at levels exceeding those anticipated during a normal mission profile.

(4) Reliability Tests - These tests determine expected life, measure degradation with time and stress, establish modes of failure or critical weaknesses, and provide data to measure reliability achievement. The tests may be independent of other tests but, in general, are included as part of or extensions to the development and qualification tests.

(5) Acceptance Tests (Production Monitoring (PMT)) These tests are performed to specified requirements under environments of sufficient severity to uncover latent defects, but not severe enough to cause any significant per-
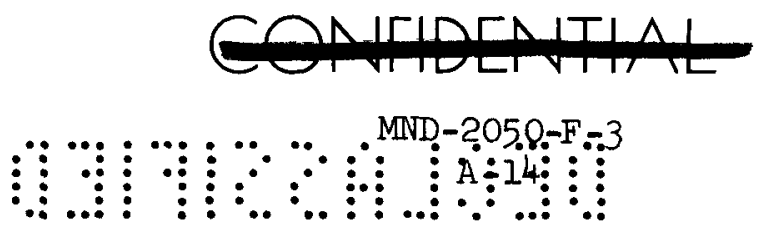
formance degradation or life reduction. The stresses applied are a predetermined percentage of the qualification test level and are applied $100 \%$ to all mission or flight-type hardware.

d. The Integrated Test Program is a detailed and comprehensive program which coordinates and directs all phases of testing from early development concepts to the final verifications at the start of the assigned mission. The Program includes all system subsystem, component, and part material level tests at in-house, subcontractor, vendor, integrating contractor, or launch complex locations that involve our Cronus hardware or the hardware buildup.

e. The Reliability Test Plan is a detailed and comprehensive test program within the scope of the Integrated Test Program to aid in assessing the established reliability goals. The plan will outline in detail each test that will provide reliability data information and the results expected from each test. The safety aspects of the operational and handling requirements place an increased emphasis on the reliability test controls and test sampling rates.

f. Controls will be established for all testing, since the final determination of the numerical reliability for the system is based on the use of valid test data. Since many phases of the Integrated Test Program will be used to assess the reliability of the system, Reliability Engineering will be directly concerned with the preparation of the test specifications and/or procedures where reliability assessment data will be involved, by providing reliability inputs and approval signature on the test document.

g. The demonstration of reliability as related to the over-all test cycle will be presented in matrix form by critical component, subsystem, or operational function. Applicable tests under the engineering development, design verification, qualification and flight test programs will be indicated for each item. 


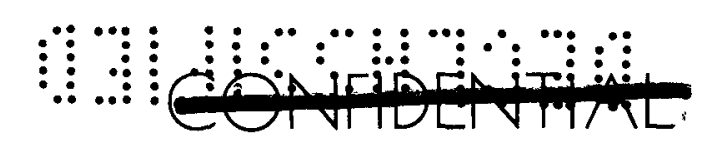

Supporting data from identical equipment usage on other programs, or from statistical reliability sampling tests, will also be indicated in the matrix.

h. Reliability Tests, which are performed primarily for establishing or verifying the reliability estimates of the system, will be covered in this section. Two basic categories of tests, operational characteristics and life tests, are considered.

(1) Operational Characteristics - These tests are primarily of a statistical sampling nature and involve tests of the following types.

(a) Operation of one-shot devices and nonoperational margin of safety.

(b) Cycling operations, such as switches, timing mechanisms, sequencers, etc., and including non-operational margin of safety and maintenance of output responses.

(c) Output parameter measurements and tolerances under prescribed operational and environmental conditions.

(2) Life Tests - Components often have a failure pattern that follows the "bathtub" or Life Characteristics curve shown in Figure 2. The curve is composed of three categories of failures:

(a) Early failures. These are generally detected through screening and burn-in techniques.

(b) Chance failures. The component population, after having been subjected to screening and burn-in tests, reaches its lowest failure rate level which is approximately constant. This period of life is the useful life period, and it is in this period that the exponential law is a good approximation. Chance failures are randomly distributed throughout this period. In Figure 2 the area under the curve identified as $B$ represents this period. For purposes of analysis the components used in Cronus system will be assumed to fall into this type of life characteristics unless test

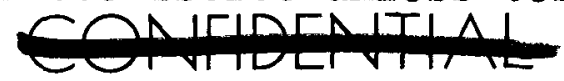


data indicates otherwise. Parts, components and subsystems will be selected so that mission life is well within the "useful life" period. Limited life components or part criteria will be established based on their life characteristics curve.

(c) Wearout failures. Eventually some portion of the hardware reaches the end of its useful life. At this point the failure rate increases rapidly. This portion of the curve is represented as the area denoted as $C$. Failure may be catastrophic or by exceeding operational limit parameters.

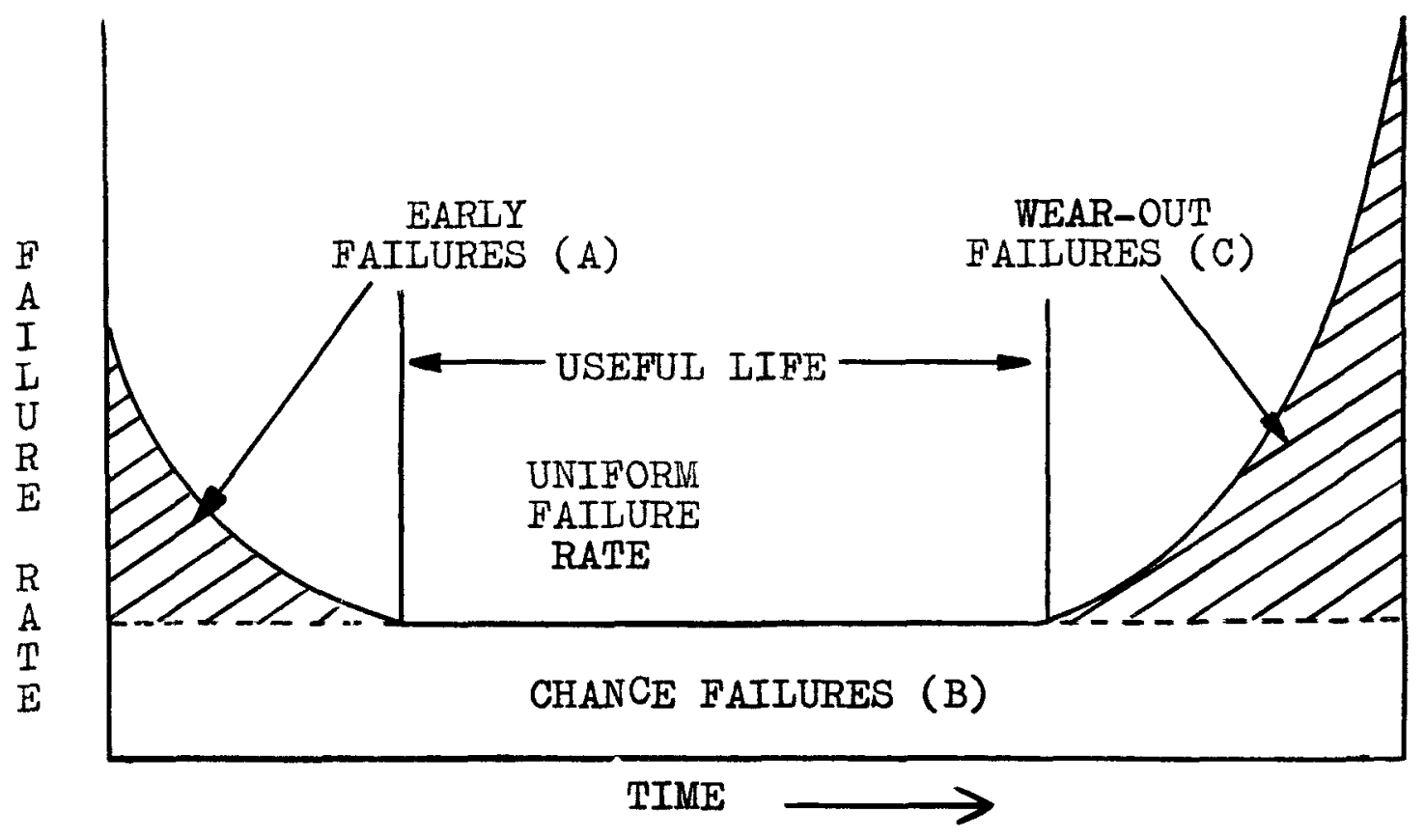

Figure 2 Iife Characteristics or Bathtub Curve 
(i) Long Iife capability demonstrations will be initiated at the component part and small module level. The approach to and scope of life test plan is as defined. below.

(1) Iife Test Data Accumulation - The accumulation of data in relation to long life capability for this operational program will be obtained from previous tests and by coordinated life test programs.

(2) Parts Screening Tests - All parts that are to be subjected to life tests must be subjected to a predetermined set of screening tests (i.e. PMT) to eliminate the majority of latent defective units and to provide a homogeneous sample for the start of test. The parts are to be from production configurations and subjected to tests representing planned operational enviornments.

6. Failure Data Collection, Analysis and Corrective Action

A failure data collection, analysis and corrective action program will be established. It will consist of:

(1) A formal method of documenting the failure

(2) Performing a parts failure analysis

(3) Assuring corrective action to preclude the failure from reoccurring.

The Quality Department is responsible for all program corrective action systems and must coordinate the activities of all departments responsible for accomplishing that action necessary to remedy discrepant conditions. Engineering has the responsibility for assuring that adequate corrective action is taken on all design, test and specification problems. The program is explained in detail in the Quality Program Plan. Figure 3 is a flow chart of the system that will be utilized in this program.

Failures and malfunctions are reported on the Martin Automatic Reporting System (MARS) regardless of location (at Martin, subcontractor, or field) and incident MARS are screened by Quality and Engineering Reliability to identify problems which require investigation or corrective action. The Nuclear Problem Report (NPR) is prepared by either Quality Engineering or Engineering Reliability.
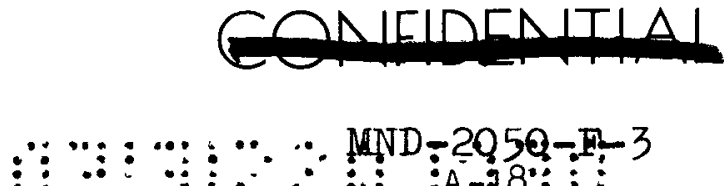


\section{$\ldots$}

A complete engineering investigation and analytical analysis into the cause of a failure or anomaly will be performed and documented on a Reliability Engineering Analysis Report (REAR). A failed parts analysis is conducted if required.

2. Reporting \& Plans

Formal documentation of Reliability Engineering activities under the various areas of effort will be in the form of reports to the Customer. The following types of reliability documents are envisioned.

(1) Reliability Program Plan

(2) Reliability Test Plan

(3) Preliminary Reliability Design Analysis Report

(4) Monthly and Quarterly Progress Reports (as part of total program periodical reports)

(5) Reliability Test Reports

(6) Final Reliability Design Analysis Report

(7) Special Reliability Study Reports (if the need develops)

(8) Design Review Reports (Summary Type)

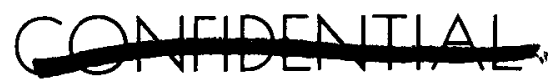




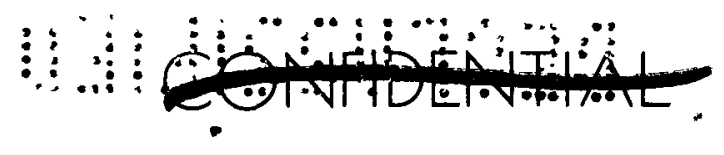

\section{MANAGEMENT HIGHLIGHTS}

A brief summary is presented of the controls and restraints that will be applied during all phases of the program, from design and development through manufacturing, testing and launch, to assure a reliable product. These controls will be defined in detail during phase I and personnel assigned to the program instructed in their meaning and methods of implementation. The Reliability program plan will define the prime responsibility areas for each control.

Controlled Critical Parts

These critical items will be identified as Controlled Critical Part (CCP) Items and be subjected to rigid disciplines. Highlights of this program are:

1. Extension of the controls to selected piece-parts within a CCP.

2. Segregation, identification and special handling of these items.

3. Special shipping controls to prevent damage during shipment.

4. Special nonconformance controls requiring review by Engineering and quality Engineering management.

5. Source inspection of all vendor produced controlled critical part.

6. Transient malfunction control will be exercised so that unexplained transients, for which conclusive cause and repair are unknown, will prevent acceptance of hardware.

7. Training of personnel handling these CCP in the control features of the CCP program.

8. Planned periodic Quality and Reliability audits of the Controlled Critical Part both in-house and at Controlled Critical Part vendor facilities.

Critical items, identified as being important to the reliability of the RTG, CIR/RB and GHE systems are given maximum attention in the design reviews and in the test activity to assure optimum selection, application and qualification.

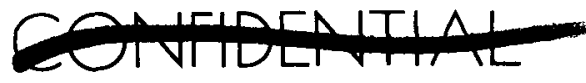


Failure Analysis

The approach to failure is through "Analyses in Depth". That is, the analysis is continued until the true mechanism of failure and effective corrective action is known. Skills and facilities have been developed to a high degree in this area and will be fully utilized on the CRONUS program. The resolution of a problem by labeling it a "random failure" is not permitted, since each failure has a cause which can be discovered if sufficiently analyzed. Special tests and evaluations will be conducted upon implementation of corrective action, before problem closure, to assure that the problem has in fact been resolved.

\section{Corrective Action System}

A rapid and responsive corrective action system will be established with well-planned communications loops between Martin and various vendors and between Martin and the proofing facilities. A system known as the Martin Automatic Reporting System (MARS) is presently in operation and will be fully utilized on the CRONUS program. The key to its success is that all unscheduled work is reported. This includes errors, discrepancies, failures, material review action, work authority, and integrity control. This system is defined in the Quality Control Chapter. The system provides complete data to the failure analysis personnel. The reports are processed onto automated tab runs (EDP) and simultaneously Quality and Engineering initiate analysis and subsequent corrective action on problem items. Problem status is reported weekly; in addition, problems are posted in a project control so that they receive top management attention and pressure for resolution. Trouble Reports and corrective actions they generate are printed out in automated tabulations to facilitate trend analysis.

\section{Single Lot Procurement}

The single lot procurement will be implemented by Quality. Lot qualification tests, screening tests, and special inspections will be performed and witnessed (including precapping of transistors; burn-in and vibration testing of semi-conductors; and radiographic inspection of relays, capacitors, resistors, and switches). Similar requirements will be passed on to lower tier suppliers to assure uniformity of quality in delivered hardware. 
Planned Over-buy

A planned over-buy will be specified on selected vendor parts so that a meaningful sample can be subjected to destructive test analysis as part of the Receiving Inspection Laboratory function. This plan would include such items as overstressed hi-pot on wire, microscopic examination of opened sealed relays, transistors and diodes, environmental tests at high stresses on selected items, etc.

Vendor Selection

Quality and Reliability personnel will participate in careful vendor selection by contributing performance history gleaned from trouble reports, failure analysis reports, test data, Interservice Data Exchange Program, Search, FARADA data analysis of bid packages, PRINCE, and other approved parts lists for sources of reliability data. Materials and shelf items will be procured from qualified vendors.

Serialization Control and Piece Part Traceability

Serialization control will be implemented to supplement lot controls for hardware traceability. The depth of failed parts analysis will undoubtedly reveal discrepancies at a piece-part level and rapid traceability is required for effective purge and research of discrepant parts. In addition, possible discrepancies can be more easily collected and withheld until analysis is completed and corrective action determined.

\section{Data Packages}

Data packages will be prepared for Controlled Critical Farts to provide a uninue history of the specific item. Such a package will contain a chronological history (i.e., acceptance test data, calibration data, trouble reports, non-conformances) associated with that serial number component, and will provide a useful history instantly available to assist in analysis.

\section{Customer Communications}

A closely knit reporting and approval cycle on corrective action system problems will be set up with AEC-Sandia. This will insure rapid action on needed design 


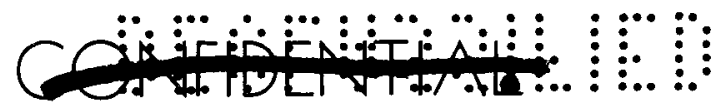

improvements and will result in expedited product improvement with minimum program delays. All corrective action will be introduced through strong configuration control.

\section{Reliability Data Center}

The large quantities of data applicable to maintaining reliability control will be processed through a reliability data center. Cataloging of tab runs and flagging of problem areas will be a function of the data center. Documentation on test specifications and procedures, test results, failure analysis, corrective action, reliability failure and time/cycle data, reliability status reports, etc., will all be directed to this center and accountability maintained for this documentation.

\section{Electronic Data Processing (EDP)}

Electronic data processing is in widespread use at Martin and facilities will be used on the CRONUS program in a variety of areas. Examples of present uses which indicate the extent of these capabilities are:

Component Trouble Report Tabulation

Tab runs of trouble reports with built-in repeatability thresholás for all components on a program have been prepared. Three or more failures (threshhold is adjustable) can be applied to effect a print out of repetitive failures. Less than the threshhold account would not print out. This easily indicates which components are experiencing repeated problems. Programs have been combined where common components are used and a combined threshhold established.

Operating Time Tabulation

Operating times are collected today on Gemini on special multi-channel recorders which punch a tape that can be directly fed into data processing equipment. Similar tapes are received daily from field sites and a tab run is produced by system, by part number and by serial number with actual operating time in hours and minutes or operating time by cycles.

Reliability Measurements

The operating time information is added failure information and also includes operating time at failure.

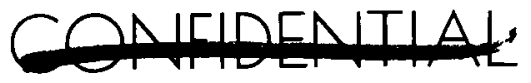


A tab run results which supplies actual measured reliability, based on operating times/cycle and failure information.

Configuration Control

A variety of configuration control tab runs are currently employed on major programs. Full control is maintained on hardware, on checkout equipment, on tools, and all test procedures. Compatibility tab runs assure that all items of hardware and paper are compatible and to the right change level.

Math Model Analysis

A computer program will be developed for CRONUS (similar to programs on Gemini) that accepts time/ cycle and failure data from tab runs and processes it to obtain failure rate data, a listing of components based on descending order of reliability and the probability of success, loss of mission or catastrophic failure.

Use of electronic data processing permits rapid access to reliability status and parts status, and it minimizes possibility of human error. Programs shown above have been developed for other contracts and are readily adaptable to the CRONUS program.

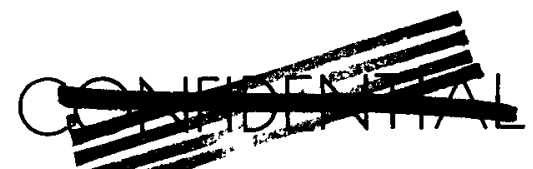




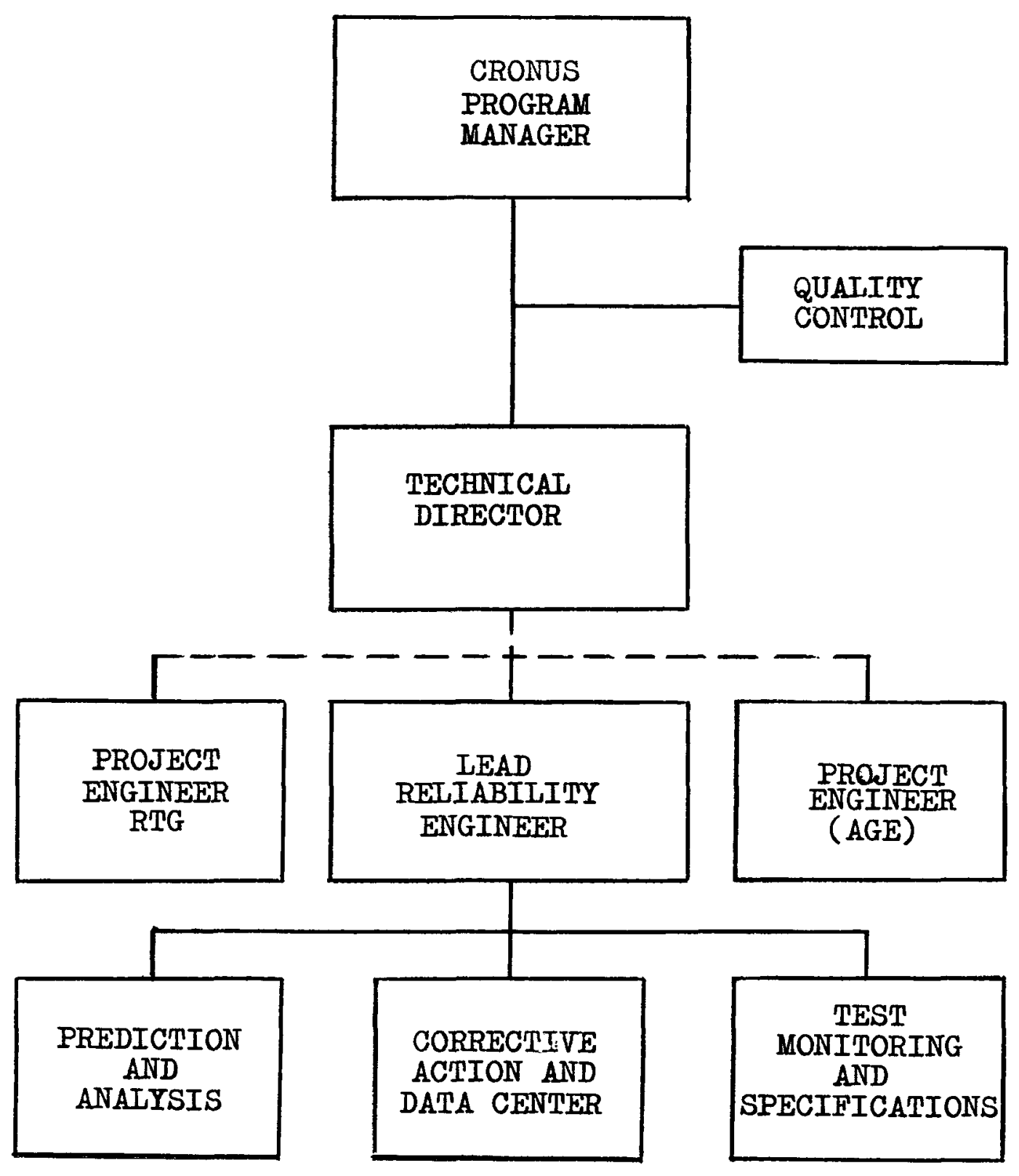

FIGURE 1 CRONUS RELIABILITY ORGANIZATION 
1.
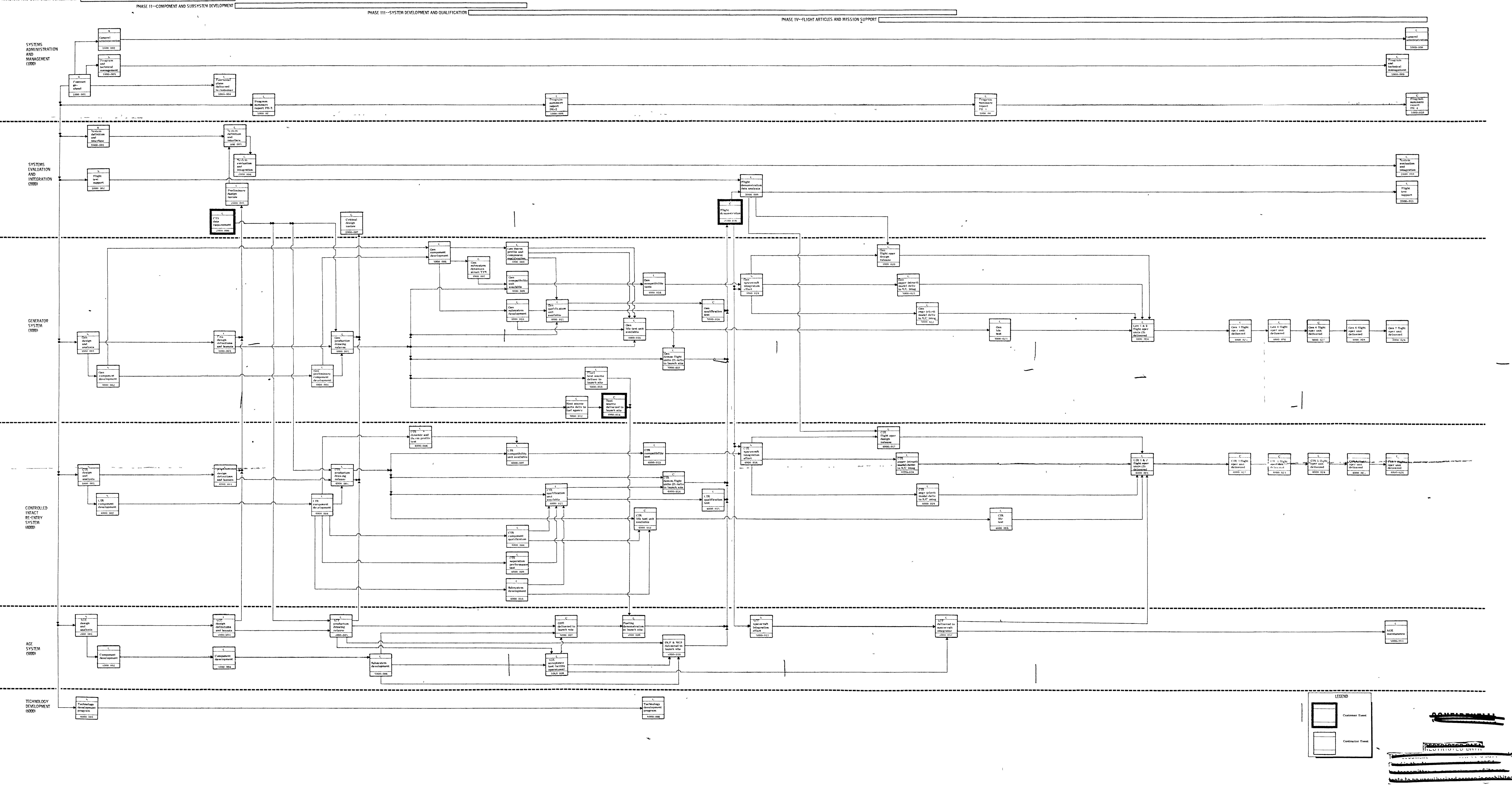